PRACTICAS DISCURSIVAS EN LAS ACELERADORAS DE EMPRESAS DE BASE TECNOLOGICA EN MEXICO.

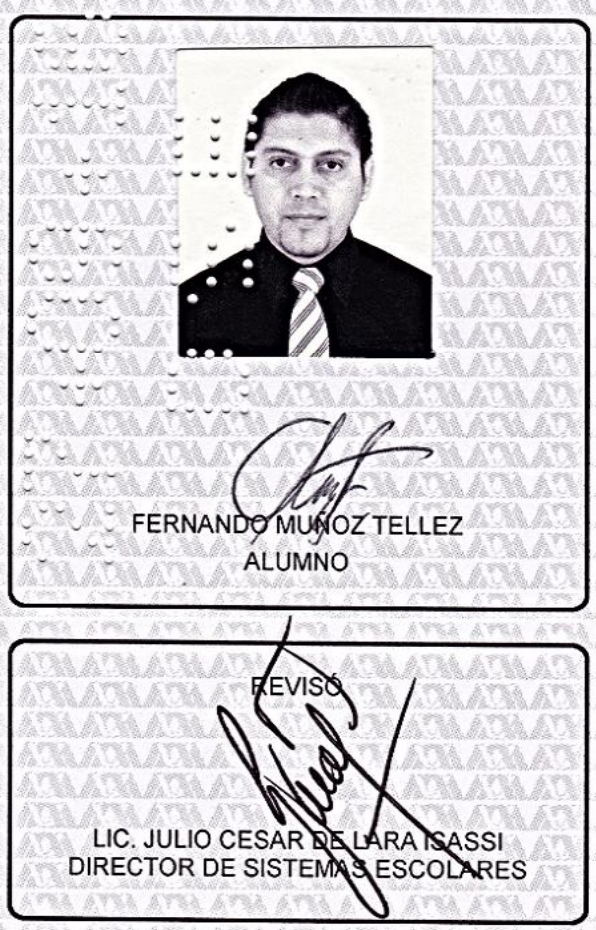

En la Ciudad de México, se presentaron a las 10:00 horas del día 9 del mes de septiembre del año 2016 en la Unidad Iztapalapa de la Universidad Autónoma Metropolitana, los suscritos miembros del jurado:

DR. VALENTINO MORALES LOPEZ

DR. DAVID SALVADOR CRUZ RODRIGUEZ

DRA. MARIA DEL ROCIO PEREZ ROSAS

Bajo la Presidencia del primero y con carácter de Secretaria la última, se reunieron a la presentación de la Disertación Pública cuya denominación aparece al margen, para la obtención del grado de:

DOCTOR EN ESTUDIOS ORGANIZACIONALES

DE: FERNANDO MUÑOZ TELLEZ

y de acuerdo con el artículo 78 fracción IV del Reglamento de Estudios Superiores de la Universidad Autónoma Metropolitana, los miembros del jurado resolvieron:

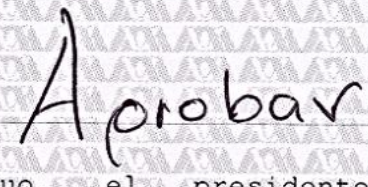

Acto continuo, el presidente del jurado comunicó al interesado el resultado de la evaluación $y$, en caso aprobatorio, le fue tomada la protesta.
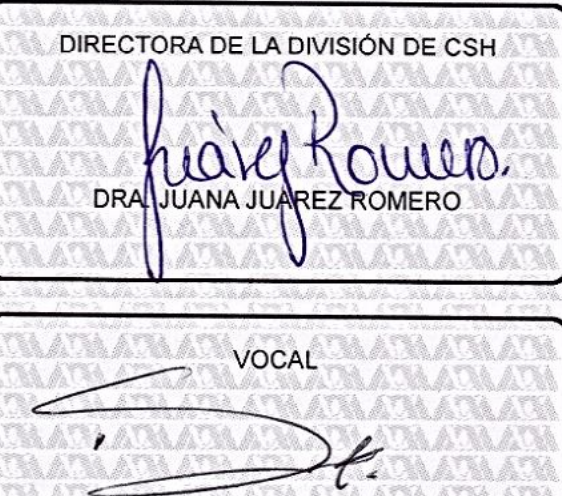

DR. DAVID SALVADOR CRUZ RODRIGUEZ

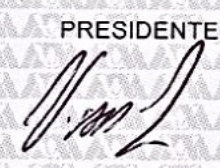

DR. VALENTINO MORALES LOPEZ

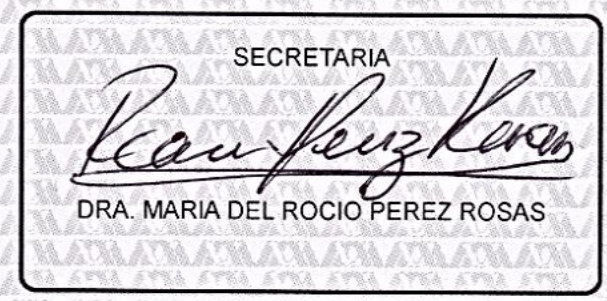




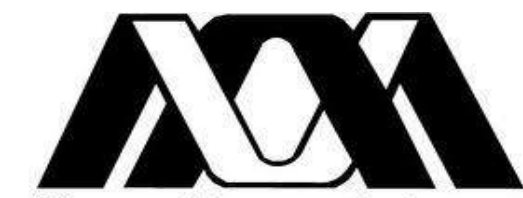

Casa abierta al tiempo

UNIVERSIDAD AUTÓNOMA METROPOLITANA

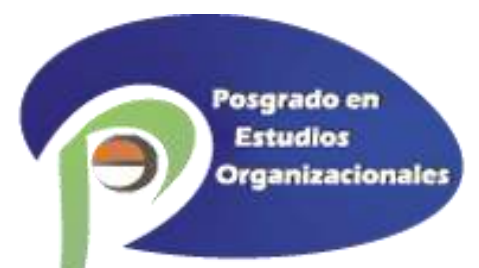

\author{
UNIDAD ITTAPALAPA \\ División de Ciencias Sociales y Humanidades
}

\title{
PRÁCTICAS DISCURSIVAS EN LAS ACELERADORAS DE EMPRESAS DE BASE TECNOLÓGICA EN MÉXICO
}

\section{TESIS}

Que para obtener el grado de

DOCTOR EN ESTUDIOS ORGANIZACIONALES

\section{Presenta}

Fernando Muñoz Téllez

Director de Tesis

Dr. Valentino Morales López

Lectores

Dra. María del Rocío Pérez Rosas

Dr. David Salvador Cruz Rodríguez 


\section{AGRADECIMIENTOS}

Este proyecto no hubiera sido posible sin la contribución y apoyo de muchas personas, a las cuales va dedicado este justo reconocimiento.

Al Consejo Nacional de Ciencia y Tecnología por el apoyo brindado a través del Programa Nacional de Posgrados de Calidad y el Programa de Becas Nacionales. A mi alma mater, la Universidad Autónoma Metropolitana, que me ha brindado la oportunidad de realizar mis estudios de licenciatura, maestría y doctorado. Al Centro de Investigación INFOTEC por el apoyo brindado.

Al Dr. Valentino Morales López por su apoyo, paciencia y valiosas observaciones, correcciones y recomendaciones desde su rol de Director de Tesis y Tutor tanto de Maestría como de Doctorado. Al Dr. Oscar Lozano Carrillo por la provocación que dio origen a la investigación desde mi etapa de licenciatura, así como su orientación y acompañamiento desde entonces, pues ha estado involucrado de principio a fin. A mis lectores, la Dra. María del Rocío Pérez Rosas y el Dr. David Salvador Cruz Rodríguez por el tiempo dedicado a revisar el borrador, por sus invaluables y oportunas correcciones y aportaciones para mejorar el trabajo.

A todos los profesores del Posgrado en Estudios Organizacionales, con especial énfasis a aquellos que contribuyeron directamente en mi formación por medio de los seminarios impartidos. A Alejandra González y Rosalba Capula por todo el apoyo brindado desde que solicité informes para ingresar hasta la conclusión de los trámites de titulación. A mis compañeros de maestría y doctorado, por compartir la aventura, desvelos, interrogatorios, mortificaciones, alegrías y celebraciones, porque simplemente no lo hubiera logrado sin ustedes.

Desde luego a mis familiares y amigos que soportaron y comprendieron el sacrificio de tiempo que no puede brindarles durante estos años. A mis padres por todo el apoyo desde mi infancia hasta ahora, a mi hermana por ser mi otredad en la que reconozco, mis sobrinos por ser tan latosos

y recordarme que no todo es estudio o trabajo. A Cristina y Pedro por adoptarme en su familia y compartir conmigo esta etapa. A Ana Cristina por soportarlo todo, lo bueno y lo malo, y seguir aquí conmigo y por regalarme a Matías que se ha convertido en mi motorcito para la vida.

¡Muchas Gracias! 


\section{Gracias a todos los que han contribuido a que sea quien soy.}

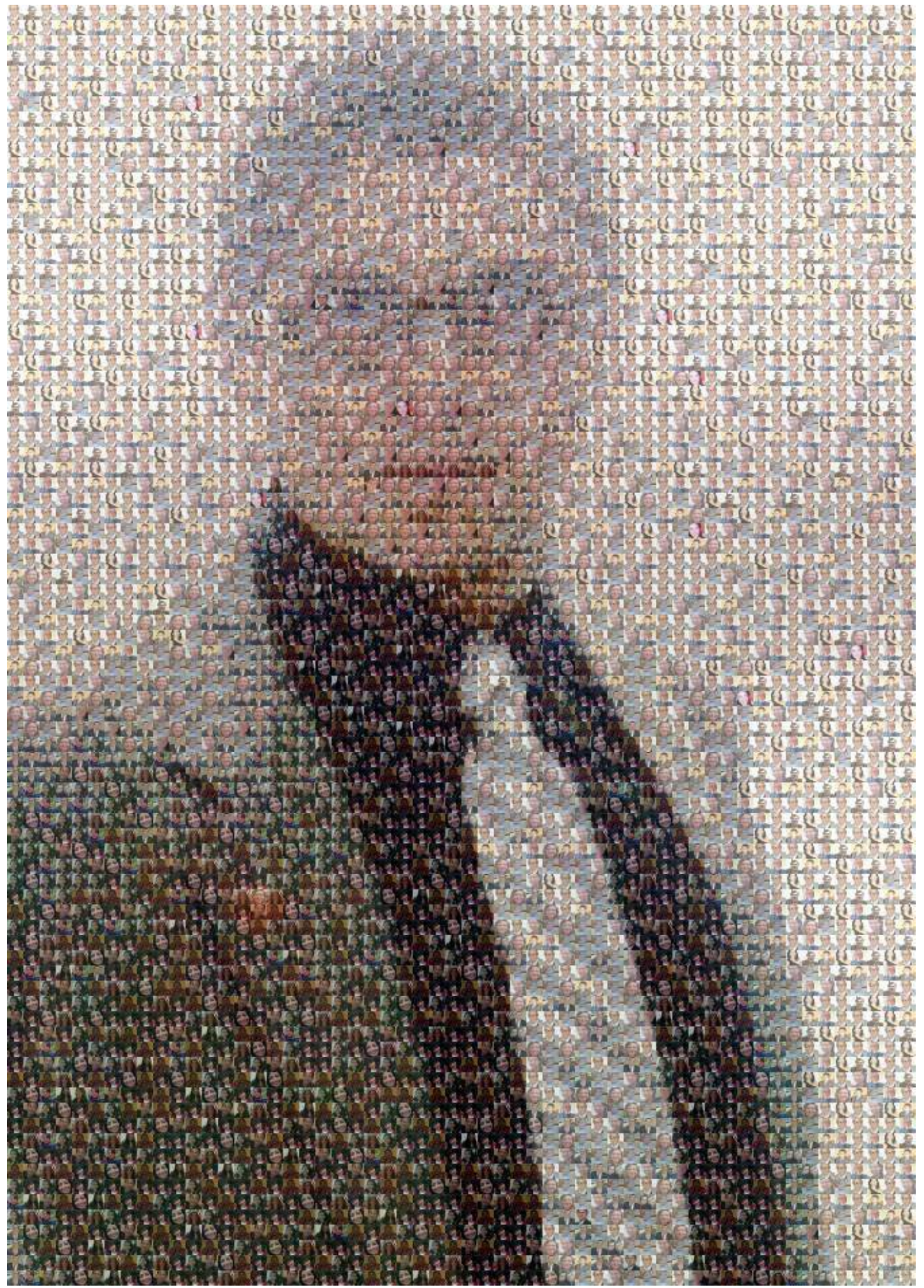


ÍNDICE

Introducción

Planteamiento del problema ii

Objetivo general iii

Preguntas de investigación iii

Capítulo 1. Acercamiento a las aceleradoras de empresas 1

1.1. ¿Qué son las aceleradoras de empresas?

1.1.1. Nuevos términos en el lenguaje de negocios 1

1.2. Revisión bibliográfica sobre las aceleradoras de empresas 3

1.3. Definición de aceleradora $\quad 8$

1.4. Emergencia de la incubación de empresas 9

1.5. Emergencia de la aceleración de empresas $\quad 10$

1.6. Diferencias entre incubación y aceleración 11

1.7. Descripción de las aceleradoras de empresas en México 12

1.8. Modelo general de Aceleración de empresas $\quad 14$

$\begin{array}{ll}\text { 1.8.1. Perfil de los candidatos } & 18\end{array}$

1.8.2. Sectores atendidos 18

1.8.3. Secuencia lógica $\quad 19$

1.9. Aclaración de términos 23

1.10. El vínculo entre MIPyME's y aceleradoras de empresas 25

$\begin{array}{ll}\text { Bibliografía } & 60\end{array}$

Capítulo 2. Elementos teóricos para el abordaje del estudio 67

2.1. Organización y Organizaciones $\quad 67$

2.2. Teoría de la Organización y Estudios de la Organización 74

2.3. Las construcciones sociales y las realidades socialmente construidas 79

2.4. El lenguaje como instrumento de construcción social de la realidad 84

2.5. Lenguaje y Discurso en la conformación de ideología en las

Organizaciones 95

2.6. Recuento histórico de la industrialización y la ciencia y tecnología mexicana 100

2.6.1. Industrialización y crecimiento económico en México 100

2.6.2. Relación entre industria y ciencia 103

2.6.3. Programas sectoriales de apoyo a la industria mexicana 106 
2.6.4. La industria mexicana ante la apertura internacional

2.6.5. Revisión de la industrialización mexicana desde la óptica estratégica

Capítulo 3. Estudio de caso: Prácticas discursivas en la Subdirección de aceleración de empresas de la Unidad Politécnica para el Desarrollo y la Competitividad Empresarial IPN

3.1. Construcción de la investigación

3.1.1. Guía para entrevista semi-estructurada

3.1.2. Búsqueda de Organización para estudio de caso

3.2. Aceleradora de empresas de la UPDCE del Instituto Politécnico Nacional

3.2.1. Misión

3.2.2. Visión

3.2.3. Política de la Calidad

3.2.4. Objetivos de Calidad

3.2.5. Marco jurídico administrativo de la UPDCE

3.2.6. La Subdirección de Aceleración

3.3. La construcción discursiva de la aceleración

3.3.1. Proceso de aceleración

3.4. Concentrado de argumentos presentes en el documento 


\section{Introducción}

El objeto de estudio de esta investigación son las aceleradoras de empresas, en particular, las que se dirigen a atender empresas de base tecnológica, a nivel nacional, circunscritas a los Estados Unidos Mexicanos. Dada la complejidad y amplitud, el estudio busca generar conocimiento respecto a estas organizaciones, concentrándose en la conformación de prácticas discursivas que permiten legitimar su emergencia y apoyo por parte del gobierno mexicano. Se reconoce el carácter complejo del estudio de la dinámica de las organizaciones y la imposibilidad de captarla o estudiarla simultáneamente, considerando todas las categorías de análisis identificadas hasta ahora por la racionalidad humana interesada en este fenómeno social.

Por tal motivo se pretende establecer una agenda de investigación para un estudio más profundo que arroje conocimiento sobre estos modelos de gestión y organizaciones al mismo tiempo, sobre todo circunscritos a la actualidad mexicana. Su estrecha relación con las políticas de desarrollo industrial, las de ciencia y tecnología y las económicas, así como el continuo intercambio de estas organizaciones con otras como las MiPyME's, o las entidades gubernamentales y privadas que otorgan financiamiento $u$ otra clase de apoyos representan situaciones dignas de considerar para su estudio, dada la importancia que puede tener su impacto a nivel no sólo económico, sino social, político y cultural.

Estas relaciones mencionadas se encuentran insertas en un contexto espaciotemporal y expuestas a coyunturas de diversa índole. A su vez, como organizaciones, la multiplicidad de categorías de análisis implica también desarrollar investigación con cada una de ellas sólo para tener un acercamiento, semejante a una fotografía instantánea, que nos permitiría describir a la organización sólo en ese preciso instante, lo que no significa que ésta se quede petrificada en esa forma. De ahí la necesidad de identificar patrones que se manifiesten a lo largo del espaciotiempo en un estudio de caso que nos permita acercarnos a organizaciones similares con mayores elementos que contribuyan a una mejor comprensión de las mismas. 
El punto de partida establecido por el autor es el acercamiento a las prácticas discursivas que otorgan legitimidad a la adopción de un modelo de aceleración, considerando que éste ha surgido en un contexto distinto al mexicano en prácticamente todos los aspectos. En las siguientes líneas se presenta la propuesta del investigador para abordar el estudio de caso.

\section{Planteamiento del problema}

Existe en México actualmente un auge de organizaciones conocidas como aceleradoras de empresas o de negocios; sin embargo, paradójicamente también existe un amplio desconocimiento de la actividad específica que estas organizaciones desarrollan para la sociedad. Las aceleradoras de empresas o de negocios en México, en tanto organizaciones emergentes, no han sido estudiadas -o estos estudios no han sido ampliamente difundidos, concediendo que los hayadesde los enfoques convencionales. Se parte del supuesto de que en la Secretaría de Economía se ha dado ya este estudio y que probablemente se ha concluido que es pertinente impulsarlo, aunque estos resultados pudieran haberse manejado de manera interna. De igual manera, al surgir el modelo de universidades estadounidenses ${ }^{1}$ de renombre, se busca rastrear los orígenes teóricos que dan sustento al modelo práctico. Si se establece que este modelo incide en el desempeño y las estructuras organizacionales de las empresas aceleradas, y que la orientación primordial del modelo apunta hacia el desarrollo económico industrial, lo que se busca es explicar de qué manera incide en las dimensiones social y ambiental a través de explicaciones alternativas a las convencionales, optando por los Estudios Organizacionales como matriz teórica explicativa.

La investigación parte de una inquietud a partir de la que se supone que el discurso que ha promovido la importación del modelo de aceleración de empresas en México ha permeado en la Secretaría de Economía y se promueve sin tener en cuenta los

${ }^{1}$ Harvard, Stanford y MIT, implementadas en el Silicon Valley. 
aspectos simbólicos y culturales que conllevan. Más que un trasplante, se plantea la idea de apropiación o reapropiación, pero también la necesidad de un estudio cuidadoso de los beneficios y daños colaterales o "externalidades" que puede acarrear para las empresas aceleradas al modificar sus estructuras organizacionales, puesto que se presume permite mejorar el desempeño y competitividad de estas organizaciones. Esta modificación es con una orientación dictada desde la economía y la administración dominantes en el plano internacional, por lo que el asunto no es cuestionar si esta incidencia se da o no, se reconoce que existe, la cuestión es determinar si es positiva o negativa y en qué dimensiones, por lo que es pertinente para los Estudios Organizacionales.

Se aborda el caso por medio del análisis del discurso organizacional, centrando la atención en la conformación de prácticas discursivas que legitiman la proliferación y financiamiento de las aceleradoras, dentro de una matriz teórica que abreva de los Estudios Organizacionales, con el fin de contribuir a la generación de conocimiento respecto a estas organizaciones desde la crítica propositiva y con una aproximación diferente a las convencionales y que ofrezcan hallazgos que lo complementen y enriquezcan.

\section{Objetivo General}

Analizar las prácticas discursivas construidas para promover el modelo de aceleración de empresas de base tecnológica en México mediante el enfoque de Análisis del Discurso Organizacional.

\section{Preguntas de investigación}

Con base en lo establecido previamente, las preguntas de investigación surgidas hasta el momento son las siguientes: 
1. ¿En qué consiste el modelo de aceleración de empresas, cuál es su fundamento teórico, de dónde surge, cómo se da su reproducción, cuál es el proceso que sigue y cómo son medidos los resultados esperados y los obtenidos?

2. ¿Por qué se busca acelerar a empresas de base tecnológica, cómo se sustenta este objetivo y de qué manera se legitima y promueve, qué importancia tiene en México para el desarrollo en los pilares económico, social y ecológico?

3. ¿Cuál es la relación entre el discurso y la transferencia de modelos organizacionales en el caso de las aceleradoras de empresas de base tecnológica en México? ¿Las prácticas de transferencia de modelos como modas han incidido en la crisis de desarrollo industrial en México?

4. ¿De qué manera podría ser reconfigurado el modelo de aceleración para incrementar su pertinencia y apropiación en México (si es el caso)?

Estas preguntas, siguiendo con una premisa fundamental de los Estudios Organizacionales de conocer, comprender y describir con el propósito de teorizar con mayores fundamentos, permiten sondear de manera profunda en la esencia de las organizaciones aceleradoras, es decir, delimitar y caracterizar claramente la particularidad y singularidad de las aceleradoras de empresas de base tecnológica mexicanas. A partir de esa comprensión estructurada, se puede partir a un análisis más profundo de las aceleradoras, previamente identificando sus elementos comunes, sus objetivos, estrategias, discursos, procesos y dinámica tanto interna como en relación con su entorno.

Dado que estas aceleradoras son una singular variedad de organización, los Estudios Organizacionales ofrecen un abanico de categorías de análisis a observar en ellas, tales como la cultura, el cambio, el poder, la estrategia, las decisiones, las estructuras, las tecnologías, el aprendizaje, el conocimiento, la innovación, la relación con el ambiente, el discurso, el conflicto, el control, la acción organizada. 
Sería ideal abordar todas las categorías de manera dinámica y simultánea, pero esto es complejo de atrapar y considerando las limitantes de tiempo y recursos, debe acotarse a elegir una o algunas, por lo que se plantea que las categorías discurso y estructura, de entrada juegan un papel fundamental pero no se descarta que en el desarrollo se tornen protagónicas otras.

La finalidad de toda investigación es el conocer, y en México el conocimiento acerca de estas organizaciones resulta escaso, limitado y restringido, aparentemente por ser organizaciones relativamente nuevas que no han sido objeto de estudio científico, y si lo han sido, este conocimiento ha sido reservado antes que difundido. ¿Para qué conocer a las aceleradoras de empresas de base tecnológica de México? La primera razón es para generar nuevo conocimiento en el ámbito académico acerca de estas organizaciones que han sido escasa o nulamente estudiadas. Con ello, se busca contribuir a una mayor comprensión acerca de las organizaciones en general, de manera global, aunque desde la particularidad de las aceleradoras de empresas de base tecnológica, específicamente localizadas en territorio mexicano. De esta manera, los Estudios Organizacionales permiten abordar las categorías de análisis relacionadas con el interior de las aceleradoras, es decir, sus procesos, lo que ocurre en la hasta ahora caja negra.

La segunda razón se sustenta en el interés surgido a partir del discurso predicado desde las propias aceleradoras objeto, las cuales afirman acelerar el crecimiento de aquellas MIPyME's ${ }^{2}$ que ingresen a su programa y llevarlas a competir en los mercados internacionales, impulsando de esta manera la economía mexicana, lo cual se alinea con las políticas públicas expresadas en los últimos dos sexenios de gobierno federal. En esta parte, los Estudios Organizacionales permiten abordar aquellas relaciones que las aceleradoras establecen con otras organizaciones y con la sociedad en la que se encuentran, así como su incidencia en la realidad objetiva -si es que la incidencia se da-.

Con base en el establecimiento del marco contextual en el que se encuentran las aceleradoras de empresas de base tecnológica, es decir, la revisión histórica del

${ }^{2}$ Micro, pequeñas y medianas empresas. 
proceso de industrialización en México en los últimos sesenta años, así como la caracterización de las MIPyME's mexicanas en este proceso histórico, dado que éstas son organizaciones que tienen relaciones estrechas con las aceleradoras objeto, se describe cómo surgió el modelo de aceleración de empresas, con fundamento en un discurso neoliberal que promueve el crecimiento económico, la competitividad internacional y el isomorfismo organizacional. Este modelo promovido por el discurso neoliberal, posee a su vez su propio discurso que busca legitimar sus acciones, prácticas y procesos.

Por tanto, el revisar la versión de las aceleradoras objeto, su discurso legitimador del modelo, el cual desarrolla procesos isomórficos en los que se promueve la transferencia de conocimiento, de tecnología y de modelos que involucran a las MIPyME's participantes, forman parte del desarrollo de la investigación. A manera de metáfora, el marco teórico basado en textos y artículos de Estudios Organizacionales permite describir y explicar en una primera aproximación a priori lo que podría estar sucediendo en la caja negra, sin mirar al interior, sino más bien, leyendo la etiqueta.

El primer capítulo está destinado a caracterizar la organización denominada aceleradora de empresas, así como el rastreo de su génesis y auge, describiendo el modelo general que reproducen con sus variaciones particulares las aceleradoras de empresas en México. Se establece también el vínculo estrecho que guardan las aceleradoras con las MiPyME's y el discurso en torno a éstas.

El segundo capítulo presenta los elementos teóricos considerados para abordar el estudio, estableciendo la aceleradora como un tipo de organización y un proceso organizado. De esta manera se introduce la perspectiva de los Estudios Organizacionales para abordar el caso por medio de su matriz teórica y la selección de la construcción social de la realidad, el lenguaje y el discurso que permiten delimitar el Análisis del Discurso Organizacional. La descripción del estudio de caso, al igual que el Análisis del Discurso requieren de la contextualización, por lo que se incorpora el recuento histórico de la industrialización y la ciencia y tecnología 
mexicana como puntos de origen que desembocan en la legitimación de las aceleradoras de empresas.

El tercer capítulo se fundamenta en los dos previos para presentar el estudio de caso desarrollado como fruto de la investigación, es decir, la realidad observada por medio del marco teórico, histórico y contextual presentado. Se presenta primero la construcción de la investigación y el proceso seguido. Después se caracteriza la aceleradora estudiada desde su configuración estructural, para después presentar los hallazgos y conclusiones emergidos del proceso de investigación. Finalmente se presentan las conclusiones fruto de la reflexión del estudio. 


\section{Capítulo I. Acercamiento a las aceleradoras de empresas}

\section{¿Qué son las aceleradoras de empresas?}

Lo primero que emerge a la vista al adentrarse en la literatura relativa a la aceleración de empresas o de negocios es el uso indistinto tanto del término empresa como el de negocio, dando por sentado que estos son sinónimos. Lo mismo ocurre con la concepción de aceleradora e incubadora, pues siempre se habla de incubación aunque en los títulos se exprese que trata de aceleración. Si bien para efectos prácticos resulta cómodo para los consultores manejar los términos indistintamente dentro de un campo semántico discursivo en torno al emprendedurismo, estos usos implican errores que inciden en las estrategias desplegadas y los resultados obtenidos, los cuales afectan principalmente a las empresas aceleradas.

El propósito de este apartado es proporcionar una mayor claridad respecto al tema de la aceleración de empresas, y con ello acercarse a una descripción de lo que las aceleradoras hacen, es decir, el sentido que justifica su creación, proliferación y financiamiento.

\section{Nuevos términos en el lenguaje de negocios.}

Se han incorporado tres términos de reciente uso en el discurso cotidiano de las empresas, las consultoras, las universidades y el entorno que discute sobre empresas y negocios. Antes de rastrear históricamente su aparición es preciso esclarecer las palabras utilizadas y el sentido que portan consigo. Éstas son:

Acelerar. Verbo que indica la acción.

Del latín celer (rápido) $\rightarrow$ accelerare (dar rapidez, apresurar) $\rightarrow$ al castellano Acelererar.

En Física se define como la variación de la velocidad en un intervalo de tiempo. 
Aceleración. Proceso organizativo.

Aceleradora. Agente que materializa la acción.

Receptor de la acción: Empresa (organización)

No son en ningún caso palabras nuevas en el lenguaje, pero si agregan nuevos sentidos en su uso, pues en el caso del verbo 'acelerar' tiene un sentido metafórico que evoca a velocidad y movimiento. Su íntimo vínculo con los términos crecimiento y desarrollo como fines perseguidos por las sociedades modernas hacen que se considere como positivo. Esto es, acelerar el crecimiento evoca crecer más rápido, disminuir el intervalo de tiempo para lograr el fin.

El cómo involucra entonces la segunda palabra: 'aceleración'. Alcanzar un crecimiento económico implica planear un proceso, una serie de pasos lógicos ordenados -secuenciales o simultáneos- para alcanzar el fin deseado. Sin embargo, en este caso el fin perseguido es bastante ambicioso y complejo, por lo que se requieren diversos procesos interconectados. La incorporación del proceso de aceleración refiere la organización de recursos de diversos tipos de una manera diferente a las ya existentes para alcanzar el objetivo específico.

La materialización de este proceso de aceleración, el lugar físico en donde se concreta la organización de recursos es la aceleradora. De esta manera, las palabras asignadas a las creaciones humanas permiten identificarlas en la interacción verbal o escrita y estas palabras evocan a estas creaciones recientes.

La aceleradora entonces es la entidad que materializa el proceso organizado de recursos diversos con el propósito de reducir el intervalo de tiempo de crecimiento económico de una empresa o negocio. A su vez, el crecimiento económico de múltiples empresas y negocios contribuye sensiblemente en el crecimiento económico del país y se aspira a que el crecimiento sostenido lleve al desarrollo. En resumen, esa es la incorporación de los 'nuevos' términos en el discurso, lo que permite legitimar la emergencia de aceleradoras de empresas, programas públicos y partidas del presupuesto para apoyar sus operaciones. 


\section{Revisión bibliográfica sobre las aceleradoras de empresas.}

El surgimiento de los computadores personales o de escritorio trajo consigo un brote exponencial de demanda, por lo que en los años noventa se incrementó la creación de nuevas empresas dedicadas a desarrollar componentes y software en el Silicon Valley de California, E.U.A. La interacción entre los emprendedores con sus ideas e innovaciones, y el apoyo de universidades, inversores privados, consultores y gobierno para generar un entorno propicio para el florecimiento de la industria, es el punto de origen al que se referencia la aceleración de empresas.

Por tanto, la literatura generada al respecto está casi en su totalidad disponible en inglés, mientras que en castellano es muy escasa, lo que sugiere poco interés o desconocimiento. Llama la atención entonces que en los últimos años se presente una proliferación de aceleradoras de empresas y que no se genere un crecimiento de textos que traten el tema, sea para describirlas, promoverlas, estudiarlas 0 criticarlas.

Los medios electrónicos actualmente son la principal fuente de información respecto al tema, pues los sitios web de las aceleradoras tanto públicas como privadas permiten acercarse a la información respecto a la aceleración y promover sus servicios. El gobierno federal también aporta información en los sitios correspondientes al apoyo al emprendedor, donde puede conocerse la política pública desde el plan nacional de desarrollo hasta los programas operativos específicos para apoyar a aceleradoras de empresas.

Entre los textos dedicados al tema de la aceleración de empresas, se encuentra un artículo publicado por J. Maurice Clark (1917) en el Journal of Political Economy, titulado "Aceleración de negocios y la ley de la demanda: Un factor técnico en los ciclos de negocios". Este artículo permite referenciar y rastrear el fundamento teórico que dota de lógica toda la argumentación en torno a la aceleración. En primer lugar vincula el término a las teorías económicas de los ciclos (Mitchell, Hawtrey, von Hayek, Fisher y Schumpeter). 
Destaca a primera vista entonces la preminencia de la doctrina económica en la construcción discursiva, en donde el positivismo hipotético-deductivo formula teorías causa-efecto, lo que puede apreciarse en la propuesta de los ciclos económicos, la innovación, el equilibrio, el boom y el crack, así como la conexión entre los comportamientos microeconómicos de los empresarios innovadores y su efecto sobre el desarrollo de nuevas industrias y nuevos mercados que inciden en la dinámica macroeconómica.

Si bien el artículo de Clark es anterior a los trabajos de los teóricos referentes mencionados, argumenta su vínculo en el debate respecto a la teoría de los ciclos económicos y la aceleración de negocios como parte de éstos. Al revisar las propuestas teóricas posteriores se observa la misma lógica, por ejemplo en la obra de Schumpeter (2002) "Ciclos de Negocios. Un análisis teórico, histórico y estadístico del proceso capitalista" ${ }^{1}$. Si bien no ha sido un tema central en el desarrollo de la teoría económica, ha tomado fuerza su importancia en los últimos 25 años, aunque no tanto en el ámbito teórico como en el práctico.

Respecto al tema se encuentran disponibles obras como la de Gooze y Mroz (2007) y Bergfeld (2015), que principalmente abordan el tema de la aceleración de empresas o de negocios. Si bien se pueden encontrar otras obras relacionadas al tema con una simple búsqueda por internet, lo que puede apreciarse es que ocupan un espacio muy breve en obras relacionadas a temas como la innovación, el financiamiento de nuevos negocios, la incubación de start-ups, o los encadenamientos productivos.

Respecto a artículos académicos o científicos, además del ya mencionado artículo de J. Maurice Clark (1917) del Journal of Political Economy de la Universidad de Chicago, Gregory C. Chow (1968) publicó un artículo en The Quarterly Journal of Economics de la Universidad de Oxford, relacionando el principio de aceleración y

\footnotetext{
1 Traducción del título original en inglés. En la traducción al castellano se ha cambiado "ciclos de negocios" por "ciclos económicos". Se desea resaltar aquí que al referirse a negocios está vinculando la microeconomía con la macroeconomía, mientras que al cambiar el título a ciclos económicos, se sobreentiende un enfoque primordialmente macroeconómico.
} 
la naturaleza de los ciclos de negocios. Este artículo aborda más el aspecto macroeconómico desde una perspectiva cuantitativa económica y estadística.

Silvia Pomar y Pamela Jiménez (2010) analizan exploratoriamente las capacidades tecnológicas desarrolladas por las aceleradoras en las empresas de base tecnológica en México y es uno de los trabajos que puede encontrarse en español, refiriéndose a casos latinoamericanos, sin ser exhaustivo.

Audretsch, Aldridge y Sanders (2011) abordan el caso de la aceleradora de innovación de la Universidad de Stanford, destacando la construcción de capital social invaluable entre emprendedores, investigadores universitarios e inversionistas privados. En el año 2012 se destacan cuatro documentos: La evaluación de la OCDE del sector de las nuevas empresas basadas en el conocimiento en México que destaca como punto débil de la política pública mexicana el escaso apoyo para la creación de empresas de base tecnológica, insuficiencia de fondos, falta de mercados de capital semilla y de riesgo, así como pocas oportunidades para que los investigadores de centros públicos de investigación puedan crear empresas de alta tecnología (OCDE, 2012: 23). Si bien el tema central de la evaluación no es la aceleración de empresas, es referente para vincular las políticas de innovación, el conocimiento y las empresas de base tecnológica, pues son temas que se cruzan con el de la aceleración que precisamente emerge para atender estas debilidades.

Otro trabajo para destacar es un estudio exploratorio realizado en el Instituto de Tecnología de California (CalTech) que describe el crecimiento explosivo de las aceleradoras de negocios en los Ángeles (Li, Kubersczyk, Asma y Yen, 2012). Thomas van Huijgevoort (2012) presenta un trabajo en cuyo título cuestiona si la aceleradora de negocios no es sino una forma diferente de nombrar una incubadora de negocios. Su investigación describe los modelos de incubación, de aceleración, sus similitudes y diferencias.

Margaret Dalziel (2012) realiza también un estudio comparativo entre incubadoras y aceleradoras de negocios en Canadá, abordando la literatura académica y el impacto de ambos modelos en Canadá, para finalizar con una comparación. 
Concluye con la complejidad para obtener mediciones comparables entre sí, dada la diversidad de mediciones de impacto empleadas y el hallazgo de contradicciones en los diversos estudios que revisó. Destaca la necesidad de invertir energías y recursos en averiguar si funcionan o no las aceleradoras e incubadoras, y en qué opciones debe invertir el gobierno de Canadá.

Un grupo de investigadores de la Universidad de Cambridge (Birdsall et al., 2013) presentan un reporte de investigación sobre las aceleradoras de negocios y su rápida y creciente evolución. Su elección metodológica es cuantitativa, con entrevistas en 14 aceleradoras del Reino Unido, Europa del Este e Israel, identificando sus mejores prácticas. Ese mismo año Hugh Mason (2013) presenta un texto que describe la aceleración de negocios con métodos de Teoría fundamentada (grounded theory). Si bien no puede negarse el rasgo económico que envuelve el tema de la aceleración, Mason recupera la perspectiva de los sistemas sociales, considerando las aceleradoras como construcciones sociales, por lo que ofrece una visión distinta que vale la pena contrastar con los anteriores textos.

Un reporte de investigación privado (Baird, Bowles y Lall, 2013) describe el rol de las aceleradoras de empresas en el desarrollo de emprendimientos de alto impacto. Resulta relevante como perspectiva de los inversores y consultores para contrastar su visión con la de la academia o los propios empresarios. Susan Cohen (2013) publica en el Journal del Massachusetts Institute of Technology un artículo descriptivo sobre qué hacen las aceleradoras.

Para el año 2014 destacan cuatro documentos. La empresa Telefónica publica un reporte de investigación sobre la emergencia del ecosistema incubador y acelerador en el Reino Unido (Telefónica, 2014). Clarysse y Yusubova (2014) del Departamento de Innovación, emprendimiento y servicios gerenciales de la Universidad de Gent, Belgica, presentan en conferencia los factores de éxito de las aceleradoras de negocios con base en la Teoría Institucional. Según los autores, estos factores de éxito son el proceso de selección y el criterio de éste, los servicios de soporte de negocios y las redes de trabajo, lo cual otorga legitimidad a las aceleradoras de negocios. 
El mismo año se encuentra un reporte de la Oficina de Administración de pequeños negocios de Estados Unidos de América, titulado "Aceleradoras de innovación: Definiendo características entre organizaciones de asistencia a Startups" (Dempwolf, Auer y D'Ippolito, 2014). Este reporte incorpora una taxonomía de las aceleradoras con base en cinco componentes de proposición de valor: mercado de clientes, actividades, recompensas, experiencia de valor del capital social creado, y alternativas y diferenciación. Esta taxonomía establece entonces seis tipos de aceleradoras:

1. Incubadoras

2. Organizaciones de capital de riesgo para el desarrollo.

3. Aceleradoras universitarias

4. Centros de "prueba de conceptos"

5. Aceleradoras corporativas

6. Aceleradoras de Innovación.

La revista Forbes publica un artículo sobre la aceleradora de Silicon Valley, promoviéndola como el modelo del futuro (Fidelman, 2014). Fehder y Hochberg (2014) del Massachusetts Institute of Technology escriben sobre la inversión de capital de riesgo y cómo las aceleradoras inciden en el ecosistema empresarial. Señalan que hay poca evidencia de su eficacia y poca información útil al respecto que permita a los tomadores de decisiones valorar la continuidad del apoyo de estos programas, por lo que sugieren que su investigación provee evidencia del impacto positivo de estos programas en el ecosistema empresarial local y regional, así como en el crecimiento económico.

Por último, en el año 2015 hay dos reportes de la iniciativa privada respecto al tema. La consultora Monitor Deloitte, financiada por la Fundación Rockefeller, presentan el documento "Impacto de la aceleración. Explorando las mejores prácticas, desafíos e innovaciones en el impacto de aceleración empresarial" (Monitor Deloitte, 2015). Itea2 presenta un artículo sobre iniciativas relacionadas a la aceleración en Europa con el propósito de superar la llamada paradoja europea, es decir, alta producción científica pero pocas innovaciones comercializables (ITEA2, 2015). 
Esta revisión permite internarse en el tema de la aceleración de empresas, identificar su vínculo con temas de mayor tradición investigativa como el desarrollo de los países menos desarrollados o periféricos, las ventajas competitivas de las economías nacionales, la Investigación y Desarrollo, la Innovación, la transferencia de conocimientos, o el desarrollo sostenible. Sin embargo, también se puede observar la jerarquía de la teoría económica sobre otras ciencias, acentuando la preocupación por los beneficios, ganancias o utilidades, el rápido crecimiento, mayor productividad, sin tocar puntos como la repartición de esas ganancias entre la sociedad, la explotación racional de los recursos naturales y su preservación, los efectos de un crecimiento económico sin regulación ni planeación a largo plazo, o la sobreproducción de mercancías que sobre estimula el consumo, la obsolescencia programada y el incremento de desechos tecnológicos e industriales.

Resulta entonces necesario volver sobre lo argumentado hasta ahora, con una visión crítica que permita recuperar lo útil del conocimiento generado y reformular aquello que no es confiable o bien, complementar con nuevos enfoques y nuevos hallazgos.

\section{Definición de Aceleradora.}

Cada uno de los textos referidos contiene al menos una breve propuesta de definición de lo que es una aceleradora o lo que es el proceso de aceleración. Sin embargo, de entre todas ellas, Bergfeld concentra los elementos contenidos de manera más estructurada:

"Una aceleradora de negocios es un programa corporativo que proporciona el marco, herramientas y métodos, así como acceso a conocimiento que requiere una joven empresa para crecer. La meta de la aceleradora, como en el significado de la palabra latina "accelerare", es incrementar la velocidad. Esto puede contextualizarse en términos de agregar velocidad a empresas jóvenes con respecto a la comprensión, desarrollo y dirección de una empresa y como resultado, 
guiarla a través de sus muy frágiles etapas tempranas de desarrollo. [...] también ofrece orientación a través de tutorías, talleres, soporte financiero e incluso la provisión de infraestructura requerida." (Bergfeld, 2015)

Como se ha planteado, el concepto de aceleradora no puede comprenderse en su totalidad si se omite el de incubación, pues vienen ligados discursivamente en la lógica del ciclo de negocios, esto es, las etapas desde la emergencia de la idea de negocio, hasta la maduración del negocio ya constituido en una empresa. La referencia metafórica referida a incubar evoca al cuidado que se tiene con un neonato que no está lo suficientemente maduro y apto para sobrevivir en su entorno. La aceleración continúa con la noción de ese crecimiento y maduración. Lo que se persigue es reducir el intervalo de tiempo que requiere un negocio o empresa para madurar, asistiéndole con lo que requiera para mejorar sus probabilidades de supervivencia, hasta que sea capaz de operar por sí misma. Gestación, incubación, crecimiento, maduración, como un ciclo biológico de infancia, adolescencia y adultez. Así entonces se asocia esta lógica a las dimensiones de una empresa: micro y pequeña $=$ infancia; mediana $=$ adolescencia; grande $=$ adultez .

\section{Emergencia de la incubación de empresas.}

Mientras las incubadoras de empresas surgen en el Silicon Valley en 1950 promovidas por la Universidad de Stanford con la finalidad de establecer vínculos que permitan la transferencia de tecnología desarrollada en la universidad hacia las empresas (Hanson, 1984). Posteriormente, en la década de los 70 's se orientó el modelo hacia el desarrollo de regiones poco industrializadas en Estados Unidos. Cabe resaltar que en Inglaterra también se consideran pioneros de este modelo en Europa, aunque con posterioridad a los estadounidenses. Las áreas apoyadas en principio fueron las de tecnología intensiva -electrónica principalmente- y el acero. 
En Latinoamérica, Brasil se reconoce como pionera en 1984 y la más avanzada en el desarrollo de este modelo en la región².

En México, aparentemente la aparición de este modelo no se dio sino hasta la década de los 90's en el parque industrial Morelos con un incipiente desarrollo debido a la época de crisis que se suscitó en esa década, situación que poco favoreció el florecimiento del modelo, dada la alta tasa de mortandad de los proyectos generados por las incubadoras ${ }^{3}$. A partir del año 2001 se ha reformulado el modelo con aparentes buenos resultados (Pérez y Márquez, 2006: 12).

\section{Emergencia de la aceleración de empresas.}

El caso de las aceleradoras de empresas es más reciente, aunque de origen similar en el Silicon Valley, California, el término de aceleración surgió prácticamente a la par del boom de los negocios electrónicos a través del internet en Estados Unidos en la década de los noventas y se utilizaba para diferenciar a las aceleradoras de las incubadoras en cuanto al sector de negocios al que estaban destinados. Rápidamente su funcionamiento se adecuó para aprovechar sus bondades en las empresas, gracias a su orientación y especialización en tecnología que le proporcionó tanto éxito 4 .

En México apareció la primera aceleradora de negocios en el año 2003, como iniciativa privada de un fondo de inversión, la cual actualmente se conoce como Visionaria. La Secretaría de Economía se interesó en el modelo de aceleración de

\footnotetext{
2FUENTE: http://incubacionempresas.wordpress.com/2007/09/25/hola-mundo/

Fecha de consulta: 12 de Enero de 2016.

${ }^{3}$ FUENTE: http://www.anuies.mx/servicios/p_anuies/publicaciones/libros/lib28/28.htm

Fecha de consulta: 28 de Marzo de 2013.

4FUENTE: www.ehow.com/facts_5903618_business-accelerator-vs_-business-incubator.html

Artículo Business Accelerator vs Business Incubator (Aceleradoras de negocios vs Incubadoras de negocios)

Fecha de consulta: 12 de Enero de 2016.
} 
negocios y conformó el primer programa de aceleración de empresas en Latinoamérica en conjunto con Visionaria.

\section{Diferencias entre incubación y aceleración.}

La principal diferencia entre una incubadora de empresas y una aceleradora de empresas viene implícita en la denominación misma: la primera está orientada a acompañar la gestación de un emprendimiento para un nuevo negocio o empresa. La asistencia es brindada ya sea por universidades o actualmente por incubadoras privadas. El acompañamiento termina en el momento en que la empresa o negocio inicia operaciones o incluso un breve periodo de tiempo después (generalmente un año desde el comienzo de la incubación).

En el caso de las aceleradoras, éstas atienden a empresas o negocios que ya se encuentran en operación y con un éxito relativo en sus operaciones, pero que su objetivo es crecer e ingresar a la competencia de los mercados internacionales. Para ingresar al programa de aceleración, deben demostrar un crecimiento sostenido en productividad, ventas y participación en el mercado durante uno a tres años.

Para el caso de las aceleradoras de empresas de base tecnológica, cabe hacer la aclaración que existen aceleradoras de negocios, las cuales pueden considerarse de base tradicional, mientras que las de base tecnológica se orientan al desarrollo de investigación y desarrollo, innovación y transferencia de tecnología en sectores manufactureros de tecnología alta y media. 


\section{Descripción de las aceleradoras de empresas en México.}

En el año 2000 se crea un fondo privado para financiar a PyME's de desarrollo de tecnología (básicamente eran empresas que desarrollaban software). Se creía que un adecuado financiamiento solucionaría los problemas de las PyME's, aunque la experiencia les llevó a descubrir que era necesario que contaran con una estructura adecuada para que las inversiones tuvieran los resultados esperados. Al incorporar una visión externa del negocio que complemente la de los empresarios, así como un énfasis en el nivel estratégico. El término "acompañamiento" en este proceso es acuñado, lo que cambia el carácter de la organización de un fondo de inversión privado a una aceleradora de negocios: Visionaria ${ }^{5}$. El año 2003 marca el surgimiento de las aceleradoras en México, apoyando a 30 empresas mexicanas.

A partir de la administración federal del periodo 2006-2012, la Secretaría de Economía incorpora el primer programa de aceleración de empresas en Latinoamérica. En un principio las aceleradoras de empresas realizaban su convocatoria por separado, pero con el surgimiento del programa nacional de Empresas Gacela en el año de 2008 se homogeneizó la forma de selección de las empresas que se pretende acelerar. Esta convocatoria es realizada cada año y parte de la difusión e identificación individual de cada empresa. A continuación, se difunde a través de Encuentros que se realizan en las principales ciudades del país (Distrito Federal, Monterrey, Guadalajara y Puebla) en donde se busca difundir públicamente el programa y convocar a empresas que pueden llegar a ser candidatas en el proceso de crecimiento acelerado.

El seguimiento de este programa en los planes de desarrollo nacionales ha permitido la continuidad a pesar de la alternancia en el poder. Así, la Subsecretaría de la pequeña y mediana empresa dio paso al Instituto Nacional del Emprendedor (INADEM) en 2013. En su labor de impulsar estrategias para el ecosistema

\footnotetext{
${ }^{5}$ FUENTE: Sitio web de la aceleradora de Negocios Visionaria, apartado "Quienes Somos". http://visionaria.axeleratum.com/?page id $=15$

Fecha de consulta: 11 de Enero de 2016.
} 
emprendedor, el Instituto Nacional del Emprendedor realiza cada año el proceso de reconocimiento de Aceleradoras e Incubadoras de empresas que ya forman parte de la Red de Apoyo al Emprendedor para mover a México.

Después de poco más de una década, han emergido cada vez más aceleradoras de empresas y de negocios, en su gran mayoría de tipo nacional, es decir, las que buscan fortalecer empresas locales e incrementar su potencial a un ámbito nacional. En el caso de las aceleradoras internacionales, su objetivo es identificar las empresas nacionales que tengan potencial para incursionar en mercados internacionales.

Para el año 2014, el Directorio de Aceleradoras Nacionales reportaba 15 organizaciones aceleradoras con 52 oficinas, distribuidas en 20 estados de la república, siendo la Ciudad de México la de mayor concentración de éstas con 14, seguida de Guadalajara con 5 y Monterrey con 4. El Estado de México y Querétaro contaban con 3 aceleradoras cada uno.

\begin{tabular}{|c|c|c|c|}
\hline & ORGANIZACIÓN ACELERADORA & OFICINAS & ESTADOS \\
\hline 01 & Impulsa & 18 & 16 \\
\hline 02 & Endeavor & 12 & 12 \\
\hline 03 & Tecnológico de Monterrey (ITESM) & 7 & 6 \\
\hline 04 & Ambar Negocios & 3 & 3 \\
\hline 05 & Universidad Anahuac & 2 & 2 \\
\hline 06 & UPDCE Instituto Politécnico Nacional & 1 & 1 \\
\hline 07 & ITESO A.C. & 1 & 1 \\
\hline 08 & Alcazar \& Compañía NETBA & 1 & 1 \\
\hline 09 & Business Coaching Firm (BCF) & 1 & 1 \\
\hline 10 & Ernst and Young & 1 & 1 \\
\hline 11 & Feher and Feher & 1 & 1 \\
\hline 12 & New Ventures México & 1 & 1 \\
\hline 13 & TechPYME & 1 & 1 \\
\hline 14 & Victoria 147 & 1 & 1 \\
\hline 15 & Servicios IGNIA SC & 1 & 1 \\
\hline
\end{tabular}

Aceleradoras Nacionales acreditadas por el INADEM, año 2014.

FUENTE: Elaboración propia con base en sitio web del INADEM. 
Debe considerarse que éstas son las aceleradoras acreditadas por el INADEM, pero existen más organizaciones aceleradoras. Para 2016, en el sitio web del INADEM se había modificado el directorio, manteniéndose las de mayor presencia (Impulsa, Endeavor y el ITESM), pero apareciendo otras aceleradoras y ausentándose otras. En el caso de la Ciudad de México, se mantuvieron 10 aceleradoras de las 14 acreditadas en 2014, el total se incrementó a 16, siendo estas 6 aceleradoras que no aparecían en el directorio dos años antes. Jalisco sólo contaba con 2 aceleradoras, de las cuales sólo el ITESO AC se mantenía. En el caso de Nuevo León, sólo se mantenía el ITESM y Servicios IGNIA SC. Para el Estado de México se conservaron tres aceleradoras, aunque Impulsa no aparece en el directorio, siendo sustituida por el ITESM Toluca. El caso de Querétaro, de 3 aceleradoras acreditadas en 2014, para 2016 sólo se mantenía en la acreditación el ITESM.

Se hace evidente la ausencia de Visionaria en ambos directorios, así como la aceleradora de la Universidad Panamericana, la cual suspendió sus actividades según informó uno de sus miembros, sin dar mayores detalles sobre los motivos. QLab es otra aceleradora que no aparece en los directorios más recientes. Estos tres casos son destacables por el hecho de participar en la red nacional de aceleradoras de la Secretaría de Economía en el sexenio 2006-2012, siendo Visionaria parte elemental del impulso y promoción del modelo de aceleración en México.

\section{Modelo general de Aceleración de empresas}

De acuerdo con Gerez y Czitróm (1982), un Modelo es una representación simplificada de carácter cualitativo o cuantitativo de un sistema, que puede estar ya funcionando o se puede estar diseñando. En el primer caso se emplea el modelo para obtener un conocimiento de su operación y estado futuro. En el segundo caso el modelo se usa para el diseño del sistema. El establecimiento de modelos es una mezcla de arte y ciencia en donde no existe ningún sustituto para la experiencia y los conocimientos. 
Chiavenato (2004: 361) destaca la representación simplificada de sistemas originales que forman parte de la realidad por medio de otros sistemas comparables -físicos o matemáticos- para la comprensión de su funcionamiento. Resalta de igual forma la creciente incertidumbre que enfrenta la administración, lo que potencializa los errores desproporcionadamente.

Un modelo es más simple que la realidad a la cual describe. Los elementos que el modelo incluye e ignora son resultado de conjeturas en torno a cuáles detalles son esenciales y cuáles no. El proceso de construir y comprobar modelos da lugar a teorías (Parkin, 2009: 12-13).

Cuando se supone que se conocen con certeza todos los aspectos del modelo, entonces se habla de un modelo determinista. Eppen et al. (2000) señalan que tendemos en forma natural a suponer que el mundo circundante es determinista, lo que permitiría entonces describir perfectamente la realidad, cosa que no es así. La utilidad de los modelos radica entonces en la aproximación razonablemente aceptable a la realidad, lo cual es casi siempre preferible a no tener algún modelo. En esta lógica de los autores, se hace referencia a que los modelos pueden optimizarse al pertenecer al mundo de lo abstracto, pero que rara vez o nunca es posible en las situaciones del mundo real (Ibíd.: 7).

De las anteriores definiciones de modelo, podemos construir una noción de su utilidad, partiendo de la base de ser representaciones simplificadas de ideas, objetos, procesos, sistemas o fenómenos que son parte de la realidad. Estas representaciones pueden ser no sólo cuantitativas sino también cualitativas, abstractas, matemáticas, conceptuales, gráficas, físicas o réplicas exactas, que ayudan al pensamiento, análisis, entendimiento, descripción, explicación, simulación o predicción razonablemente aceptable de la realidad al organizar o clasificar conceptos confusos o inconsistentes.

Sin embargo, al incorporar a la definición la complejidad, la incertidumbre y la racionalidad limitada, es posible delimitar el marco de utilidad de los modelos. El 
pensamiento complejo ${ }^{6}$ exige el reconocimiento de múltiples dimensiones de la realidad, interactuando con diferentes intensidades, direcciones y velocidades simultáneamente. El reduccionismo, la simplificación y abstracción de la realidad que implica la formulación de modelos conlleva el riesgo de obtener lecturas y visiones parciales, dejando de lado el entramado complejo y la incidencia determinante de fuerzas desestimadas al momento de construir el modelo. Al hacer referencia a los modelos determinísticos o probabilísticos se desestiman factores o categorías de análisis que resulta imposible hasta ahora medir y operacionalizar, lo que no significa que no tengan una carga decisiva en el fenómeno observado.

La incertidumbre forma parte de esta complejidad, pues como demostró Herbert Simon (1988: 78-81), los seres humanos poseemos una racionalidad limitada, lo que implica que no podemos considerar todas las causas del problema, todas las consecuencias, todas las alternativas de solución, todas sus consecuencias, todos los medios disponibles, todos los fines perseguidos y así tomar la decisión óptima. El acceso que se tiene sólo a ciertas partes de cada una de las categorías señaladas da cuenta de la complejidad a la que refiere Morin y la incertidumbre que expresaba Simon.

Montaño (2006: 4) define los modelos organizacionales como "representaciones generales de las estructuras y los procesos formales básicos asumidos para lograr los objetivos planteados por la organización [que] corresponden a una visión racional instrumental".

El pensamiento complejo debe complementar la toma de decisiones tratando de incorporar al análisis factores desechados u omitidos, muchas veces ocultos, o menospreciados por su naturaleza cualitativa, por lo que se requieren métodos diferentes de análisis que permitan reducir al menos la incertidumbre y mayor profundidad para anticipar comportamientos futuros del tema de interés en cuestión.

\footnotetext{
${ }^{6}$ Se sigue el concepto propuesto por Edgar Morín, en contraposición a la noción ortodoxa que emerge de la Cibernética de Wiener y la Teoría de Sistemas de Bertalanffy, la Investigación de Operaciones y los Sistemas Complejos Adaptables. Esto no implica su desestimación, sino más bien otorgarles la posición que les corresponde y complementarles en sus debilidades, aunque existan puntos inconmensurables. (Para ahondar en el tema, se sugieren: Velilla, 2002; Morin y Lemoigne, 2006 y; De Almeida, 2008).
} 
Con base en la revisión de la literatura y sitios de internet de las aceleradoras, se puede esbozar un modelo general de aceleración, ya que en estos años se ha homogenizado la forma de operar del modelo. Cada aceleradora desarrolla su propio modelo, lo esquematiza y utiliza los términos que considera apropiados, pero el proceso de certificación del INADEM ha llevado a un isomorfismo que se hace evidente ya en la descripción ofrecida en el portal del mismo al revisar cada una de las aceleradoras certificadas.

En el proceso de pre-aceleración, todas las aceleradoras de empresas buscan a las posibles candidatas a ingresar a sus procesos de aceleración, mediante una evaluación inicial. El tiempo en el cual se evaluará a los candidatos tomando en consideración diferentes características varía entre una y dos semanas, dependiendo de la aceleradora y de las diferentes características que evalúe cada una. Todas las aceleradoras de empresas tienen como requisito fundamental que la empresa esté legalmente constituida, que posea un potencial de crecimiento anual entre el 15 y el 25\% de sus ventas y que en los últimos tres años de operación hayan registrado ganancias. De aquí se desprenden diferentes criterios de selección de empresas, que varían desde la iniciativa del emprendedor hasta el nivel de facturación anual que tiene la empresa a acelerar.

Los principales requisitos que solicitan estas aceleradoras son que la idea de negocio tenga oportunidad de mercado, que el modelo de negocios que se presente sea innovador, con un alto perfil emprendedor y que posea un alto impacto positivo al medio ambiente y a la sociedad donde se encuentra inmersa.

En general, todas las aceleradoras de la Red Nacional se enfocan a acelerar comercialmente a las empresas que ingresan al programa. En una primera instancia, se aprovecha la inercia positiva que las empresas poseen en cuanto a crecimiento y ventas. La idea es acelerar ese crecimiento y volumen de ventas anual, consolidándose primero en el mercado local, aprovechando la diferenciación de sus productos, calidad, innovación, estudiando también la conveniencia para cada caso de expandirse regional o nacionalmente, de diversificar sus productos, crear nuevos canales de distribución, fortificar y acrecentar su red de contactos, 
todo esto orientado en explotar el mercado local y estableciendo metas cuantitativas antes de pasar a la etapa de exportación.

\section{Perfil de los candidatos:}

La valoración de los candidatos incluye el perfil del empresario y la particularidad de la empresa. Para el caso del primero se evalúan el compromiso y aspiración de cambiar para hacer crecer su empresa, mientras que, por las diferencias puntuales ya señaladas previamente, la organización candidata debe cumplir con el requisito de estar ya consolidada y con crecimiento sostenido en los últimos años (valorado por un mínimo de ventas anuales que es fijado por la aceleradora), desempeñarse en sectores con alta oportunidad de crecimiento, tener propuestas innovadoras y competitivas. Se evalúa también el tipo de tecnología desarrollada o incorporada en sus procesos productivos y el potencial de generación de empleos.

\section{Sectores atendidos:}

Las aceleradoras otorgan prioridad a sectores de vanguardia, aunque algunas manejan en su discurso la posibilidad de aceptar empresas de cualquier sector. Destacan en el directorio del INADEM los siguientes:

1. Tecnologías para la salud (Biotecnología, dispositivos médicos, pruebas clínicas, nuevos fármacos).

2. Mecatrónica y Manufactura avanzada (aeroespacial, automotriz).

3. Tecnologías de la información y comunicación [TIC's] (Cómputo en la nube, Tecnologías móviles, multimedia).

4. Química y petroquímica.

5. Tecnologías limpias (consumo sustentable, energía alternativa, vivienda y construcción sustentable, protección de biodiversidad).

6. Alimentos y agroindustria 


\section{Secuencia lógica:}

El isomorfismo referido ha derivado en una homogenización de prácticas, por lo que los modelos son más parecidos entre sí de lo que eran trece años atrás. El proceso de aceleración se puede reducir a cinco pasos o etapas:

1. Análisis de los postulantes (habilidades gerenciales y potencial del negocio)

2. Diagnóstico profundo (FODA, entrevistas)

3. Preparación con enfoque estratégico de la expansión (Matriz de decisión)

4. Transformación-aceleración

5. Evaluación, ajuste y Corresponsabilidad

El criterio de selección es la valoración subjetiva. Se suele entrevistar a los postulantes y revisar las características de la empresa. El rubro de innovación y generación de cadenas de valor es esencial y común para todas y cada una de las aceleradoras que conforman la Red Nacional, por lo que se encuentra como requisito indispensable para ingresar al programa de aceleración. Esto es, ser empresas en operación cuyos procesos productivos o productos finales sean innovadores y generar encadenamiento y valor agregado. De esta manera se da preferencia a procesos productivos por sobre procesos tradicionales, servicios 0 negocios de compra-venta sin valor agregado.

Si se considera apto para avanzar a la siguiente etapa, entonces se realiza una visita a la empresa. Se conforma el equipo de consultores, asesores o mentores, especialistas en las diferentes áreas estratégicas y se entrevistan con el empresario. Se expresa constantemente el análisis de Fortalezas, Oportunidades, Debilidades y Amenazas (FODA) como parte de la segunda etapa. Las áreas estratégicas analizadas para el diagnóstico abarcan los procesos administrativos, financieros, recursos humanos, mercadotecnia y ventas, control de calidad, productividad, competitividad y valor agregado, sensibilidad a requerimientos del cliente, 
cumplimiento jurídico y fiscal. No todas las aceleradoras contemplan todas las áreas, aunque las más consolidadas sí las mencionan en sus espacios.

Una vez concluido el diagnóstico -entre uno y tres meses-, se procede a la elaboración de planes estratégicos, basándose en lo arrojado en la etapa de diagnóstico por los especialistas. Es notoria la influencia persistente de la planeación estratégica en esta fase, pues se recurre a Cuadros de mando, matrices de decisión, reingeniería de procesos, análisis de sistemas e investigación de operaciones, o sistemas japoneses -kanban, Just in Time, Poka yoke, 5S's, Kaizencomo medios que permitirán alcanzar los objetivos planeados. Se establecen estados iniciales, escalas de medición, se asignan metas, responsables y plazos para alcanzarlas. El discurso se extiende al referirse a dar solidez a la estructura, profesionalizar y optimizar los procesos, emerger el liderazgo, elevar la competitividad, adoptar las mejores prácticas internacionales, incrementar el valor agregado y generar cadenas de valor integrales.

Tras la planeación se procede a la implementación de los planes, a la ejecución de las tareas, las cuales dependerán de las particularidades y necesidades de cada organización acelerada. Esta es propiamente la fase de aceleración, en donde se hace énfasis en el incremento de las ventas, la penetración de mercados y el crecimiento de la empresa o negocio. La obtención de financiamiento, sea por parte de la propia aceleradora, o bien por inversores privados, banca comercial o banca de desarrollo, juega un papel importante para lograr materializar los planes. Otro factor relevante es el acceso a las redes de contactos que proporciona la aceleradora a la organización acelerada, lo cual elimina la fricción resultante, facilitando el cumplimiento de los planes.

La última fase en realidad ocurre prácticamente al mismo tiempo, pues en eso consiste el término "acompañamiento", que conlleva control, evaluación y ajuste, por lo que la corresponsabilidad de los especialistas y empresarios toma un matiz particular, propio del modelo de aceleración.

Todo el proceso de aceleración se desarrolla en un intervalo de entre seis meses y un año, dependiendo de la aceleradora y la organización a acelerar. Este proceso 
resume el modelo general de una aceleradora nacional, es decir, partiendo de una candidata que atiende un mercado local o regional y cuyo tope alcanza el ámbito nacional -de ahí su denominación-. La aceleración internacional no es más que otro bucle del mismo proceso, sólo que el principio de éste se encuentra en las candidatas que ya dominan el ámbito regional o nacional y su objetivo es la exportación, por lo que los planes y redes se extienden más allá de las fronteras, lo que agrega complejidad y demanda mayor sensibilidad a la formulación de planes.

Una vez consolidado el crecimiento en el mercado local, se inicia la etapa de orientación a la exportación o ingreso al competido mercado internacional. Para ello, las empresas son asesoradas en cuanto a las normas internacionales de calidad y ambientales, en cuanto a empaque y embalaje de productos, barreras comerciales de tipo arancelario o administrativo, medio de transporte, canales de distribución, brokers, o en su caso, pros y contras de la apertura de una oficina comercial que los represente en el país o países destino. Uno de los puntos importantes tiene que ver con la capacidad de producción que permita obtener excedentes exportables de alta calidad internacional y con un margen de ganancia conveniente. Se requiere por tanto aprovechar la base tecnológica al máximo y poseer una rápida capacidad de respuesta e innovación frente a los competidores internacionales.

Una constante adicional que posee el modelo general es el ajuste continuo, actualización y refinamiento del mismo. Como ya se ha mencionado, se pueden encontrar documentos en internet de los modelos que se utilizaban en las aceleradoras a principios de la década pasada y contrastarlos con los más recientes que promueven en sus sitios web y propagandas que reparten en eventos para emprendedores y empresarios. La inclusión más notoria es la de propiedad intelectual y certificaciones de todo tipo, que en su gran mayoría no incluían en los modelos obsoletos y que se han incorporado recientemente como consecuencia del isomorfismo que la certificación del INADEM ha estimulado.

La generación de empleos, el desarrollo de clústers y empresas competitivas internacionalmente con productos y procesos innovadores tecnológicamente, la fabricación y aplicación de los mismos bajo parámetros de calidad, cuidado del 
ambiente y responsabilidad social, el fortalecimiento de la industria nacional, la disminución de la dependencia tecnológica y un impacto positivo en la economía, medible por el PIB y la balanza comercial son ideales que comparten las aceleradoras.

Para ello, cada una configura y pone en funcionamiento sus recursos y su estructura con características particulares y diferentes con respecto a las otras, pero en busca de realizar esa idealización. Sin embargo, hay puntos en los que coinciden para lograrlo, como el patentar procesos y productos innovadores para protegerlos y explotarlos por sus creadores, la utilización de la red de contactos para encontrarles mercados y aplicaciones en las industrias tecnológicas tanto en territorio nacional como internacional, así como el intercambio de conocimiento y transferencia de tecnología; el trabajo conjunto para optimizar y hacer eficientes los procesos productivos y de gestión sin restar flexibilidad, agilidad y capacidad de adaptación a la organización. Todas las aceleradoras de la Red Nacional ofrecen orientación y alternativas de financiamiento a las empresas que participan en el programa, ya sea por parte del gobierno federal, estatal o por organismos internacionales 0 instituciones de banca múltiple.

Se aprecia entonces que la participación de Universidades Públicas era nula todavía en estos programas hasta la incorporación del IPN (subdirección de aceleración de empresas de la UPDCE), mientras que el gobierno permite que la orientación económica neoliberal de las universidades y organizaciones privadas domine en la toma de decisiones de las organizaciones que ingresan al programa de aceleración. Respecto al funcionamiento de las Aceleradoras, existe escasa información disponible, lo que nos remite a la que proporciona tanto la Secretaría de Economía a través de los portales de México emprende, el Fondo PyME, el Sistema de Información Empresarial Mexicano, el portal de empresas gacela y los sitios web de cada una de las aceleradoras de empresas mencionadas.

Finalmente, cabe destacar la importancia de abordar desde los Estudios Organizacionales el caso de las aceleradoras de empresas de base tecnológica por las siguientes razones: 
Las aceleradoras de empresas pueden estudiarse considerándolas como organizaciones, contrastándolas con los diversos enfoques tanto de la Teoría de la Organización como de los Estudios Organizacionales, lo que implica un enriquecimiento en el conocimiento de estas organizaciones que pueden considerarse escasamente estudiadas. De igual manera, se puede considerar como una forma de organización el modelo de aceleración de empresas, colocándose entonces también dentro del ámbito de estudio de ambas corrientes teóricas.

Otro argumento es el hecho de que, al considerarse organizaciones, éstas se encuentran inmersas en el contexto social e inciden voluntaria o involuntariamente sobre otras organizaciones y sobre la sociedad misma en diversos ámbitos, no sólo en el económico. Recuperando la perspectiva contingencial, la organización incide en su entorno y éste simultáneamente lo hace sobre la organización. Conviene por tanto conocer de qué manera y en qué medida se da esta relación, sus implicaciones y efectos.

\section{Aclaración de términos}

Antes de continuar con el análisis, es importante esclarecer algunos términos que se encuentran constantemente en la literatura y el discurso respecto al tema. Como se ha apreciado, el aspecto del financiamiento se encuentra entrelazado a lo largo de la argumentación. De ello se derivan los términos "start-up, capital semilla, inversores ángeles y venture capital".

Start-up: Idea de negocio en construcción, en donde la tecnología e innovación son factores clave, pues son las bases sobre las que operan, los medios por los cuales abordan el mercado, y el diferencial que aportan en sus productos y servicios. Su costo de operación es bajo y el potencial de ganancias es exponencial, por lo que resulta atractivo para inversionistas tanto de capital de riesgo (Venture) como Ángeles (padrinos). Se consideran inversiones de alto riesgo debido a la alta tasa de mortandad de los nuevos negocios, los cuales deben superar los costos de 
operación durante un periodo de tiempo de alrededor de dos años y tener ganancias mínimas o nulas, mientras se posicionan y consolidan en el mercado y se cumple el periodo de recuperación de la inversión (pay-back).

Capital semilla: Sugiere que se trata de una inversión temprana, en la fase de creación del negocio hasta que consigue generar su propio cash flow (flujo de caja), o hasta que está listo para una nueva inversión. Es necesario para actividades como la investigación de mercado y el desarrollo de producto, por lo que se considera una inversión de riesgo, en donde la valoración subjetiva como la confianza y la fe determinan la inversión. La principal fuente de capital semilla se conoce coloquialmente como las Tres F (Familiares, amigos y locos; en inglés, family, friends and fools, respectivamente). Otras fuentes son los inversores ángeles y los Venture capital (entidades de capital de riesgo).

Inversores Ángeles: Mecenas empresariales que invierten sus propios fondos para proveer capital para las start-up, así como conocimientos empresariales o profesionales adecuados para el desarrollo de la sociedad en la que invierten a cambio de participación accionaria. La decisión de invertir implica la valoración del plan de negocio presentada por el emprendedor al inversor y los criterios personales para invertir de éste.

Venture Capital: Las entidades de Capital de riesgo o capital emprendedor administran profesionalmente dinero de terceros a través de un fondo (fondo de capital de riesgo). Este fondo es invertido en empresas start-up con el propósito de aumentar su valor y madurar la inversión. Esta es la principal diferencia con respecto a la "private equity", orientada a inversiones en empresas ya consolidadas. A cambio, los inversionistas obtienen derechos de propiedad del activo de éstas, aunque sólo mientras transcurre el periodo de recuperación de la inversión y obtienen ganancias prefijadas al momento de concretar el trato. Se obtiene este fondo si el emprendedor propone un plan de negocios que resulte atractivo para el comité de inversión. 


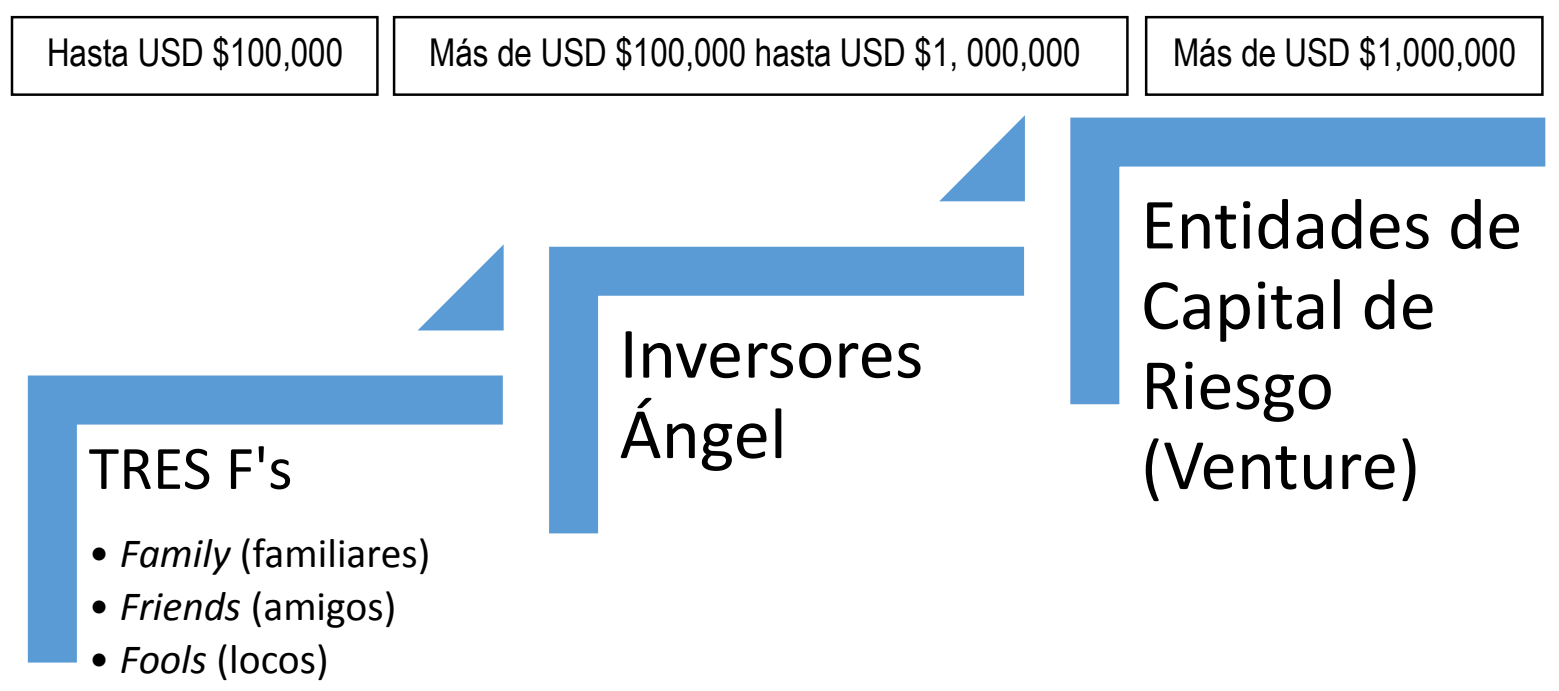

Opciones de financiamiento a start-ups.

FUENTE: Elaboración propia.

\section{El vínculo entre MIPyME's y aceleradoras de empresas}

Es de aceptación generalizada el argumento de que las empresas constituyen el principal motor que impulsa el desarrollo económico, la riqueza y la prosperidad de las naciones, por lo que los esfuerzos se han orientado a incentivar su desarrollo y a superar las problemáticas a las que se enfrentan. Sin embargo, aunque ciertos sectores industriales han logrado consolidarse, otros no lo han logrado a pesar de todo el esfuerzo intelectual y de recursos de todo tipo. Una probable explicación propuesta es la orientación mayoritariamente económica con la que se tratan las problemáticas, convirtiendo hechos y fenómenos en variables operacionales con las cuales realizar operaciones aritméticas, estadísticas y econométricas que hacen que se pierda de vista que la competitividad, la calidad, la productividad y otros conceptos no son más que eso, constructos abstractos para tratar de explicar fenómenos que no son explorados ni analizados desde otras perspectivas como la sociológica, la psicológica, la antropológica e incluso la jurídica y la política. Tras los fríos números que indican crecimientos porcentuales en la producción bruta o mejor 
posicionamiento frente a otras naciones en cuanto a competitividad o comercio, se mueven intereses personales, inquietudes, anhelos, proyectos de vida, conflictos, patrimonios familiares, todos ellos ámbitos que los modelos y explicaciones económicas no alcanzan a describir.

Si se considera entonces que esta lógica económica racionalista plantea soluciones causales en las que a un determinado incremento en una variable se inducirá un cambio en otra dependiente de ésta, siempre y cuando "todo lo demás permanezca igual" y que de esta manera se plantean las políticas de desarrollo industrial, los programas sectorial, los financiamientos y mecanismos de apoyo, se puede atisbar la razón de tan pobres resultados. Un ejemplo claro lo constituye la consideración del sector de mipymes como un bloque homogéneo al cual se dirigen planes y recursos para incrementar su número y su competitividad.

Dentro del periodo en que la apuesta estratégica fue hacia la gran industria, la actividad económica de las Micro, Pequeñas y Medianas Empresas (MIPyME's) siguió siendo un sector fundamental para el desarrollo del país, tanto por su número y porcentaje productivo en el país, el empleo que ofrecían, así como por la capacidad de adaptación y respuesta a las contingencias de su entorno.

En 1985 los resultados arrojados por el censo de INEGI mostraban ya la importancia de las microempresas mexicanas en cuanto a número, pero también las deficiencias en cuanto a la generación de empleos y la participación en la producción interna bruta. Elizondo y Delgado hacen la comparación con Japón para el mismo periodo, evidenciando la importancia que las microempresas japonesas tenían por su aporte al PIB, a la generación de empleos y al número total de empresas (Elizondo y Delgado en Mulás 1995: 86).

En el transcurso de estos años, a pesar de las estrategias y políticas encaminadas al apoyo de las MIPyME's en cuanto a financiamiento, capacitación y asesorías, no se logró un apoyo relevante al sector. En cada periodo establecido por Unger es visible la importancia estratégica que se ha dado por parte del Estado al desarrollo de la ciencia y la tecnología como pilar de crecimiento industrial. Sin embargo la participación gubernamental ha ido decreciendo desde los ochenta a la fecha, 
enfocándose hoy en día la estrategia en el desarrollo de infraestructura y atracción de inversión extranjera con propuestas específicas como exención de impuestos o mano de obra barata, que impactó más en el ámbito maquilero.

De la Rosa, Montoya y Pomar plantean el interés en el sector MiPyME's desde la academia y el gobierno, dada su importancia en términos de generación de empleos, aportación al producto interno bruto, el número de establecimientos que representa y su potencial como actor económico (De la Rosa, Montoya y Pomar, 2009: 23). De igual manera reconocen la utilidad y necesidad del conocimiento del sector desde la perspectiva económica sin ser suficiente para explicar cabalmente al mismo.

En un artículo previo, De la Rosa refiere al discurso general de las MiPyME's (2000: 184) se refiere al conjunto de escritos argumentativos, explicativos, interpretativos y/o declarativos que se entretejen para establecer nociones y significados generales o específicos acerca de algún tema. Por su parte, Mumby y Clair (1997:181) plantean que las organizaciones existen sólo en la medida en que sus miembros las crean a través del discurso. Esto no es afirmar que los organizaciones son "nada más que" discurso, sino más bien que el discurso es el principal medio por el cual los miembros de una organización crean una realidad social coherente que enmarca su sentido de quienes son.

De lo anterior entonces se establece la necesidad de rastrear los argumentos que justifican y legitiman la estratificación de empresas según el tamaño, el cual se mide por el número de personas que laboran para las empresas, así como la producción de riqueza (ingreso). Generalmente el discurso oficial ${ }^{7}$ se convierte en la principal fuente legitimadora, pues en México no se desconfía de los argumentos que se sustentan en la estadística del Instituto Nacional de Estadística y Geografía. La revisión contenida en este documento busca algo más en el argumento de que el

\footnotetext{
${ }^{7}$ De la Rosa (2000: 184) establece la existencia simultanea de tres discursos que conforman el Discurso General de la MiPyME: el discurso oficial, proveniente de entidades oficiales como la Secretaría de Economía y el INEGI; el discurso académico, el cual genera información y conocimiento desde la investigación académica de universidades y otros centros de investigación; y el discurso managerial o administrativo, sustentado en la experiencia de gerentes, administradores y consultores empresariales. Cada uno de estos discursos persigue objetivos diferentes, movidos por intereses diversos que le dan a cada uno su caracterización respecto a los otros,.
} 
sector de las MiPyME's requiere ser apoyado para impulsar su crecimiento por su relevancia para la economía nacional.

La declaración expresada por el propio INEGI refleja esta orientación económica al abrir su marco teórico en el documento dedicado a las micro, pequeñas y medianas empresas, destacando la necesidad de fortalecer su desempeño al incidir de manera fundamental en el comportamiento de las economías nacionales tanto en países industrializados como en los de menor grado de desarrollo (2009: 11).

Si bien es innegable que los gráficos y estadísticos presentados refuerzan esta postura que se difunde y multiplica en artículos, textos y ponencias oficiales, académicas y empresariales, parece pasarse por alto algo más, la heterogeneidad de un sector que se ha estratificado para comodidad de los analistas y no de acuerdo a las necesidades reales de los quienes componen las empresas, lo cual trata de mostrarse a continuación.

Para este ejercicio se utilizaron los tabulados nacionales de unidades económicas por sector privado y paraestatal, específicamente los de manufacturas, comercio al por mayor, al menudeo y servicios, al igual que el de personal ocupado.

Las variables extraídas para este análisis son:

Número Total de Establecimientos

Número Total de Personal ocupado

Ingreso Total Bruto de las unidades económicas

Estas son consideradas relevantes por el autor, dado que son las mismas que se consideran para segmentar a las empresas en la Secretaría de Economía ${ }^{8}$, al igual que en otras partes del mundo. Las variables están referenciadas de acuerdo con la base de datos a los totales por entidad federativa para el año 2008 para los sectores manufactura, comercio y servicios, por ser considerados tanto desde el ámbito gubernamental como el académico como los que en mayor proporción concentran micro, pequeñas y medianas empresas.

${ }^{8}$ De acuerdo con el más reciente ajuste, publicado en el DOF el 30 de Junio de 2009. 
La clasificación en estos sectores se hace en México tomando como referencia el Sistema de Clasificación Industrial de América del Norte (SCIAN), según el cual, los sectores económicos seleccionados para este estudio se clasifican como sigue:

\begin{tabular}{|c|c|c|}
\hline ACTURAS & COMERCIO & SERVICIOS \\
\hline $\begin{array}{l}\text { Transformación mecánica, física } 0 \\
\text { química, maquila, ensamble. } \\
\\
21 \text { Subsectores } \\
86 \text { Ramas } \\
182 \text { subramas } \\
292 \text { clases de actividad } \\
\\
\text { Industrias características } \\
\text { Industria Siderúrgica } \\
\text { Industria Automotriz } \\
\text { Industria Cementera } \\
\text { Industria Cervecera } \\
\text { Refinación de petróleo } \\
\text { Licores } \\
\text { Pinturas } \\
\text { Herrería } \\
\text { Panadería } \\
\text { Tortillería } \\
\text { Purificación de agua } \\
\text { Entre otras }\end{array}$ & $\begin{array}{l}\text { Compra-Venta (sin transformar) de } \\
\text { bienes de capital, materias primas, } \\
\text { suministros y bienes para uso } \\
\text { personal o para el hogar. (40 ramas) } \\
\text { Comercio al por mayor } \\
7 \text { subsectores } \\
\text { Bodegas, poca o nula exhibición de } \\
\text { mercancías, venta de grandes } \\
\text { volúmenes. } \\
\text { Comercio al Por menor } \\
9 \text { subsectores } \\
\text { Ubicación y diseño del } \\
\text { establecimiento, extensa exhibición } \\
\text { de mercancías, publicidad masiva. }\end{array}$ & $\begin{array}{l}\text { Actividades económicas que tienen } \\
\text { por objeto la satisfacción de un } \\
\text { tercero, ya sea en su persona o en } \\
\text { sus bienes. } \\
11 \text { Sectores } \\
\text { Información en medios masivos } \\
\text { Servicios financieros y de seguros } \\
\text { Servicios inmobiliarios y de alquiler de } \\
\text { bienes muebles e intangibles } \\
\text { Servicios profesionales, científicos y } \\
\text { técnicos } \\
\text { Servicios corporativos } \\
\text { Servicios de apoyo a los negocios y } \\
\text { manejo de desechos y servicios de } \\
\text { remediación } \\
\text { Servicios educativos } \\
\text { Servicios de salud y de asistencia } \\
\text { social } \\
\text { Servicios de esparcimiento, culturales } \\
\text { y deportivos y otros servicios } \\
\text { recreativos } \\
\text { Servicios de alojamiento temporal y } \\
\text { de preparación de alimentos y } \\
\text { bebidas } \\
\text { Otros servicios excepto servicios } \\
\text { gubernamentales (Reparación y } \\
\text { mantenimiento, salones y clínicas de } \\
\text { belleza, baños públicos, lavanderías, } \\
\text { tintorerías, servicios funerarios, } \\
\text { asociaciones religiosas, políticas, } \\
\text { civiles y similares). }\end{array}$ \\
\hline
\end{tabular}

Clasificación de sectores productivos en México.

FUENTE: Elaboración propia con base en sitios web del SCIAN e INEGI.

Son seleccionadas de acuerdo con el discurso en torno a la competitividad de las naciones vigente, el cual Porter (1991: 12) expresa la falta de consenso respecto al término competitividad, pues "para las empresas, competitividad significaba la capacidad de competir en los mercados mundiales con una estrategia mundial. Para muchos miembros del congreso, competitividad significaba que la nación tuviera 
una balanza comercial positiva. Para algunos economistas, competitividad significaba un bajo coste unitario de mano de obra ajustado a los tipos de cambio."

Sin embargo, a pesar de que esta afirmación supera ya las dos décadas, sigue prevaleciendo esta confusión y se sigue persiguiendo una competitividad basada en factores de tipo económico. Por ello es considerado que el tamaño, el número de trabajadores, la producción bruta entre otras como el agregado de valor, la calidad, los salarios bajos y las condiciones prevalecientes en la región son variables operacionales que permiten cuantificar y medir su comportamiento, así como la posibilidad de incidir sobre ellas de manera causal.

En años recientes se ha manifestado el interés en la competitividad de las naciones a través del desarrollo de sus empresas, desarrolladas a partir de la revolución industrial y que se han consolidado como pieza fundamental en el siglo XX para la prosperidad de las naciones o su rezago cuando éstas no son lo suficientemente competitivas. Uno de los teóricos más consultados para la argumentación al respecto es Michael E. Porter, el cual desde los años ochentas se ha centrado en el análisis de la relación de las empresas, los sectores industriales y la competitividad y prosperidad económica.

Porter (1991) destaca que lo relevante del término competitividad se encuentra en la productividad de las empresas y de los sectores industriales que permiten a las naciones competir con otras y obtener ventajas que se reflejan en la economía y en el nivel de vida de la población de cada nación.

La base de datos se construyó a partir de diferentes archivos del INEGI, generados en el Censo Económico 2009. Este método estadístico es empleado para poder conocer las características de los establecimientos productores de bienes, comercializadores de mercancías y prestadores de servicios a nivel nacional, con un gran nivel de detalle geográfico y sectorial.

De acuerdo con el Censo Económico 2009, en el año 2008 se contabilizaron $3,724,019$ unidades económicas ${ }^{9}$ en el sector privado y paraestatal. El $98.4 \%$ de

${ }^{9}$ El INEGI utiliza indistintamente los términos Unidad Económica, Establecimiento y Negocio. 
ellas y el $90.2 \%$ del personal ocupado en unidades económicas privadas 0 paraestatales están concentrados en tres sectores: Manufacturas, comercio y servicios.

Número de Unidades Económicas en México por sector al año 2008

FUENTE: Elaboración propia con base en INEGI (2009)

\begin{tabular}{lrr} 
SECTOR & \multicolumn{1}{c}{ Unidades } \\
Económicas & \\
Manufacturas & 436,851 & $11.7 \%$ \\
Comercio & $1,858,550$ & $49.9 \%$ \\
Servicios & $1,367,287$ & $36.7 \%$ \\
Sumatoria & $3,662,688$ & $98.4 \%$ \\
Total Nacional & $3,724,019$ & $100 \%$ \\
Otros & 61,331 & $1.6 \%$
\end{tabular}

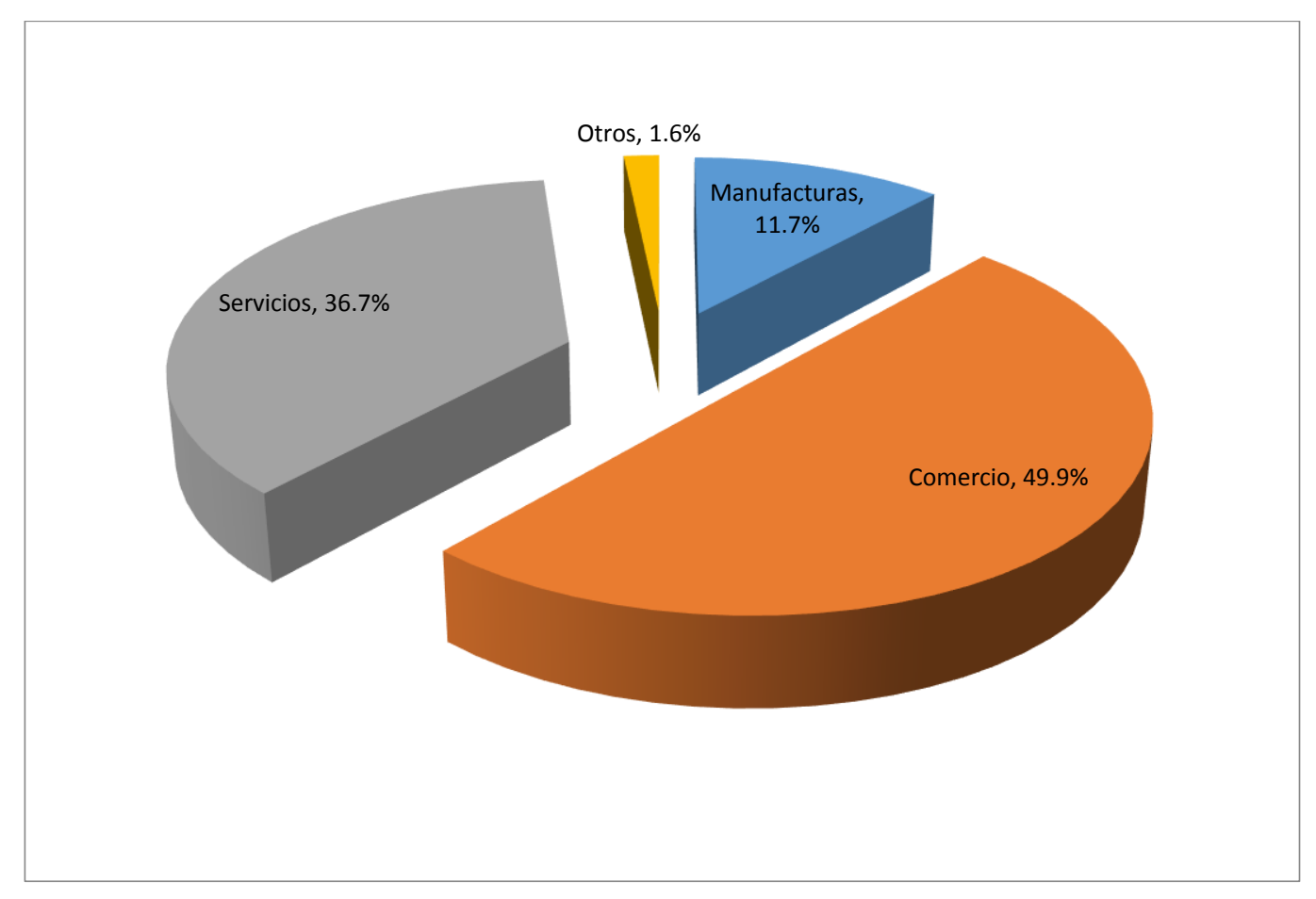


Personal ocupado por sector en México al año 2008

FUENTE: Elaboración propia con base en INEGI (2009)

SECTOR

Manufacturas

Comercio

Servicios

Sumatoria

Total Nacional

Otros

$\begin{array}{rr}\text { Personal ocupado } & \\ 4,661,062 & 23.2 \% \\ 6,134,758 & 30.5 \% \\ 7,340,216 & 36.5 \% \\ 18,136,036 & 90.2 \% \\ 20,116,834 & 100 \% \\ 1,980,798 & 9.8 \%\end{array}$

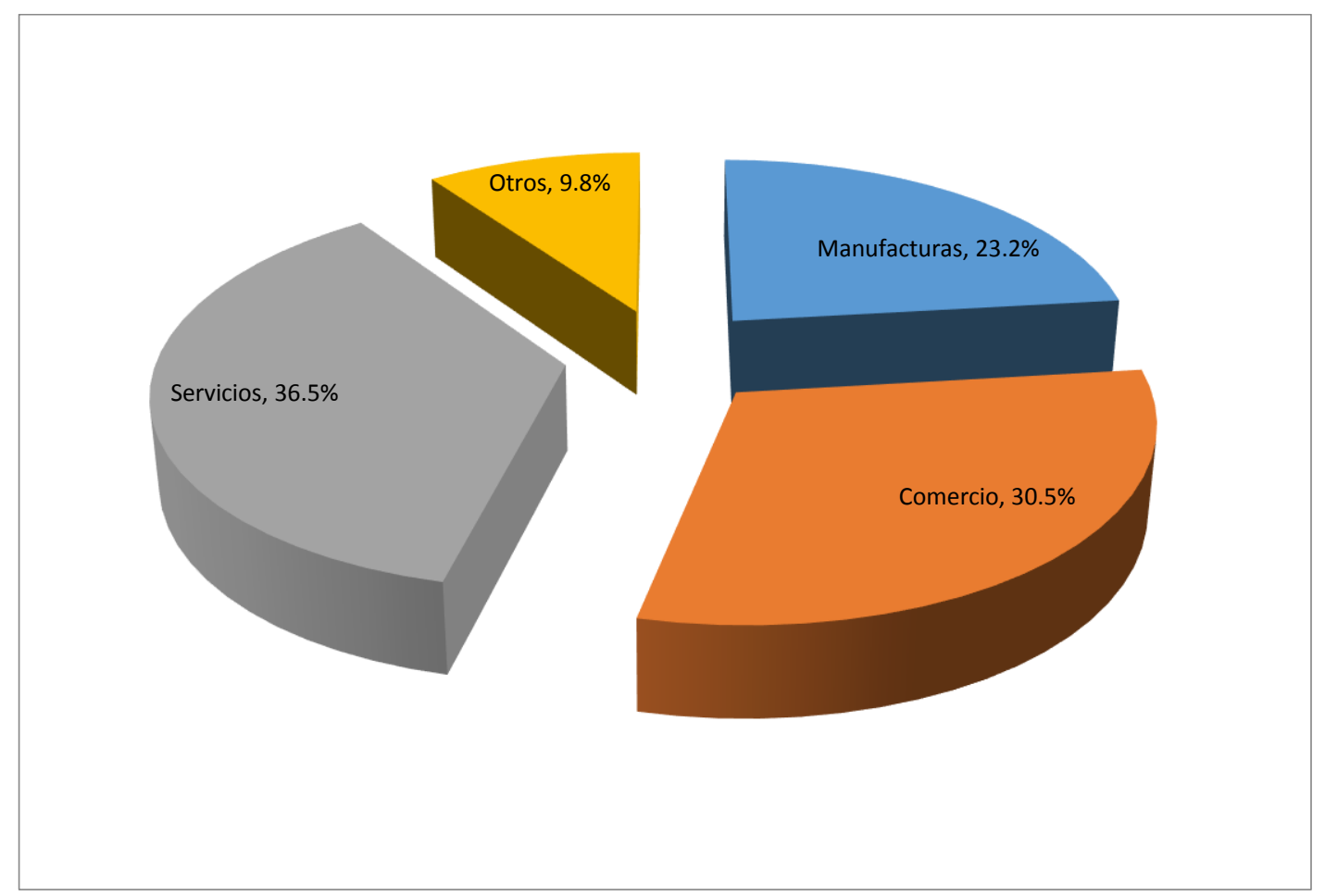

Utilizando la base de datos que segmenta por número de trabajadores a las unidades económicas, tenemos el siguiente cuadro: 


\section{Clasificación por número de trabajadores, número de Unidades Económicas, Porcentaje y \\ Tamaño en México al año 2008}

FUENTE: Elaboración propia con base en INEGI (2009) y México (2002)

\begin{tabular}{|c|c|c|c|c|c|c|}
\hline \multirow{3}{*}{$\begin{array}{l}\text { Número de } \\
\text { Trabajadores } \\
0-2\end{array}$} & \multirow{2}{*}{\multicolumn{2}{|c|}{$\begin{array}{l}\text { Unidades } \\
\text { Económicas }{ }^{10}\end{array}$}} & \multicolumn{3}{|c|}{ Clasificación } & \\
\hline & & & $\begin{array}{l}\text { Unidades } \\
\text { Económicas }\end{array}$ & Tamaño & Porcentaje & \\
\hline & $2,389,447$ & $65.2 \%$ & \multirow{3}{*}{$3,499,035$} & \multirow{3}{*}{ Micro } & \multirow{3}{*}{$95.5 \%$} & \multirow{8}{*}{$\begin{array}{c}\text { Sector de la Micro, } \\
\text { Pequeña y Mediana } \\
\text { Empresa mexicana } \\
\text { (Censo Económico 2009) }\end{array}$} \\
\hline $3-5$ & 894,028 & $24.4 \%$ & & & & \\
\hline $6-10$ & 215,560 & $5.9 \%$ & & & & \\
\hline $11-15$ & 58,199 & $1.6 \%$ & \multirow{3}{*}{132,130} & \multirow{3}{*}{ Pequeña } & \multirow{3}{*}{$3.6 \%$} & \\
\hline $16-20$ & 27,633 & $0.8 \%$ & & & & \\
\hline $21-50$ & 46,298 & $1.3 \%$ & & & & \\
\hline $51-100$ & 15,379 & $0.4 \%$ & \multirow{2}{*}{25,454} & \multirow{2}{*}{ Mediana } & \multirow{2}{*}{$0.7 \%$} & \\
\hline $101-250$ & 10,075 & $0.3 \%$ & & & & \\
\hline $251-500$ & 3,502 & $0.1 \%$ & \multirow{3}{*}{6,069} & \multirow{3}{*}{ Grande } & \multirow{3}{*}{$0.2 \%$} & \\
\hline $501-1000$ & 1,635 & $0.04 \%$ & & & & \\
\hline 1001 o más & 932 & $0.03 \%$ & & & & \\
\hline Total & $3,662,688^{11^{*}}$ & $100 \%$ & & & & \\
\hline
\end{tabular}

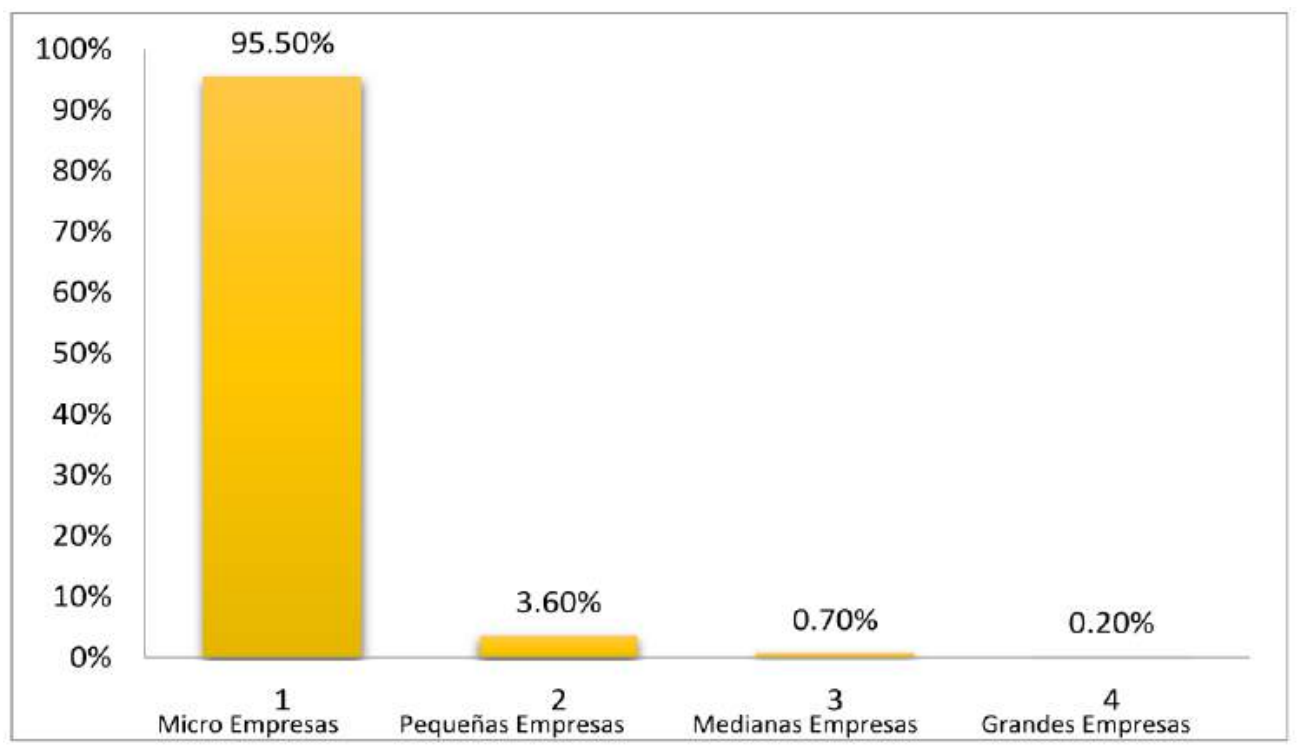

10 Considerando sólo los sectores de Manufacturas, Comercio y Servicios que representan el $98.4 \%$ del total de establecimientos contabilizado en el Censo Económico 2009.

* Este total es el que corresponde a la sumatoria de establecimientos de Manufacturas, Comercio y Servicios, es decir, el $98.4 \%$ del total de establecimientos contabilizados en el Censo Económico 2009. 
De esta tabla se puede entonces aplicar el criterio utilizado en México de acuerdo a la Secretaría de Economía, la Secretaría de Hacienda y el Instituto Mexicano del Seguro Social para clasificar a las unidades económicas por el número de trabajadores de las mismas, según el Diario Oficial de la Federación del 30 de diciembre de 2002.

Esta clasificación se ha generalizado tanto en las secretarías de estado como en aquellas organizaciones relacionadas como los centros de investigación y universidades, considerando un solo bloque conocido como Micro, pequeña y mediana empresa, o bien MiPyME o simplemente PyME. Si lo consideramos de esta forma, el 99.8\% de las empresas de Manufacturas, Comercio y Servicios del país pertenece a este bloque o sector. Si se consideran el total de establecimientos contabilizados en el censo -en todos los sectores y subsectores productivos-, constituyen el $98.2 \%$ del total de empresas en el país.

En las siguientes gráficas se aprecia la distribución de empresas manufactureras, así como también la de establecimientos de comercio y servicios:

Total Establecimientos manufactureros por Entidad Federativa (2009)

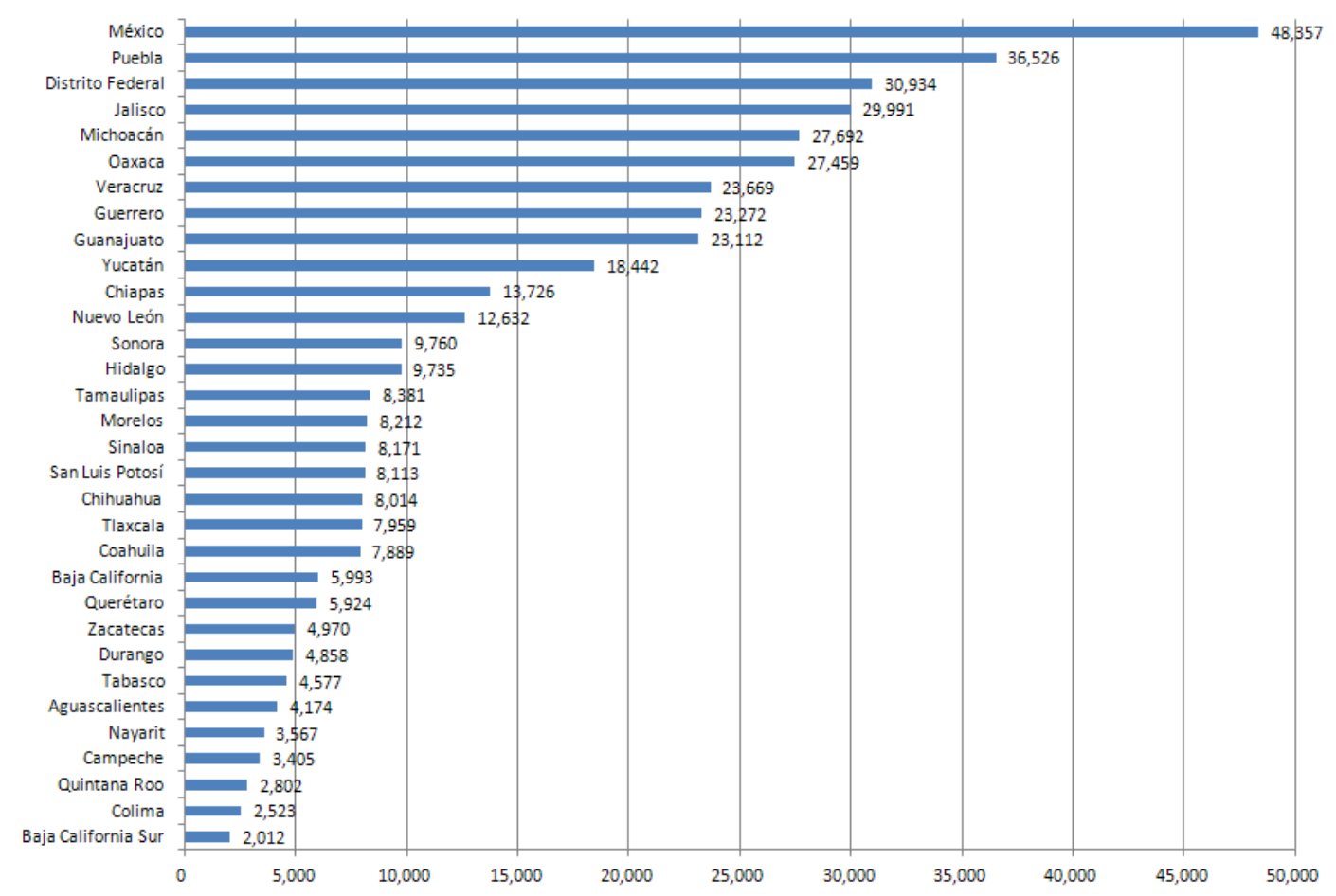

FUENTE: Elaboración propia con base en INEGI (2009) 
Desde esta grafica se percibe la enorme diferencia existente en el número de establecimientos manufactureros, en donde se destacan estados cuyo desarrollo industrial e intensa actividad económica les permite despegarse de otros estados menos favorecidos, como se verá en las gráficas sucesivas. En esta gráfica se está considerando el total de empresas de manufacturas, comercio y servicios privadas y paraestatales, como se argumenta al principio, correspondientes al $98.4 \%$ del total de empresas.

Se aprecia una distribución asimétrica sesgada por los valores extremos que en este caso lo constituye el estado de México.

Para hacer un acercamiento al sector de empresas manufactureras y poder diferenciar entre el sector conocido como MiPyME's se elaboró la siguiente gráfica que muestra la distribución porcentual que compone el total de las empresas manufactureras.

Distribución porcentual de empresas manufactureras por entidad federativa y tamaño (2009)

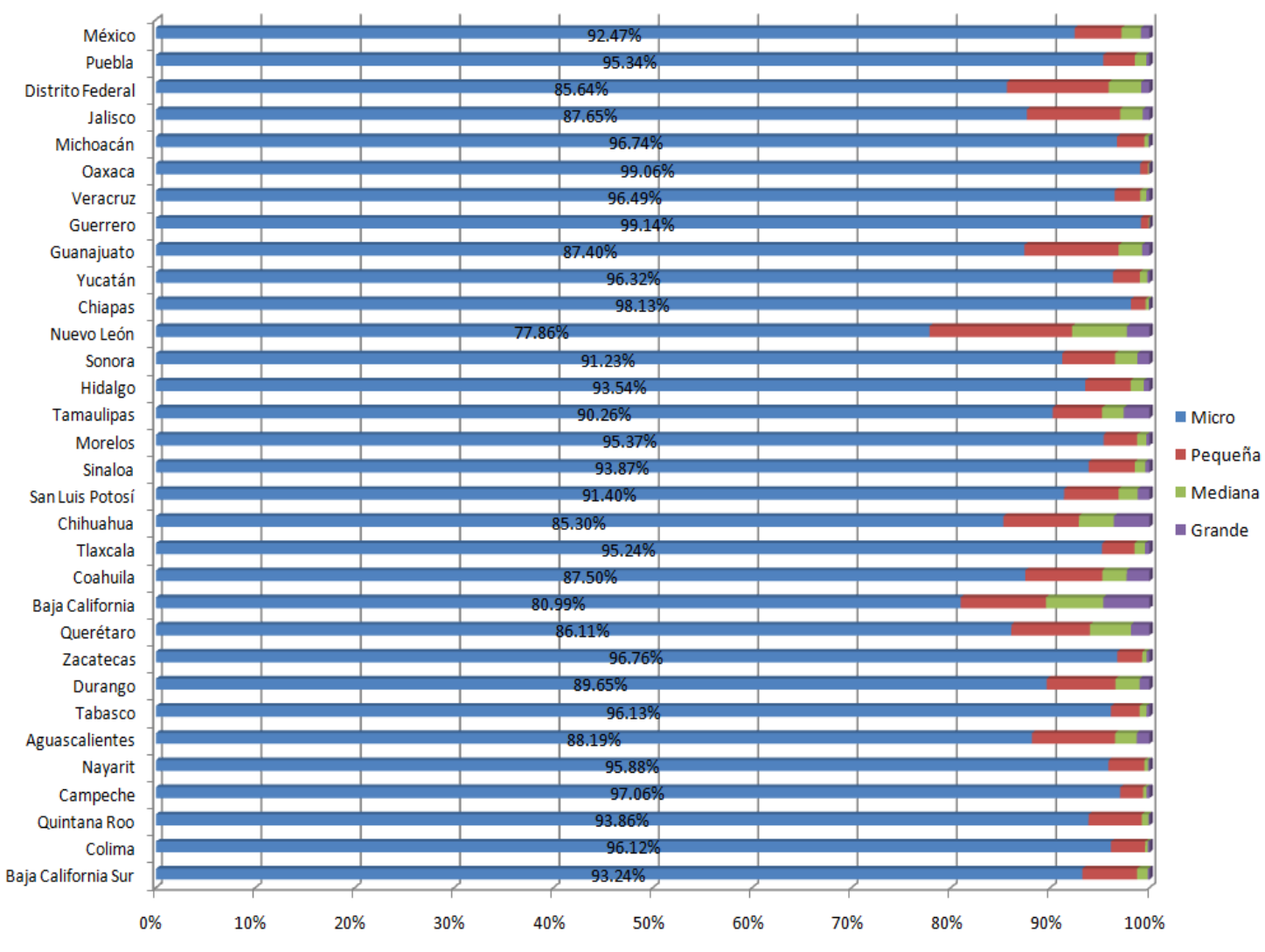

FUENTE: Elaboración propia con base en INEGI (2009) 
Como puede observarse, existe una alta composición de micro empresas manufactureras en cada estado, sin importar su ubicación geográfica regional. Con excepción de Nuevo León (77.86\%), en el resto de los estados las micro empresas manufactureras superan el $80 \%$ del total de manufactureras, llegando en el caso de Oaxaca hasta el 99\%. Puede entonces concluirse que en cuanto a empresas manufactureras se refiere, al menos 8 de cada 10 están conformadas por menos de 10 trabajadores. El porcentaje para pequeñas y medianas es en realidad bajo; y sin embargo se acostumbra considerarlas como un bloque homogéneo junto con las microempresas.

En cuanto al sector comercio, se observa una heterogeneidad de igual magnitud, comenzando con la siguiente gráfica:

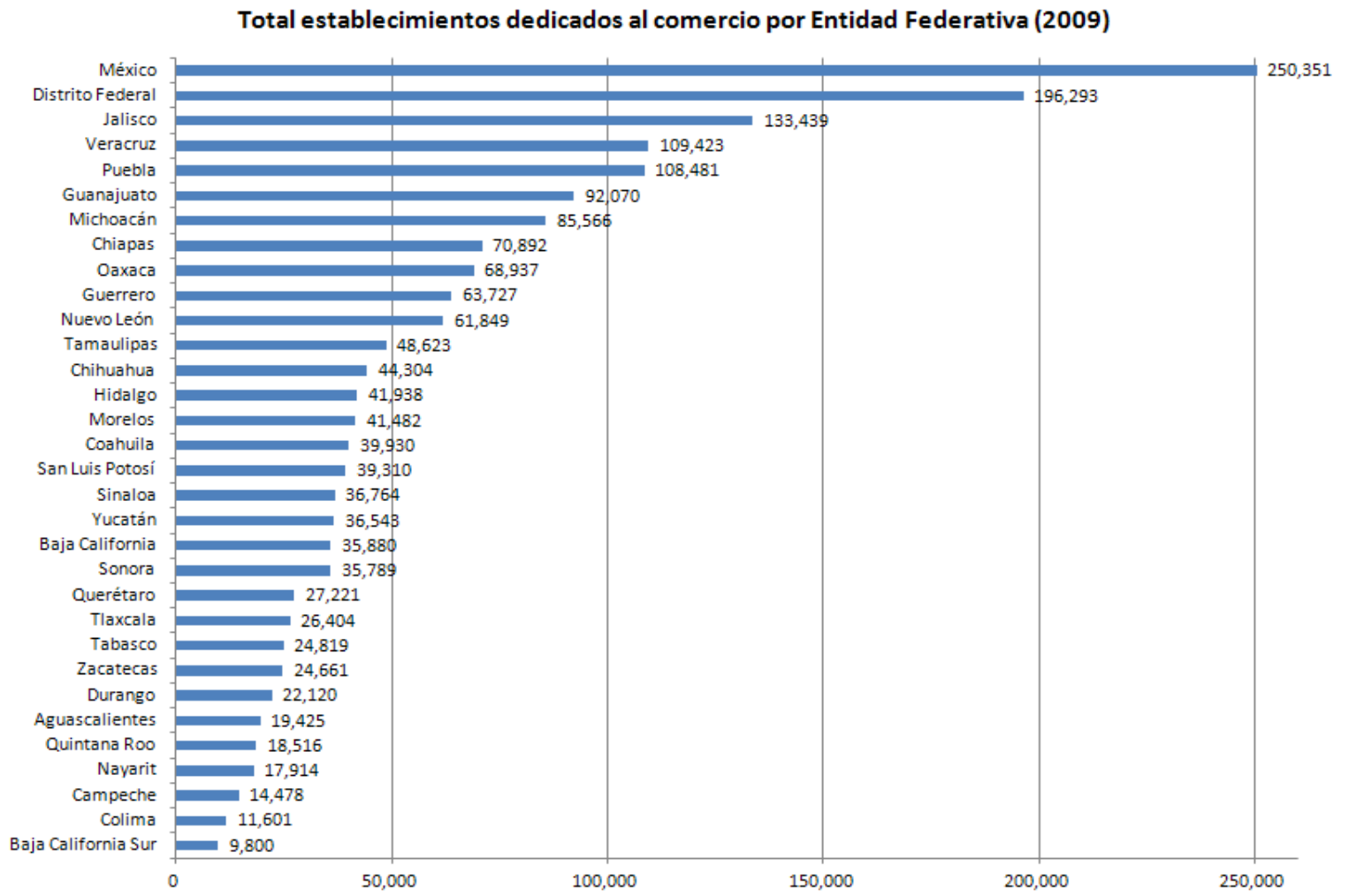

FUENTE: Elaboración propia con base en INEGI (2009) 
Nuevamente el estado de México se diferencia altamente del resto de los estados, junto con el Distrito Federal. La actividad económica de empresas comerciales es altamente concentrada en esta región del centro del país.

Al revisar la composición por tamaño de estas empresas dedicadas a la comercialización, se aprecia que nuevamente las micro empresas comercializadoras conforman 9 de cada 10 empresas dedicadas a esta actividad económica. El porcentaje menor nuevamente lo representa Nuevo León con un 93\%, siendo todos los demás estados de una composición superior a este porcentaje. En Tlaxcala, el 99\% de las empresas del sector comercio tienen menos de 10 trabajadores. De igual manera, el porcentaje de pequeñas y medianas empresas en este sector es reducido.

Distribución porcentual de empresas dedicadas al comercio por entidad federativa y tamaño (2009)

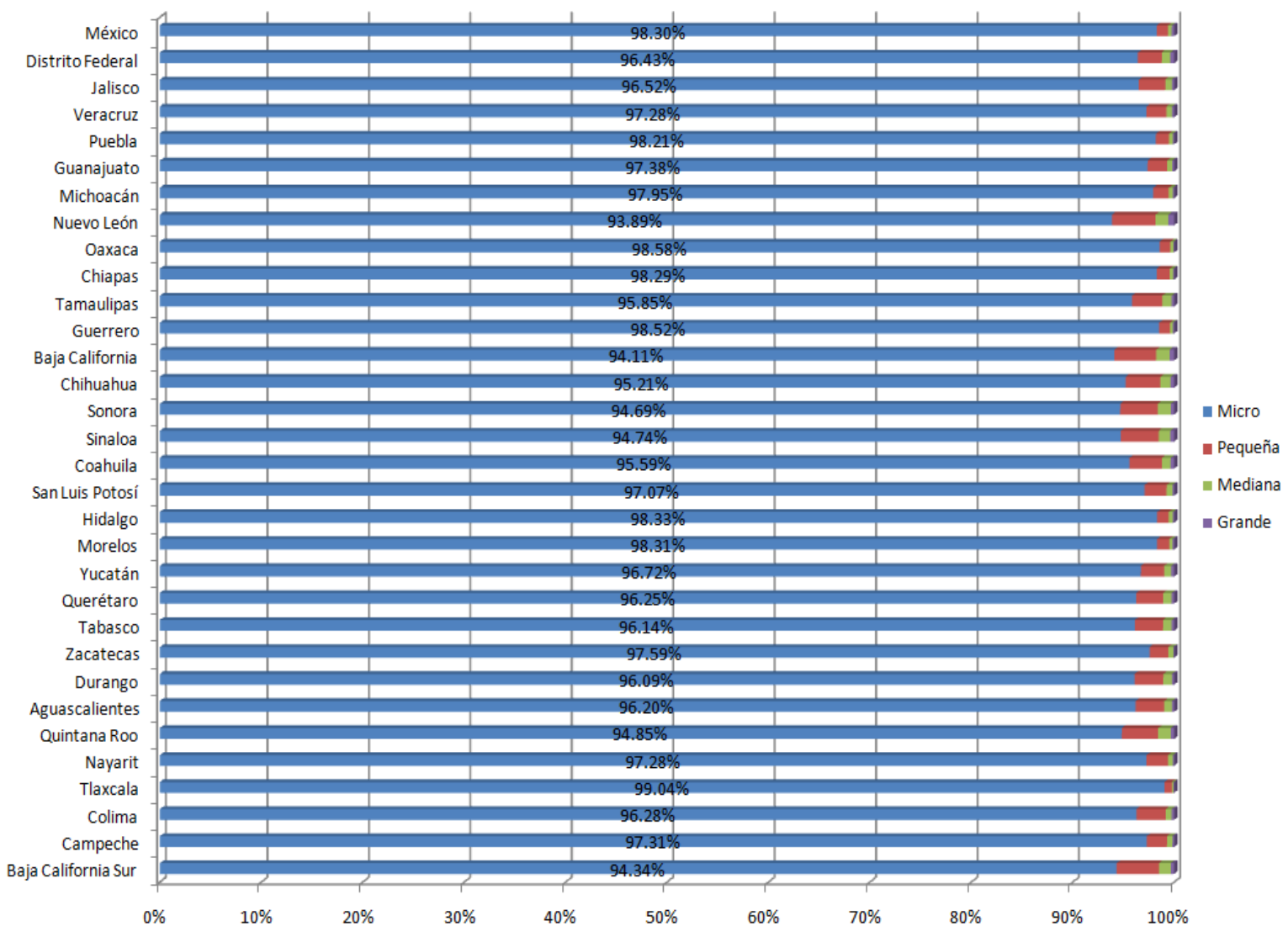

FUENTE: Elaboración propia con base en INEGI (2009) 
En el sector de empresas dedicadas a prestación de servicios, el número de establecimientos también es altamente heterogéneo, como se aprecia en la gráfica que contiene el total de empresas por entidad federativa en este sector:

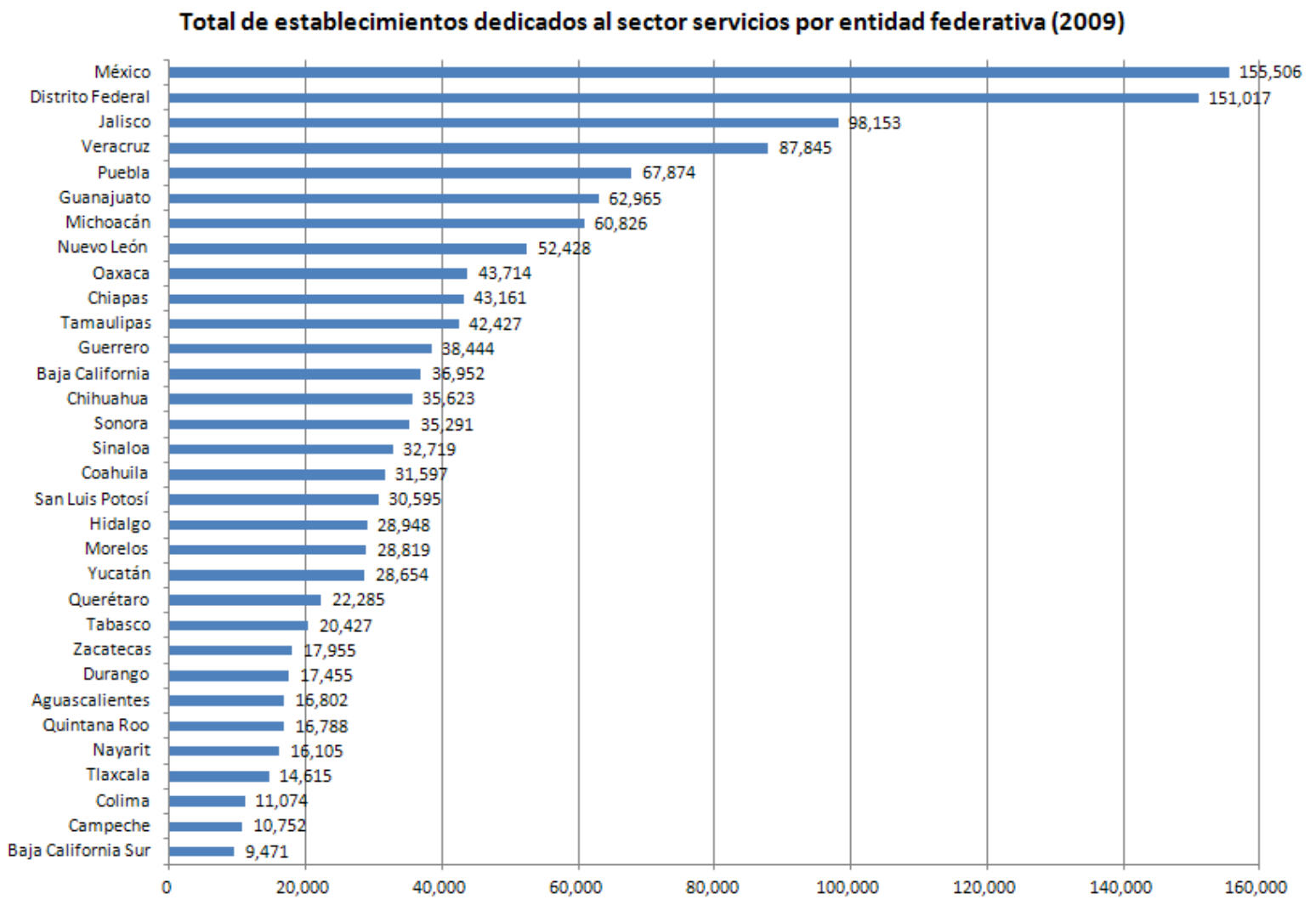

FUENTE: Elaboración propia con base en INEGI (2009)

Al igual que en los sectores anteriores, en la siguiente gráfica se observa que la composición de empresas dedicadas al sector servicios es mayoritariamente representada por micro empresas, pues con excepción de Quintana Roo (88.85\%), en el resto de los estados 9 de cada 10 empresas dedicadas al sector servicio están compuestas por menos de 10 trabajadores. De igual forma se aprecia la composición de pequeñas empresas respecto a las medianas y a las grandes. 
Distribución porcentual de empresas de servicios por entidad federativa y tamaño (2009)

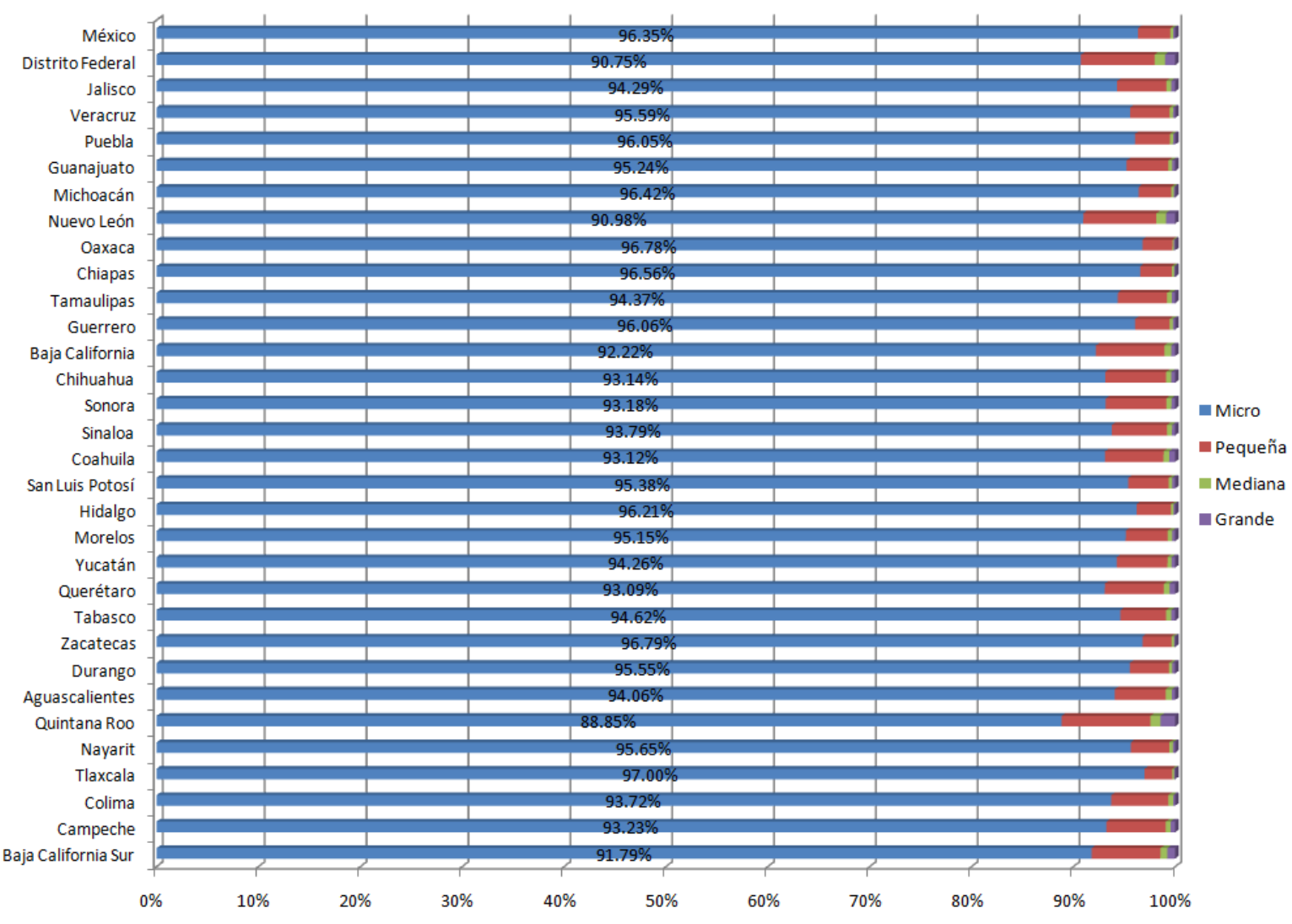

FUENTE: Elaboración propia con base en INEGI (2009)

En resumen, si consideramos que el discurso general en torno a las MiPyME's se refiere a este como un bloque homogéneo ("las MiPyME's" o "el sector MiPyME"), en realidad la mayor concentración es compuesta por micro empresas en cualquiera de los tres sectores, sin importar la ubicación geográfica. La heterogeneidad puede explicarse siguiendo a Porter en el mayor desarrollo de ciertas regiones como consecuencia de las condiciones de infraestructura y facilidades existentes y otorgadas. Sin embargo, esto no cambia el hecho de que aún en esas regiones la composición de micro empresas sea abrumadora.

Entonces, existe un sesgo discursivo al incluir a las pequeñas y medianas empresas en un solo bloque junto con las microempresas, puesto que se constituyen estas últimas en el fundamento legitimador para argumentar la importancia de las primeras, dado el enorme número de MiPyME's. Al destinarse recursos a este 
sector, la mayoría son absorbidos por medianas y pequeñas empresas, más que por las microempresas.

\section{Personal Ocupado}

Otro argumento del discurso general de las MiPyME's es el que refiere a la importancia del sector debido a la alta concentración de fuentes empleo en este sector. Como se había expresado previamente en este documento, poco más de 20 millones de personas se encuentran empleadas en empresas del sector privado y paraestatal, de las cuales 18 millones 136 mil se concentran en los sectores de manufacturas, comercio y servicios aquí revisados. La distribución sigue una correspondencia. En los estados con mayor número de empresas se observa una mayor cantidad de trabajadores insertos en éstas.

Personal ocupado en el sector privado por entidad federativa al año 2008

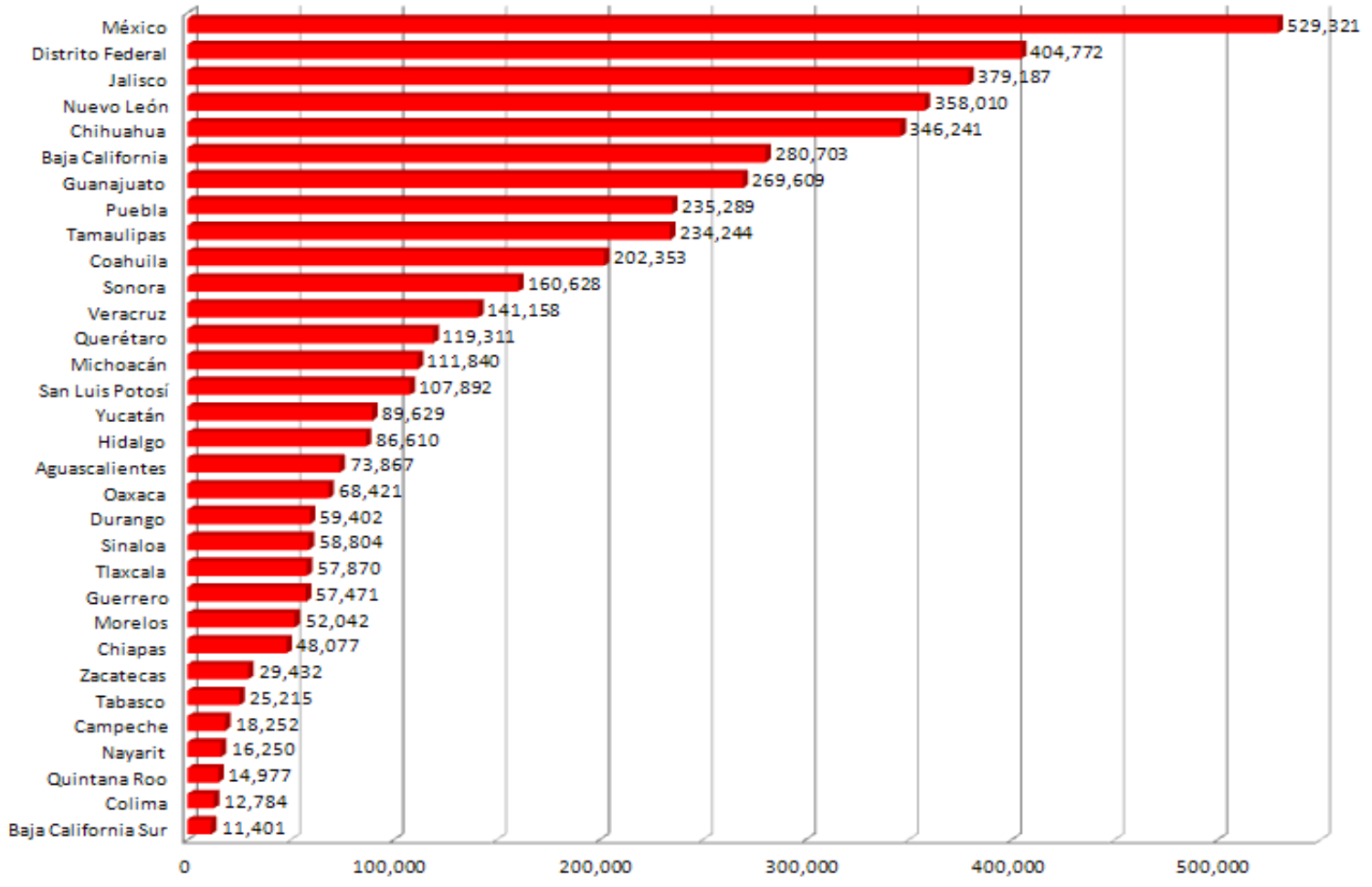

FUENTE: Elaboración propia con base en INEGI (2009) 
Se puede apreciar la heterogeneidad de trabajadores en empresas manufactureras. Esta heterogeneidad se manifiesta en la distribución respecto a la media, con los correspondientes casos atípicos.

Se puede apreciar entonces una elevada dispersión que no parece indicar más que datos confusos. Sin embargo, esto es de utilidad para desmitificar el bloque de MiPyME's, pues como se observa en la siguiente gráfica, al analizar la concentración de personal por tamaño de empresa, se observa una alta concentración en la gran empresa, sin que sea un patrón común. Esta heterogeneidad es tan variable de acuerdo al estado que demanda una atención específica de acuerdo al sector y entidad que se tenga interés. Por ejemplo, en Oaxaca el $75 \%$ se emplea en microempresas manufactureras, mientras que en Chihuahua sólo el $5.9 \%$ trabaja en microempresas, mientras que el $80 \%$ de los trabajadores están concentrados en las grandes empresas, mientras que en Baja California Sur sólo el 9.21\% trabaja en grandes empresas.

Distribución \% personal ocupado en manufactureras por Entidad Federativa y tamaño (2009)

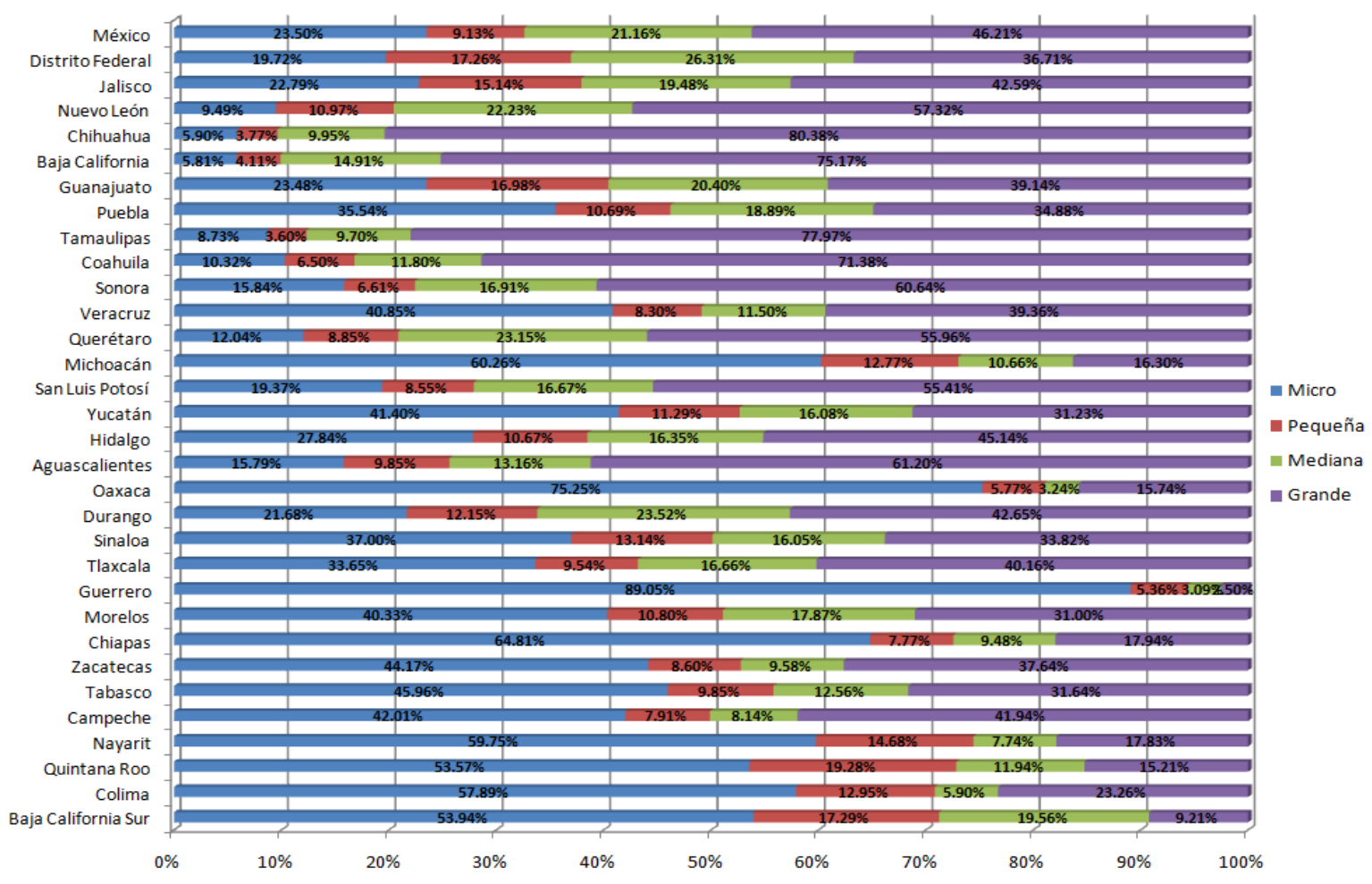

FUENTE: Elaboración propia con base en INEGI (2009) 
Al observar el total de personal ocupado en el sector comercio, se observa la misma heteronegeidad, tanto en el comercio al por mayor, como en el comercio al menudeo.

\section{Personal total ocupado por Estado, Sector Comercio al por Mayor} (2009)

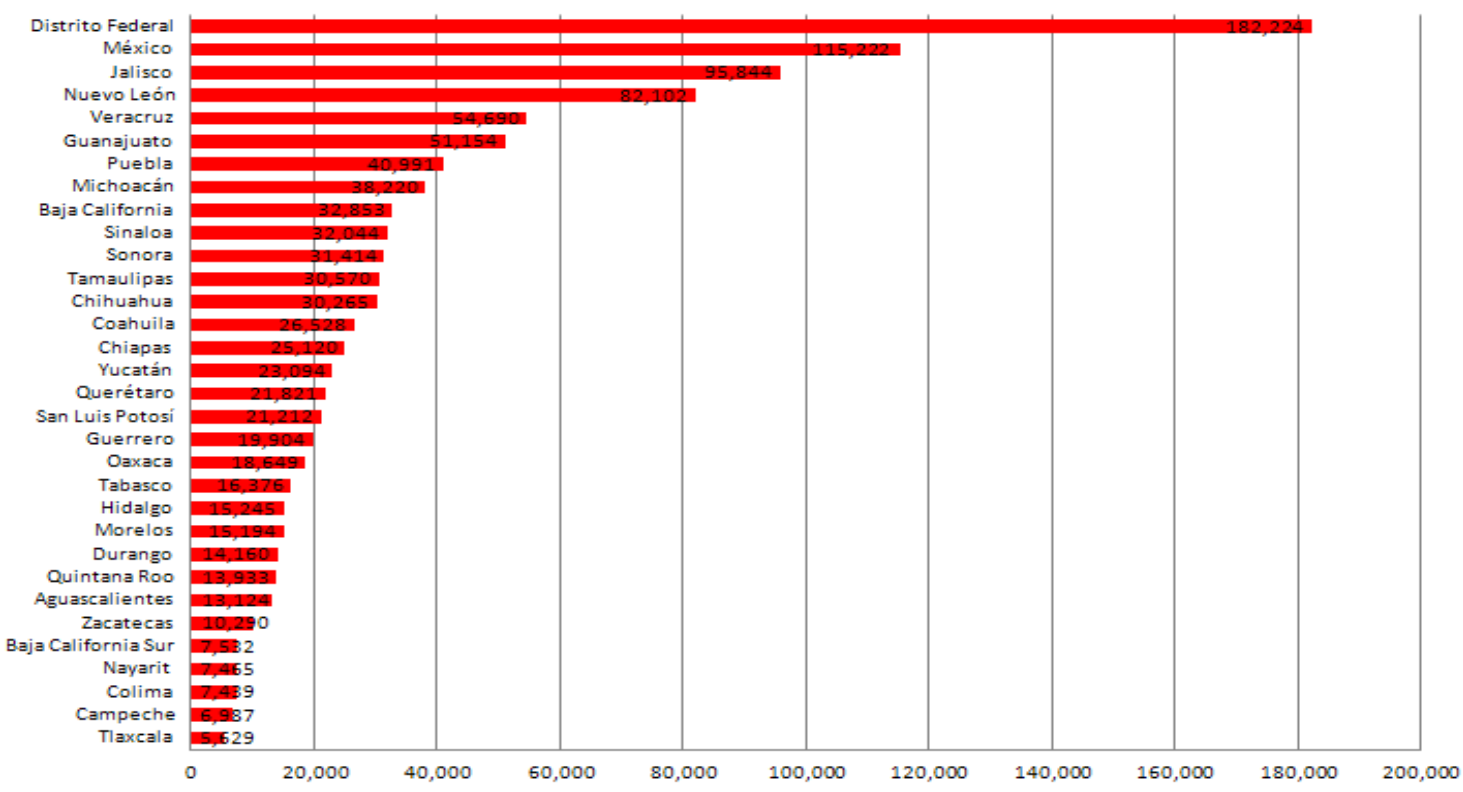

Personal Total Ocupado Comercio al menudeo (2009)

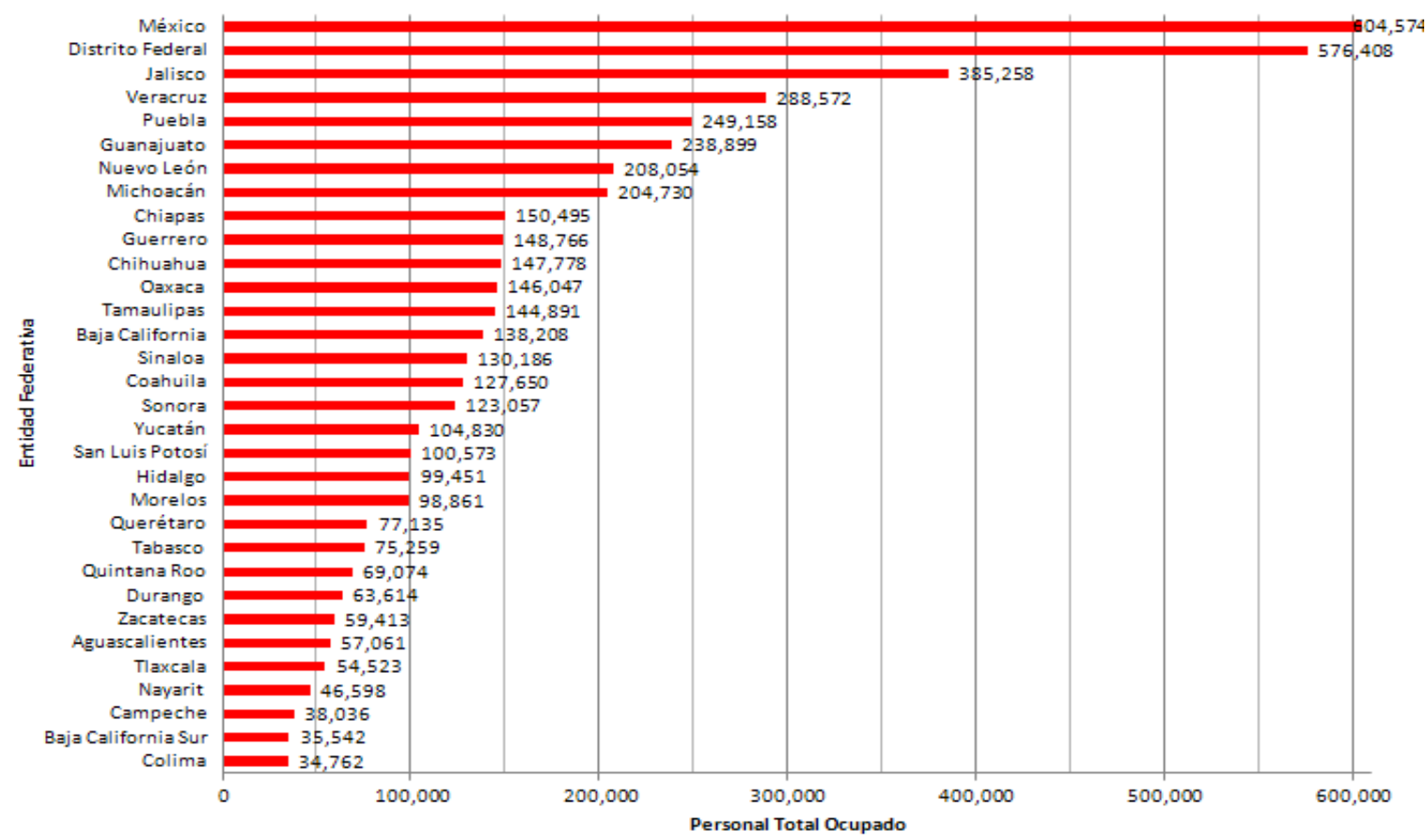

FUENTE: Elaboración propia con base en INEGI (2009) 
Como se aprecia en las gráficas, existe una mayor concentración de personal en el comercio al menudeo y de igual manera, la concentración se da en los estados en donde esta actividad se encuentra más dinamizada (Estado de México y Distrito Federal). Esta separación del sector comercio permite también observar la heterogeneidad incluso en cada entidad, pues como se aprecia, el Distrito Federal concentra una gran cantidad de empleados en comercio al por mayor, pero es superado en comercio al menudeo por el Estado de México. Lo mismo sucede con la comparación en las otras entidades.

Sin embargo, al enfocar el análisis a la composición por tamaño y entidad, se aprecia una mayor consistencia en la composición de personal empleado en empresas dedicadas al comercio de tamaño micro que en el sector manufacturero. Con excepción de Nuevo León (48.29\%), 1 de cada 2 trabajadores empleados en empresas comerciales, se encuentra laborando en una micro empresa.

Distribución \% personal ocupado en empresas de comercio por Entidad Federativa y tamaño (2009)

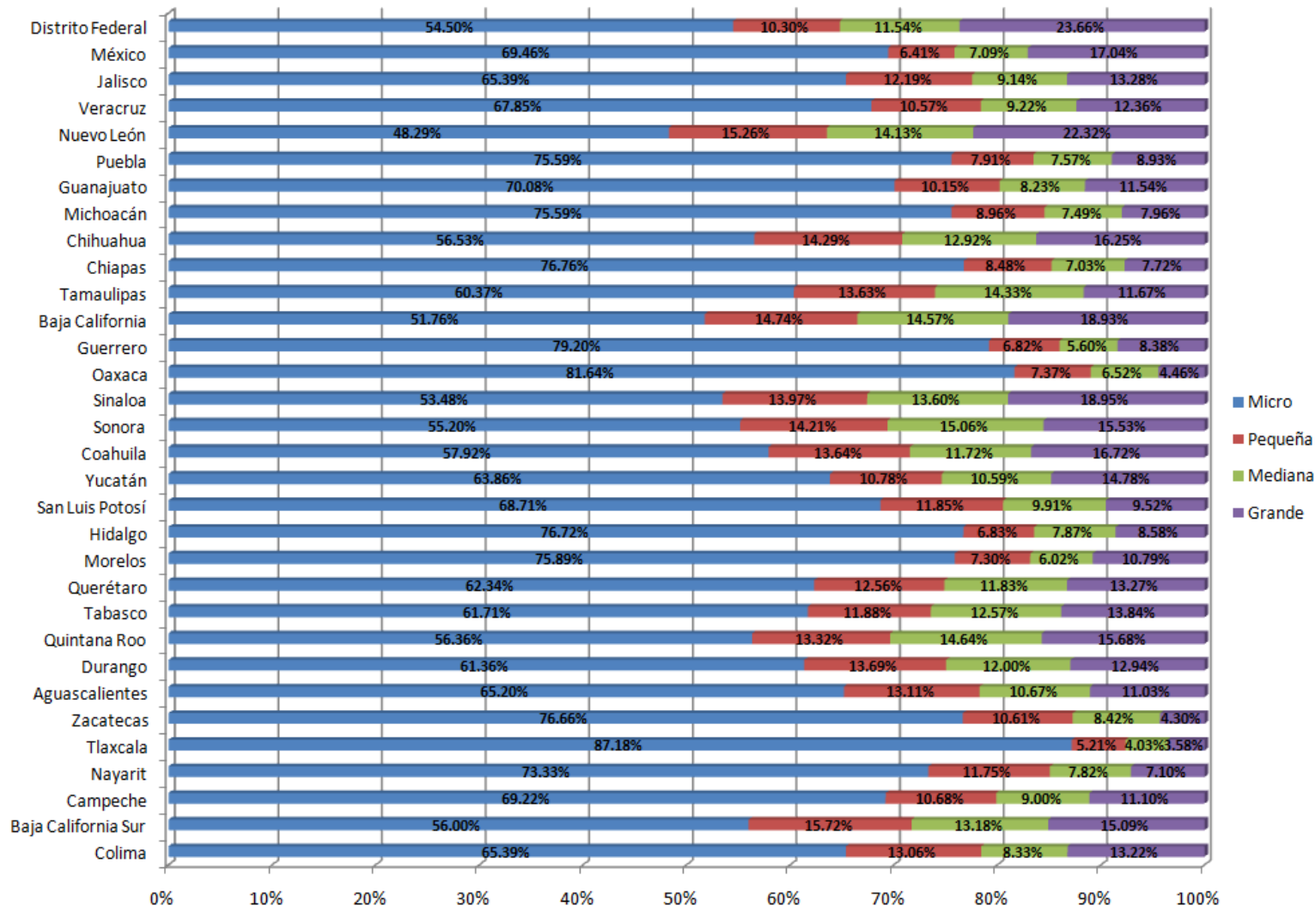

FUENTE: Elaboración propia con base en INEGI (2009) 
En el sector servicios se observa un dato extremo o atípico considerable, puesto que el número de trabajadores empleados en empresas de servicios en el Distrito Federal es casi 3 veces mayor que el segundo estado (México).

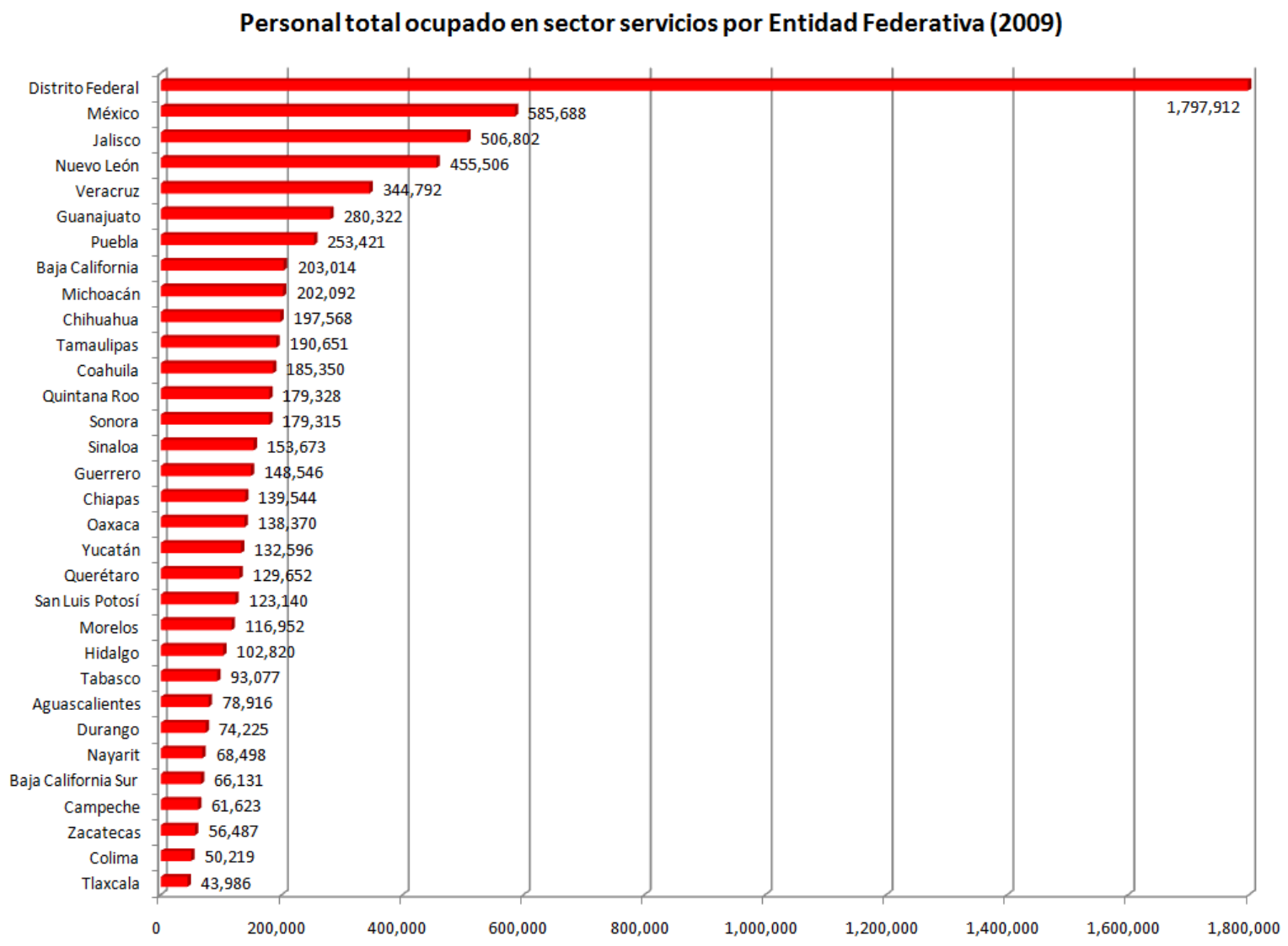

FUENTE: Elaboración propia con base en INEGI (2009)

En este caso se puede apreciar que la desviación estándar es mayor que la media como consecuencia del valor atípico que representa el número de personas trabajando en el Distrito Federal en el sector servicios, el cual no es representativo del resto de los estados y sí altera los valores estadísticos.

Ahora bien, esta alta concentración de personal en el sector servicios del Distrito Federal, como se aprecia a continuación, se da en las grandes empresas dedicadas a este sector ( 6 de cada 10 en el DF). Aunque es altamente heterogénea esta distribución, se puede apreciar cierto predominio de micro empresas, aunque nuevamente depende del interés particular que se tenga en una entidad. 
Porcentaje de Micro, Pequeñas, Medianas y Grandes empresas por entidad federativa al año 2008

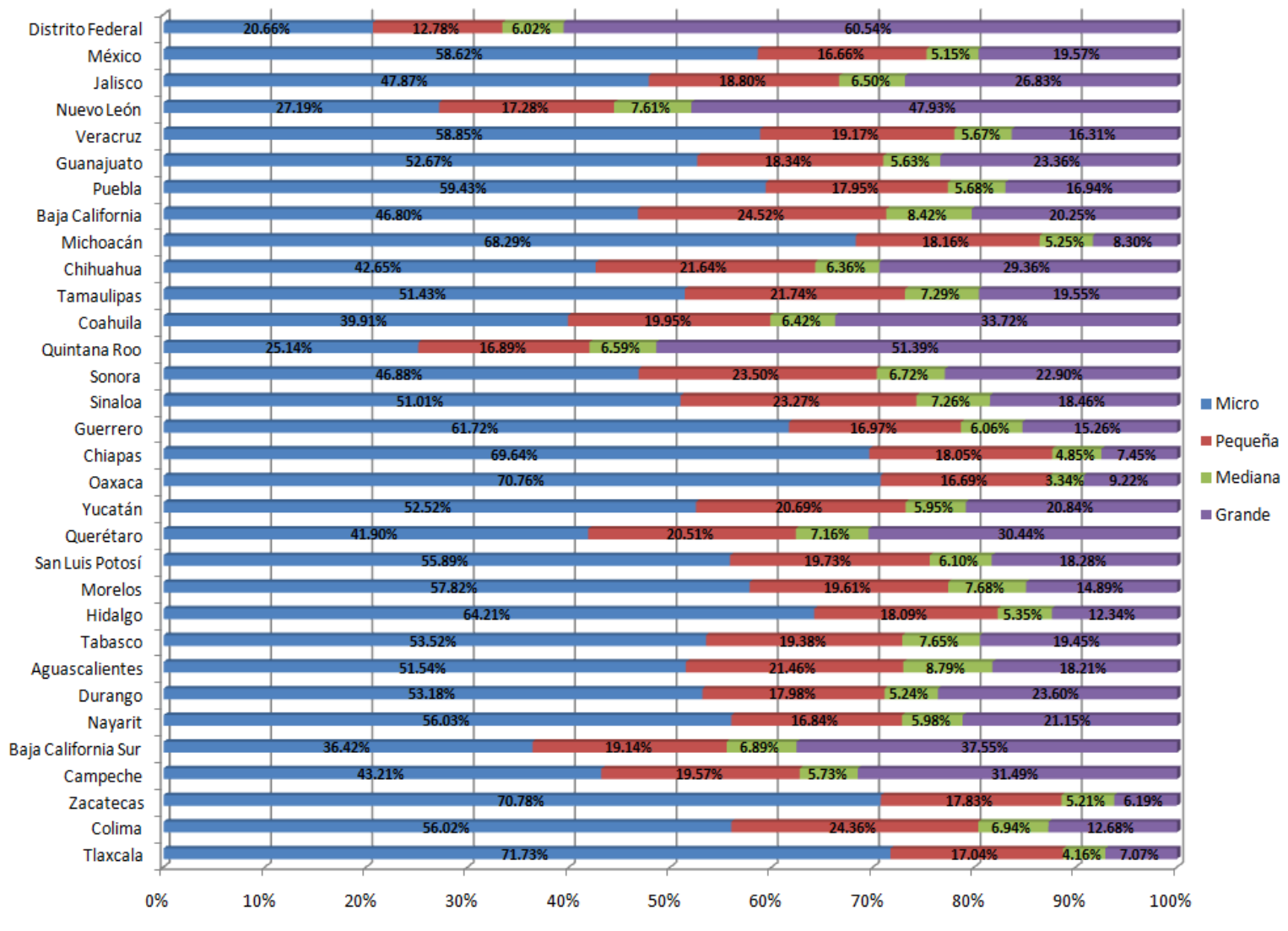

FUENTE: Elaboración propia con base en INEGI (2009)

En resumen, si bien el argumento respecto a la importancia de las MiPyME's por la generación de empleo que representan se valida, no se encuentra una razón contundente que indique una correspondencia o comportamiento homogéneo entre micro, pequeñas y medianas empresas, pues mientras en algunas entidades la concentración es mayor en microempresas, en otras la mayor concentración se da en las grandes empresas, no encontrándose un patrón de comportamiento homogéneo que respalde la conformación del bloque de MiPyME's. 


\section{Ingresos por producción bruta}

Un tercer argumento tiene que ver con la participación o aportación del sector MiPyME's a la economía del país. Pareciera lógico pensar que si en el sector MiPyME's se concentra más del $90 \%$ de las empresas y alrededor del $90 \%$ del personal -refiriéndonos al sector privado y paraestatal-, su participación debe ser sustanciosa. Si bien, no puede despreciarse la participación del sector en la economía, sea esta baja o alta, la relevancia se concentra en razones más profundas, como se verá a continuación.

En la siguiente gráfica se han acomodado las entidades de acuerdo a los ingresos brutos percibidos de las manufactureras establecidas en su geografía. Se puede apreciar la diferencia significativa y la enorme dispersión.

Ingresos sector manufacturas por entidad federativa en millones de Pesos (2009)

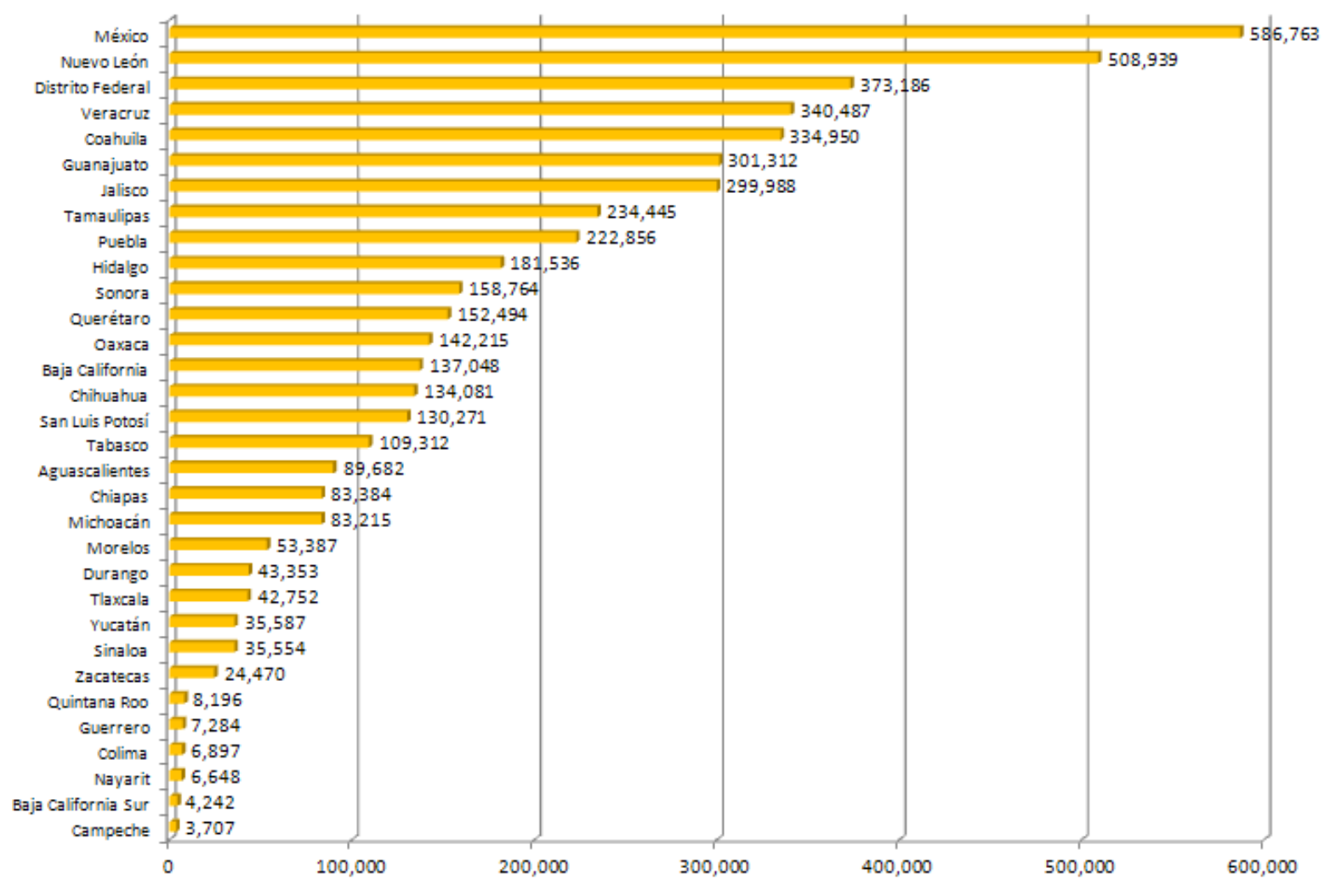

FUENTE: Elaboración propia con base en INEGI (2009) 
Al prestar atención en los ingresos generados por tamaño de empresas manufactureras, se puede apreciar que en la mayor parte de las entidades las grandes empresas son las que generan el mayor número de ingresos brutos, a pesar de que como se había apreciado anteriormente, el número de empresas grandes es significativamente reducido. Existen casos particulares, como el caso de Guerrero y Baja California, en donde esto no se cumple o casos como el de Tabasco, en donde las grandes empresas generan el 95\% de los ingresos por manufacturas.

Distribución de los ingresos brutos totales de las manufactureras por tamaño y entidad federativa (2009)

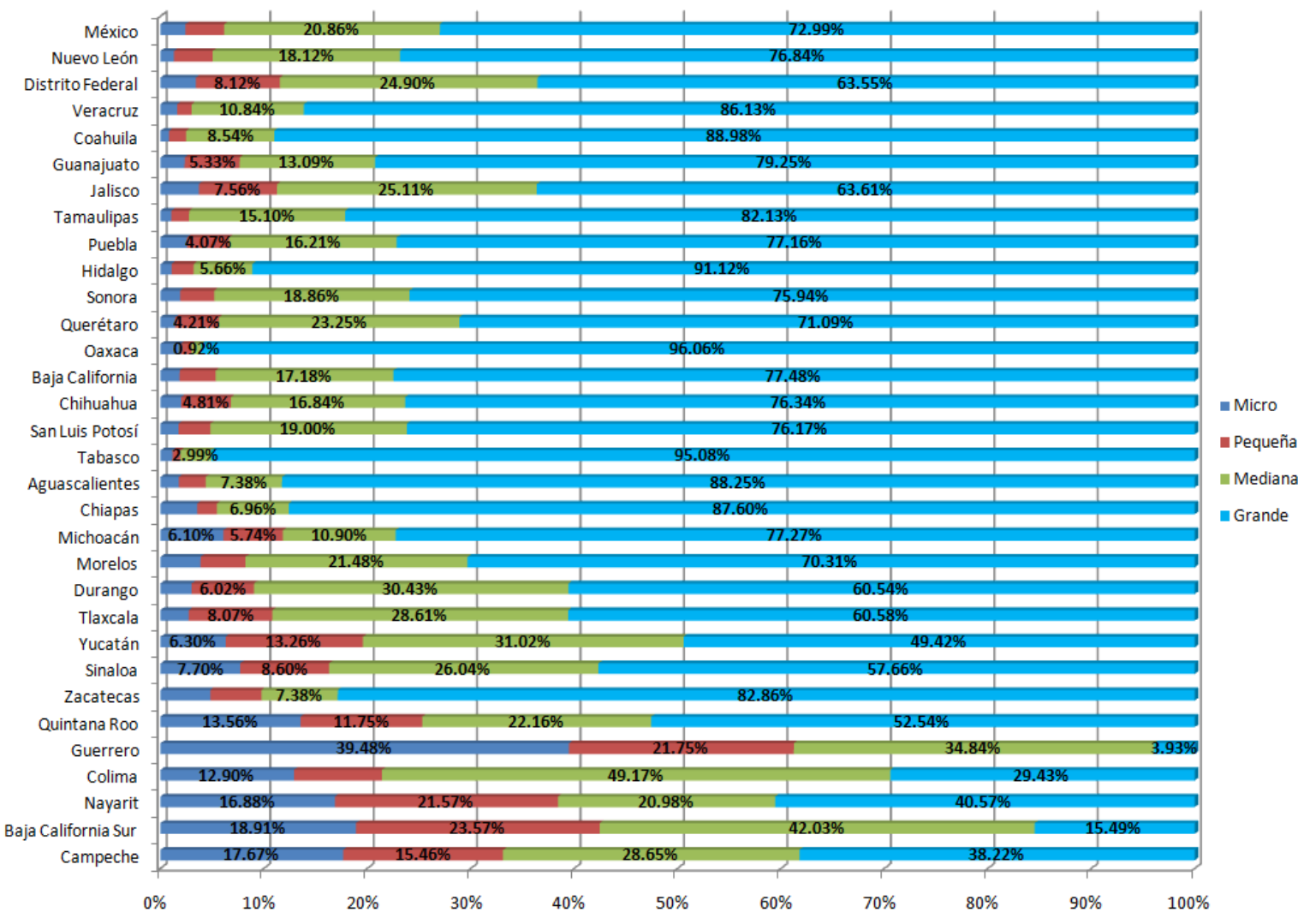

FUENTE: Elaboración propia con base en INEGI (2009)

El sector manufacturero merece especial atención debido a que se considera que en la transformación se puede dar mayor valor agregado a lo producido, en comparación con el comercio y los servicios, generando entonces una ventaja competitiva, diferenciando los bienes y generando mayor riqueza. Sin embargo, se 
puede apreciar que a pesar de que las microempresas manufactureras son mayoría, no generan tanta riqueza comparativamente con las medianas o las grandes. Usualmente se culpa a la falta de preparación de los administradores o dueños de las mismas, al desconocimiento de técnicas efectivas de gestión o información sobre diversos apoyos ofrecidos tanto por el gobierno como por el sector privado. Si bien, esto puede tener parcialmente su parte de razón, también se está dejando de lado la responsabilidad del gobierno en la creación de infraestructura, entorno y políticas que permitan un mejor desempeño de las empresas, así como el aprovechamiento adecuado de los apoyos y recursos producto de las políticas de desarrollo industrial. Esta inconsistencia entre lo idealizado en planes y programas de política pública y los resultados obtenidos está altamente relacionada con el abordaje incompleto, sesgado o parcial de la problemática desde una óptica predominantemente económica y administrativa.

\section{Ingresos sector comercio por entidad federativa en millones de pesos (2009)}

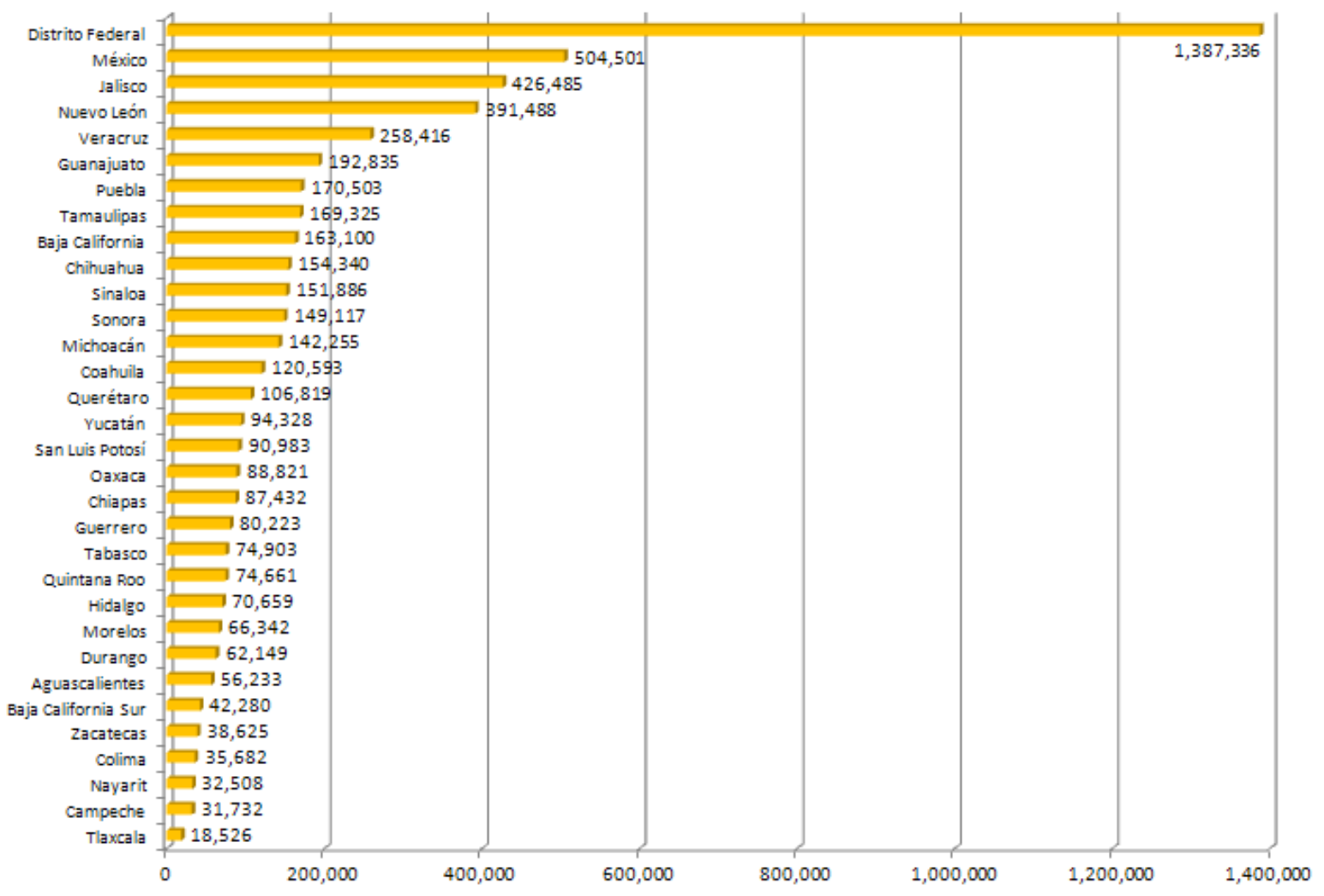

FUENTE: Elaboración propia con base en INEGI (2009) 
En la gráfica destinada a los ingresos del sector comercio se aprecia de igual manera un dato atípico para el Distrito Federal, que casi triplica el del segundo estado con mayores ingresos brutos (México). Se observa una generación de ingresos heterogénea.

Sin embargo, en este sector (comercio) existe una generación más homogénea entre los sectores por número de personal, como puede apreciarse en la siguiente gráfica. Si se observa a los estados de en medio de la gráfica, se aprecia que hay un balance en la generación de ingresos, mientras que en los estados de la parte superior e inferior, existe un sesgo hacia las grandes empresas o a las micro.

Distribución de los ingresos brutos totales de empresas de comercio por tamaño y entidad federativa (2009)

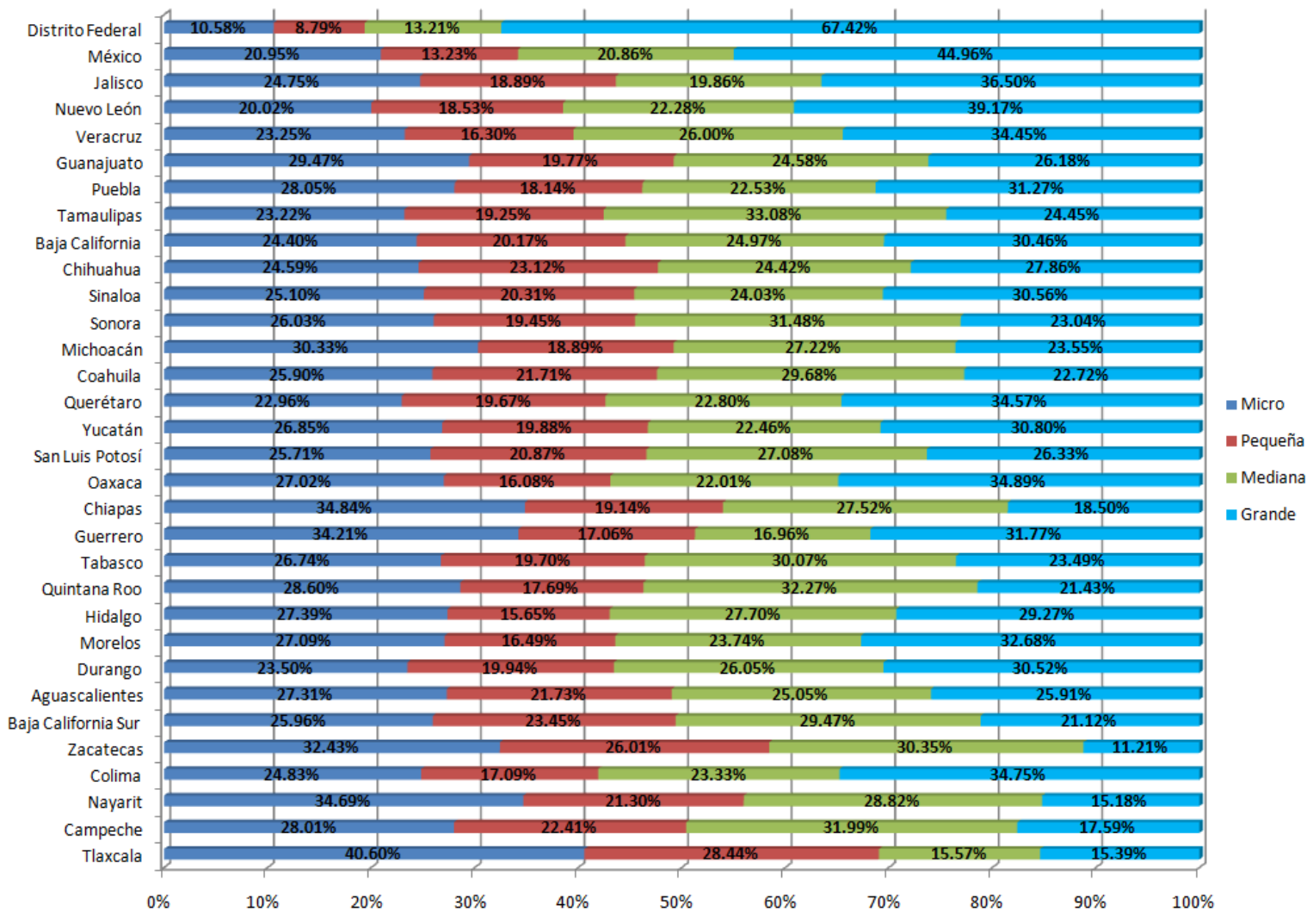

FUENTE: Elaboración propia con base en INEGI (2009)

Si consideramos las gráficas anteriores de número de empresas y personal ocupado, se destaca entonces que a pesar de la diferencia existente en cuanto al número de micro empresas en comparación con las pequeñas, medianas y grandes, 
la generación de ingresos no es proporcional al número de empresas del sector, es decir, aunque mayoritariamente haya más microempresas, esto no implica mayor generación de ingresos, puesto que aunque las pequeñas, medianas y grandes son menos, generan cantidades similares o superiores de ingresos brutos que los generados por las micro empresas de comercio.

En cuanto a los ingresos brutos de empresas de servicios, se aprecia de igual manera un dato atípico para el Distrito Federal en comparación con los ingresos generados en el resto de las entidades:

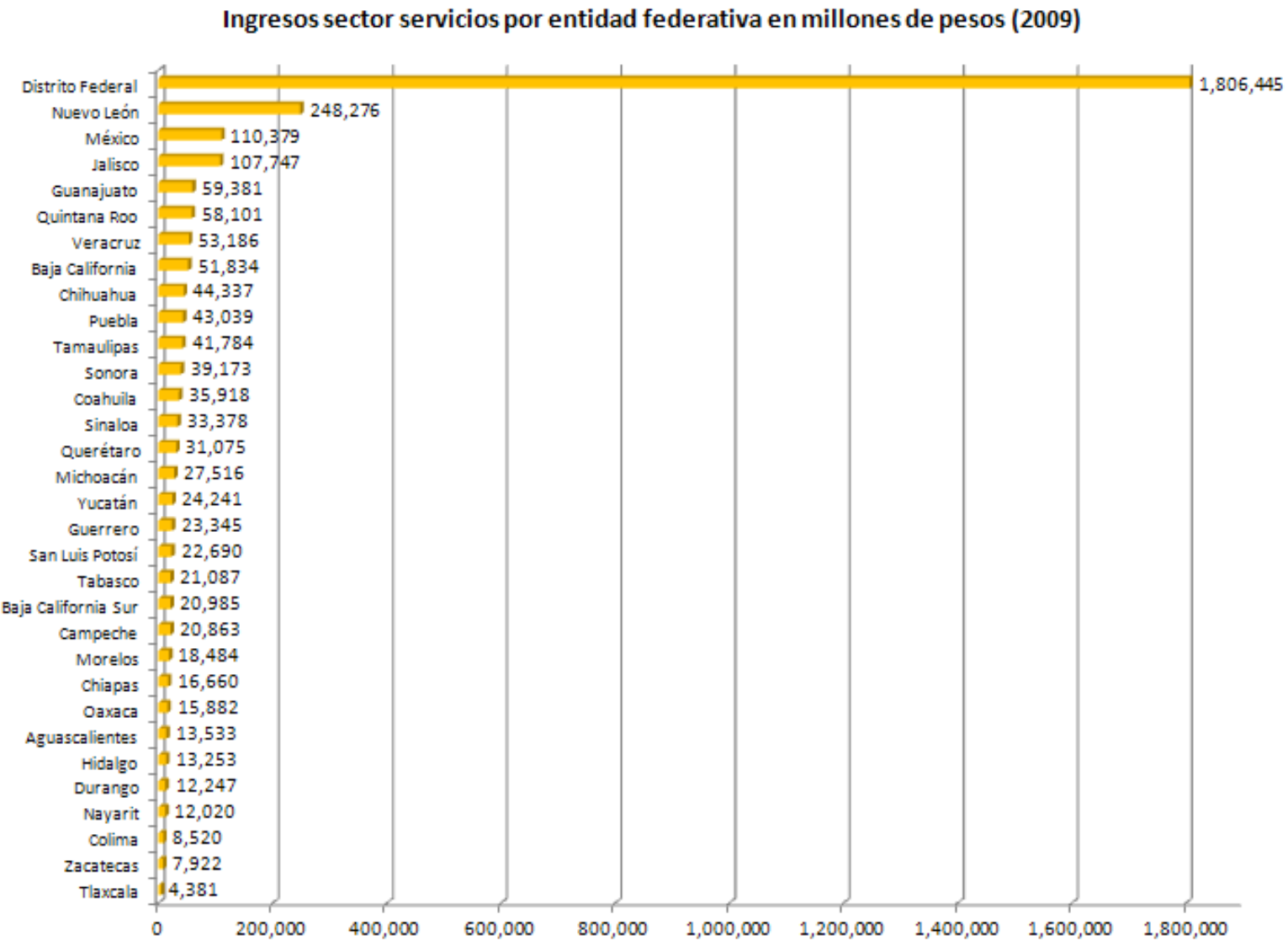

FUENTE: Elaboración propia con base en INEGI (2009)

Si se contrasta con la gráfica de número de empresas de servicios, a pesar de que el estado de México tiene más empresas de este sector, las del Distrito Federal e incluso las de Nuevo León generan mayores ingresos que el estado de México. En 
la distribución de datos en el diagrama de puntos se aleja demasiado el valor atípico del resto de la distribución.

Al analizar los porcentajes de participación de cada sector por tamaño de empresas de servicios, se aprecia que el $82 \%$ de esos ingresos generados en el Distrito Federal son de grandes empresas de servicios y en una vista total de la gráfica, se aprecia que hay una concentración entre las micro empresas y las grandes empresas, aunque es necesario analizar los casos particularmente, dependiendo del interés que se tenga en alguna entidad o sector específico.

Distribución de los ingresos brutos totales de empresas de servicios por tamaño y entidad federativa (2009)

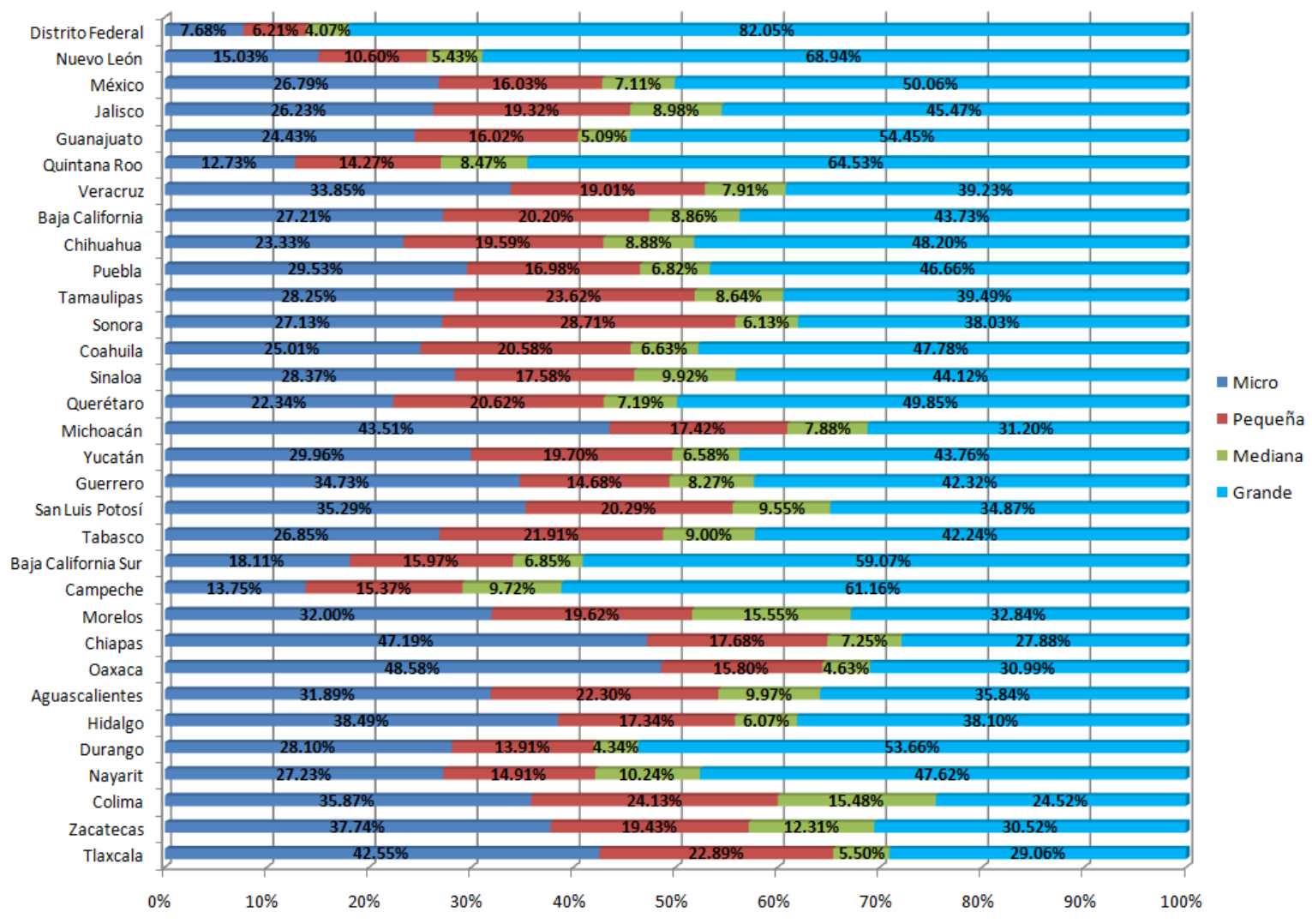

FUENTE: Elaboración propia con base en INEGI (2009)

Resumiendo, se puede pensar por un lado que es destacable que el sector de micro empresas con menos de 10 trabajadores puedan generar ingresos similares a empresas grandes, o bien, pensar que son ineficientes porque las empresas 
grandes a pesar de ser menos generan altas cantidades de ingresos. Se puede apreciar entonces esta distorsión trasladada al discurso general de la MiPyME.

\section{Distribución porcentual de microempresas de los tres principales sectores por entidad federativa (2009)}

Para el sector de microempresas podemos extraer de la siguiente tabla lo siguiente:

Comúnmente se considera el bloque de MiPyME's como importante gracias al porcentaje que representa en cuanto al número de unidades económicas. Como se observa, del total de empresas del sector privado y paraestatal, el $98.19 \%$ pertenecen al sector MiPyME's. Discursivamente suele escucharse en los medios y en eventos destinados a emprendedores y empresarios que 9 de cada 10 empresas en el país son micro, pequeñas y medianas empresas. Pero si se observa comparativamente, al calcular la proporción entre el total de unidades económicas del censo y el número de micro empresas, el $93.96 \%$ pertenece a este grupo. Es decir, de igual manera se puede argumentar que 9 de cada 10 empresas del país son micro empresas -no pequeñas ni medianas-, e incluso, que 6 de cada 10 empresas del país (64.16\%) son micro empresas que tienen entre 1 y 2 trabajadores.

Parece un ejercicio ocioso, sin embargo tiene grandes implicaciones en la forma de concebir a las empresas, puesto que en realidad esas microempresas constituyen un grupo particular que se diferencia de las pequeñas y medianas empresas. Por ejemplo, considerar a empresas con uno o dos trabajadores del sector servicios o de comercio dentro de la competencia internacional es un absurdo, pues más bien se orientan a la economía interna, localizada y circunscrita en espacios relativamente pequeños y que seguramente son regidos por lógicas distintas a la competencia sino más bien a la subsistencia. 
Ponderación del total de Unidades Económicas y personal ocupado en México al año 2008

UNIDADES
ECONÓMICAS Personal ocupado

\begin{tabular}{|c|c|c|c|c|}
\hline Total contabilizado & $3,724,019$ & $100.00 \%$ & $20,116,834$ & $100.00 \%$ \\
\hline Manuf.+Comer.+Serv. & $3,662,688$ & $98.35 \%$ & $18,136,036$ & $90.15 \%$ \\
\hline Mipymes $M+C+S$ & $3,656,619$ & $98.19 \%$ & $12,549,648$ & $62.38 \%$ \\
\hline Micro $M+C+S$ & $3,499,035$ & $93.96 \%$ & $8,285,590$ & $41.19 \%$ \\
\hline Total contabilizado & $3,724,019$ & $100.00 \%$ & $20,116,834$ & $100.00 \%$ \\
\hline Micro $M+C+S$ & $3,499,035$ & $93.96 \%$ & $8,285,590$ & $41.19 \%$ \\
\hline
\end{tabular}

\begin{tabular}{|c|c|c|c|c|}
\hline Manuf.+Comer.+Serv. & $3,662,688$ & $100.00 \%$ & $18,136,036$ & $100.00 \%$ \\
\hline Micro M+C+S & $3,499,035$ & $95.53 \%$ & $8,285,590$ & $45.69 \%$ \\
\hline
\end{tabular}

\begin{tabular}{|c|c|c|c|c|}
\hline Mipymes M+C+S & $3,656,619$ & $100.00 \%$ & $12,549,648$ & $100.00 \%$ \\
\hline Micro M+C+S & $3,499,035$ & $95.69 \%$ & $8,285,590$ & $66.02 \%$ \\
\hline
\end{tabular}

\begin{tabular}{|c|c|c|c|c|}
\hline Micro M+C+S & $3,499,035$ & $100.00 \%$ & $8,285,590$ & $100.00 \%$ \\
\hline Micro M+C+S de 0 a 2 trab. & $2,389,447$ & $68.29 \%$ & \multicolumn{1}{|c}{} \\
\cline { 1 - 3 } & &
\end{tabular}

FUENTE: Elaboración propia con base en INEGI (2009)

Entonces, si las políticas de apoyo al sector MiPyME's están omitiendo esto por el simple hecho o comodidad de considerar un bloque homogéneo a las micro, pequeñas y medianas empresas, se puede encontrar una noción de los pobres resultados de estas políticas. Al considerar el bloque estadísticamente puede generarse información sesgada que no cuadra con la realidad. En la siguiente gráfica se puede apreciar por ejemplo que, si bien ha habido incentivos para la generación de empresas, en el caso de las microempresas se concentran en el sector comercio y servicios, mientras el sector manufacturero se encuentra menos promovido. 


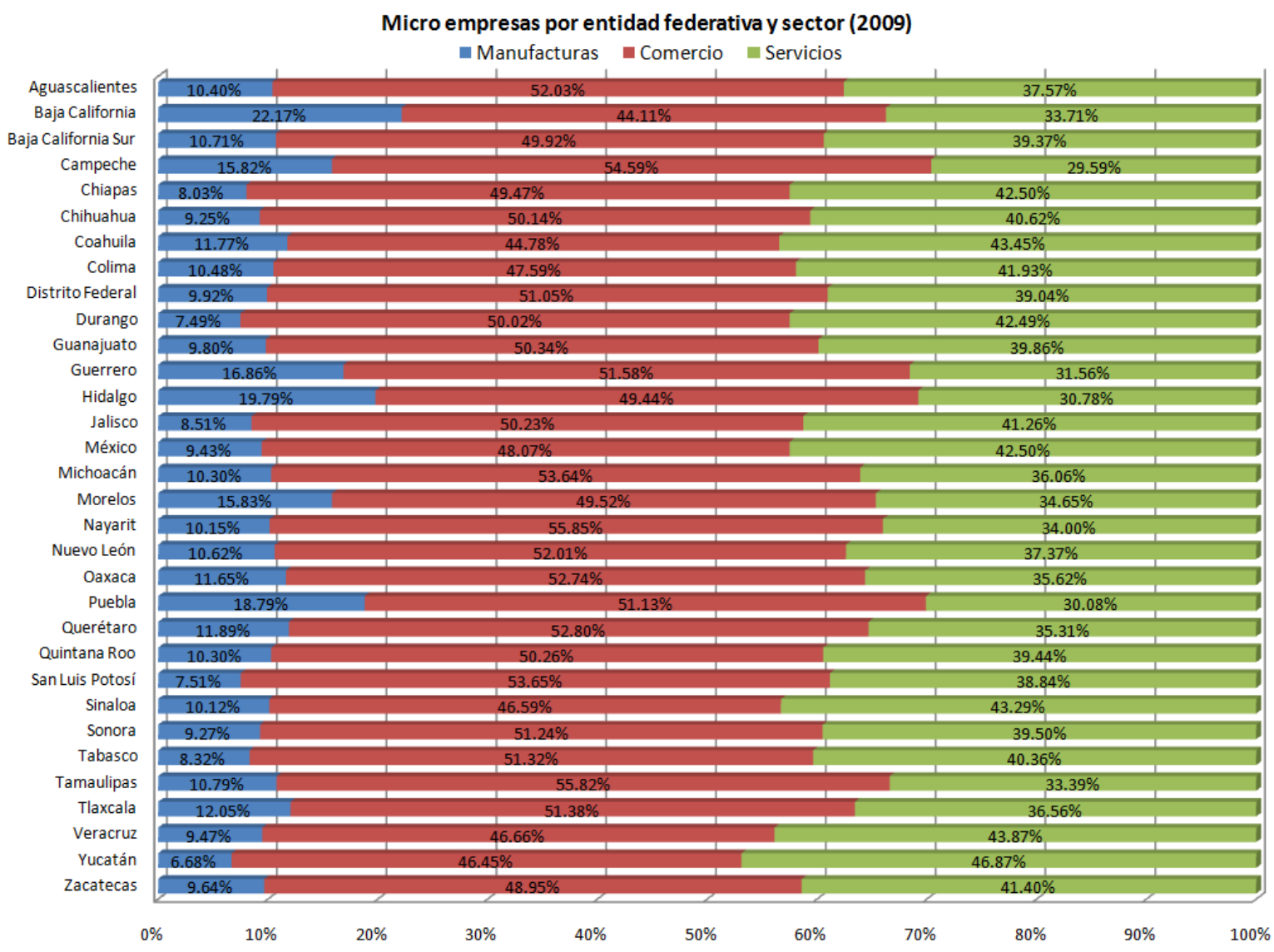

FUENTE: Elaboración propia con base en INEGI (2009)

Como puede apreciarse, la revisión de los datos arrojados por el censo económico permite reflexionar más allá de las estadísticas y porcentajes y valorar detenidamente el alcance y veracidad del discurso que se genera con base en estos.

De igual manera, el abordaje de este sector conocido como las MiPyME's puede y debe hacerse de manera más detallada, puesto que como se ha observado, el colocar a todas las empresas con menos de 250 trabajadores sin importar la región en la que se encuentran, el sector económico al que se adscriben y el dinamismo de su mercado lleva a generalizaciones que no concuerdan con la realidad de los casos particulares. La revisión de textos y artículos en torno al sector de la MiPyME se concentra en resaltar los factores económicos y administrativos. Bajo esta óptica, la distribución de la riqueza, el poder adquisitivo o el desarrollo del nivel de vida de 
la población se ve como una función económica que se puede medir, mas no se sensibiliza en cuanto a las implicaciones que tienen. Por ejemplo, poco nos dicen respecto al alto porcentaje de microempresas que cuentan con hasta dos empleados. Esto puede darse debido a la falta de fuentes de empleo y la necesidad de subsistir honradamente.

El generar prescripciones tanto en las políticas públicas como en el nivel micro consultorías, incubadoras, aceleradoras- fundamentados solamente en esta perspectiva no garantiza el éxito de las empresas que se acercan en busca de ayuda. De igual manera, los recursos destinados no son aprovechados en los sectores en donde son más necesarios.

Por tanto, se hace necesario reevaluar el conocimiento generado y socialmente aceptado en torno a la problemática de las MiPyME's pues como se ha observado, de acuerdo con el discurso general es cierto que son un sector importante, pero más allá de lo obvio, sino porque se están prescribiendo recetas plantilla por igual para microempresas manufactureras con dos trabajadores que para medianas empresas prestadoras de servicios con 200 empleados. Resulta primordial profundizar en el estudio del sector a partir de grupos más homogéneos que guarden mayor relación entre sí como la región en la que se encuentran, el sector y el número de trabajadores antes que adoptar estrategias o planes estandarizados.

Como bien resumen De la Rosa, Montoya y Pomar (2009:32), las empresas también son organizaciones, espacios difusos, cambiantes, estructurados y estructurantes, en donde los individuos realizan diversos procesos con mayor o menor grado de ambigüedad e incertidumbre, que se relacionan o no con objetivos diversos y ambiguos, tanto personales como organizacionales, en el contexto de la acción organizada, la cual, a su vez, es restringida de múltiples formas por marcos institucionales internos y externos y cruzada por lógicas de acción económica, instrumental, tecnológica, política, social, sentimental, cultural, simbólica, psicológica, discursiva y metafórica.

Estas lógicas de acción distintas a la económica complejizan por un lado el análisis y la generación de un conocimiento más confiable de esa realidad específica. Sin 
embargo, es necesario ese esfuerzo para poder prescribir acciones más efectivas que incidan positiva y tangiblemente en las empresas y en el nivel de vida de la población y no sólo en los porcentajes y estadísticas.

De este análisis se puede identificar que resulta complicado manejar el término de MiPyME's o PyME's, puesto que se supone que tienen características, problemas y comportamientos similares, cuando desde la segmentación por tamaño se establece que no es así. Si se considera adicionalmente al tamaño, el sector en el que se desempeñan, por ejemplo, manufactura, comercio -al por mayor o al menudeo-, o servicios, la ubicación geográfica en la que están insertas, los montos de facturación de cada una, el tipo de tecnología que emplean o la razón de su puesta en marcha por parte del o los empresarios, se observa entonces que es un grupo bastante heterogéneo como para pretender atenderlo como uno sólo. Por tanto, si se pretenden implementar planes de apoyo, debiera respetarse cada segmento como tal. Se puede afirmar que 9 de cada 10 empresas del país son micro empresas, y no pequeñas o medianas. De igual manera se observó que existen entidades con mayor grado de desarrollo industrial y sin embargo, la concentración de apoyos sigue siendo centralizada, lo que amplía la brecha entre entidades como el Distrito Federal o el Estado de México y las entidades menos desarrolladas.

En este escenario, el impulso del estado hacia el al sector industrial encuentra mecanismos que cada vez son menos directos, lo que sin duda es la postura de la estrategia neoliberal adoptada en México. Algunos de estos mecanismos directos son apoyados desde dependencias administrativas como la Secretaría de Economía (SE) y apoyados por asociaciones y confederaciones patronales, siendo los más relevantes los programas de créditos, asesorías y las Incubadoras de Negocios, ahora cambiadas en un proceso evolutivo hacia las Aceleradoras de Negocios, tema al cual se encuentra orientada la investigación por resultar interesante no sólo para observar como el Estado continua ofreciendo un impulso directo al desarrollo industrial y comercial del país, sino también para observar cuál es su impacto actual y particularmente conocer su operación. 
El 30 de Diciembre de 2002 se publicó en el Diario Oficial de la Federación la Ley para el Desarrollo de la Competitividad de la Micro, Pequeña y Mediana Empresa, la cual en su artículo primero refiere su interés por promover el desarrollo económico nacional a través del fomento a la creación de MiPyME's y el apoyo para su viabilidad, productividad, competitividad y sustentabilidad (México, DOF, 2002).

En la referida ley, se le encomienda a la Secretaría de Economía lo referente a la observación de la misma. Para ello, se ha creado la Subsecretaría para la Pequeña y Mediana Empresa, la cual a su vez se integra por tres direcciones generales (Capacitación e Innovación Tecnológica, Promoción Empresarial, y Desarrollo Empresarial y Oportunidades de Negocio) y una coordinación general (Programa Nacional de Financiamiento al Microempresario) que configuran la respuesta del órgano gubernamental a las necesidades de las MiPyME's, de acuerdo a lo expresado por la propia Secretaría de Economía en su portal web ${ }^{12}$.

Existe una alineación de acuerdo con el Plan Nacional de Desarrollo 2007-2012, en el Segundo Eje referente a la Economía competitiva y generadora de empleos, en su punto seis, referente a la productividad y competitividad de las pequeñas y medianas empresas, donde se destaca que las MiPyME's constituyen el $99 \%$ del total de Unidades Económicas del país, representando alrededor del $50 \%$ del PIB y contribuyendo a generar el 70\% de los empleos en México (PND 2007-2012: 111).

De igual forma, como lo destaca el INEGI en los resultados de los censos económicos del año 2009, a nivel mundial representan el segmento que aporta el mayor número de Unidades Económicas y personal ocupado, y en México se puede apreciar la importancia de las MiPyME's como resultado de estos censos:

\footnotetext{
12 FUENTE: http://www.economia.gob.mx/conoce-la-se/estructura-organica\#t!prettyPhoto Fecha de consulta: 28 de Marzo de 2013.
} 


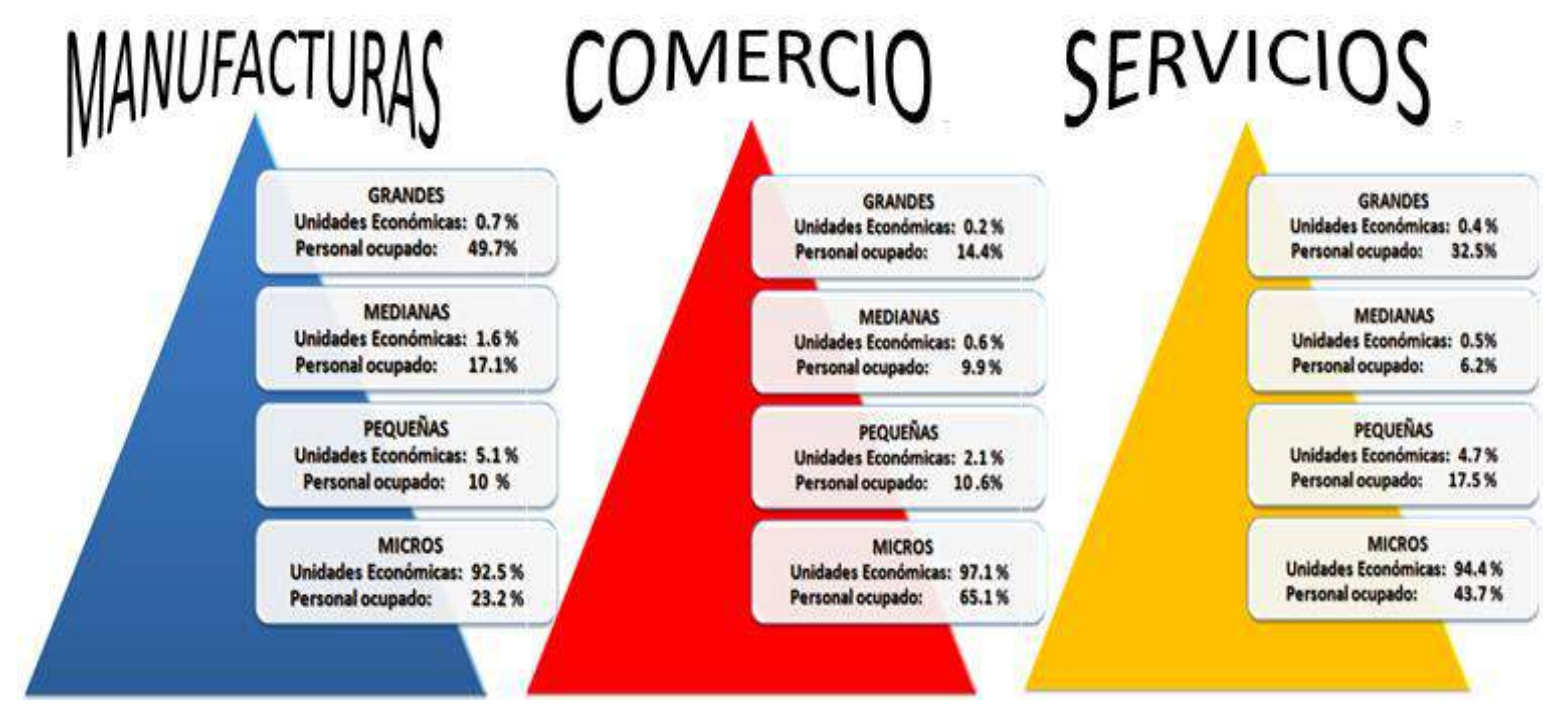

Distribución de las Unidades Económicas en México al año 2008

FUENTE: Elaboración propia con base en INEGI (2009).

Como puede apreciarse, la importancia del segmento de la Micro, Pequeña y Mediana Empresa para la economía y la generación de empleos es importante, por lo cual demanda su atención desde la agenda pública y las políticas públicas del gobierno federal, así como de la academia. Sin ser el objeto de estudio de este documento, basta mencionar que otros autores han hecho ya referencia con mayor profundidad a la problemática que enfrenta este segmento en México ${ }^{13}$.

En este sentido, el sexto objetivo contenido en el referido plan considera la creación, desarrollo y consolidación de las MiPyME's a través de cuatro estrategias orientadas a:

1. Favorecer el aumento de la productividad de las MIPyME's e incrementar el desarrollo de productos acorde con sus necesidades.

2. Consolidar los esquemas de apoyo a las MIPyME's en una sola instancia.

3. Impulsar el desarrollo de proveedores, elevando el porcentaje de integración de los insumos nacionales en los productos elaborados en México y consolidando cadenas productivas que permitan una mayor generación de valor agregado en la producción de bienes que se comercian internacionalmente.

\footnotetext{
${ }^{13}$ Entre los que destacan: Jurado (1997), De la Rosa (2000), Murguía (2000), Andrade Romo (2003), Dussel (2004),
} Cabello, Reyes y Solís (2004) y De la Rosa (2007). 
4. Revisar y ajustar los programas actuales de apoyo para que permitan lograr un escalamiento de la producción hacia manufacturas y servicios de alto valor agregado.

En la primera estrategia mencionada se establece una segmentación para facilitar la atención de este sector, es decir, se segmenta el conjunto que se conoce como MiPyME's como sigue:

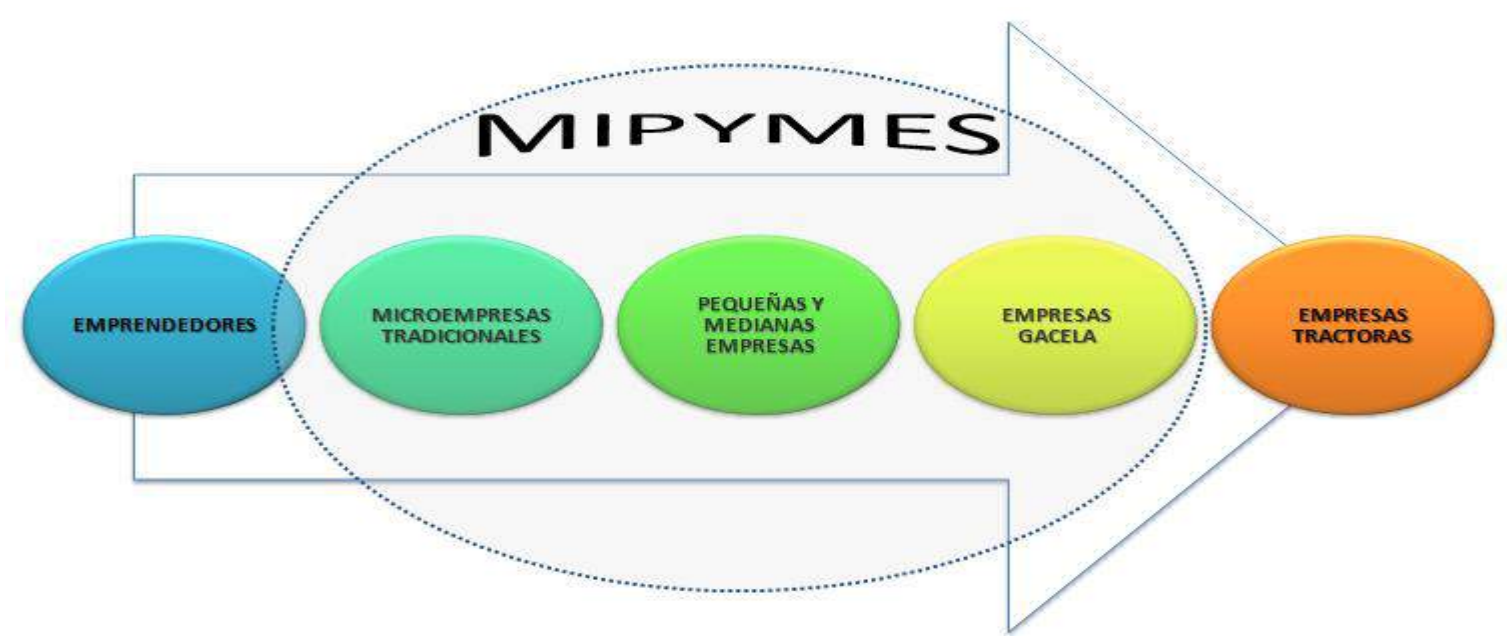

1. Emprendedores (proceso de creación y desarrollo de una empresa)

2. Microempresas tradicionales

3. Pequeñas y Medianas Empresas

4. MIPYMES con mayor dinamismo en su crecimiento y generación de empleos respecto del promedio (empresas gacela)

5. Empresas que vertebran las cadenas productivas (empresas tractoras) $)^{14}$

Segmentación de empresas en México.

FUENTE: Elaboración propia con base en el Plan Nacional de Desarrollo 2007-2012

(Eje 2, Objetivo 6, Estrategia 6.1, pp. 111-112)

Cada segmento debe recibir alternativas de financiamiento, comercialización, capacitación, consultoría, gestión, innovación y desarrollo tecnológico por parte del gobierno federal. Esto se complementa de igual forma con el programa sectorial de

14 Conocidas coloquialmente como grandes empresas. 
la Secretaría de Economía, en su eje uno, referente a detonar el desarrollo de la MiPyME (México, DOF, 2008: 5).

En este programa sectorial se identifica entonces en su objetivo rector 1.1, la línea estratégica referente a atender cada segmento, correspondiendo por ejemplo la línea estratégica 1.1.1 a las acciones para apoyar a los emprendedores, por medio del Programa Nacional de Incubadoras, y para el tema de interés de este documento, la línea estratégica 1.1 .5 se enfoca a la atención a las empresas gacela mediante programas de aceleración de empresas, un Programa Nacional de Franquicias, el desarrollo de esquemas y programas orientados a oferta exportable e innovación tecnológica, así como el fomento al desarrollo de parques tecnológicos (México, DOF, 2008: 14) 


\section{BIBLIOGRAFÍA}

Andrade Romo, Salvador (2003) "Las pequeñas y medianas empresas en México.

Su organización y su ambiente (1950-1994)", en Administración y organizaciones, Año 6, Núm. 1, Diciembre, pp. 97-115.

Audretsch, David B., T.Taylor Aldridge y Mark Sanders (2011), "Social capital building and new business formation: A case study in Silicon Valley", en International Small Business Journal, Vol. 29, Núm. 2, SAGE, pp. 152-169.

Bergfeld, Alexander F. (2015), Business Acceleration 2.0: A new knowledge-based approach to busines acceleration, young technology venture building and business growth ; [the strategic acceleration of successful startups] (1. Aufl.). Norderstedt : Books on Demand. ISBN 978-3-7347-9531-2.

Birdsall, Michael et al. (2013), Business Accelerators. The Evolution of a Rapidly growing Industry, Reporte de investigación, University of Cambridge, Judge Business School.

Cabello Chávez, Adalberto, Rafael Reyes Avellaneda y Pedro C. Solís Pérez (2004) "El perfil organizacional de la PyMEs (microempresas, pequeñas y medianas empresas) en el sector manufacturero: un análisis integral", en Administración y Organizaciones, Año 7, Núm. 13, Diciembre, pp. 69-89.

Chiavenato, Idalberto (2004), Introducción a la teoría general de la administración, McGraw-Hill, México.

Chow, Gregory C. (1968), "The acceleration principle and the nature of business cycles", en The Quarterly Journal of Economics, Vol. 82, Núm. 3, Oxford, University Press, pp. 403-418.

Clarysse, Bart y Ayna Yusubova (2014), "Success factors of Business accelerators" (conferencia), en Technology Business Incubations Mechanisms and Sustainable Regional Development, Toulouse Business School, Toulouse, Francia. Document disponible en:

\section{https://biblio.ugent.be/publication/6842877}


Clark, J. Maurice (1917), "Business acceleration and the law of demand: A technical factor in economic cycles", en Journal of Political Economy, The University of Chicago Press, Vol. 25, Núm. 3, pp. 217-235.

Cohen, Susan (2013), "What do accelerators do? Insights from incubators and angels", en Innovations, Vol. 8, Núm. 3-4, MIT Press Journals, pp. 19-25.

Dalziel, Margaret (2012), A study of business incubators and accelerators in Canadá, The Evidence Network, Ottawa.

De Almeida, María Da Conceiçáo (2008), Para comprender la complejidad, Multiversidad Mundo Real Edgar Morin A.C., México.

De la Rosa Alburquerque, Ayuzabet (2000) "La micro, pequeña y mediana empresa en México: sus saberes, mitos y problemática”, en revista Iztapalapa, Año 20, Núm. 48, Enero-Junio, pp. 183-220.

De la Rosa Alburquerque, Ayuzabet (2007), La micro, pequeña y mediana organización en la perspectiva de los estudios organizacionales. Una mirada al caso de una microorganización desde la óptica del poder, Tesis Doctoral, UAMIztapalapa, México, pp. 21-126.

De la Rosa Alburquerque, Ayuzabet, María T. Montoya, Flores, Silvia Pomar, Fernández (2009) "Análisis organizacional y micro, pequeñas y medianas organizaciones: estado actual y perspectivas", en De la Rosa Alburquerque, Ayuzabet, María T. Montoya, Flores y Silvia Pomar, Fernández (Coordinadores) Pequeñas organizaciones: complejidad y diversidad organizacional. Estudio de casos de organizaciones mexicanas, UAM/Juan Pablos. Pp. 23-54.

Dempwolf, C. Scott; Jennifer Auer y Michelle D'Ippolito (2014), Innovation Accelerators: Defining characteristics among startup assistance organizations, Small Business Administration Office of Advocacy, USA. 
Dussel Peters, Enrique (2004), "Pequeña y mediana empresa en México: condiciones, relevancia en la economía y retos de política", en Economía UNAM, Núm. 2, Mayo-Agosto, pp. 64-84.

Eppen, G. D. et al. (2000), Investigación de operaciones en la Ciencia Administrativa, Prentice-Hall, México.

Fehder, Daniel C. y Yael V. Hochberg (2014), "Accelerators and the regional supply of Venture Capital Investment", artículo disponible en Social Science Research Network: http://papers.ssrn.com/sol3/papers.cfm?abstract id=2518668

Fidelman, Mark (2014), "This Silicon Valley Accelerator is the model of the future", artículo disponible en:

http://www.forbes.com/sites/markfidelman/2014/03/06/this-silicon-valleyaccelerator-is-the-model-of-the-future/\#6d474c7768d5

Gerez, Victor y Verónica Czitróm (1982), Introducción al análisis de sistemas e investigación de operaciones, Representaciones y Servicios de Ingeniería S.A., México.

Gooze, Mitchell y Ralph Mroz (2007), Value Acceleration. The secrets to building an unbeatable competitive advantage, Elevate, USA. ISBN 978-1601940049.

Hanson, Dirk (1984), Los nuevos alquimistas. Silicon Valley y la revolución microelectrónica, Editorial Planeta, Caracas, Venezuela.

INEGI (2009), Micro, Pequeña, Mediana y Gran Empresa (Estratificación de los establecimientos), Censos Económicos 2009, INEGI, Aguascalientes.

ITEA2 (2015), "Digital Accelerators" -Related initiatives at the European level (H2020), ITEA2 Information Technology for European Advancement.

Jurado Arellano, Araceli (1997) "Diagnóstico integral de la micro y pequeña empresa en México D.F.", en Corona Treviño, Leonel (Coord.), Pequeña y mediana empresa: del diagnóstico a las políticas, Centro de Investigaciones Interdisciplinarias en Ciencias y Humanidades de la UNAM, México, pp. 19-34. 
$\mathrm{Li}$, Benjamin, Hanna Kuberczyk, Asma y Melanie Yen (2012), The explosive growth of Business Accelerators in Los Ángeles in 2012, California Institute of Technology. Mason, Hugh (2013), Guild for Geeks. Describing Business Acceleration using Grounded Theory Methods, documento disponible en: http://www.academia.edu/11662129/Guilds for Geeks -

\section{Describing Business Acceleration using Grounded Theory Methods}

México, Diario Oficial de la Federación (2002), Ley para el Desarrollo de la Competitividad de la Micro, Pequeña y Mediana Empresa, publicada el 30 de Diciembre de 2002, última reforma publicada el 05 de Agosto de 2011.

México, Presidencia de la República (2007), Plan Nacional de Desarrollo 20072012.

México, Diario Oficial de la Federación (2008), Programa Sectorial de Economía 2007-2012, decretado el 14 de Mayo de 2008.

Monitor Deloitte (2015), Accelerating impact. Exploring best practices, challenges, and innovations in impact Enterprise acceleration, Monitor Deloitte y Rockefeller Foundation.

Montaño, Luis (2006), "Cambio y transferencia de modelos organizacionales", en V Congreso Nacional AMET 2006, Trabajo y Reestructuración: Los retos del nuevo siglo, México.

Morin, Edgar y Jean-Louis Le Moigne (2006), Inteligencia de la complejidad. Epistemología y Pragmática, Ediciones de l'aube.

Mulás del Pozo, Pablo (coord.) (1995), Aspectos tecnológicos de la modernización industrial de México, Academia de Investigación Científica, Fondo de Cultura Económica, México D.F.

Mumby, D, and Clair, R. (1997), "Organizational discourse" In van Dijk, T.A. (ed) Discourse as Structure and Process: Discourse Studies, Volume 2, Sage, London. 
Murguía Ashby, Luz (2000) "El sector de la microempresa en México y sus características" en Skertchly Molina, Ricardo W. (Coord.), Microempresa, financiamiento y desarrollo: el caso de México, Universidad Anáhuac del Sur y Miguel Ángel Porrúa, México, pp. 15-37.

OCDE (2012), Evaluación de la OCDE del sector de las nuevas empresas basadas en el conocimiento. México., Organización para la Cooperación y el Desarrollo Económicos.

Parkin, Michael (2009), Economía, Pearson Educación, México.

Pérez Hernández, Pilar y Alejandro Márquez Estrada (2006), "Análisis del sistema de incubación de empresas de Base Tecnológica de México", en I Congreso Iberoamericano de Ciencia, Tecnología, Sociedad e Innovación CTS+l, México.

Pomar, Silvia y Pamela Jiménez (2010), "El papel de las aceleradoras en el apoyo a empresas de base tecnológica", ponencia presentada en $5^{\circ}$ Congreso Internacional de Sistemas de Innovación para la Competitividad SINNCO: Tecnologías convergentes para la competitividad. Homenaje a Peter Drucker, Consejo de Ciencia y Tecnología del Estado de Guanajuato CONCYTEG, ISBN 978-607-9503-7-9.

Porter, Michael E. (1991), La ventaja competitiva de las naciones, Plaza \& Janes Editores, Barcelona.

Schumpeter, Joseph Alois (2002), Ciclos económicos: análisis teórico, histórico y estadístico del proceso capitalista, Prensas Universitarias de Zaragoza, Zaragoza España.

Simon, Herbert (1988), El comportamiento administrativo. Estudio de los procesos decisorios en la organización administrativa, Aguilar, Buenos Aires.

Telefónica (2014), The rise of UK accelerator and incubator ecosystem, Telefónica UK Limited, England.

Van Huijgevoort, Thomas (2012), The 'Business Accelerator': just a diferent name for a Business Incubator?, Utrecht School of Economics, Netherlands. 
Velilla, Marco Antonio (Comp.)(2002), Manual de iniciación pedagógica al pensamiento complejo, UNESCO, Instituto Colombiano de Fomento de la Educación Superior, Corporación para el desarrollo Complexus. 


\section{Capítulo II. Elementos teóricos para el abordaje del estudio}

En este capítulo se presentan las bases teóricas con las que se aborda el estudio de las aceleradoras de empresas planteado en la primera parte. La perspectiva elegida es la de los Estudios Organizacionales, por lo que se introduce una descripción de ésta para referenciar el resto del estudio. La conexión entre la construcción social de realidad y el análisis del discurso son necesarias para abordar el enfoque seleccionado.

La segunda parte del capítulo extiende la perspectiva del capítulo anterior con el referente histórico que dota de sentido al discurso de la aceleración de empresas. Para encontrar las raíces lógicas y retóricas de la aceleración de empresas de finales de los noventas, se rastrea el origen del cambio de actividad predominante dando lugar a la industrialización del país con base en el progreso, el crecimiento económico y el desarrollo promovido por la CEPAL en Latinoamérica.

\section{Organización y Organizaciones}

Las Organizaciones son el centro de atención, el objeto de estudio de los Estudios Organizacionales, traducción al castellano del término anglosajón Organization Studies. También resulta ser el objeto de estudio, o bien, el espacio en donde se lleva a cabo algún fenómeno que resulta de interés para otras ciencias y disciplinas en alguna de sus ramas, entre las que destacan la Economía, la Sociología, la Administración -pública y Privada-, la Antropología, la Etnografía, la Psicología, la Ciencia Política, incluso la Ingeniería Industrial o la lingüística, la Filosofía o la Ecología, que parecieran a simple vista no guardar relación alguna con las Organizaciones. 
Hablar de Organización ${ }^{1}$ y de Organizaciones ${ }^{2}$ resulta ser de lo más común tanto en textos, artículos, ponencias, congresos y otros eventos celebrados al respecto, sin importar la ciencia o disciplina a la que se represente. Pareciera ser que es un término común que todos comprenden o que se ha alcanzado un consenso entre las diferentes ciencias y disciplinas interesadas respecto a lo que uno y otro término significa. Sin embargo, esto no es así. En realidad, cada quien tiene su propia acepción de Organización, basándose en los elementos, características y variables a las que atribuyen mayor valor desde su perspectiva y desvalorizando, rechazando o desechando otros tantos por no considerarlos importantes, adecuados o válidos.

La realidad siempre supera a la ficción, y en el caso de las organizaciones se cumple esta sentencia. En la vida real, las organizaciones están en todos lados, existen en una amplia y heterogénea variedad, nacen, crecen, se desarrollan, se preservan, cambian, se fusionan, se reducen, se segmentan y eventualmente mueren, todo ello como consecuencia de ser creaciones humanas, o más bien, constructos sociales ${ }^{3}$.

\footnotetext{
${ }^{1}$ Cabe aclarar que difícilmente puede rastrearse en qué momento como sociedad se comenzó a hablar de Organización en el sentido moderno, puesto que etimológicamente existe la raíz griega Organon (herramienta, instrumento, método, aquello con lo que uno trabaja) que nos evoca a la obra del mismo nombre de Aristóteles dedicada a la lógica, aunque su título se asignó en la Edad Media. Órgano, Organismo, Organizar y Organización comparten entonces una misma raíz y puede ser entonces que implique la noción de una construcción lógica humana que conlleva cierta complejidad, utilidad e importancia, puesto que forma parte de un sistema. Del griego pasó al latín bajo el vocablo Organum que derivó en el neologismo latino Organisatio y con la caída y fragmentación en feudos del imperio romano, así como con la censura y quema de las obras greco-latinas por la jerarquía católica en la edad media, se perdió el rastro histórico del mismo, reapareciendo en la lengua francesa -una derivación del latín-como organisation en el siglo XVIII en tratados de medicina - Biología y de ahí trasladándose por analogía entre el arreglo ordenado del cuerpo humano (formado por órganos diferentes con funciones específicas) y el arreglo ordenado del cuerpo social. Se sigue entonces que el sentido metafórico de esta lógica haya prevalecido tanto en la concepción orgánica, como en la mecanicista y en la sistémica. Esta explicación desde luego es débil, dado que se fundamenta en la versión occidental europea de la historia de la humanidad surgida precisamente en la Grecia clásica y que cuenta poco o nada de otras civilizaciones y su conocimiento, tanto por conveniencia discursiva (la hegemonía del mundo europeo occidental) como porque si en verdad los primeros historiadores griegos -si es que fueron los primeros- daban cuenta del conocimiento, cultura y avances de otras civilizaciones, al parecer toda evidencia de ello fue destruida por los eventos previamente mencionados.

${ }^{2}$ En este documento se utiliza el término Organización para referirse al concepto teórico abstracto; mientras que el término Organizaciones se referirá al conjunto de entidades diversas que cobran vida en la realidad y de las que comúnmente se hacen abstracciones para construir el concepto de Organización.

3 Peter L. Berger y Thomas Luckmann desarrollaron la teoría de la Construcción Social de la Realidad, dándola a conocer con ese título en 1966. A groso modo, plantean que los grupos sociales construyen, modifican y moldean la realidad, a través de múltiples procesos y mecanismos, sea por dominación o consenso, de tal forma que la realidad es lo que el grupo social nos dice que es, en tanto no surja una proposición que demuestre lo contrario y sea capaz de dominar o persuadir, modificando la realidad, o al menos la percepción de lo que se considera socialmente real. Para la aplicación de esta teoría en el estudio de las organizaciones, se recomienda el texto de Silverman, 1975.
} 
Esta heterogeneidad de organizaciones en principio se debe a que son creadas - 0 construidas para seguir con la noción de construcción social- para alcanzar los múltiples fines que los miembros de la sociedad persiguen. Se promueve entonces la generación de organizaciones militares, gubernamentales, policiacas, de salud, de asistencia social, educativas, religiosas, políticas, sindicales, bancarias, comerciales, manufactureras, cooperativas, integradoras y hasta criminales. Las hay micros, pequeñas, medianas, grandes, transnacionales y multinacionales, cada una comportándose de manera particular, de acuerdo al ambiente en el que se ubica y que la dota tanto de ventajas comparativas como del grado de incertidumbre y las restricciones que enfrenta; los fines que persigue, la composición social que la hace funcionar, su configuración estructural y las ventajas competitivas que genera. Hall (1983: 3) comienza su obra confirmando ampliamente que las organizaciones nos rodean. Como sociedad creamos organizaciones y éstas inciden en todos los ámbitos de nuestra vida, de tal forma que difícilmente puede pensarse en una actividad social que no se desarrolle en una organización, puesto que para eso han sido creadas.

Y sin embargo, las organizaciones siguen siendo hasta hoy creaciones que no alcanzamos a comprender y explicar del todo, aun siendo nuestras creaciones y construcciones sociales. Intentos ha habido muchos y los más esforzados se han llegado a convertir en teorías y paradigmas que nos permiten explicar o al menos tener una idea menos vaga de lo que son las organizaciones, de aproximarnos a lo que sucede en su interior, a su dinámica y satisfacer en cierta medida nuestra necesidad humana de encontrar un sentido a todo (Teleología).

La Economía goza de la tradición más larga y el reconocimiento de acompañar a las organizaciones desde su aparición -al menos a las modernas, surgidas a raíz del advenimiento de la revolución industrial y el florecimiento de la burguesía y los gobiernos democráticos que propiciarían el capitalismo-. Por su cuerpo argumentativo-discursivo de cientificidad al utilizar el método científico y los modelados matemáticos ha logrado obtener credibilidad y legitimidad, ostentando una especie de derecho de antigüedad. 
El proceso de transformación histórico de las sociedades -vistas también como naciones- está relacionado comúnmente con el cambio en la base del sistema de producción de las mismas ${ }^{4}$. Karl Marx establece esta relación por medio de una revisión histórica de los modos de producción, transitando desde el comunismo primitivo, pasando por el esclavista, el feudal, el capitalista, el socialista y el ideal comunista. De esta manera, las relaciones sociales y económicas se encuentran interrelacionadas y la forma en la que estas sociedades se organizan para producir bienes y servicios para su consumo está acompañada también por el conocimiento y la tecnología de que se valen para llevarlo a cabo.

Aunque eventos históricos como la llustración o siglo de las luces en Europa del siglo XVII, la revolución industrial, suscitado en Inglaterra a finales del siglo XVIII, pueden considerarse momentos de transición tanto a nivel intelectual como tecnológico e indudablemente implicaron transformaciones en las relaciones sociales del mundo occidental de esa época, la construcción argumentativa de Marx resulta más esclarecedora para encontrar la emergencia de la Organización como objeto de estudio, pensando en el tránsito del sistema feudal al sistema capitalista, cuyo modo de producción se basa en la propiedad privada de los medios de producción, así como en el ordenamiento social en aquellos que son propietarios (capitalistas) y aquellos que no lo son (proletarios). La riqueza y estatus que implicaba poseer tierras fértiles ahora se trasladaba a poseer tierras para construir talleres y fábricas y dotarlas con instrumentos de trabajo, mientras que la posesión de esclavos cambió a la contratación como obreros para laborar en los centros fabriles. La producción de artículos se intensificó con la aplicación de los artefactos tecnológicos aplicados a la manufactura de mercancías, mismos que se desarrollaron con el auge de la observación científica, el empirismo y la razón y los gobiernos monárquicos cedieron paso a los Estados-nación basados en la división

\footnotetext{
4 "En la producción social de su existencia, los hombres contraen determinadas relaciones necesarias e independientes de su voluntad, relaciones de producción que corresponden a una determinada fase de desarrollo de sus fuerzas productivas materiales. El conjunto de estas relaciones de producción forma la estructura económica de la sociedad, la base real sobre la que se eleva un edificio [Uberbau] jurídico y político y a la que corresponden determinadas formas de conciencia social. El modo de producción de la vida material determina [bedingen] el proceso de la vida social, política y espiritual en general." [Karl Marx (1987:4), en el prólogo a la contribución a la crítica de la economía política, publicado en 1859].
} 
de poderes y la participación de los ciudadanos en la elección de sus gobernantes. La figura del mercader burgués se consolidaría y adquiriría un papel determinante en el ordenamiento social bajo un nuevo adjetivo, el empresario capitalista.

El desarrollo del capitalismo se ha combinado con el arreglo de rasgos tecnológicos, económicos e institucionales que constituyen la modernidad (Gergen y Thatchenkery, 1996: 356), el intento racional de imponer sobre las tradiciones y los afectos (Montaño, 2003; 2009), el imperio de la razón, la observación empírica, la dominación legítima con base en la autoridad, la lógica de mercado, y en donde la empresa ha conquistado un lugar privilegiado hasta convertirse en un referente institucional de la modernidad (Montaño, 2001: 192), un patrón digno de imitar en sus formas de administrar, en la búsqueda del desempeño óptimo, de asegurar la calidad, de satisfacer al cliente, de ser el espacio social en el cual los miembros de la sociedad ingresan y pueden alcanzar sus objetivos individuales y dar sentido a su vida.

La empresa constituye una forma de organización, y dada la importancia que ha cobrado en el desarrollo del sistema de producción capitalista, en la modernidad y en la vida social hasta ahora, los estudios y obras dedicadas a la operación, administración, organización, desempeño y legitimación de las mismas han conformado un robusto cuerpo teórico conocido como la Teoría de la Organización.

Desde luego que los términos empresa y organización no son sinónimos, a pesar de que comúnmente se les considera como tales. La descripción de la sociedad de organizaciones proporcionada por Etzioni permite identificar la amplitud del término organización:

"Nacemos dentro de organizaciones, somos educados por ellas y la mayor parte de nosotros consumimos buena parte de nuestra vida trabajando para organizaciones. Empleamos gran parte de nuestro tiempo libre gastando, jugando, y rezando en organizaciones. La mayoría de nosotros morirá dentro de una organización, cuando llegue el día del entierro la organización más grande de todas -el Estado- deberá otorgar su permiso oficial' (Etzioni, 1972: 1). 
Hospitales, escuelas, universidades, iglesias, el Estado, figuran en el párrafo anterior, e implícitamente pueden considerarse las propias empresas, presidios, organizaciones civiles y todas aquellas en donde "consumimos buena parte de nuestra vida trabajando". Cada una de ellas es creada con un propósito que sus fundadores le atribuyen, con objetivos particulares que las hacen diferentes entre sí. Se identifica sin embargo en esta cita de Etzioni la asociación del término organización con el espacio físico temporal en el que los miembros de una sociedad interactúan, a través del cual las instituciones como patrones interiorizados cobran vida. Si se reconoce la relativamente reciente conformación de la empresa moderna y su institucionalización ${ }^{5}$, ¿cómo puede constituirse en el modelo ideal a seguir si existen otros referentes institucionales con mayor antigüedad y arraigo?

A partir del desarrollo fabril producto de la revolución industrial, las empresas representaron la fuente de la que emanaba la riqueza ${ }^{6}$, la prosperidad, el progreso, el empleo, el acceso a más bienes y servicios con menor costo, con calidad homogénea -comparada con la producción artesanal-, accesibles en menor tiempo, lo que en el sistema de producción anterior eran privilegio de nobles, realeza y religiosos. ¿Cómo dudarlo si las potencias industrializadas se fortalecían mientras España y sus grandes extensiones de tierras coloniales y riquezas basadas en metales preciosos se desvanecían? Las empresas eran sinónimo de modernidad y con ella, las promesas de una nueva condición humana, liberada del trabajo pesado y tedioso, una vida más confortable y placentera, tiempo suficiente para el ocio, la convivencia, la contemplación y el cultivo de las artes, la paz duradera, parecían cercanas (Montaño, 2008: 335-336).

Si no se lograba, era porque las empresas no estaban funcionando en su máximo potencial, por lo que era prioridad aplicar la razón, la ciencia y la tecnología para mejorar su productividad, lo que dio paso entonces a una transición del ejercicio empírico de su administración a los primeros intentos por documentar las prácticas

\footnotetext{
${ }^{5}$ La institucionalización de la empresa moderna implica la imposibilidad de concebir la vida moderna sin la empresa. Resulta necesaria, independientemente de los daños y consecuencias negativas que pueda implicar su operación.

${ }^{6}$ Los fundamentos de la economía clásica se han encargado de legitimar esta noción a través de las obras de Adam Smith sobre la investigación sobre la naturaleza y causa de la riqueza de las naciones, publicada en 1776; y los principios de Economía política y tributación de David Ricardo (1817).
} 
exitosas en determinados contextos y la sistematización del conocimiento en torno a la gestión de las empresas.

En la década de los cincuentas, Joan Woodward (1975) desarrolló una investigación en cien empresas manufactureras con el propósito de verificar si realmente la aplicación de los principios de la Teoría de la Organización desarrollada hasta entonces tenía una correlación con el éxito de las organizaciones. Como revela en sus resultados, sólo en alrededor de la mitad esto fue así, por lo que el nuevo cuestionamiento ahora se enfocaba en explicar el éxito de las manufactureras que no aplicaban los principios científicos en su administración, o bien, explicar la aplicación de los mismos y su relación con el posterior fracaso. Woodward considera determinantes la diferencia de personalidad entre los directivos, el trasfondo histórico de cada empresa, su tamaño, su estructura, ramo industrial en el que se inscriben, objetivos que persiguen.

Por otro lado, desde el nuevo institucionalismo se parte de una noción de que las organizaciones tienden a parecerse entre sí, lo cual se logra a través de procesos de cambio isomórficos (Powell y DiMaggio, 1983). Existe entonces una contraposición entre si las organizaciones son heterogéneas (siguiendo a Woodward) o si las organizaciones se homogenizan (Powell y DiMaggio, 1983). Ambas aproximaciones tienen argumentos válidos y pruebas empíricas que lo demuestran, lo que nos revela entonces la complejidad y ambigüedad de estudiar a las organizaciones. Se asume que es necesario abordarlas a partir de casos particulares y que la explicación se circunscribe a esa organización particular en ese momento determinado.

Las organizaciones son abordadas por campos específicos de conocimiento de las ciencias aplicadas y sociales. Una organización de cualquier tipo puede ser estudiada como objeto desde la perspectiva de la Ingeniería Industrial, de la Economía, de la Psicología, de la Sociología, de la Antropología, de la Política. De acuerdo al interés particular que el sujeto observador tenga en su organización objeto y considerando su formación profesional, su configuración socio-cultural y su contexto espacio-temporal, elegirá bajo qué perspectiva observará a su objeto. Esta 
elección inevitablemente implica la no-elección de otras perspectivas, por tiempo, recursos, condiciones y por la mencionada limitación racional de no dominar esas perspectivas no elegidas.

\section{Teoría de la Organización y Estudios de la Organización}

La Teoría de la Organización (TO) constituye un exitoso esfuerzo para explicar y justificar a las organizaciones, dada su amplia aceptación, difusión e implementación a pesar de las corrientes críticas, y su reconocimiento como la conciencia teórica de la práctica administrativa. Ésta última se nutre tanto de la Teoría Económica como de la Teoría de la Organización para justificar y legitimar el despliegue de sus diversos instrumentos, técnicas, herramientas y demás artilugios en las actividades cotidianas de cada Organización (Ramírez, Vargas y De la Rosa, 2011; Berglund y Werr, 2000).

La revisión histórica de la Teoría de la Organización como conjunto de conocimientos desarrollados, relacionados y acumulados en torno al objeto de estudio que constituyen las organizaciones se identifica en seis corrientes clásicas y cuyo punto de partida se establece a partir de la emergencia de las organizaciones surgidas con la revolución industrial y la recuperación por escrito de las observaciones hechas por los sujetos interesados.

En estas seis corrientes la constante es la búsqueda sistemática del funcionamiento ideal de la organización, por medio de la racionalización científica. El punto de partida son las fábricas, a partir de las cuales se comienza a teorizar y registrar las observaciones y experimentos llevados a cabo en las mismas. Desde entonces, el sesgo que ha prevalecido es que estas empresas privadas se identifican principalmente con el objetivo de la maximización de ganancias a través de métodos racionales y desarrollos mecánicos y tecnológicos. Al establecerse el concepto de 
"one best way", se buscaba identificarlo o desarrollarlo e incluso, en caso de que no se consiguiera, imitarlo de otra organización que lo tuviera.

Dentro de la Teoría de la Organización suele incluirse el tipo burocrático de dominación ideal planteado por Weber e interpretado y trasladado a las organizaciones por Merton para consolidar el modelo burocrático basado en la lógica racional-instrumental y lo que se conoce como Teorías de la Burocracia. De esta manera, se consolida el cuerpo del discurso alrededor del cual las organizaciones en la modernidad operan y se legitiman ante la sociedad en la que se circunscriben, y a través del cual se convence y se interioriza institucionalizándose, es decir, tomándose como algo natural su operación. De la práctica surgida de las fábricas inglesas a raíz de la revolución industrial y como producto de la labor intelectual de los primeros teóricos que pretendían explicar el funcionamiento operativo y administrativo de estas singulares organizaciones, se conformaron a nivel micro y macro tanto la Teoría Económica como la de la Organización, así como el ejercicio de la Administración moderna ${ }^{7}$, convirtiéndose en un paradigma aceptado y difundido a través de revistas y libros, en el modelo a seguir, el paradigma dominante que dicta las pautas y ofrece soluciones.

Este cuerpo discursivo -llámese paradigma funcionalista (Burrell y Morgan, 1979: 25), perspectiva dominante (Zey-Ferrell, 1981), racionalismo triunfante (Reed, 1996: 34), funcionalismo ortodoxo, ciencia normal (Clegg y Hardy, 1996: 2), pensamiento tecnocrático, positivismo, racionalidad instrumental-funcionalista (Ibarra y Montaño, 1986) - ha influido decisivamente en todas las dimensiones y variables de las organizaciones y, en consecuencia, en el desarrollo histórico, económico, político, social, cultural y organizacional de las sociedades modernas y contemporáneas -

\footnotetext{
7 Basta citar en el ámbito de la Economía la corriente clásica reconocida como liberalismo económico, cuyos principales exponentes son David Ricardo, Adam Smith y John Stuart Mill (Difusor de las ideas utilitaristas de Jeremy Bentham), así como la vertiente crítica personificada por Karl Marx y su obra El Capital, los cuales son estudiados en los primeros cursos de Economía básica. En el caso de la Teoría de la Organización, el desarrollo no fue tan inmediato como en el caso de la Economía, aunque se identifican obras importantes que sirvieron como inspiración y base para el proclamado padre de la administración científica, Frederick W. Taylor (Para una revisión más extensa del desarrollo de la Teoría de la Organización, ver Ibarra y Montaño, 1986).
} 
¿acaso postmodernas? ${ }^{8}-$, acentuándose la influencia estadounidense ${ }^{9}$ a partir del desenlace de la segunda guerra mundial y posteriormente con la fragmentación de la Unión Soviética (March, 2007), lo que se sumó a la revitalización del liberalismo económico -bajo el nombre de neoliberalismo-, el utilitarismo ${ }^{10}$, el surgimiento de la escuela filosófica pragmática ${ }^{11}$, y la tradición de la ética protestante.

Kuhn establece que los paradigmas son "[...] realizaciones científicas universalmente reconocidas que, durante cierto tiempo, proporcionan modelos de problemas y soluciones a una comunidad científica" (Kuhn, 2004: 13). Esta noción kuhniana destaca el cuerpo de conocimientos respecto a un campo de estudio, conocimientos validados científicamente y aprobados por la comunidad científica y académica, que pretenden ofrecer soluciones a problemas propios del campo. La precisión de Kuhn respecto a la dimensión temporal se convierte en crucial, dado que establece una caducidad del paradigma, caducidad que está en función del contexto histórico, económico, político, social y cultural. Entonces, se reconoce que un paradigma dominante y vigente en un periodo determinado de tiempo, en otro perderá su dominio y eventualmente será superado, relegándose incluso a la obsolescencia parcial o total.

Una de las principales confrontaciones entre los defensores de la T.O. y los críticos de la misma ha sido generada por la obstinación en teorizar respecto a las organizaciones en busca de la teoría que englobe la totalidad del fenómeno organizacional para prescribir entonces los pasos a seguir en busca de la

\footnotetext{
8 Para profundizar en el debate acerca de la modernidad y la postmodernidad en los Estudios Organizacionales, se sugieren como opciones representativas: Clegg, 1990; Montaño, 1994 y; Calás y Smircich, 1999).

${ }^{9}$ Atendiendo a la recomendación de la Real Academia Española, en contraposición al gentilicio o calificativo americano, ampliamente utilizado para referirse a los Estados Unidos de América, cuya ambigüedad puede interpretarse con una carga colonialista-imperialista a la que los presidentes Adams, Monroe y Roosevelt colaboraron en formar, gracias a la conocida Doctrina Monroe ("América para los Americanos", original de Adams y atribuida a Monroe) y al Corolario Roosevelt ("si un país latinoamericano y del Caribe situado bajo la influencia de los EE.UU. amenazaba o ponía en peligro los derechos o propiedades de ciudadanos o empresas estadounidenses, el gobierno de EE.UU. estaba obligado a intervenir en los asuntos internos del país "desquiciado" para reordenarlo, restableciendo los derechos y el patrimonio de su ciudadanía y sus empresas.") entre 1823 y 1904 (Selser, 1962; Perkins, 1964).

${ }_{10}$ Referido a lo útil para la satisfacción de preferencias, en la búsqueda del mayor bienestar para el mayor número de personas.

${ }_{11}$ Particularmente, aquella vertiente que destaca lo práctico, tomando la acepción de pragmático como sinónimo.
} 
consecución de los objetivos de manera eficiente y eficaz, maximizando ganancias y reduciendo costos.

Desde esta perspectiva, uno de sus principales críticos ha argumentado que las organizaciones han sido representadas en diversos términos modernistas. Por ejemplo, han sido imaginadas en términos de tipos ideales y sus desviaciones, sistemas y sus procesos de rendimiento, organizaciones y sus contingencias, mercados y sus estructuras y fallas, poblaciones de organizaciones y sus ecologías, culturas y sus mitos institucionalizados y ceremonias, así como la realpolitik de poder" (Clegg, 1990: 3). De igual manera, esta caracterización de organizaciones modernas es tomada como referente para establecer las diferencias respecto al surgimiento de organizaciones que rompían con la lógica establecida, a través de diferentes o "multiple best ways", logrando sus objetivos con éxito, eficiencia y rentabilidad sin seguir las pautas de la Teoría de la Organización. (Woodward, 1975), organizaciones cuya forma es el resultado de la transición del capitalismo industrial al capitalismo postindustrial" (Heydebrand, 1989: 323).

Por otro lado, las organizaciones diferentes a las fabriles, empresariales o gubernamentales burocráticas, con objetivos sociales o políticos más que económicos pusieron en tela de juicio la legitimidad y el prestigio de la T.O. Lo que en principio era altamente efectivo y confiable al explicar a las organizaciones fabriles estadounidenses, británicas o francesas de principios del siglo XX, de pronto fue incapaz de hacerlo con organizaciones japonesas de la postguerra, después con organizaciones familiares, artesanales, cooperativas, ONG's. Pese a todo lo anterior, la fuerza retórica del discurso sobre las organizaciones basado en la teoría de la organización continúa vigente como paradigma dominante por su discurso pragmático, utilitarista, positivista, en gran medida por la efectividad de su discurso que logra permear en las organizaciones. Precisamente se puede entonces considerar que la Teoría de la Organización, la teoría económica y las teorías de la burocracia, bajo las nociones de construcción social de la realidad propuestas por Berger y Luckmann (1999) y Silverman (1975) en el ámbito organizacional, permiten entonces considerar esta influencia teórica convencional dominante como un paradigma (Kuhn, 2004) y un discurso (Alvesson y Kärreman, 2000). Paradigma 
porque se parte del supuesto de que se encuentra sustentado en la comunidad científica y en experimentación probada empírica y científicamente, por lo que alcanza la legitimidad por convención de esa comunidad (Astley, 1985; Gabriel, 2010). Discurso porque se socializa con el propósito de difundirse hasta alcanzar la aceptación general, es decir, darse por sentado, a través de la propia comunidad científica por medio de publicaciones en revistas, congresos, ponencias, libros; a través de la comunidad académica en los cursos, talleres, seminarios impartidos en las universidades; a través de despachos de consultoría; de medios impresos y electrónicos como columnas en periódicos y revistas dirigidas a empresarios, inversionistas, gerentes, entre otras (Clark y Salaman, 1996; Berglund y Werr, 2000; Gómez, 2004).

El surgimiento de discursos provenientes de las universidades estadounidenses principalmente ha sido una constante influencia a nivel mundial y ésta se ha visto exacerbada a raíz del fenómeno globalizante, pues ya no sólo se transmiten estos discursos vía publicaciones, congresos o consultorías, sino que también se han propagado con mayor rapidez a través de las revistas especializadas y las nuevas tecnologías de la información y la comunicación.

Los contrapesos teóricos a su vez han acompañado este desarrollo tanto en la Economía como en la Teoría de la Organización (Morales, 2008: 1). Sin embargo, dada la falta de "una perspectiva unificada que incorpore todas las hipótesis alternativas, métodos, teorías sustantivas e ideologías" (Zey-Ferrell, 1981: 200), capaz de desmitificar el discurso de la perspectiva dominante, ésta sólo ha hecho eco en ciertos círculos académicos e intelectuales, logrando tal vez la desaceleración de la dinámica de dominación pero sin derrocarla. La defensa del paradigma se da igualmente de forma vigorosa, replicando precisamente con discursos borrascosos y rebuscados la invalidez de las observaciones, calificando de mal informados, desconocedores y negligentes a los investigadores que publican las críticas en artículos y libros de corte crítico a la Teoría de la Organización ${ }^{12}$.

\footnotetext{
${ }^{12}$ Dos muestras de la defensa y rechazo a la crítica sobre la Teoría de la Organización convencional se pueden encontrar en Donaldson (1985) y en Hickson (1988).
} 
El aporte de los Estudios Organizacionales a grandes rasgos consiste en formas diferentes a las tradicionales ${ }^{13}$ de estudiar a las organizaciones. El objeto de estudio en un primer nivel es la organización, lo cual es visto como un constructo abstracto, como un ente tangible y observable o como un proceso (Clegg y Hardy, 1996: 3), para adentrarse después en categorías de análisis ${ }^{14}$ que constituyen una parte explicativa del fenómeno dinámico de la organización observada.

\section{Las construcciones sociales y las realidades socialmente construidas}

Una vez planteado lo que se considera una organización, así como las diferencias y complementariedades respecto a los planteamientos de la Teoría de la Organización y los Estudios Organizacionales, es necesario esclarecer un término necesario para continuar con el desarrollo del texto, con la finalidad de identificar su relación con el lenguaje y el Discurso Organizacional: La construcción social de la realidad.

Desde los debates filosóficos de la Grecia antigua existen posturas ontológicas y epistemológicas que plantean la relación entre los seres humanos y la realidad, mundo objetivo, ambiente, entorno o contexto, según el punto con el que cada cual se identifique. Las discusiones entre lo ideal y lo material, el mundo de las ideas y de las cosas, la esencia y la existencia, la razón y la percepción, constituyen el cuerpo milenario de la filosofía, la cual ha sido una ciencia de élites, reservada para pocos iniciados, lejos del alcance de las masas.

Los planteamientos de Schutz y Berger y Luckmann (1999) permitieron acercar un poco este debate, haciendo comprensible para aquellos poco familiarizados con la filosofía la dicotomía entre el voluntarismo y el determinismo. Mientras éste último

\footnotetext{
${ }^{13}$ Entendidos como el cúmulo de paradigmas establecidos desde el ámbito de la Economía, la administración y la Teoría de la Organización Convencional.

${ }^{14}$ Entre estas categorías de análisis principalmente pueden destacarse el poder, la cultura, el discurso, la institución, la forma organizacional, la ambigüedad e incertidumbre en los procesos decisorios, el acoplamiento de sistemas.
} 
sostiene la pasividad y conformismo, la resignación de los seres humanos ante las fuerzas que no puede conocer, comprender o controlar, el voluntarismo plantea la capacidad del ser humano de actuar ante estas fuerzas, de modificar su realidad e incluso crearla, valiéndose del cerebro desarrollado que posee, así como de su conformación biológica, psicomotriz y fisiológica que le permite construir artefactos a partir de la modificación y manipulación de los elementos y materiales que tiene a su disposición en la naturaleza.

La acuñación del término construcción social de la realidad conlleva la idea voluntarista de que el ser humano se vale de su cerebro, de sus sentidos y de su cuerpo para interpretar su mundo, su alrededor, para percibir, para sentir, para generar ideas, para establecer comunicación a través del lenguaje con sus semejantes con las mismas capacidades, pero que pueden interpretar, percibir, sentir, pensar y comunicarse diferente. Como animal social y político, esta convivencia e interacción lleva tanto a conflictos como a consensos, donde entran en juego la identidad de cada individuo, sus creencias, su ideología y de esta mezcla surgen nuevas creencias, ideologías e identidades construidas colectivamente, como resultado del conflicto o del consenso. A esto se le conoce como construcción social de la realidad, es decir, el acuerdo o consenso de los miembros de la sociedad respecto a la realidad que perciben y describen. Como puede apreciarse, no significa que esa realidad sea verdadera o real, sino que es la realidad que la sociedad decidió tomar por verdadera o real porque surgió de la colectividad y permite mantener su equilibrio por cierto tiempo, dota de certidumbre y disminuye la ansiedad.

Desde la Grecia clásica se planteaban las nociones del animal racional, social y político, se planteaba también la importancia de los discursos y se enaltecía la habilidad de los oradores, incluso Sócrates censuraba a los sofistas, que aparentaban saber valiéndose de su habilidad con las palabras para hacerlas pasar como verdaderas gracias a la ignorancia de quienes les escuchaban y creían. Las religiones han sido también históricamente beneficiarias de esta construcción de realidades, cuyas técnicas y estrategias se refinaron y se heredaron a los reyes, 
militares o todo aquel que se encontrara en una posición de poder y estuviera decidido a preservarlo o aumentarlo.

Ejemplos actuales podemos encontrarlos en los científicos ${ }^{15}$, en los académicos, en los políticos, en los activistas y en los mercadólogos y publicistas, así como en la literatura de todo tipo, el cine, la radio, la prensa, el internet. La capacidad de construir realidades requiere de imaginación e inventiva, de ideas, de lenguaje, de palabras, de argumentos y de persuasión. Se observa que cada uno de estos roles lo desempeña un ser humano, el cual construye realidades de acuerdo a sus intereses, su identidad, ideología y cultura, se encuentra a su vez con otras realidades construidas y se confrontan para imponerse, sucumbir o emerger como una síntesis de las realidades participantes que conformarán así la realidad socialmente construida.

Retomando la crítica que hacia Sócrates a los sofistas, la construcción de realidades se encuentra sujeta a los intereses que se busca proteger o a los objetivos perseguidos por aquellos que las construyen, pudiendo ser éstos tanto lícitos como ilícitos. Esto nos adentraría a cuestiones éticas y morales, como lo ha hecho con la filosofía, la política, el derecho y la teología. En la construcción de realidades se encuentran las mayores virtudes humanas y los aspectos más oscuros y maquiavélicos de la humanidad.

Si el mundo es la morada del sufrimiento, como plantea Schopenhauer (2009: 79), el ser humano construye realidades para aliviar su sufrimiento en esta vida; si su estancia en este mundo es aburrida (ibid, 73), construye realidades para mitigar su aburrimiento; si no están contentos con su suerte y desean una vida distinta a la que viven, construyen ficciones para tener las vidas que no se resignan a no tener (Vargas Llosa, 2007: 16).

En esta variedad de realidades socialmente construidas se encuentran las creaciones humanas. Las organizaciones son creadas socialmente, las naciones, el

\footnotetext{
${ }^{15}$ Podemos considerar como ejemplo los modelos de sistemas solares que se han propuesto históricamente (geocéntrico, heliocéntrico, de Dalton, de Thomson, de Rutherford, de Bohr, de Sommerfeld, de Schrödinger), los cuales han sido sustentados científicamente y aceptados como verdades hasta que un nuevo modelo más preciso termina por desplazarlo y éste nuevo es adoptado ahora como la nueva verdad que explica la realidad.
} 
lenguaje, la cultura, los valores, incluso hay quien se atreve a plantear que los mismos individuos son sujetos construidos socialmente, lo que nos lleva a la construcción de identidad. Este concepto implica el autorreconocimiento del individuo, es decir, su autodefinición. No es posible reconocerse como ser humano si no es en función de otros. La identidad entonces lleva implícita esa dicotomía desde su raíz etimológica. "Yo" y "lo mismo". Para ser humano preciso ser yo, no mono, ni perro, ni árbol ni planta. No soy ni me parezco a la piedra ni al agua. Pero sí me parezco a este otro, pues me reconozco, no es el mismo que yo, pero sí lo mismo que yo: humano.

La identidad se conforma entonces a partir del reconocimiento del individuo en el otro o los otros, diferentes a él e iguales a él. Como animal social y político, no puede ser sólo "yo", necesita ser "nosotros". Nosotros los humanos, nosotras las mujeres, nosotros los solteros, nosotros los mexicanos. Los valores compartidos, las costumbres, los ritos, el lenguaje permiten una asociación de "iguales" que se reconocen mutuamente, mientras que al mismo tiempo reconocen a otros que no son como ellos. Esto es la otredad. Nosotros los humanos (los otros: los animales); nosotros los hombres (los otros: las mujeres); nosotros los jóvenes (los otros: los viejos); nosotros los mexicanos (los otros: los extranjeros). Aquí la esencia del animal político.

La valoración respecto a las diferencias forma parte de la ideología, construida también socialmente. Siendo un término relativamente nuevo, su gran promotor lo encontramos en Karl Marx ${ }^{16}$, quien lo plantea como el "sistema de ideas, de representaciones, que domina el espíritu de un hombre o un grupo social [...] pura ilusión, puro sueño, es decir, nada. La ideología es pensada por lo tanto como una construcción imaginaria" (Althusser, 2008).Louis Althusser se propone desarrollar una teoría de la ideología en general que, a su juicio, Marx no terminó por exponer en sus obras. Para Althusser, la ideología es "una representación de la relación imaginaria de los individuos con sus condiciones reales de existencia [...] en la

\footnotetext{
${ }^{16}$ Althusser (2008: 43) señala como fuentes inspiradoras de Karl Marx respecto al término "ideología" a Cabanis, Destutt de Tracy y sus amigos, quienes le asignaron por objeto la teoría (genética) de las ideas. Marx retomará ese concepto cincuenta años después en sus obras de juventud, pero con un sentido muy distinto, como puede apreciarse.
} 
ideología [,] los hombres se representan en forma imaginaria sus condiciones reales de existencia" (ibid, 49-50).

De esta manera, la asociación de los términos propuestos hasta ahora permite establecer una diferencia importante entre los términos identidad e ideología y su relación con la noción de construcción social de la realidad. Si atendemos a las posturas psicoanalíticas y neurobiológicas, partiríamos del desarrollo del cerebro en la edad temprana del ser humano para ser capaz de reconocerse y ser consciente de su ser. Todavía infante, el ser humano reconoce a su madre y a aquellos seres que pasan más tiempo cerca de él (padre, hermanos, primos, abuelos), madurando en el proceso hasta ser capaz de identificar a los que habitan la casa y los extraños. La educación que recibe en el seno familiar representa la primera acción de la sociedad sobre él para constituirlo como un ser construido socialmente: si debe vestir de rosa o azul, si vestir pantalones o vestidos, si usar diadema o gorra, si jugar con carritos o con muñecas. En estos primeros meses o años de vida desarrollará el lenguaje y adoptará un idioma por influencia de la sociedad a la que pertenece la familia en la que se encuentra. Así aprenderá a identificar y nombrar a su progenitora como "mamá" o "mami", palabras propias del idioma español, y no "mom" como en el inglés, o "mutter". Siguiendo está lógica, restringe otras "realidades" que desconocerá muchos años más.

Esto resulta importante porque, en el caso de palabras que designan a cosas, acciones o fenómenos, la relación que se establece entre el individuo y el objeto, fenómeno o acción que cataloga la palabra será muy diferente. Por ello la dificultad de traducir ciertas palabras a otros idiomas, como el "cafuné17" de Brasil, o más técnicas como downzizing, empowerment, outsourcing, organizingentre muchas otras. La dificultad se encuentra en que esos términos son construidos para designar una acción, un objeto o un fenómeno pero con base en la relación que se establece entre los individuos de la sociedad que habla esa lengua y la realidad que

\footnotetext{
${ }^{17}$ Pasar suavemente los dedos a través de los cabellos de una persona repetidamente para reconfortarlo o como gesto de cariño.
} 
ellos asumen. Se aprecia que una sola palabra en ese idioma se convierte en muchas palabras para tratar de dar una aproximación a lo que se quiere decir.

Retomando el aspecto de la educación, el individuo es moldeado desde edad temprana de acuerdo a los patrones socialmente aceptados, continuándose en la educación formal que reciba desde la guardería, preescolar y hasta que concluya o la abandone. De tal forma que, cuando el individuo llegue a conocer las palabras, identidad, libre albedrío, original, auténtico, único, libre, autónomo, éste las utilizará para evaluarse y autorreferirse, probablemente nunca se dé cuenta del grado de influencia que ha tenido la sociedad en la constitución de su "yo", de su identidad y de su ideología. Los valores éticos y morales y su ausencia o degeneraciones también se adquieren en la sociedad, en la interacción cotidiana y forman parte de la ideología de los individuos.

\section{El lenguaje como instrumento de construcción social de la realidad}

Resulta necesario establecer una ruta desde el lenguaje hacia el discurso, las prácticas discursivas y el discurso como estrategia, dado que se ha presentado al comenzar este documento como el interés sobre el que se centrará la investigación en el estudio de caso.

Como se ha expuesto previamente, el lenguaje de los grupos sociales juega un papel determinante en la construcción de la identidad, de la ideología, de la cultura y de la realidad. El lenguaje humano es altamente complejo, valiéndose de sonidos guturales, movimientos gestuales, ademanes, iconográficos, pero todos estos requieren ser dotados de un significado. Retomando el ejemplo de la palabra mamá, si se considera al ser humano como especie, la cantidad de palabras, sonidos e íconos para referirse al ser progenitor es elevado, tanto como los idiomas, lenguas y dialectos existentes en el mundo puedan crear, designando por un lado al ser progenitor, y al mismo tiempo otorgándole un carácter único, puesto que si se lee o escucha "mamá", "madre" o "jefesita", el significado es a un tiempo el mismo y diferente. De igual manera, cambiar de "madre" a "mother", evoca a pensar en dos 
"madres" de características diferentes, el estereotipo de una típica mexicana o una madre estadounidense ${ }^{18}$.

Este ejemplo simple es un punto de partida para algo más complejo. Permite primero destacar la maleabilidad del lenguaje, la flexibilidad y sus transformaciones a través del tiempo. Si se considera la palabra "racional", ésta evoca en cada individuo un significado distinto, en función de su ideología, educación, cultura y experiencia de vida. La antropología se ha legitimado como ciencia gracias al estudio de la otredad. Esta otredad está referenciada al eje occidental dominante Europa occidental y Estados Unidos de América-, en donde los otros son los bárbaros, los "indios", "los moros", "los negros", "los asiáticos”, "los aborígenes". Todos aquellos que no tienen las mismas costumbres, las mismas creencias, los mismos ritos, a los que hay que "evangelizar", "civilizar", "modernizar", porque no son "racionales". Ser irracional contiene la idea de "no pensar" y eso implicaría "no ser humano", por tanto, no se es un animal racional, sino un simple animal.

La construcción argumentativa que se ha generado en torno a la razón ha permitido los más grandes avances en la ciencia y la tecnología, pero también sigue sustentando la ideología de superioridad del "europeo racional y civilizado" y el "primitivo bárbaro subdesarrollado". Como un acto loable, el superior le hace un bien al inferior al civilizarlo, educarlo y enseñarle a razonar, aunque el primitivo se resista a ello, lo hace porque no alcanza a comprender el bien que se le hace.

Lo mismo sucede con la Ciencia. Todo aquel que no fundamenta sus argumentos en torno a una ciencia reconocida, está condenado a la censura. Y existen ciencias con más prestigio que otras, así como métodos más "infalibles" que otros. Se asume que los avances científicos y tecnológicos, las formas de organización, gestión y evaluación sólo pueden venir de los países "desarrollados" y los libros de texto, las conferencias y congresos y hasta los títulos profesionales tienen más validez si provienen de expertos de universidades europeas y estadounidenses.

\footnotetext{
18 "Con el lenguaje el hombre accede a la facultad de simbolizar, es decir, a la facultad de representar lo real por un signo y de comprender el signo como representando lo real, y establecer por lo tanto una relación de significación entre dos realidades distintas, una concreta, la otra abstracta" (Chanlat y Bedard, 2000: 80).
} 
En este caso, se incorpora el concepto del discurso ${ }^{19}$ como forma particular de representar ciertas partes o aspectos del mundo (físico, social, psicológico) (Fairclough, 2005), como forma de acción de los individuos, esto es, el discurso hace cosas, provoca situaciones y modos de interacción (García y Mendoza, 2007: 61). El sentido lógico del que surge el concepto de discurso es el siguiente: La noción de cultura ha sido cambiante, tomando connotaciones diversas según el tiempo y el contexto. Este concepto ha sido ambiguo desde su significado original (cultivo) en el imperio romano, resignificado metafóricamente por Cicerón como cultivo del alma, pasando por la ilustración francesa y el romanticismo filosófico alemán hasta llegar a la antropología y etnografía anglófona del cual se toma la noción para los estudios organizacionales. Sin embargo, se reconocen en la cultura elementos como los símbolos, los cuales constituyen a su vez al lenguaje, entendido como el sistema de símbolos que, desde la perspectiva postmoderna ha pasado de la representación de la realidad a la acción social misma (Gergen y Thatchenkery, 1996). Rescatando a Wittgenstein en su obra Investigaciones filosóficas, "el lenguaje adquiere sus significado ya no de sus bases mentales o subjetivas sino de su utilización en los hechos ("juegos del lenguaje")."

Chanlat y Bedard (2000: 80) destacan que luego de las heridas narcisistas infringidas a la humanidad por la ciencia de Galileo, Darwin y Freud, su especificidad se circunscribe a ser animales que hablan. Por medio del lenguaje representa y construye su realidad a través de los juegos del lenguaje señalados por Wittgenstein y Lyotard en donde el conocimiento se produce en relatos breves o narrativas modestas (Calás y Smircich, 1999: 6). La concepción de verdad y de razón planteado por Schopenhauer se distingue al plantear que la verdad objetiva de una tesis y su validez en la aprobación de los contrincantes y los oyentes son dos cosas distintas (Schopenhauer, 1997). De tal forma, los juegos del lenguaje que representan la realidad y la construyen no necesariamente lo hacen con argumentos de verdad, sobre lo que la realidad es, sino sobre lo que se pretende que sea, persuadiendo a los receptores de que esa representación es real, gracias a los

\footnotetext{
${ }^{19}$ Tradicionalmente el discurso es abordado desde la lingüística, en la política, la sociología o la antropología.
} 
artilugios o estratagemas que forman parte de los juegos del lenguaje, construyendo socialmente la realidad y legitimándose con argumentos de razón, mas no de verdad.

Schopenhauer ${ }^{20}$ ofrece una explicación argumentando que la humanidad posee una maldad natural y una vanidad innata susceptible a la capacidad intelectual que no se resigna a aceptar el error y al mismo tiempo, que la verdad la posea el otro. Así, la identificación de un lenguaje argumentativo y otro narrativo (Bruner, 1988) coincide con lo planteado por Schopenhauer, pues la argumentación se presenta como el lenguaje científico que persigue la verdad -al menos idealmente, puesto que suelen formularse argumentos de razón y hacerse pasar por argumentos de verdad, dada la maldad natural humana-, mientras que el lenguaje narrativo es creador de relatos, busca ser creíble, construir realidades (García y Mendoza, 2007: 64).

Majone por su parte establece la interacción necesaria existente entre argumentos empíricos -es decir, argumentos basados en evidencias- y argumentos persuasivos, en su aplicación en la formulación y análisis de políticas públicas, dado que rescata el concepto de retórica como el arte de la persuasión, el estudio de todas las formas de hacer cosas con palabras (Majone, 1997: 42-43). No basta con elaborar argumentos empíricos que sirvan de evidencia, sino que se requiere de los argumentos persuasivos, narrativos o dialéctico-erísticos ${ }^{21}$ que persuadan, que convenzan de que se tiene la razón, lo que lleve a la construcción de realidades, de verdad socialmente aceptada aunque no lo sea pero lo parezca, y de allí se parta hacia la acción. Así entonces se construye el discurso que no es más que el evento que comunica desde ideas, hipótesis, teorías, argumentos empíricos y narrativos, evidencias, que buscan convencer, persuadir al público con el que se debate de aceptar las razones como verdades y actuar en consecuencia.

\footnotetext{
20 Opcit.

${ }^{21} \mathrm{Al}$ respecto, Schopenhauer comienza su obra como sigue: "La dialéctica erística es el arte de discutir, pero discutir de tal manera que se tenga razón tanto lícita como ilícitamente. Puede tenerse ciertamente razón objetiva en un asunto y sin embargo, a ojos de los presentes y algunas veces también a los de uno mismo, parecer falto de ella."
} 
Ahora bien, se da un salto entre el concepto de lenguaje y el de discurso, y otro más al adjetivarlo como discurso organizacional. Se suele utilizar indiscriminadamente uno u otro como sinónimos y ello puede ser causa de la confusión y ambigüedad generada respecto al tema. Desde luego, como interesados en el fenómeno de la organización, no podemos obviar que dentro de ésta se reproducen prácticas propias de lo social, por lo que mucho de lo investigado por los estudiosos del lenguaje y del discurso, sea de utilidad para abordar desde una perspectiva enriquecedora el estudio de las organizaciones.

A partir del interés por el lenguaje y el discurso, también se ha producido información, investigaciones, y documentos específicamente para dar cuenta de cómo se aplica el uso de los estudios del discurso en el análisis organizacional. De esta manera, se tiene un corpus del llamado Discurso Organizacional, el cual posee particularidades y especificidades que lo distinguen de otros discursos, como el político, educativo, etc.

Hablando ya propiamente del Discurso Organizacional, si bien existe un nutrido corpus del cual abrevar, lo que se encuentra es una diversidad de formas de abordar el discurso o de aplicar el análisis de éste en las organizaciones. Desde 2001 se creó el Centro Internacional para la investigación sobre Discurso, Estrategia y Cambio Organizacional (ICRODSC, por sus siglas en inglés), el cual genera vinculación internacional entre aquellos interesados en el desarrollo y aplicación de métodos discursivos en el estudio de las organizaciones. La confluencia de múltiples disciplinas, nacionalidades y experiencias ha conformado una masa crítica en la experiencia en investigación ${ }^{22}$. Importantes representantes de Organization Studies y Critical Management Studies se encuentran vinculados a este centro (Cynthia Hardy, Graham Sewell, David Grant, Gibson Burrell, Cliff Oswick, Hugh Wilmott, Mike Reed, Glenn Morgan, Tom Keenoy, Stanley Deetz, Linda Putnam, Mats Alvesson y Dan Kärreman, entre muchos otros).

\footnotetext{
${ }^{22}$ Para mayor información, consultar el sitio web del instituto: http://icrodsc.org.au/
} 
Desde 1994 se celebra cada dos años la Conferencia Internacional sobre Discurso Organizacional, en la cual se ha abordado este importante enfoque, lo que da cuenta de la relevancia y vigencia que ha tenido a partir del llamado giro lingüístico. La participación y organización del ICRODSC en este evento representa un punto de confluencia de expertos en el tema y el centro del debate, consensos y controversias respecto al Análisis del Discurso en las Organizaciones.

Como resultado se pueden encontrar una vasta cantidad de artículos en torno al Discurso Organizacional en las más importantes revistas, como son: Organization Studies, Academy of Management Review, Academy of Management Journal, Academy of Management Annals, Human Relations, Organization, Culture and Organization, Discourse \& Society, Discourse \& Communication, Discourse Studies, International Studies of Management \& Organization, Management Communication Quarterly, Journal of Change Management, British Journal of Management, Communication Theory, Journal of Applied Behavioral Science, International Journal of Sociology and Social Policy. Los especialistas en discurso organizacional también han aportado obras especializadas, tanto en forma individual como colectiva. Cabe destacar también la publicación del Manual o Handbook de Discurso Organizacional, de Grant, Hardy, Oswick y Putnam (2004).

En cuanto a México, existe ya un avance en cuanto al estudio del Discurso en general, como lo demuestra la publicación desde 1983 de la revista Discurso ${ }^{23}$ del Instituto de Investigaciones Sociales de la UNAM o la participación de exponentes mexicanos en la Asociación Latinoamericana de Estudios del Discurso (ALED) y la publicación a partir de 2001 de la revista de dicha asociación ${ }^{24}$. En cuanto al Discurso organizacional, ya se encuentran también trabajos que incorporan este enfoque en México, como son el del Sindicato Nacional de Trabajadores de la Educación de los Adultos (SNTEA), propuesto por Rogelio Mendoza (2002), y Rosa Isela García (García y Mendoza, 2007; García, 2008); el de la prisión, desarrollado por Ángel Wilhelm Vázquez (2004; 2006), el discurso administrativo en la MiPyME,

\footnotetext{
${ }^{23}$ Una de las tres primeras de su tipo en el mundo y la primera en América Latina. Se encuentran disponibles en formato electrónico para su consulta en: http://www.iis.unam.mx/indexcontent.php? module=380\&

${ }^{24}$ Para mayor información sobre la asociación, consultar su sitio web: http://www.aledportal.com/
} 
de Oscar Lozano, Ayuzabet de la Rosa y Anabela López (2008); la organización radiofónica, destacada por Pablo Armando Solís (2010); un centro para la sustentabilidad de la región Sierra Nevada, presentado por Nayeli Pérez (2012); los cuerpos académicos de una universidad estatal, realizado por Augusto Renato Pérez (2013); una empresa chocolatera familiar, presentado por Salvador Octavio Aguilar (2013); o bien, la reflexión sobre el tema de Anahí Gallardo (2012) y la sugerentes obras de Rafael Montesinos (2007) sobre la conformación de un discurso político por parte de organizaciones empresariales, y la de Marcela Hernández (2004) sobre la cultura empresarial mexicana.

Si bien existe un trayecto recorrido por décadas, no puede afirmarse que exista un consenso respecto a lo que significa Discurso, o cómo analizar el mismo, sea en la sociedad o en las organizaciones, por lo que las muestras presentadas previamente representan más bien lo avanzado hasta ahora, lo que conforma el corpus del discurso al cual referenciarse, disentir, concordar, replantear, agregar. Las obras citadas en este documento representan años de trabajo y dedicación de especialistas, las cuales serán de mayor utilidad para quien desee conocer los orígenes y estado del arte respecto al Discurso y el Discurso Organizacional. Como este trabajo no busca desarrollar ese punto, lo que realmente se quiere destacar de todo lo anterior es mostrar que existe una tradición de estudios o análisis del discurso, en los ámbitos social y organizacional, principalmente en Europa, Estados Unidos de América y otros países como Australia, Canadá u Holanda. De ello se desprende también que el corpus al cual remitirse es en su gran mayoría anglosajón, dado que las publicaciones de mayor influencia son publicadas en inglés.

Para el caso de Latinoamérica, en donde gran parte de la población que la compone habla -y lee- el español, esto representa las dificultades obvias del idioma, pero además se detecta lo poca o nula participación en general en el debate en torno a las organizaciones, y en particular, respecto al discurso organizacional. Para dar cuenta de las realidades locales, regionales y nacionales en Latinoamérica, resulta entonces necesario tanto recuperar crítica, espacial y temporalmente la vasta obra científica y académica, para detectar qué de todo ello permite estudiar estas 
realidades e incluso confrontarlas proponiendo propias que permitan explicar con mayor precisión y certeza los procesos y fenómenos de las organizaciones locales. La subjetividad, cultura, y otras particularidades propias de lo local muy seguramente escapan de las matrices teóricas importadas, que deben ser tomadas sólo como marcos referenciales generales o auxiliares, pero no absolutos.

Alvesson y Kärreman $(2000 ; 2011)$ expresan claramente la diversidad de enfoques de análisis del discurso, reduciendo a dos niveles que engloban éstos: el discurso con "d" minúscula, para referirse al análisis de tipo micro, en las interacciones cotidianas, conversaciones personales o cara a cara, informales, etcétera; y el Discurso con " $D$ " mayúscula para referirse a los Macro discursos, a un abordaje de gran alcance, que implica política, economía, sociedad, tiempo y espacio. Se habla también de un nivel intermedio o Meso, aunque en realidad no quedan claras las fronteras, por lo que no puede determinarse en qué momento se debe abordar el análisis con "d" o con " $D$ " y sus respectivas herramientas metodológicas.

Las advertencias de Alvesson y Kärreman llaman a evitar ver todo como discurso, y evitar la pretensión de que el discurso como enfoque de análisis es capaz de explicarlo todo, las cuales concuerdan con lo perseguido en este documento. Respecto a separar "discurso" y "Discurso", parece caer en el propio reduccionismo que censuran, puesto que no se puede determinar qué forma de abordaje sea la "one best way", si sea más efectivo o científico un análisis de conversación o un Análisis Crítico del Discurso. De la misma manera que la Ciencia y la Filosofía han sido confrontadas al pretender la universalidad o supremacía de una forma de hacer ciencia o de filosofar, la diversidad es la que caracteriza tanto la realidad como la manera en que se atrapa, se describe, se estudia y se transforma o se crea. No se trata de proclamar un método como superior a otro, sino de explotar las bondades que puede ofrecer cada uno, así como sus hallazgos, manteniendo siempre en perspectiva sus deficiencias, dificultades y limitaciones. Puede hablarse de aproximaciones simultáneas desde diferentes perspectivas que permitan recabar mayores datos, información e imágenes del fenómeno de interés, lo que desde luego será más provechoso y de utilidad que conformarse con sólo una perspectiva. 
Con base en lo anterior, se presentan a continuación las referencias consideradas para la construcción de la investigación:

\section{Autores y Definiciones de Discurso}

FUENTE: Elaboración propia con base en İ̃iguez Rueda (2006) y Vázquez García (2004).

\begin{tabular}{|c|c|}
\hline AUTOR & DEFINICIÓN DE DISCURSO \\
\hline M. Foucault (1969) & $\begin{array}{l}\text { Un discurso es algo más que el habla, algo más que un } \\
\text { conjunto de enunciados. El discurso es una práctica } \\
\text { (discursiva). [...] Todo discurso tiene un contexto de } \\
\text { producción. Ese contexto es la formación discursiva [...] un } \\
\text { conjunto de relaciones que articulan un discurso, cuya } \\
\text { propiedad definitoria es la de actuar como regulaciones del } \\
\text { orden del discurso mediante la organización de estrategias, } \\
\text { facultando para la puesta en circulación de determinados } \\
\text { enunciados en detrimento de otros, para definir } \\
\text { caracterizar un determinado objeto [...] Los discursos son, } \\
\text { pues, prácticas sociales }{ }^{25} \text {. }\end{array}$ \\
\hline $\begin{array}{l}\text { Knights y Morgan } \\
\text { (1991) }\end{array}$ & $\begin{array}{l}\text { Una serie de ideas y prácticas que condicionan la manera } \\
\text { de relacionarse de las organizaciones que conforman un } \\
\text { campo determinado, así como de los miembros que las } \\
\text { integran. }\end{array}$ \\
\hline $\begin{array}{l}\text { L. Íñiguez y C. } \\
\text { Antaki (1994) }\end{array}$ & $\begin{array}{l}\text { Un discurso es un conjunto de prácticas lingüísticas que } \\
\text { mantienen y promueven ciertas relaciones sociales. El } \\
\text { análisis consiste en estudiar cómo estas prácticas actúan } \\
\text { en el presente manteniendo y promoviendo estas } \\
\text { relaciones: es sacar a la luz el poder del lenguaje como una } \\
\text { práctica constituyente y regulativa. }\end{array}$ \\
\hline $\begin{array}{l}\text { Cabruja et al. } \\
\qquad(2000)\end{array}$ & $\begin{array}{l}\text { Representa un dispositivo creado y modelado para la } \\
\text { interiorización de ciertos aspectos simbólicos que, como } \\
\text { artefacto factual lingüístico, permite un agrupamiento de } \\
\text { unidad y coherencia a significaciones narrativas propias. }\end{array}$ \\
\hline $\begin{array}{l}\text { D.Grant y C. Hardy } \\
\text { (2004) }\end{array}$ & $\begin{array}{l}\text { El término 'Discurso Organizacional' se refiere a las } \\
\text { colecciones estructuradas de textos incorporados en las } \\
\text { prácticas del hablar y escribir (así como también una } \\
\text { amplia variedad de representaciones visuales y artefactos } \\
\text { culturales) que introducen objetos relatados identificados } \\
\text { con lo organizacional según esos textos son producidos, } \\
\text { diseminados y consumidos. }\end{array}$ \\
\hline $\begin{array}{l}\text { Ángel Wilhelm } \\
\text { Vázquez }\end{array}$ & $\begin{array}{l}\text { Un artefacto lingüístico que le confiere a la organización } \\
\text { sentido y coherencia tanto en su dinámica social como para }\end{array}$ \\
\hline
\end{tabular}

25 Tomado de Íñiguez Rueda (2006: 81-82). 


\begin{tabular}{|c|l|}
\hline (2004: 268-271) & $\begin{array}{l}\text { quienes la ven desde fuera. [...] El discurso es una } \\
\text { articulación de verdad para la organización, que los } \\
\text { individuos producen y comparten con otros en su interior. }\end{array}$ \\
\hline & $\begin{array}{l}\text { El discurso es una práctica articulada con otras prácticas } \\
\text { también enmarcadas en el orden de la discursividad. } \\
\text { Discursos relacionados con otros discursos que se } \\
\text { retroalimentan, que se interpelan, que se interrogan; } \\
\text { discursos a los que sorprender, descubrir y saquear; } \\
\text { discursos productores y socavadores de otros discursos; } \\
\text { discursos que se transforman, pero a los que también es } \\
\text { posible transformar. }\end{array}$ \\
\hline $\begin{array}{l}\text { Cliff Oswick } \\
\text { (2011: 104) }\end{array}$ & $\begin{array}{l}\text { Discurso es un proceso de creación de significado a través } \\
\text { del habla y el texto. }\end{array}$ \\
\hline
\end{tabular}

Grant et al (2004) refieren cuatro áreas que prevalecen y son ampliamente abordadas en los estudios del Discurso Organizacional: la conversación y el diálogo, las narraciones e historias, la retórica, y los tropos. La conversación y el diálogo implican el conjunto de interacciones e intercambios de mensajes entre personas a través del tiempo. De esta área se desprende la noción de que las organizaciones se producen a través de continuos intercambios lingüísticos y textuales entre actores organizacionales que se basan en discursos más amplios. A su vez, el estudio de los diálogos trata de mostrar la forma en que se utilizan para generar nuevos significados y comprensión, la creación de espacios para cuestionar y criticar, la mediación y la convergencia de puntos de vista.

El análisis de las narraciones e historias -ciertas o ficticias- se acerca a éstas como dispositivos simbólicos y retóricos, centrándose en temas, ideas, personajes y tramas dentro de un determinado texto o textos (ibíd.); su particularidad es la construcción conjunta de los lectores e interlocutores que influyen en la dirección que estas toman. Una función particular incluye la ideológica, mediante la cual se representan los intereses de un grupo particular. Su importancia determina la forma de pensar y de pensarse, así como las relaciones e interacciones entre los participantes.

El análisis retórico y argumentativo por su parte considera la función del discurso como medio para lograr fines particulares, cómo los mensajes estimulan respuestas, persuadiendo y configurando prácticas organizativas como la imagen corporativa, 
la disociación de la organización respecto a un problema que le concierne (o no), la toma de decisión y la negociación. Se rastrean las razones detrás del uso del discurso, cargado evidentemente hacia la dimensión estratégica. Se observa a la organización como el resultado o efecto de la persuasión retórica.

Finalmente los tropos implican patrones de sustitución que se derivan de la retórica. Los principales tropos son la metáfora, la sinécdoque, la metonimia y la ironía. Éstas permiten comparar dos dominios conceptuales diferentes, por ejemplo, para entender lo abstracto en términos de lo concreto, relaciones causa-efecto, partes de un todo, conexiones entre dos cosas de un mismo dominio e incluso -en el caso de la ironía-, la descripción de algo paradójico o contradictorio.

En el ámbito metodológico, existe una variedad importante de métodos de análisis del discurso, sobre todo gracias al llamado giro lingüístico de la segunda mitad del siglo XX y el interés que despertó en las Ciencias Sociales. De ahí se desprenden el Análisis de conversación, que se enfoca en lo verbal y lo paralingüístico (calidad del sonido, pausas, lagunas, gesticulación, postura, etc.). Otros enfoques metodológicos son el Análisis de interacción y los actos del habla. Ambos se concentran en lo que se ha llamado "enfoque de lenguaje en uso" (Grant et al, 2004).

En cambio, el "enfoque sensible al contexto" se conforma por los métodos que incorporan la relación de los textos con su contexto social, histórico, cultural, económico, político, etc. Se incorporan la pragmática, la lingüística, el análisis de sistemas semióticos sociales y el análisis crítico del discurso, considerado como el más influyente en este enfoque. Una de las aportaciones más relevantes es la noción de intertextualidad, que considera un texto como un eslabón de una cadena de textos que reacciona y transforma otros textos. 


\section{Lenguaje y Discurso en la conformación de ideología en las Organizaciones}

A través de la retórica, la narrativa, la persuasión, la demagogia ${ }^{26}$ y otros artilugios del lenguaje, el discurso ha institucionalizado mitos racionalizados ${ }^{27}$ (Meyer y Rowan, 1977) que alteran la realidad y presentan una visión editada de ésta, que favorece a intereses capitalistas.

En otras palabras, el discurso de la perspectiva dominante (Zey-Ferrell, 1981) ha logrado convencer al mundo -o al menos a una gran parte de éste- de los beneficios del sistema capitalista y sus mercados, de la visión funcionalista racional, de la legitimidad y precisión científica de la economía y la estadística, así como de la eficiencia administrativa en cuanto a la asignación y control de los recursos, y el modelo burocrático como la mejor forma de organizar racionalmente los medios y recursos de las organizaciones, por nombrar los aspectos más representativos.

Ahora bien, estos discursos inciden sobre la memoria colectiva (Robles, Soto y Paoli, 2009: 15) legitimándose a través de las fuerzas de inspiración y aspiración ${ }^{28}$ (Desroche, 1976), moldeando y reconstituyendo el imaginario social, reorientando el sentido de las prácticas sociales, y en el caso de las organizaciones, de las prácticas organizacionales. Si esta idea se asocia con la Teoría de la Construcción Social de la Realidad (Berger y Luckmann, 1999; Silverman, 1975), se tiene entonces un discurso construido socialmente por ciertos grupos para alcanzar sus fines o bien proteger sus intereses. Así, tanto las necesidades como las

\footnotetext{
${ }^{26}$ Entendida en el sentido de la apelación a prejuicios, emociones, miedos y esperanzas del público para ganar apoyo popular mediante el uso de la retórica y la propaganda. Para mayor desarrollo del concepto, consultar Alayón Gómez, (2008).

${ }^{27}$ La noción de Mito Racionalizado se refiere sintéticamente a que las reglas institucionales afectan a las estructuras institucionales y el desempeño de éstas, reflejando la realidad socialmente construida. Estas estructuras se conforman a través del tiempo por medio de la adopción de mitos racionalizados que legitiman el desempeño de la organización haciéndola parecer racionalmente eficiente, más allá de su eficiencia real. (Meyer y Rowan, 1977: 86).

${ }^{28}$ Las fuerzas de aspiración -siguiendo a Desroche (1976)- representan "...el conjunto de significaciones imaginarias culturales, utópicas, ideológicas- que des-determinan una realidad que amenaza." (Robles, Soto y Paoli, 2009: 22). En otras palabras, aquello a lo que se aspira. Las fuerzas de inspiración complementan a las primeras al constituirse en aquello que mueve, que inspira en pos de aquello a lo que se aspira. Se distinguen en las primeras estados deseados futuros, mientras que las segundas se nutren de la memoria colectiva constituida por hechos pasados. En suma, la interacción entre estas fuerzas dota de sentido a la acción, en este caso, a las prácticas organizacionales.
} 
aspiraciones e inspiraciones organizacionales son redefinidas desde el capital y el poder, asociado generalmente a Europa y Estados Unidos (Abrahamson, 1996; Dussel, 2006) -aunque actualmente con el fenómeno de globalización y el flujo internacional de capitales esta noción se vuelve difusa-, llegando hasta los estratos más altos, donde se toman las decisiones: presidentes, gerentes, ministros, secretarios de Estado, e incluso los investigadores de las universidades ${ }^{29}$.

Recuperando una cita al respecto, Clegg, Courpasson y Phillips (2006), el ser humano nace libre pero encadenado, y los eslabones de las cadenas son eminentemente organizacionales. [...] Con organización casi cualquier cosa puede ser intentada. [...] Los medios organizacionales que forman condensan y distribuyen las relaciones sociales forman poder y lo pueden formar de cualquier manera.

Estos autores dejan claro que el poder constituye una acción fundamental que no puede pasar por alto al estudiar cualquier organización. Recuperando las discusiones en torno a las críticas a la modernidad y al capitalismo, a la racionalidad y a la enajenación del ser humano en el ámbito organizacional, Aldrich sintetiza una realidad que forma parte del lado oscuro del cuerpo discursivo mencionado: "Podemos ver el crecimiento de la sociedad organizacional como un rastro de gente esclavizada y dominada por organizaciones." (Hinnings y Greenwood, 2002: 415).

Esta racionalidad en nombre de la modernidad ha llevado al extremo el uso funcional del poder no de manera explícita, sino en formas violentamente psíquicas, como lo ha demostrado la corriente del psicoanálisis orientado a las organizaciones. El poder puede alcanzar cada una de esas cosas buenas pero puede traer consigo el desencadenamiento de violencia, la dominación ser forzada y la manipulación ser empleada. Cuando estas palabras son asociadas con poder, éste es usualmente visto como negativo, innoble. (Clegg, Courpasson y Phillips, 2006:2)

Sewell y Wilkinson (1992) proporcionan un revelador ejemplo de cómo las técnicas de gestión japonesas consideradas por algunos como postmodernas, pueden verse

\footnotetext{
${ }_{29}$ Al respecto, Enrique Dussel lo plantea categóricamente como sigue: "A pesar del hecho de que muchos de los investigadores en los países colonizados se consideran a sí mismos críticos orgullosos (o avanzados) pensadores, rara vez reconocen el grado al cual son Eurocéntricos, aunque ellos no sean europeos. [...] sus mentes han sido colonizadas a tal punto que su idea de "lo otro" es el reflejo de la identidad Europea o americana." (Dussel, 2006: 491)
} 
en realidad como formas sutiles pero sofisticadas de dominación, que permiten vigilar, controlar, disciplinar y sancionar a los trabajadores. Cabe aclarar que aunque los conceptos de poder y dominación son en principio distintos, estos están íntimamente relacionados, puesto que en la práctica cotidiana, el ejercicio de poder se da sutilmente a través de la dominación, la cual tiene la connotación de convencimiento, negociación y consentimiento, aunque en realidad lleva implícita la marca del poder para hacer que el otro haga la voluntad del uno (Clegg y Hardy, 1996:623-626; De la Rosa, 2006: 64).

Las organizaciones operan y consiguen sus objetivos con relativo éxito al desarrollarse una dinámica interna en la que los actores persiguen sus objetivos personales y defienden sus interés al interior de la organización de tal forma que los objetivos organizacionales sean alcanzados aunque con ciertas desviaciones para que los actores también satisfagan los suyos (Crozier y Friedberg, 1990). Los juegos de poder y el despliegue de estrategias de los actores dentro de ciertos límites o reglas del juego previamente establecidos se superponen a lo que la corriente burocrática y la Simoniana decisional plantean desde la Teoría de la Organización. Ahora el actor en realidad es capaz de canalizar sus fuentes de poder dentro de la organización hasta donde las reglas del juego le permitan, las reglas son flexibles o maleables, contrario a lo que la burocracia plantea, y aunque las decisiones sean programadas, los actores encuentran formas de reprogramarlas.

Precisamente el tema del poder se hace presente en esta pugna, siendo uno de los conceptos constituidos como bastiones para los Estudios de la Organización. E discurso posee capacidad de acción, lo que lleva entonces implícito un ejercicio de poder sublimado. Clegg, Coupparson y Phillips entrelazan los conceptos de Poder y Discurso, pues son igualmente entremezclados en la medida en que constituyen la estructura política de las organizaciones a través de diversos circuitos de poder. Los discursos forman estructuras y proveen los medios para ordenar la estructura política. Entonces, las organizaciones y los individuos usan discursos a propósito para formar las situaciones políticas en y a través del cual ellos pueden actuar y desempeñarse. No todo poder requiere organización, pero la mayoría se vale de ella. (Clegg, Courpasson y Phillips, 2006) 
Si bien, el discurso sobre el que se ha hablado en la primera parte es sumamente amplio, tanto como para abarcar los ámbitos de la política, la economía e incluso la cultura tanto a nivel micro como macro, el centro de interés de este documento es el discurso que legitima y promueve ciertos modelos de gestión organizacionales y su transferencia hacia otras organizaciones.

Estos modelos organizacionales surgen en organizaciones consideradas como referentes dignas de imitar, puesto que son los que se valen de los medios referidos anteriormente para propagarse a través del discurso que lo legitima y se propaga por los medios y agentes señalados anteriormente hasta generar cambios institucionales isomórficos. Siguiendo este argumento, se plantea entonces no sólo el discurso que funciona como promotor del modelo, sino también se genera el anhelo de adoptarlo para realizar las promesas y aprovechar las bondades del modelo.

Se omite obviamente la observación de traducir y entender bien cómo opera el modelo que se desea adoptar, tal traducción es un proceso de la idea general al director, como debe ser transferida y reinterpretada, en nuevos ajustes (Czarniawska et al., en Morris y Lancaster, 2005:207). Este discurso aunado a la dinámica vertiginosa en la que se encuentran las organizaciones contemporáneas del mundo globalizado, las lleva a optar por importar modelos a manera de "plug and play", listos para implementarse y comenzar a reportar beneficios a la organización, generando una tendencia a imitar o parecerse a aquellas organizaciones exitosas que forman parte del discurso, en términos académicos, una tendencia al isomorfismo estructural ${ }^{30}$ (DiMaggio y Powell, 1983: 150). Para ello es necesario el proceso de institucionalización, el cual involucra la innovación, la habituación, la objetivación y la sedimentación (Tolbert y Zucker, 1996: 180-184). De esta manera, se seleccionan, promueven e implementan los cambios estructurales necesarios para interactuar de mejor manera con el entorno, se

\footnotetext{
30 Sintéticamente, el isomorfismo estructural expuesto en la obra citada de DiMaggio y Powell se concibe como la tendencia de las organizaciones a parecerse entre sí en cuanto a su configuración estructural, generando campos organizacionales. Lo que se busca es reducir la incertidumbre proveniente del ambiente turbulento en el que se encuentran, así como legitimar sus acciones a través de tres mecanismos: el coercitivo, el mimético y el normativo.
} 
legitiman por medio del consenso y la abstracción teórica y se culmina con la adopción y socialización generalizada al interior de los campos organizacionales de estos cambios estructurales.

Con relación al término de transferencia, Montaño (2006) destaca no sólo la transferencia de conocimiento, sino de este conocimiento o saber hacer (knowhow) en las organizaciones. Por ello, se sigue que las prácticas, las configuraciones estructurales e incluso la orientación hacia qué objetivos deben perseguirse, así como las estrategias para alcanzarlos son transferidas hacia las organizaciones gracias a la efectiva intervención del discurso en el imaginario colectivo.

Se parte del supuesto de que las aceleradoras de empresas de base tecnológica en México son constituidas o creadas por seres humanos con un propósito, cuyo sentido proviene del consenso existente entre sus fundadores. Estas organizaciones están orientadas a atender a empresas de base tecnológica con el propósito de "acelerar" su crecimiento a través de herramientas administrativas. Se supone que todo ello se encuentra inmerso en prácticas discursivas (como lo argumenta Foucault) que legitiman sus actividades. Por tal motivo, el analizar estas prácticas resulta de interés académico. 


\section{Recuento histórico de la industrialización y la ciencia y tecnología mexicana}

Este apartado tiene como propósito establecer la relación entre el proceso de industrialización de México y la emergencia de las aceleradoras de empresas. El intervalo de tiempo se constituye como fuente donde se construye el entramado discursivo que legitima y otorga sentido a estas organizaciones, esto es, la relación del texto con su contexto.

\section{Industrialización y crecimiento económico en México}

Generalmente los textos que tratan el proceso de industrialización en México hacen un recuento histórico desde el periodo conocido como colonial. La razón es que en esos textos se enfocan en la perspectiva histórica partiendo desde las incipientes fábricas textiles y las empresas mineras con tecnología muy precaria y cuyos beneficios terminaban en manos del imperio Español. Posteriormente se trata el periodo de la independencia y el surgimiento de México como país, continuando sobre la misma línea hasta llegar al periodo del Porfiriato y la consecuente guerra civil conocida como la revolución mexicana.

El desarrollo industrial en México se ha fomentado a partir de la segunda mitad del siglo XX, a través de diferentes estrategias. Primero, al impulsar el florecimiento y fortalecimiento de la industria nacional; después, protegiéndola de la competencia extranjera; y por último, orientándola hacia la competencia en mercados internacionales. Sin embargo, ha habido altibajos en este proceso de alrededor de sesenta años. Como consecuencia, se han implementado estrategias para intentar fortalecer el desarrollo industrial en todos sus estratos, desde las grandes empresas hasta las MiPyME's, desde desarrollo de clústers y parques industriales, hasta incubadoras y recientemente aceleradoras de empresas. En México, este proceso no ha sido instantáneo, pero estas prácticas de imitación han sido una constante en su proceso de cambio de una economía rural a una economía industrial. 
En 1930 la constitución de la productividad del país se basaba primordialmente en el sector agropecuario, donde se concentraba alrededor del $68 \%$ de la fuerza laboral, lo que nos indica una organización económica eminentemente rural (Mulás, 1995). A partir de las iniciativas industriales del gobierno federal, la expropiación petrolera suscitada en 1938 y la creciente demanda surgida como consecuencia de la participación de los países industrializados en la segunda guerra mundial, en México inicia una reorientación de la actividad económica, tradicionalmente enfocada a la producción de granos, ganado, extracción de minerales y materias primas, hacia un enfoque manufacturero, es decir, producción de bienes de consumo más duradero. Esta transición que en un primer momento derivó en el conocido milagro mexicano de mediados del siglo $X X$, se vio afectada no sólo por factores de tipo interno, sino también por las variables externas que terminaron por enviar al país a una situación de crisis y a decidirse por un cambio de modelo orientado a la manufactura para exportación (Unger en Mulás, 1995).

Durante la segunda guerra mundial, México logró alcances moderados en cuanto a la investigación aplicada. Como ejemplos se tiene la llamada revolución verde de la agricultura (1944) y la investigación realizada en materia de salud. Sin embargo, desde entonces se ha arrastrado un problema que hasta fechas actuales no se ha solucionado: El predominio de la investigación básica sobre la aplicada se ha convertido en un fuerte obstáculo para la integración del quehacer universitario con el aparato productivo (Sullivan en Mulás, 1995). A partir de este momento el gobierno mexicano comienza a impulsar diferentes fórmulas de política industrial que proveen al país de infraestructura y desarrollo en diferentes niveles. La estrategia se orienta al desarrollo de la industria nacional que produzca los bienes y servicios demandados por la sociedad con el propósito de reducir la importación y consumo de los mismos venidos del exterior o importados. Se combina tanto el fomento a la creación de empresas y ramos industriales como la protección de las mismas gracias a un mecanismo de barreras a la importación de bienes que pueden ser de tipo arancelario y/o administrativo (Cárdenas, 1992).

En México se aplicó esta estrategia a partir de la caída de la oferta de importaciones obligada por las necesidades del autoabastecimiento de los países industrializados 
involucrados en la segunda guerra mundial, lo cual dificultaba obtener productos que habitualmente se importaban. Como consecuencia, el país tuvo que desarrollar una incipiente industria nacional que logró entre 1940 y 1945 un promedio de crecimiento anual del PIB del 5.9\% (Elizondo y Delgado en Mulás, 1995).

Históricamente se tiene documentado que esta estrategia se adopta desde antes de 1946, sin embargo se considera realmente a prueba su efectividad a partir de que las economías anteriormente en guerra restablecen su producción y la exportación de sus productos al mercado internacional, lo que somete a las empresas mexicanas y sus productos a una competencia a la cual tendrían que enfrentar.

Por tanto, la naciente industria mexicana logró soportar la oleada gracias a las estrategias de protección de las mismas bajo un argumento de defensa temporal a las nacientes empresas, con lo que se logró que éstas maduraran. Las importaciones que se buscaban sustituir eran los bienes de consumo duradero, tales como automóviles, equipos de radio y televisión, enseres domésticos y similares. Estas estrategias de posicionamiento desde la perspectiva de la escuela del mismo nombre, se evidencian como ficticias, pues en realidad no se basan en ventajas competitivas, sino en un proteccionismo que evitó que éstas desarrollaran estrategias que les permitiesen ser competitivas en un mercado competitivo internacional (Mintzberg, 1998).

En ese momento la política obtuvo resultados, puesto que a nivel internacional se hablaba del milagro mexicano y de un desarrollo estabilizador. Las tasas de crecimiento anual promediaban entre 6 y $8 \%$. Con excepción de la devaluación de 1954, México logró una estabilidad cambiaria durante 25 años, así como una estabilidad política y la modernización de su perfil productivo. Desde la implementación de las estrategias para la industrialización, la política de desarrollo industrial favoreció a las manufacturas, la construcción, la electricidad y el transporte, aunque no hay que perder de vista que la agricultura seguía siendo la generadora más importante de divisas -hasta 1973-, las cuales permitían la adquisición de equipo y bienes intermedios de importación necesarios para el 
desarrollo industrial. La agricultura mantenía un crecimiento anual importante sobre la industria. No sería hasta 1975 que el petróleo remplazaría a la agricultura en la generación de divisas (Mulás, 1995).

Paradójicamente, la sustitución de importaciones se detuvo en el nivel de bienes de consumo y algunos intermedios -telas e hilos de algodón, molienda de trigo, producción de azúcar, cerveza, aceites vegetales, jabón, puros y cigarros, fundición de hierro y acero, telas de lana y papel-, por lo que condujo a una mayor dependencia de importaciones de otros intermedios -vidrio y cemento, entre otrosy de bienes de capital. Se observó en este periodo un crecimiento mayor de las importaciones, el uso de tecnología extranjera e inversiones de empresas transnacionales que de la industria nacional y las exportaciones agrícolas y mineras que terminarían por estancarse. Se instalaron en México empresas de origen estadounidense y europeo. Se importó tecnología -maquinaria y equipo y tecnología no incorporada - por lo que se obstruyó la transferencia tecnológica, profundizando así la dependencia tecnológica del país (Elizondo y Delgado en Mulás, 1995).

\section{Relación entre industria y ciencia}

Adicionalmente se percibe en este periodo la poca o nula vinculación del sistema científico nacional con el aparato productivo, el cual recurrió también a la importación para dar satisfacción a sus demandas científico-tecnológicas. En este punto se establece el inicio del cambio en el modelo, puesto que entre 1967 y 1972 la UNAM fomentó la coordinación de las tareas de investigación, se iniciaron los estudios interdisciplinarios y se buscó fortalecer la vinculación entre la investigación y la problemática nacional para hacer frente a esta situación (Unger en Mulás, 1995). El Artículo 73 constitucional faculta al poder legislativo para promulgar leyes sobre la promoción del desarrollo científico y tecnológico, por lo que se han promovido la Ley para coordinar y promover el desarrollo científico y tecnológico (1984) y la ley del Consejo Nacional de Ciencia y Tecnología (1970). 
De igual manera, la comunicación entre el Estado y la comunidad universitaria se encontraba en una situación tan ríspida que como ya es conocido, desembocó en el conflicto estudiantil de 1968. Por tanto, la nula cooperación y la poca comunicación existente entre los actores principales del proceso de modernización industrial -Estado, industriales, centros universitarios de investigación-, sumados a un evidente retraso tecnológico y la dependencia tecnológica de México con otros países dan como consecuencia una estructura endeble que ante las primeras arremetidas de una contingencia macroeconómica se vería derrumbada.

En 1970, a raíz de la investigación y los trabajos realizados por el Instituto Nacional de Investigación Científica se señalaron los problemas descritos anteriormente y se estableció el diseño de una política nacional de ciencia y tecnología. Se señala también la falta de apoyo a la investigación científica, que se traduce en el bajo monto de los recursos que se proporcionan; deficiencias del sistema educativo en términos de las necesidades de formación de personal científico y tecnológico y; un desequilibrio en la actividad de investigación con preponderancia de lo básico que ha frenado por diversos motivos las posibilidades de obtener mejores resultados de la asignación de los recursos para la ciencia y la tecnología (Mulás, 1995).

Kurt Unger (en Mulás, 1995) marca una separación en este periodo debido a la crisis en la que cae la macroestrategia a causa de su petrificación o la incapacidad de evolucionar y adaptarse a las nuevas condiciones existentes en el entorno y señalando también particularmente el surgimiento del Consejo Nacional de Ciencia y Tecnología (CONACYT) en diciembre de 1970, como producto de la investigación mencionada. De igual forma se señala la puesta en marcha de la estrategia para desarrollar la industria de bienes de capital.

EI CONACYT surge con la encomienda de convertirse en el órgano central del sistema de promoción de esfuerzos y recursos de la ciencia y la tecnología. Ha permitido una toma de conciencia respecto a la complejidad de los problemas del atraso científico y tecnológico. Con la creación de esta institución se dio lugar a la implantación de las políticas de ciencia y tecnología más firmes que habrían de verse en muchos años, como la promulgación en diciembre de 1972 de la Ley sobre 
el registro de transferencia de tecnología y el uso y explotación de patentes y marcas; y en marzo de 1973 la ley para el control de la inversión extranjera (Unger en Mulás, 1995).

De igual manera, con el establecimiento del CONACYT se buscó disminuir los costos para el país derivados de la transferencia de tecnología del exterior y de la operación de empresas extranjeras en el mismo, así como la generación de capacidades competitivas de la industria local evitando las restricciones al comercio, uso de insumos nacionales y otras prácticas, pero -según la perspectiva de Ungeréstas no tuvieron la continuidad ni la puesta en práctica más efectiva (Unger en Mulás, 1995).

En este periodo se establece también, con base en el estudio realizado en 1977 por NAFINSA-ONUDI ${ }^{31}$, la iniciativa para desarrollar la industria de bienes de capital, pues se demostró la importancia estratégica e influencia de éstos en el progreso y aprendizaje tecnológico y la transmisión de éste al resto del aparato productivo (Unger en Mulás, 1995).

Para Unger (ibíd) esta etapa marca con mayor claridad que en las otras que el objetivo es desarrollar el complejo de capacidades científico-tecnológicas como condición indispensable para la profundización de un crecimiento industrial autosostenible. Sin embargo, se dio prioridad a los objetivos administrativos creación de órganos gubernamentales encargados de fomentar la ciencia y la tecnología-, y financieros -incrementar en 6 años el gasto nacional en ciencia y tecnología de $0.13 \%$ a $0.40 \%$ del PNB sobre el establecimiento de una adecuada estructura de soporte con una visión a largo plazo y al encadenamiento de las políticas de cada régimen sucesivo (Unger en Mulás, 1995).

${ }^{31}$ México: una estrategia para desarrollar la industria de bienes de capital. 


\section{Programas sectoriales de apoyo a la industria mexicana}

En este periodo se resalta también el surgimiento de la programación sectorial, antecedente de los actuales Planes Nacionales de Desarrollo. Con la programación sectorial se intentó racionalizar las acciones del sector público. Así surgieron programas en educación, agricultura, e incluso programas para la industria (Núñez, 1995).

Durante la etapa inicial de auge de la planeación en el aparato administrativo gubernamental se empezaron a formar cuerpos especializados, llegándose a establecer subsecretarías de planeación en casi todas las Secretarías de Estado e incluso la Secretaría de Programación y Presupuesto, que fue la entidad que tenía como responsabilidad la formulación y el seguimiento del Plan. Al final de la década el presidente en turno, José López Portillo, presentaba un Plan Global de Desarrollo (Núñez, 1995).

Con la irrupción de la programación en los ámbitos gubernamentales se plantean los objetivos de beneficio social y el mejoramiento de los niveles de vida de la población. La perspectiva del desarrollo económico y su incidencia en el bienestar social se convierte en estandarte del discurso político. Con esta justificación se fijan metas de alto crecimiento del producto interno bruto (que en realidad es un índice de crecimiento). Se percibe en este proyecto una programación sin evaluación de los resultados (Núñez, 1995).

En cuanto a la situación macroeconómica, el modelo de desarrollo estabilizador buscaba corregir los fallos en la sustitución de importaciones por medio de una disciplina de política industrial y tecnológica dictada por el CONACYT y NAFINSA, pero gracias al incremento de divisas generado por el aumento de precios del petróleo se acentuó aún más la problemática arrastrada. De igual manera, esta bonanza petrolera llevó a un engordamiento del aparato burocrático del CONACYT, el cual consumía más recursos para sus operaciones administrativas que para cumplir con sus objetivos que le dieron origen. Con ello, la disciplina de política industrial y tecnológica se relajó, recayendo en las importaciones masivas donde 
incluso el Estado importaba tecnología para las principales empresas paraestatales, buscando ampliar la planta instalada para petróleo, petroquímica, electricidad y otros (Unger en Mulás, 1995).

En medio de la crisis de la deuda externa, y con una complicada situación en la balanza comercial que mostraba debilidad económica, se acentuaron también la carencia de capacidades de la industria, una falta de competitividad resultado de la sobreprotección estatal, la falta de integración industrial y la ya señalada ausencia de capacidades tecnológicas, junto con una devaluación severa de la moneda nacional, la ola de desempleo y el incremento de la pobreza se convirtieron en la justificación de la ideología neoliberal y la promoción de la dinámica de la competencia entre privados con la reducción de la participación del Estado en la regulación de la actividad económica, abandonándose así las estrategias seguidas durante los años anteriores y estableciendo un rumbo totalmente diferente (Unger en Mulás, 1995).

La estrategia de sustitución de importaciones y el desarrollo estabilizador que se promovió en México desde los años 40's desembocó en una severa crisis que se combinó con las contingencias económicas internacionales. Las políticas de desarrollo industrial se cuestionaron severamente por los promotores de la doctrina neoliberal, principalmente por ser dictadas por el Estado y porque éste se encargaba de las áreas principales de la producción (Unger en Mulás, 1995).

La retracción de las principales economías del mundo, el difícil acceso a financiamiento, el estancamiento económico y los desequilibrios estructurales y financieros se convirtieron en la referencia de la inoperancia estratégica y en la justificación para promover su sustitución por una estrategia diferente. México se sumergió en una macrodevaluación, se disparó la inflación, y se generó una caída de la inversión con recesión profunda. 


\section{La industria mexicana ante la apertura internacional}

El ascenso al poder de la corriente neoliberal del Partido Revolucionario Institucional instauró rápidamente una serie de adecuaciones de emergencia a las variables financieras, monetarias y comerciales buscando la reinserción del país a la economía internacional. Se firmó el ingreso al GATT en 1986 y se comprometió la reducción sustancial a los controles de exportaciones e importaciones, con lo que se establece claramente el cambio estratégico de una sustitución de importaciones a una orientación hacia la exportación y la apertura comercial. La devaluación del peso encareció los productos de importación y como resultado se favoreció rápidamente la competitividad de la oferta nacional dentro del propio mercado (Mulás, 1995).

México se desplazó hacia estrategias que apalancaron las fuerzas de la competencia y de los mercados privados, incluyendo una gran reforma en la política macroeconómica, así como también una apertura de la economía a la inversión extranjera y a la liberalización del comercio, entre otras importantes medidas. La estrategia prioritaria fue el crecimiento de la industria sobre otros sectores (Mulás, 1995).

En el sexenio de Miguel De la Madrid y en el de Carlos Salinas de Gortari se elaboran los primeros Planes Nacionales de Desarrollo, retomando la programación pero con énfasis en la concepción política neoliberal, sobrepasando el mero ejercicio técnico. Cabe resaltar que en estos planes no se incluía textualmente la implementación de estrategias como la venta masiva de empresas públicas, la reprivatización de los bancos, el ingreso al TLC, firmas de acuerdos internacionales que comprometen la soberanía nacional, etc. Aunado a ello, los recortes presupuestales desaparecieron las dependencias especializadas encargadas de la programación del presupuesto, convirtiendo el ejercicio de planeación en un requisito a cumplir porque así lo señala la Constitución y la Ley de Planeación (Núñez, 1995). 
La nueva estrategia de la política industrial favoreció principalmente a las empresas manufactureras y comercializadoras de exportación -particularmente la petrolera, químico petroquímicas y las manufacturas automotrices, maquinaria eléctrica y no eléctrica- a través de medidas como el PITEX (Programa de Importación Temporal para la producción de artículos de Exportación), el DIMEX (Derechos de Importación para la Exportación), el ALTEX y la devolución de impuestos de importación a las exportadoras, la exención del IVA a las importaciones temporales y el financiamiento al comercio exterior a través de BANCOMEXT (Unger en Mulás, 1995: 57).

De igual forma, La Ley para el Desarrollo y Protección de la Propiedad Industrial de Junio de 1991 deroga la Ley sobre el registro de Transferencia de tecnología y el uso y explotación de patentes y marcas, lo que permite a las empresas mayor libertad para las decisiones que tienen que ver con la adquisición de tecnología (IMPI y SECOFI).

En cuanto a la integración de los actores que inciden en el desarrollo de la estructura científico-tecnológica-industrial, es evidente que se ha relegado a segundo plano buscando primero asegurar estrategias en un marco económico sobre el cual maniobrar, además de consolidar las posiciones políticas para asegurar la continuidad de la estrategia.

La liberalización de las importaciones, incluidas las de tecnología, llevó a buscar cualidades competitivas antes que capacidades tecnológicas e industriales. Desde la perspectiva de Unger, el desarrollo de las capacidades científicas y tecnológicas no puede dejarse a la dinámica del sector empresarial, ni extranjero ni nacional (Unger en Mulás 1995). Se ha convertido en constante en una y otra estrategia la debilidad de las empresas nacionales en general, con la excepción de las joyas de la corona que han aprovechado sus nexos políticos y económicos para despuntar y adentrarse en la competencia internacional. Fuera de eso, los principales exportadores son empresas transnacionales o grandes grupos corporativos y mismos que no encuentran una alineación directa con los objetivos perseguidos por 
los Planes Nacionales de Desarrollo del país sino que marcan a sus objetivos particulares en función de proyectos particulares (Unger en Mulás, 1995: 76).

El poder político y económico ejercido por este liderazgo empresarial dejó expuestos a los sectores industriales nacionales, tanto por sus debilidades comerciales como por la dependencia tecnológica existente. De igual forma, a pesar de que se ha generado atracción de inversión extranjera, ésta se ha concentrado principalmente en los servicios y el mercado de valores y no se ha materializado en plantas 0 proyectos industriales que permitan desarrollar capacidades científico-tecnológicas para la competitividad de largo plazo.

Los defensores de las estrategias neoliberales orientadas a la exportación argumentan como éxito la consolidación en México de actividades industriales relativamente maduras, incluso la integración de algunas a redes internacionales de producción. Sin embargo, al observar con detenimiento se descubre que esta integración sólo aprovecha los bajos costos indirectos de fabricación y de mano de obra, puesto que el abastecimiento de insumos y productos proviene del exterior, lo que permite minimizar costos pero no establecer un desarrollo de largo alcance basado en el desarrollo e independencia tecnológica. La supervivencia de la industria mexicana en una economía abierta y globalizada está condicionada a una modernización tecnológica en sus procesos de producción (Olivares, 1995).

Las ventajas comparativas de que gozaban anteriormente la producción de textiles, vestido, madera y cuero, y que no son intensivas en tecnología, han perdido gradualmente su posición competitiva en el mercado internacional. La configuración actual que ha establecido la nueva estrategia es un aparato productivo dependiente del ensamble de partes, componentes e insumos intermedios de importación. El caso más claro es el de la industria automotriz con un contenido de componentes importado de entre el 80-85\% (Mulás, 1995).

La modernización industrial involucra variables administrativas, financieras y tecnológicas, de las cuales, éstas últimas representan una inversión considerable con un periodo largo de retorno. Esto resulta poco atractivo tanto para 
inversionistas, industriales e incluso el propio gobierno si sólo se considera cuantitativamente o económicamente.

En 1991 se estableció el Fondo de Investigación y Desarrollo para la Modernización Tecnológica (FIDETEC) del CONACYT con el objetivo de apoyar esfuerzos en Investigación y Desarrollo en las industrias mediante financiamiento y garantías de riesgo compartido para el desarrollo de esta fase tecnológica. La fase de comercialización se apoya a través del Programa de Desarrollo Tecnológico de Nacional Financiera (Elizondo y Delgado en Mulás, 1995).

La importancia de las industrias de alta tecnología radica en su asociación con la capacidad de innovación, en el incremento en la participación de los mercados, en la creación de empleos de mayor valor agregado y un uso más eficiente y productivo de los recursos. La participación del Estado ha consistido en los últimos años en el acondicionamiento de la infraestructura necesaria para el sector productivo telecomunicaciones, rutas de transporte, servicios de información, asesoría industrial-, aunque todavía no son suficientes ni parecen ser utilizados como ventajas para gran parte de las empresas (Elizondo y Delgado en Mulás, 1995).

Debido al eminente auge que adquirió el enfoque económico en la formulación de políticas públicas, los gobiernos mexicanos de la época apostaron por una industrialización que permitiera alcanzar grandes niveles de crecimiento económico, lo que permitiría desarrollar a la nación. Sin embargo, la falta de sensibilidad ante los cambios en el entorno, así como la limitación en cuanto al desconocimiento de las fortalezas y debilidades del país y una ineficiente estrategia -prácticamente inexistente-que sustentara el cambio gradual del modelo agrícola al manufacturero sin desproteger al primero, llevaron consigo como consecuencia una configuración desfavorable para la competitividad del país. Actualmente, parece que se repiten estos patrones de comportamiento al implementar estrategias sin considerar lo sucedido en el pasado, omitiendo el aprendizaje generado de esos casos.

En el siglo anterior se observó una evolución del pensamiento económico desde las teorías clásicas del crecimiento económico, pasando por la concepción de un desarrollo económico que consideraba a la economía en cuestión como parte de un 
sistema mayor con el que tenía relaciones que le afectaban positiva o negativamente, tanto en lo macro como en lo microeconómico.

A finales del siglo se acuñó el término desarrollo sostenible, con el cual se incorporan ambiente, sociedad y comunidad como dimensiones a la perspectiva económica que se venía manejando en las diversas teorías y posturas de los estudiosos de la economía (Clarke y Clegg, 1998). Pero la cuestión es que este desarrollo tiene que contar indispensablemente con un avance en la investigación científica y tecnológica, así como en su aplicación práctica a través de la innovación y la transferencia de tecnología hacia los ramos productivos de la nación, acentuándose este proceso en los últimos años.

En el caso de México, el Plan Nacional de Desarrollo es el documento a través del cual el gobierno en turno -poder ejecutivo federal- expresa a los ciudadanos y dependencias gubernamentales las macro acciones a seguir durante su mandato, esbozo general de las políticas públicas a las que se les otorgará prioridad. En este sentido, con la transición de gobierno y el retorno del Partido Revolucionario Institucional al poder, resulta de interés identificar los cambios respecto al sexenio anterior con otro partido en la cúpula -Partido Acción Nacional.

Una de las estrategias ha sido la legitimación del Plan Nacional a través de consultas a la población respecto a los temas que deben considerarse prioritarios para el gobierno entrante en funciones. Se destaca entonces la participación conjunta que hace corresponsables del desarrollo del país a los ciudadanos. Para el tema de interés de este documento, se destaca que en el Plan Nacional vigente se plantea la tercera estrategia general una mayor productividad para llevar a México a su máximo potencial (PND 2013-2018: 19). Esta estrategia se combina con dos de las metas nacionales plasmadas en el plan: Educación de calidad y México próspero.

Para la primera meta nacional, Educación de calidad, se plantea un plan de acción, articular la educación, la ciencia y el desarrollo tecnológico para lograr una sociedad más justa y próspera. Se hace énfasis en el conocimiento científico, en el desarrollo tecnológico y en la innovación como pilares para el progreso económico y social 
sostenible y en la necesidad de fortalecer la vinculación entre escuelas, universidades, centros de investigación y sector privado. Adicionalmente se plantea el incremento de la inversión pública y privada en los mencionados pilares como agregados de valor (Ibíd.: 67-68).

Se desprende entonces el objetivo 3.5 que busca hacer del desarrollo científico, tecnológico y la innovación pilares para el progreso económico y social sostenible. En la primera estrategia de este objetivo se plantea que la inversión en estos pilares se incremente anualmente y alcance un nivel del 1\% del PIB (lbíd.: 128). La estrategia 3.5.4 titulada: Contribuir a la transferencia y aprovechamiento del conocimiento, vinculando a las instituciones de educación superior y los centros de investigación con los sectores público, social y privado. Las líneas de acción de esta estrategia destacan entre otras el desarrollo de programas para la vinculación entre universidades, centros de investigación y sector público y privado, la promoción del desarrollo emprendedor, el fomento a la innovación tecnológica y la generación de pequeñas empresas de alta tecnología (Ibíd.: 129). Se destaca que en el apartado de Indicadores no existe uno para medir esta articulación planteada.

En el caso de la segunda meta nacional mencionada, México próspero, se considera una necesidad urgente la atención a la investigación y desarrollo y la mayor disponibilidad de créditos al financiamiento para la creación y expansión de pequeñas y medianas empresas ${ }^{32}$, tanto por parte de la banca privada como la de desarrollo. Se considera por tanto un sector estratégico y una pieza angular de la agenda del gobierno. Según datos incluidos en el PND, las MiPyME's aportan alrededor del 37.4\% de la Producción Bruta Total y generan el 73\% de los empleos (lbíd.: 80).

Por tanto, la estrategia 4.2.4 enuncia la ampliación al acceso a créditos y otros servicios financieros a través de la banca de desarrollo, a actores económicos en sectores estratégicos prioritarios con dificultades para disponer de los mismos, destacando como tal las pequeñas y medianas empresas, así como la innovación (lbíd.: 132). De igual manera, la estrategia 4.8.4 destaca el impulso a los

\footnotetext{
${ }^{32}$ Considerada en el PND como área prioritaria.
} 
emprendedores y el fortalecimiento de las MiPyME's con líneas de acción como la de insertar exitosamente a las mismas en las cadenas de valor de los sectores estratégicos de mayor dinamismo, con más potencial de crecimiento y generación de empleo; el diseño e implementación de un sistema de información, seguimiento, evaluación y difusión del impacto de emprendedores, y MiPyME's; mejorar los servicios de asesoría técnica para generar cultura empresarial; apoyar su escalamiento empresarial; incrementar su capacidad exportadora; fomentar su creación y sostenibilidad, así como el desarrollo de capacidades intensivas en tecnologías de información y comunicación y la creación de ecosistemas de alto valor agregado (Ibíd.: 139-140).

Se preparan los correspondientes programas sectoriales, de los cuales se referenciarán las acciones propuestas en el Programa de Desarrollo Innovador, el Programa Especial de Ciencia, Tecnología e Innovación, así como la transición por decreto del ejecutivo federal de la Subsecretaría de la Pequeña y Mediana Empresa al Instituto Nacional del Emprendedor (DOF, 2013) como órgano desconcentrado de la Secretaría de Economía

\section{Revisión de la industrialización mexicana desde la óptica estratégica}

Ahora bien, se puede observar a lo largo de este recorrido histórico cómo el sentido estratégico se hace presente en cada toma de decisiones gubernamental, en donde la barrera entre la estrategia y la política pública como la concebía Lindblom en 1959 es muy tenue. Podemos identificar diferentes errores en la toma de decisiones y en la selección o diseño de estrategias. Por principio, se ha mencionado ya la apuesta por la industrialización sin antes considerar el carácter endeble del sector agrícola, mismo que en este mismo periodo de revisión histórica se ha visto sumamente menospreciado por los estrategas gubernamentales.

Justamente como plantean Luis Montaño (2002) y Luis Rubio (2001), se han alcanzado límites funcionales y los resultados son mixtos. Evidentemente se ha 
alcanzado por momentos una bonanza económica que sin embargo no ha sido constante ni duradera, mucho menos ha propiciado un desarrollo industrial homogéneo, privilegiando sólo a unos grupos y perjudicando enormemente a la gran mayoría que conforman el núcleo de industriales mexicanos y por consiguiente, los obreros, empleados y familias que dependen de ellos.

Por otro lado, Ansoff menciona la importancia de la relación de la tecnología con respecto al mercado y los productos. De igual manera, el entorno juega un papel fundamental dentro de esta relación al presentar tanto oportunidades como amenazas, agregando la limitación de recursos y crecimiento, así como la necesidad de legitimar a la firma (Ansoff, 1979). Trasladado al caso en cuestión, se hace evidente el desconocimiento o la omisión de estos elementos en el momento de la elección de las estrategias de desarrollo industrial, pues lo que en los años 50 's representó el llamado "milagro mexicano", visto en un espectro más amplio de tiempo como lo plantea Danny Miller en su perspectiva cuántica del cambio (Mintzberg,1998: 394), ha significado un elevado costo perdurable en el largo plazo. El saldo lleva sucesivas devaluaciones a cambio de breves periodos de bonanza económica.

Visto desde la perspectiva de Mintzberg en el Safari a la estrategia, se pueden apreciar de igual forma la confluencia de escuelas de la estrategia en diferentes momentos. El comienzo de esta reconfiguración estratégica se remonta a la aparición de los tecnócratas en los años 50's, arribando al montículo desde el cual dictaban las estrategias con su discurso semejante al de la escuela de planificación que tanto ha caracterizado sobre todo en cuanto a la estructura del aparato burocrático de la segunda mitad del siglo XX. Sin duda no podemos tampoco omitir la incidencia de la escuela de poder a lo largo del recorrido histórico, pues como resalta Vincent Ostrom, lo que en un principio se perfilaba como una separación de lo político y lo científico para garantizar la profesionalidad en las estrategias de política pública, se convirtió en un nuevo ente político que ejerció su poder y degeneró el proceso de diseño e implementación de estrategias (Ostrom, 1973). Por tanto, el jaloneo político en el gobierno se hace presente transversalmente en las estrategias a nivel racional, organizacional y burocrático (Allison, 1987). 
A esto se agrega por cierto, la presión ejercida tanto políticamente por el entorno, en este caso, organismos internacionales y corporaciones transnacionales, como lo destaca la escuela ambiental. Por un lado, se observa la confluencia entre el determinismo y el voluntarismo, pues el ejercicio de las decisiones que llevaron a implementar las estrategias de industrialización modificó el entorno del gobierno, es decir, a la sociedad y a la estructura socioeconómica del país. Por otro lado, el ambiente incidió ejerciendo presión para adoptar la estrategia de neo liberalización del mercado, con sus conocidas consecuencias.

Nos queda pendiente conocer qué pasaba por la mente de los estrategas del gobierno -escuelas de aprendizaje y cognoscitiva- para considerar esas opciones sin contemplar las consecuencias que acarreaban. Tal vez la justificación se pueda encontrar en las páginas de Simon, referente a la racionalidad limitada.

En conclusión, retomando a Clarke y Clegg, la tecnología forma parte de la estrategia mexicana, para bien o para mal, sin embargo, es necesario apuntalar los sectores primarios como base fundamental para el desarrollo sustentable. La apuesta por captar inversión extranjera a través de la especulación en la bolsa y la poca inversión de capitales extranjeros en plantas industriales -con las consabidas concesiones que benefician su apetito depredador- continúan demostrando que justamente ese aprendizaje incremental del que Lindblom y Quinn hablaban, no parece llegar al gobierno mexicano, por lo que pareciera estar condenado a repetir la trágica historia (Mintzberg, 1998: 226-227).

Pareciera justamente que ante los nuevos paradigmas que se vislumbran en el entorno y con su turbulencia tan característica, el gobierno mexicano no se encuentra habilitado para encarar el siglo XXI, con estructuras burocráticas pesadas, lentas para reaccionar al entorno, con serios problemas de corrupción y burócratas politizados que se resisten a cooperar e incluso a actualizarse tecnológicamente, que no satisface las demandas de la población y que cada vez le cuesta más mantener su ineficiente funcionamiento, además de una considerable pérdida de legitimidad. Parece pedir a gritos un cambio revolucionario, un cambio cuántico en términos de Miller (Mintzberg, 1998). 
El problema del desarrollo industrial se encuentra vinculado con el del desarrollo agropecuario y evidentemente con todos los problemas sociales que aquejan al país, mientras el gobierno se ha petrificado ante su realidad. Ahora la iniciativa la toman las OSC's y las privadas, con sus respectivos intereses particulares. En el caso de la revitalización industrial, las aceleradoras de empresas han surgido como organizaciones privadas que atienden ese sector de empresas de base tecnológica, mientras el gobierno imita sus estrategias de manera emergente, sin considerar las implicaciones que esto conlleva. Por ello, la importancia de reconocer el pensamiento estratégico dentro del aparato gubernamental para reconfigurarse hacia el futuro, pero aprendiendo de los errores cometidos e incorporando tanto las estrategias premeditadas como las emergentes a su proceso de toma de decisiones. 


\section{BIBLIOGRAFÍA}

Abrahamson, Eric (1996), "Management Fashion", en Academy of Management Review, vol. 21, no. 1, pp. 254-285.

Aguilar Martínez, Salvador Octavio (2013), El papel del lenguaje en la construcción de la identidad en la organización de tipo familiar. Caso de estudio: Chocolatera Wolter, Universidad Autónoma Metropolitana-Iztapalapa, México. [Tesis Doctoral].

Alayón Gómez, Jerónimo (2008), "Retórica, Democracia, Demagogia y Autoritarismo", en Revista Rhêtorikê, Núm. 1, Outubro 2008, Portugal.

Allison, Graham (2000) "Modelos conceptuales y la crisis de los misiles cubanos", en Luis F. Aguilar Villanueva, La hechura de las políticas, Miguel Ángel Porrúa, México, pp. 119-174

Althusser, Louis (2008), Ideología y aparatos ideológicos de Estado. Práctica teórica y lucha ideológica, Grupo editorial Tomo, México.

Alvesson, Mats y Dan Kärreman (2000), "Varieties of Discurse: on the Study of Organizations through Discourse Analysis", en Human Relations, 53(9) p.p. 11251149.

Alvesson, Mats y Dan Kärreman (2011), "Decolonializing discourse. Critical reflections on organizational discourse analysis", en Human Relations, 64(9) pp. 1121-1146.

Ansoff, Igor (1979) "The Changing Shape of the Strategic Problem", in Schendel and Hofer (ed), Strategic Management: a New View of Business Policy and Planning, Little Brown, 30-52.

Astley, W. Graham (1985), "Administrative Science as socially constructed truth", en Administrative Science Quarterly, 30/4, pp. 497-513.

Berger, Peter y Thomas Luckmann (1999), La construcción social de la realidad, Amorrortu. Argentina. pp. 33-65. 
Berglund, Johan y Andreas Werr (2000), "The Invincible Character of Management Consulting Rhetoric: How One Blends Incommensurates While Keeping them Apart", en Organization, 7(4), pp. 633-655.

Bruner, Jerome (1988), Realidad mental y mundos posibles. Los actos de la imaginación que dan sentido a la experiencia, Gedisa, Barcelona, España.

Burrell, Gibson y Gareth Morgan (1979), Sociological Paradigms and Organisational Analysis, Heinemann, New Hampshire.

Cabruja, Teresa, Lupicinio Iñíguez, y Félix Vázquez (2000), Cómo construimos el mundo: relativismo, espacios de relación y narratividad, en Análisi, 25, 61-94.

Calás, Marta B. y Linda Smircich (1999), "¿Y después del posmodernismo? Reflexiones y direcciones tentativas", en Montaño, Luis, Antonio Barba y Guillermo Ramírez (2005), Nuevas perspectivas de los Estudios Organizacionales, Antologías de Ciencias Sociales y Humanidades, no. 3, Universidad Autónoma Metropolitana Iztapalapa, México.

Cárdenas, Enrique -Compilador- (1992), Historia económica de México, Fondo de Cultura Económica, México D.F.

Chanlat, Alain y Renée Bedard (2000), "La gestion, une affaire de parole", en Chanlat, Jean François, L'individu dans l'organisation. Les dimensions oubliées, Les presses de l'Université Laval y Editions Eska, Montréal, pp. 79-99.

Clark, Timothy y Graeme Salaman (1996), "The Management Guru as Organizational Witchdoctor", en Organization, 3(1), pp.85-107.

Clarke, Thomas y Stewart Clegg, (1998), Changing paradigms. The transformation of Management Knowledge for the 21st Century, Harper Collins Business, London.

Clegg, Stewart (1990), Modern Organizations. Organization studies in the postmodern world, Sage, London, págs. 1-24 y 176-207.

Clegg, Stewart R., Cynthia Hardy (1996) "Introduction. Organizations, Organization and Organizing", en Clegg, Stewart R., Cynthia Hardy y Walter R. Nord, Handbook of Organization Studies, Sage, Londres, Págs. 1-28. 
Clegg, R, Stewart, David Courpasson y Nelson Phillips (2006), Power and Organizations, Sage, London.

Crozier, Michel y Erhard Friedberg (1990), El actor y el sistema, Alianza, México, (1977).

De la Rosa, Ayuzabet (2006), "El estudio del poder en las organizaciones: hacia una reconsideración crítica", en Reflexiones, 10, Colegio de posgraduados del CIDE A.C., México, pp.59-76.

Desroche, Henry (1976), Sociología de la Esperanza, Herder, Barcelona.

DiMaggio, Paul J. y Walter W. Powell (1983), "The Iron Cage Revisited: Institutional Isomorphism and Collective Rationality in Organizational Fields", en American Sociological Review, Vol. 48, núm. 2, pp. 147-160.

Donaldson, L. (1985), In defense of Organizational Theory. A reply to the critics, Cambridge University Press, Cambridge.

Dussel Peters, Enrique (2006), "Globalization, Organization and the Ethics of Liberation", en Organization, vol. 13, no.4, pp. 489-506.

Etzioni, Amitai (1972), Organizaciones modernas, UTEHA, México.

Fairclough, Norman (2005), "Discourse Analysis in Organization Studies: The Case for Critical Realism", en Organization Studies, no. 26, vol. 6, Londres. pp.915-939. Foucault, Michel (1969), La arqueología del saber, Siglo XXI, México.

Gabriel, Yannis (2010), "Organization Studies. A space for Ideas, identities and agonies", en Organization Studies, 31(06), pp. 757-775.

Gallardo Velázquez, Anahí (2012), "El fenómeno organizacional a través de la mirada crítica del Análisis del Discurso", en Revista Estudios Interdisciplinarios de la Organización, No. 2, Julio-Diciembre, Universidad de Guanajuato, Guanajuato, pp. 23-33.

García Herrera, Rosa Isela y Rogelio Mendoza Molina (2007), "Discurso y Organización. El caso del Sindicato Nacional de Trabajadores para la Educación de los Adultos", en Rendón Cobian, Marcela Victoria (Coord.), Organización y Cultura. 
Tradición, Poder y Modernidad en México, Universidad Autónoma Metropolitana Iztapalapa, México. pp. 61-93.

García Herrera, Rosa Isela (2008), "Reflexiones en torno a las dimensiones del poder y el lenguaje dentro de la organización", en Revista Análisis Organizacional, Vol. 1, No. 1, Red Mexicana de Investigadores en Estudios Organizacionales, México, pp. 28-48.

Gergen, Kenneth J. y Tojo Joseph Thatchenkery (1996), "Organizational Science as Social Construction: Postmodern potential", en The Journal of Applied Behavioral Science, Vol. 32, Núm.4, pp. 356-377.

Gómez, Carlos (2004), "La retórica del cambio en las organizaciones: ¿problemas que buscan soluciones o soluciones que buscan problemas?" En Revista Empresa $y$ Humanismo, Vol. VII, 1/04, pp.11-36.

Grant, David, Cynthia Hardy, Cliff Oswick y Linda Putnam (2004), The Sage Handbook of Organizational Discourse, SAGE, London.

Hall, H. Richard (1983) Organizaciones, estructura y proceso, Dossat, España.

Hernández Romo, Marcela (2004), La cultura empresarial en México, H. Cámara de Diputados LIX Legislatura, Universidad Autónoma de Aguascalientes y Miguel Ángel Porrua, México.

Heydebrand, Wolf (1989) "New organizational forms", en Work and occupations, Vol. 16, núm. 3, Agosto, págs. 323-357

Hickson D. (1988), "Offense and Defense”, en Organization Studies, Vol. 9, Núm.1, pp. 1-32.

Hinnings, C.R. y Royston Greenwood (2002), "Disconnects and Consequences in Organization Theory?", en Administrative Science Quarterly, Vol. 47, Núm.3, pp.411-421.

Ibarra Colado, E. y Luis Montaño H. (1986) "Teoría de la Organización: Desarrollo histórico, debate actual y perspectivas", en Ibarra Colado, E. y Luis Montaño H. 
(comp.) Teoría de la organización: Fundamentos y controversias, Universidad Autónoma Metropolitana Iztapalapa, México. pp. Vii-xxvi.

Iñiguez, Lupicinio y C. Antaki (1994), "El análisis del discurso en psicología social”, en Boletín de Psicología, Núm. 44, pp. 57-75.

Iñiguez Rueda, Lupicinio [editor] (2006), Análisis del Discurso. Manual para las Ciencias Sociales, Editorial UOC, Barcelona.

Knights, David y Glen Morgan (1991), Corporate Strategy, Organizations, and Subjectivity: A Critique, en Organization Studies 12(2): 251 - 273.

Kuhn, Thomas S. (2004), La estructura de las revoluciones científicas, Fondo de Cultura Económica, Argentina.

Lozano, Oscar; Ayuzabet de la Rosa y Anabela López (2008), "El discurso sobre 'la administración de la micro, pequeña y mediana empresa': una perspectiva crítica", en VI Congreso Internacional de Análisis Organizacional (Memoria): Perspectivas multidisciplinarias en el Análisis Organizacional: Complejidad, Ambigüedad y Subjetividad, Universidad Autónoma de Nayarit, Universidad Autónoma Metropolitana Iztapalapa y REMINEO, Nuevo Vallarta, Nayarit. [Mesa 4: Estrategias empresariales contemporáneas].

\section{http://remineo.org/images/archivos/memorias/ciao/viciao/viciaot4m4.pdf}

Majone, Giandomenico (1997), Evidencia, Argumentación y Persuasión en la formulación de políticas, Colegio Nacional de Ciencias Políticas y Administración Pública y Fondo de Cultura Económica, México.

March, James G. (2007), "The Study of Organizations and Organizing Since 1945", en Organization Studies, 28 (1), pp. 9-19

Marx, Karl (1987), Contribución a la crítica de la economía política, Siglo XXI, México. 
Mendoza Molina, Rogelio (2002), Discurso y funcionamiento organizacional: el caso del Sindicato Nacional de Trabajadores de la Educación de los Adultos, Universidad Autónoma Metropolitana-Iztapalapa, México [Tesis Doctoral]

México, Diario Oficial de la Federación (2013), Decreto por el que se reforman, adicionan y derogan diversas disposiciones del Reglamento Interior de la Secretaría de Economía, decretado el 14 de Enero de 2013.

México, Presidencia de la República (2013), Plan Nacional de Desarrollo 20132018.

Meyer, John W. y Brian Rowan (1977), "Institutionalized Organizations: Formal structure as myth and ceremony", en The American Journal of Sociology, vol. 83, Núm. 2, pp. 340-363.

Mintzberg, Henry, Bruce Ahlstrand y Joseph Lampel (1998), Safari a la estrategia. Una visita guiada por la jungla del management estratégico, Granica, Buenos Aires. Montaño Hirose, Luis (1994) "Modernidad, postmodernismo y organización. Una reflexión acerca de la noción de estructura postburocrática”, en Montaño Hirose, Luis (Ed.) Argumentos para un debate sobre la modernidad. Aspectos organizacionales y económicos, UAM-I, México. pp. 67-91.

Montaño, Luis (2001), "La razón, el afecto y la palabra: reflexiones en torno al sujeto en la organización", en Iztapalapa, núm. 50, 2003, Universidad Autónoma Metropolitana - Iztapalapa, México, pp. 191-212.

Montaño Hirose, Luis (2003), "Modernidad y cultura en los Estudios Organizacionales. Tres modelos analíticos”, en Iztapalapa, núm. 55, 2003, Universidad Autónoma Metropolitana-Iztapalapa, México, pp. 15-33.

Montaño, Luis (2006), "Cambio y transferencia de modelos organizacionales", en $V$ Congreso Nacional AMET 2006, Trabajo y Reestructuración: Los retos del nuevo siglo, México.

Montaño Hirose, Luis (2008), "Cultura y violencia en las organizaciones", en Rafael Carvajal Baeza (ed.), Gestión crítica alternativa, Universidad del Valle, Cali, Colombia, pp. 335-366. 
Montesinos, Rafael (2007), El discurso político de las organizaciones empresariales. La transición mexicana desde la teoría de los sistemas, Universidad Autónoma Metropolitana Unidad Iztapalapa, México, D.F.

Morales López, Valentino (2008), “Análisis epistemológico de los estudios organizacionales", en VI Congreso Internacional de Análisis Organizacional 2008, Perspectivas multidisciplinarias en Análisis Organizacional: Complejidad, Ambigüedad y Subjetividad, Nayarit.

Morris, Timothy y Zöe Lancaster (2005), "Translating Management Ideas", en Organization Studies, no. 27, vol. 2, Londres. pp. 207-233.

Mulás del Pozo, Pablo (coord.) (1995), Aspectos tecnológicos de la modernización industrial de México, Academia de Investigación Científica, Fondo de Cultura Económica, México D.F.

Núñez Estrada, Héctor Rogelio (1995), "Consideraciones críticas al Plan Nacional de Desarrollo 1995-2000. Perspectivas de una alternativa Neokeynesiana”, en Gestión y Estrategia, Núm. 7, Universidad Autónoma Metropolitana Azcapotzalco, pp. 5-17.

Olivares, Enrique (1992), México: crisis y dependencia tecnológica, UAM-X y Nuestro tiempo, México D.F.

Ostrom, Vincent (1973), The intellectual crisis in American public administration, University of Alabama Press, Tuscaloosa, pp.1-115.

Pérez Juárez, Nayeli (2012), Influencia del Discurso en la construcción de estrategia de permanencia. El caso del Centro para la Sustentabilidad Incalli Ixcahuicopa (CENTLI), Universidad Autónoma Metropolitana-Iztapalapa, México. [Tesis Maestría].

Pérez Mayo, Augusto Renato (2013), Discurso, Representaciones Sociales y Narrativa en las Organizaciones. El caso de tres cuerpos académicos de la Universidad Juárez Autónoma de Tabasco, Universidad Autónoma MetropolitanaIztapalapa, México. [Tesis Doctoral] 
Perkins, Dexter (1964), Historia de la Doctrina Monroe, Editorial Universitaria de Buenos Aires, Argentina.

Powell, Walter W. y Paul J. DiMaggio (1983), “The Iron Cage Revisited: Institutional Isomorphism and Collective Rationality in Organizational Fields", en American Sociological Review, Vol. 48, núm. 2, pp. 147-160.

Ramírez, Guillermo, Germán Vargas y Ayuzabet de la Rosa (2011), "Estudios Organizacionales y Administración. Contrastes y complementariedades. Caminando hacia el eslabón perdido", en Revista Electrónica Fórum Doctoral, Núm.3, Edición Especial, Universidad EAFIT, Medellín. pp.7-51.

Reed, Michael (1996) "Organizational Theorizing: a historically contested terrain", en Clegg, Stewart R., Cynthia Hardy y Walter R. Nord, Handbook of Organization Studies, Sage, Londres, Págs. 31-56.

Robles, Mariana, M. Adriana Soto y Antonio Paoli (2009), "De inspiraciones y aspiraciones. Memoria y sentido de la lucha en Atenco", en Veredas, núm. Extraordinario, UAM-X, pp. 7-25.

Rubio, Luis [Coord.] (2001), Políticas económicas del México contemporáneo, FCECONACULTA, México, 25-49.

Sewell, Graham y Barry Wilkinson (1992) "'Someone to watch over me': surveillance, discipline and the just-in-time labour process", en Sociology, vol. 26, núm. 2, pp. 271-289.

Schopenhauer, Arthur (1997), Dialéctica erística o el arte de tener la razón, Trota, Madrid.

Schopenhauer, Arthur (2009), El amor, las mujeres y la muerte y otros ensayos, Grupo Editorial Tomo, México.

Selser, Gregorio (1962), Diplomacia, garrote y Dólares en América Latina, Palestra, Buenos Aires.

Silverman, David (1975) Teoría de las organizaciones, Nueva Visión, Buenos Aires. (1970). 
Solís Chávez, Pablo Armando (2010), El estudio de la Cultura, Comunicación Organizacional y Discurso en la Organización: El caso de XHTLAX Radio Altiplano, Universidad Autónoma Metropolitana-Iztapalapa, México. [Tesis Maestría]

Tolbert, Pamela S. y Lynne G. Zucker (1996) “The Institutionalization of Institutional Theory", en Clegg, Stewart R., Cynthia Hardy y Walter R. Nord (eds.), Handbook of Organization Studies, Sage, Londres, pp. 175-190.

Urquiza Reséndiz, Rafael (2011), Transferencia de modelos administrativos para la captación de recursos. El caso de las instituciones de asistencia privada de San Juan del Río, Querétaro, Tesis doctoral, Universidad Autónoma de Querétaro, Facultad de Contaduría y Administración, México.

Vargas Llosa, Mario (2007), La verdad de las mentiras, Punto de lectura, Madrid. Vázquez García, Ángel Wilhelm (2004), "Discurso y narrativa en el análisis de organizaciones autoritarias: el caso de la prisión", en Iztapalapa, Núm. 56, Año 25, pp.267-287.

Vázquez García, Ángel Wilhelm (2006), El discurso de la prisión. Estudio de caso del reclusorio preventivo varonil en el Distrito Federal, Universidad Autónoma Metropolitana-Iztapalapa, México. [Tesis Doctoral].

Woodward, Joan (1975), "Management and Technology" en Pugh, D. S., Organization Theory, Penguin Books, Londres, pp. 56-71

Zey-Ferrell, Mary (1981), "Criticisms of the dominant Perspective on Organizations", en The Sociological Quarterly, 22 (spring), pp. 181-205. 
Capítulo III. Estudio de Caso: Prácticas discursivas en la Subdirección de aceleración de empresas de la Unidad Politécnica para el Desarrollo y la Competitividad Empresarial IPN

La elección metodológica para abordar la investigación ha sido valorada considerando la variedad de enfoques y métodos disponibles para las Ciencias Sociales, tanto cuantitativos como cualitativos. Cabe precisar que la elección no implica la descalificación o menosprecio de otros métodos, puesto que se reconoce la importancia y utilidad de cada uno, según el interés que se tenga en ciertos aspectos o dimensiones de los fenómenos a estudiar.

Para la investigación que se desarrolla en este documento se ha optado por el Estudio de caso, el cual implica la descripción de un evento en curso en relación a un resultado/consecuencia/desenlace de interés particular sobre un tiempo fijado en el 'aquí y ahora'. Permite una revisión más profunda de una situación particular, en comparación con otros métodos. La información producida puede ser rica y esclarecedora y puede proveer o plantear nuevas preguntas guías que de otra manera no surgirían (Brewerton y Millward, 2001: 53).

Se reconocen como debilidades de este método tanto la interpretación del investigador que puede ser sesgada por su formación profesional, su adscripción a alguna escuela de pensamiento y sus experiencias de vida. Otra objeción al método es el riesgo de poner excesiva atención a los detalles, es decir, 'concentrarse en el árbol y olvidar su relación con el bosque'. Se corre el riesgo también de involucrarse tanto con el caso que se pierda la imparcialidad, o bien, que los sujetos observados o entrevistados se sientan bajo un intenso escrutinio si son conscientes de que están siendo investigados. De igual manera, la información conseguida puede ser difícil de analizar y consumir demasiado tiempo. Sin embargo, la mayor objeción consiste en que la evidencia producida no puede ser generalizada más allá de circunstancias locales (Ibíd.). Esto concuerda con lo planteado en torno a que ni las MiPyME's son un cuerpo homogéneo, ni las aceleradoras siguen el mismo programa de aceleración. Por tanto, abordar una investigación al respecto demanda 
considerar sus particularidades y la evidencia surgida permitirá avanzar en el conocimiento del fenómeno.

Este método es privilegiado en el ámbito de los Estudios Organizacionales al partir de la convicción de que no existe un modelo aplicable a todas las organizaciones, sino que existen tantas como los contextos en los que se encuentran (Morales, 2008: 2).

\section{Construcción de la investigación}

El tipo de investigación propuesto puede clasificarse de la siguiente forma:

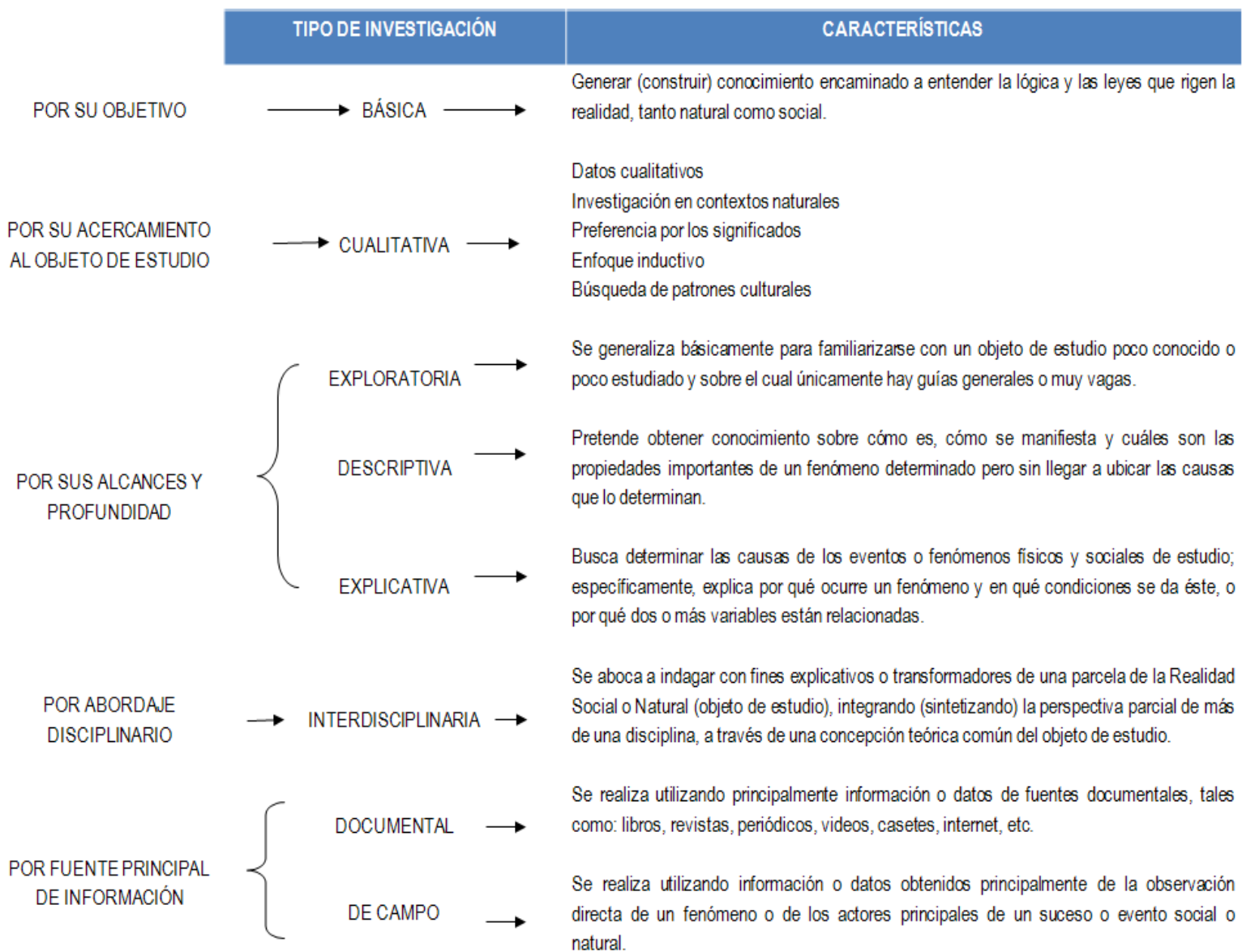

FUENTE: Elaboración con base en Pacheco, Arturo (2013), El problema (reto) metodológico en el análisis socio-organizacional, Material de apoyo visual (diapositivas) para el Seminario de Investigación II del Doctorado en Estudios Organizacionales de la Universidad Autónoma Metropolitana-Unidad Iztapalapa, México. 
En el caso de una investigación en ciernes respecto a la conformación del discurso que promueve la aceleración de empresas en México con fundamento en un discurso de mayor envergadura, al cual se ha hecho referencia en los apartados anteriores.

Para el abordaje metodológico del análisis del discurso existen diferentes propuestas, entre las que destacan las siguientes:

Métodos de Análisis del Discurso Organizacional.

FUENTE: Elaboración propia con base en Î́niguez Rueda (2006).

\begin{tabular}{|c|c|c|c|}
\hline MÉTODO & $\begin{array}{c}\text { AUTORES } \\
\text { PRINCIPALES }\end{array}$ & DESCRIPCIÓN & $\begin{array}{l}\text { FUNDAMENTOS } \\
\text { TEÓRICOS }\end{array}$ \\
\hline $\begin{array}{l}\text { Sociolingüística } \\
\text { interaccional. }\end{array}$ & $\begin{array}{l}\text { ErvinGoffman } \\
\text { JhonGumperz }\end{array}$ & $\begin{array}{l}\text { Análisis de situaciones de interacción en donde los } \\
\text { agentes sociales en relación son miembros de culturas } \\
\text { distintas, de diferentes grupos socioculturales, de } \\
\text { diferentes estatus, etc. }\end{array}$ & $\begin{array}{l}\text { Antropología } \\
\text { Sociología } \\
\text { Lingüística }\end{array}$ \\
\hline $\begin{array}{l}\text { Etnografía de la } \\
\text { comunicación } \\
\text { (Antropología } \\
\text { lingüística). }\end{array}$ & Dell Hymes & $\begin{array}{l}\text { Se enfoca en la competencia comunicativa, entender } \\
\text { como el conocimiento social, psicológico, cultural y } \\
\text { lingüístico gobierna el uso apropiado del lenguaje. } \\
\text { Comprender los variados aspectos del lenguaje en tanto } \\
\text { marco de prácticas culturales, como un sistema de } \\
\text { comunicación que permite las representaciones } \\
\text { interpsicológicas e intrapsicológicas, y que contribuye a } \\
\text { que las personas utilicen esas representaciones para } \\
\text { realizar actos sociales constituyentes. }\end{array}$ & $\begin{array}{l}\text { Antropología } \\
\text { Lingüística }\end{array}$ \\
\hline $\begin{array}{l}\text { Análisis de } \\
\text { Conversación }\end{array}$ & $\begin{array}{l}\text { Harold } \\
\text { Garfinkel }\end{array}$ & $\begin{array}{l}\text { Las categorías de análisis han de ser, en la medida de } \\
\text { lo posible, las mismas que utilizan los participantes a la } \\
\text { hora de comprender la interacción. Trata los relatos de } \\
\text { las personas en su contexto; estudia el orden, el } \\
\text { desorden y la organización de la acción social cotidiana, } \\
\text { aprendiendo de lo que la gente dice, cuenta o hace. Se } \\
\text { desplaza la orientación de los analistas a los } \\
\text { participantes. }\end{array}$ & $\begin{array}{c}\text { Sociología de la } \\
\text { situación. } \\
\text { Etnometodología }\end{array}$ \\
\hline $\begin{array}{l}\text { Análisis Crítico } \\
\text { del Discurso }\end{array}$ & $\begin{array}{l}\text { Norman } \\
\text { Fairclough } \\
\text { Ruth Wodak } \\
\text { Teun A. Van } \\
\text { Dijk }\end{array}$ & $\begin{array}{l}\text { Asume una postura problematizadora, se centra en } \\
\text { aquellas acciones sociales que se ponen en práctica a } \\
\text { través del discurso, como el abuso del poder, el control } \\
\text { social, la dominación, las desigualdades sociales o la } \\
\text { marginación y exclusión sociales. Constituye una } \\
\text { estrategia para acercarse a los discursos, mediante la } \\
\text { cual la teoría no preconfigura ni determina la manera de } \\
\text { enfocar los análisis, ni delimita el campo de la } \\
\text { indagación y de la exploración. El discurso es } \\
\text { considerado una práctica social tridimensional porque } \\
\text { opera simultáneamente tres dimensiones: Texto, } \\
\text { situación social concreta y constitución de identidades, } \\
\text { prácticas y relaciones. La teoría es una caja de } \\
\text { herramientas que permite urdir y abrir nuevos enfoques } \\
\text { y nuevas miradas. }\end{array}$ & Multidisciplinario \\
\hline $\begin{array}{l}\text { Psicología } \\
\text { Discursiva }\end{array}$ & $\begin{array}{l}\text { Derek } \\
\text { Edwards }\end{array}$ & $\begin{array}{l}\text { Se enfoca en la construcción del conocimiento en el } \\
\text { discurso, cómo se produce y construye la interpretación }\end{array}$ & Multidisciplinario \\
\hline
\end{tabular}




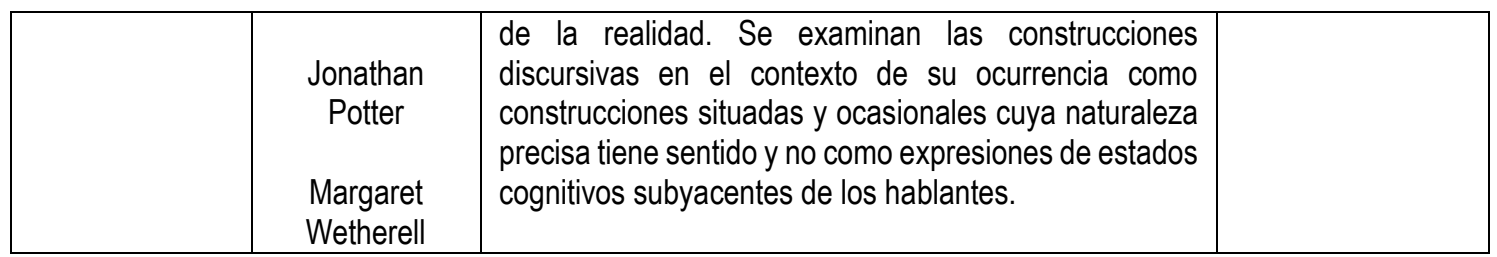

Como se puede apreciar, existen múltiples enfoques de estudio de las prácticas discursivas en las organizaciones. No se pretende seleccionar una sobre el resto, pues se considera que existen elementos de utilidad en cada una para explicar el caso de interés, por lo que se consideran más bien una matriz teórica a la cual recurrir en busca de explicaciones y bases teóricas.

\begin{tabular}{|c|c|c|c|}
\hline ¿Qué organización? & Problema & $\begin{array}{l}\text { Consecuencias del } \\
\text { problema }\end{array}$ & $\begin{array}{c}\text { Alternativas de solución no } \\
\text { planteadas al problema }\end{array}$ \\
\hline $\begin{array}{c}\text { Acẹleradoras de } \\
\text { empresas de bạse } \\
\text { tecnológica en México }\end{array}$ & $\begin{array}{l}\text { Desconocimiento respecto } \\
\text { del funcionamiento interno } \\
\text { de las aceleradoras, su } \\
\text { fundamento teórico y su } \\
\text { incidencia en el entorno. } \\
\text { Este desconocimiento lleva } \\
\text { a confiar en los expertos } \\
\text { ciegamente sin } \\
\text { cuestionarlos respecto a lo } \\
\text { que es más conveniente } \\
\text { hacer. }\end{array}$ & $\begin{array}{l}\text { Se presupone que, al } \\
\text { ser un modelo } \\
\text { importado, no se hayan } \\
\text { contemplado las } \\
\text { diferencias culturales y } \\
\text { contextuales que lo } \\
\text { hagan jneficiente, } \\
\text { consolidando a unas } \\
\text { empresas, pero } \\
\text { contribuyendo a la } \\
\text { desaparición de otras. }\end{array}$ & $\begin{array}{l}\text { Al final, el investigador } \\
\text { planteará conclusiones de la } \\
\text { investigación, así como } \\
\text { reflexiones en torno al caso, } \\
\text { con el propósito de contribuir a } \\
\text { la reflexión en torno al tema, a } \\
\text { la discusión y aportar a } \\
\text { generar nuevo conocimiento } \\
\text { en torno a estas particulares } \\
\text { organizaciones. }\end{array}$ \\
\hline $\begin{array}{l}\text { ¿Por qué esa } \\
\text { organización? }\end{array}$ & Raíces del problema & $\begin{array}{c}\text { Soluciones } \\
\text { propuestas y/o } \\
\text { implementadas }\end{array}$ & $\begin{array}{l}\text { Resultados obtenidos por } \\
\text { las soluciones }\end{array}$ \\
\hline $\begin{array}{l}\text { Por su discurso de apoyo } \\
\text { a las empresas MiPyME's } \\
\text { gacela que les permite } \\
\text { incrementar } \\
\text { ganancias, ampliar sus } \\
\text { mercados } \\
\text { internacionalmente, } \\
\text { vincularse con industrias } \\
\text { afines. }\end{array}$ & $\begin{array}{l}\text { Difusión del modelo pero } \\
\text { no de sus fundamentos } \\
\text { teóricos. } \\
\text { Casi nula literatura } \\
\text { existente respecto al } \\
\text { modelo, casos de éxito o } \\
\text { teóricoos fundadores. } \\
\text { Suptesto de origen en el } \\
\text { paradigma económico } \\
\text { administrativo } \\
\text { positivista, funcionalista. }\end{array}$ & $\begin{array}{l}\text { Descubrir por medio de } \\
\text { la investigación } \\
\text { (entrevisstas, } \\
\text { observación) si se han } \\
\text { detectado sto estos } \\
\text { problemas si exte } \\
\text { conciencia de ellós y } \\
\text { qué medidas se han } \\
\text { tomado al respecto. }\end{array}$ & $\begin{array}{l}\text { Si ha sido el caso, de qué } \\
\text { manera ha incidido en los } \\
\text { resultadøs y cómo se miden } \\
\text { estos progresos. }\end{array}$ \\
\hline
\end{tabular}

FUENTE: Elaboración propia. 
Esquemáticamente se puede resumir la propuesta de investigación como sigue:

\section{OBJETIVO}

Analizar las prácticas discursivas construidas para promover el modelo de aceleración de empresas de base tecnológica en México mediante el enfoque de Análisis del Discurso Organizacional.

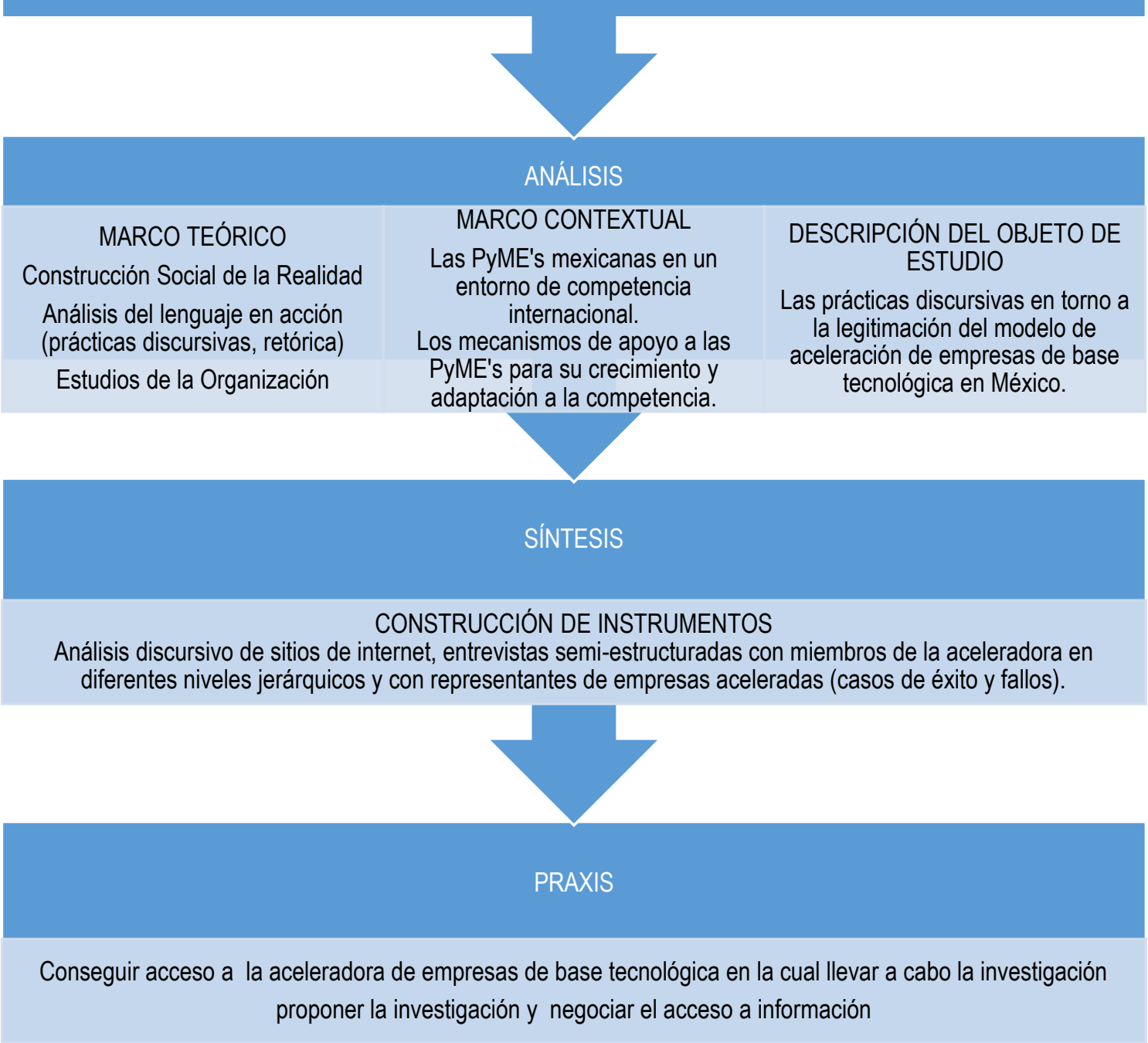

Elaboración propia con base en Pacheco, Arturo (2013), El problema (reto) metodológico en el análisis socio-organizacional, Material de apoyo visual (diapositivas) para el Seminario de Investigación II del Doctorado en Estudios Organizacionales de la Universidad Autónoma Metropolitana-Unidad Iztapalapa, México.

Lo siguiente entonces es verificar si lo que dice la etiqueta que sucede en la caja negra, en verdad es lo que sucede. Verificar de igual forma si los productos (outputs) que presume lograr son lo que dicen que son y si además de estos, también arroja 
productos no contemplados. Hay que considerar que no es sólo una aceleradora la que se pretende conocer, pues se desea contrastar en sus operaciones con otras para descubrir similitudes y divergencias que permitan llegar a generalizaciones relativamente válidas para otras aceleradoras. Se intuye que habrá diferencias entre las aceleradoras auspiciadas por universidades privadas y las aceleradoras privadas o las colaboradoras internacionales del gobierno.

El abordaje entonces se constituye por una investigación documental de tipo exploratoria, principalmente en los portales de internet de las propias aceleradoras.

\begin{tabular}{|c|c|c|}
\hline $\begin{array}{c}\text { TIPO DE } \\
\text { INSTRUMENTO }\end{array}$ & DÓNDE & QUÉ SE BUSCA \\
\hline $\begin{array}{c}\text { Investigación } \\
\text { exploratoria }\end{array}$ & $\begin{array}{l}\text { Portales de internet de las } \\
\text { aceleradoras de empresas } \\
\text { de base tecnológica en } \\
\text { México y de la Secretaría } \\
\text { de Economía. }\end{array}$ & $\begin{array}{l}\text { Determinar el tamaño de la } \\
\text { población de aceleradoras de } \\
\text { empresas de hase } \\
\text { tecnológica, historia, } \\
\text { orientación, evolución, } \\
\text { resultados, proyecciones. }\end{array}$ \\
\hline $\begin{array}{l}\text { Investigación } \\
\text { documental }\end{array}$ & $\begin{array}{l}\text { Búsqueda bibliográfica y } \\
\text { hemerográfica sobre el } \\
\text { tema de aceleración de } \\
\text { empresas y los modelos. }\end{array}$ & $\begin{array}{l}\text { Fundamentos teóricos que } \\
\text { dieron origen a la aceleración } \\
\text { de empresas y el diseño de } \\
\text { modelos de aceleración. } \\
\text { Estado del arte del tema. }\end{array}$ \\
\hline $\begin{array}{c}\text { Fundamento } \\
\text { Teórico }\end{array}$ & $\begin{array}{l}\text { Revisión de literatura que } \\
\text { proporcione explicaciones } \\
\text { sobre transferencia de } \\
\text { modelos organizacionales, } \\
\text { análisis del discurso, } \\
\text { isomorfismo } \\
\text { organizacional, nuevas } \\
\text { formas organizacionales, } \\
\text { ecología de organizaciones. }\end{array}$ & $\begin{array}{l}\text { Explicar mediante paradigmas } \\
\text { de la Teoría de la } \\
\text { Organización y los Estudios } \\
\text { Organizacionales a las } \\
\text { aceleradoras de empresas de } \\
\text { base tecnológica. }\end{array}$ \\
\hline \multirow[t]{2}{*}{$\begin{array}{c}\text { Marco } \\
\text { Contextual }\end{array}$} & \multirow{2}{*}{$\begin{array}{l}\text { Revisión bibliográfica, } \\
\text { hemerográfica y en la red } \\
\text { sobre el contexto histórico, } \\
\text { jurídico, económico y } \\
\text { político que enmarca a las } \\
\text { organizaciones objeto. }\end{array}$} & $\begin{array}{l}\text { Los factores que inciden tanto } \\
\text { en las aceleradoras de } \\
\text { empresas como en las } \\
\text { organizaciones con las que se } \\
\text { relaciona. }\end{array}$ \\
\hline & & $\begin{array}{llr}\text { Políticas } & \text { públicas de } \\
\text { desarrollo } & \text { industrial en } \\
\text { México, } & \text { cambios }\end{array}$ \\
\hline
\end{tabular}


macroeconómicos suscitados, alineación estratégica entre leyes, planes y programas.

Conocer el discurso que los

Actores clave en las Aceleradoras de empresas de Base tecnológica.

Entrevistas

Semiestructuradas

Observación
Actores clave en la Secretaría de Economía, involucrados

Programa Aceleradoras.

Visita a las diferentes
aceleradoras de empresas.
y a Secretaría de

actores utilizan para legitimar y difundir su modelo. Complementar datos generales de la Aceleradora, casos de éxito, buscar el "efecto bola de nieve" para acceder a otros actores informantes. Obtener acceso a documentos confidenciales de las aceleradoras.

\section{Economía.}

Visita a casos de éxito de empresas participantes en el proceso de aceleración.
Observar y anotar elementos que se consideren importantes, gráficamente. Considerar aspectos tanto de comunicación verbal, gestual, visual.

\section{Guía para entrevista semi-estructurada}

Brewerton y Millward (2001: 69) proponen cuatro tipos de entrevistas: Estructurada, no estructurada, semi-estructurada y etnográfica. Se propone utilizar la entrevista semi-estructurada por la facilidad para explorar en mayor profundidad ciertas áreas de interés. El análisis de la información recabada puede realizarse a través de análisis de contenido, de análisis del discurso o análisis de transcripción (opcit: 73). Se propone para abordar las entrevistas la siguiente guía de tópicos: 
La semblanza de la organización, desde la motivación para constituirse como tal, sus primeros objetivos y cómo se han modificado a través del tiempo y de qué manera el contexto socioeconómico ha influido en ello. Otros datos de importancia, como el número de colaboradores, principales socios comerciales e institucionales, convenios de colaboración, etc.

Sus fundamentos teórico-metodológicos. Este punto se refiere a la conformación de su ideología que guía tanto sus objetivos y estrategias, como sus procesos y métodos de operación. Esto por lo general parte de la formación académica y profesional de los fundadores, y en el caso de organizaciones enfocadas a actividades económicas de negocios, existe una alta influencia de la Economía y la Teoría de la Organización desarrollada en Estados Unidos de América. Lo interesante surge al mezclar esa formación con la historia de vida en un contexto específico, en este caso, el vivir en México. Por tanto, la síntesis de estas líneas ideológicas arroja una forma particular de entender el entorno y de actuar en consecuencia.

El proceso de aceleración. El interés se centra en la motivación para incluir un proceso de aceleración de empresas. Es decir, ¿por qué acelerar? Es claro que es una metáfora, pero lo interesante es su testimonio, pues algo de lo que busca esta investigación es conformar una idea concreta de la aceleración de empresas, que se puede encontrar plasmada teóricamente en la bibliografía, pero que se modifica y particulariza en cada organización que se apropia del concepto y actúa para llevarlo a la realidad. Desde la perspectiva del posgrado, no se habla de lo mismo cuando se dice "business accelerator" en el contexto estadounidense, que cuando se habla de aceleración de negocios o de empresas en la realidad mexicana. Dado que existen más organizaciones en México que incluyen en su oferta la aceleración de empresas, cada una de ellas tiene una particular forma de entender el concepto, lo que no significa que todos entiendan lo mismo. Vistos como competidores, se requiere diferenciar sus servicios y ofrecerlos a los clientes. Para diferenciarlos, habrá que conocer lo que ofrecen otras aceleradoras; mientras que para lanzar una oferta, debe conocerse al mercado-objetivo y decidir cuáles son los canales más adecuados para persuadir y convencer. Estoy interesado entonces 
también en estos puntos, así como si existe un modelo internacional sobre el cual se hayan basado para desarrollar el propio.

Casos de éxito. Antes del boom de las formas de gestión japonesas, el fracaso estaba estigmatizado en las organizaciones. Sin embargo, se ha cambiado paulatinamente la aversión al riesgo y al fracaso. Normalmente las organizaciones ostentan sus casos de éxito y minimizan los casos fallidos. El interés en este punto es el aprendizaje del fracaso, a manera de feedback y el establecimiento de medidas correctivas o de control, de estrategias de ajuste que han sido determinantes en el funcionamiento de la organización. Si este aprendizaje se ha dado, los posteriores casos de éxito serán el más claro indicador.

Clientes satisfechos. El mejor testimonio proviene del cliente, pues no existe una relación subordinada a la organización y es uno de los principales beneficiarios del funcionamiento de la misma. Estoy interesado en conocer el testimonio de empresas que hayan participado en su modelo de aceleración para conocer su motivación que los hizo elegirlos y la sensación generada luego de participar con ustedes.

Retos y áreas de oportunidad. Con base en todo lo anterior, describir los principales retos y áreas de oportunidad que enfrentan tanto al interior de la organización como en el entorno -competidores, clientes, mercado internacional, sociedad, gobierno, economía, otras instituciones-, y si existen ya estrategias para abordarlos, todo esto, desde su percepción, pues lo importante es lo que la organización percibe y piensa. 


\section{Búsqueda de Organización para estudio de caso}

El proceso de selección se realizó tomando en consideración la actualización del padrón de aceleradoras publicado por el Instituto Mexicano del Emprendedor en su portal de internet. Se consideraron por cercanía las aceleradoras ubicadas en el Distrito Federal y el Estado de México. En el siguiente cuadro se enlistan las organizaciones contactadas:

\begin{tabular}{|c|c|c|c|}
\hline ORGANIZACIÓN & TIPO & UBICACIÓN & RESPUESTA \\
\hline $\begin{array}{l}\text { Instituto Nacional } \\
\text { del Emprendedor }\end{array}$ & $\begin{array}{l}\text { Instituto } \\
\text { Público }\end{array}$ & $\begin{array}{l}\text { Distrito } \\
\text { Federal }\end{array}$ & No se obtuvo respuesta \\
\hline TechBA & $\begin{array}{l}\text { Público- } \\
\text { Privado }\end{array}$ & $\begin{array}{l}\text { Distrito } \\
\text { Federal }\end{array}$ & No se obtuvo respuesta \\
\hline Visionaria & $\begin{array}{l}\text { Aceleradora } \\
\text { Privada }\end{array}$ & $\begin{array}{l}\text { Distrito } \\
\text { Federal }\end{array}$ & No se obtuvo respuesta \\
\hline New Ventures & $\begin{array}{l}\text { Aceleradora } \\
\text { Privada }\end{array}$ & $\begin{array}{l}\text { Distrito } \\
\text { Federal }\end{array}$ & No se obtuvo respuesta \\
\hline Endeavor México & $\begin{array}{l}\text { Aceleradora } \\
\text { Privada }\end{array}$ & $\begin{array}{l}\text { Distrito } \\
\text { Federal }\end{array}$ & No se obtuvo respuesta \\
\hline Q-Lab & $\begin{array}{l}\text { Aceleradora } \\
\text { Privada }\end{array}$ & $\begin{array}{l}\text { Distrito } \\
\text { Federal }\end{array}$ & No se obtuvo respuesta \\
\hline Impulsa & $\begin{array}{l}\text { Aceleradora } \\
\text { Privada }\end{array}$ & $\begin{array}{l}\text { Distrito } \\
\text { Federal }\end{array}$ & No se obtuvo respuesta \\
\hline $\begin{array}{l}\text { Alcazar\& } \\
\text { Compañía } \\
\text { NETBA }\end{array}$ & $\begin{array}{l}\text { Aceleradora } \\
\text { Privada }\end{array}$ & $\begin{array}{l}\text { Distrito } \\
\text { Federal }\end{array}$ & $\begin{array}{l}\text { 05-Feb-2014: Solicitó mayores } \\
\text { detalles de la investigación. } \\
\text { "Leyendo tu propuesta de } \\
\text { investigación, entiendo que tu } \\
\text { interés es analizar a nuestra } \\
\text { aceleradora como tu caso de } \\
\text { estudio, siendo así, podrías } \\
\text { explicarme un poco más a } \\
\text { detalle que tanto requerirías de } \\
\text { nosotros, en cuanto a } \\
\text { información, documentación y } \\
\text { demás, en el entendido de que } \\
\text { gran parte de esta por obvias } \\
\text { razones se considera } \\
\text { confidencial. Así como si parte } \\
\text { del proceso lo realizarías en } \\
\text { nuestras instalaciones, cuánto }\end{array}$ \\
\hline
\end{tabular}




\begin{tabular}{|c|c|c|c|}
\hline & & & $\begin{array}{l}\text { tiempo estarías considerando } \\
\text { para eso. } \\
\text { Mi otra pregunta es ¿porqué } \\
\text { estarías eligiendo Alcázar \& } \\
\text { Compañía - NETBA en tu } \\
\text { propuesta? } \\
\text { Te envío un cordial saludo y } \\
\text { quedo en espera de tus } \\
\text { comentarios." } \\
\text { No se obtuvo respuesta }\end{array}$ \\
\hline $\begin{array}{ll}\text { Business } & \\
\text { Coaching Firm } \\
\text { BCF }\end{array}$ & $\begin{array}{l}\text { Aceleradora } \\
\text { Privada }\end{array}$ & \begin{tabular}{|l|} 
Distrito \\
Federal
\end{tabular} & $\begin{array}{l}\text { 13-Feb-2014: "Gracias por tu } \\
\text { invitación, la cuestión es que } \\
\text { somos aceleradora de } \\
\text { empresas, pero ni soy de base } \\
\text { tecnológica, ni me enfoco en ese } \\
\text { sector, la verdad es que no sé, si } \\
\text { en realidad pueda ayudarte con } \\
\text { tus propósitos... } \\
\text { Gracias" }\end{array}$ \\
\hline Ernst \& Young & $\begin{array}{l}\text { Aceleradora } \\
\text { Privada }\end{array}$ & \begin{tabular}{|l|} 
Distrito \\
Federal
\end{tabular} & No se obtuvo respuesta \\
\hline Feher\&Feher & $\begin{array}{l}\text { Aceleradora } \\
\text { Privada }\end{array}$ & \begin{tabular}{|l|} 
Distrito \\
Federal \\
\end{tabular} & No se obtuvo respuesta \\
\hline TechPYME & $\begin{array}{l}\text { Aceleradora } \\
\text { Privada }\end{array}$ & \begin{tabular}{|l|} 
Distrito \\
Federal
\end{tabular} & No se obtuvo respuesta \\
\hline Victoria 147 & $\begin{array}{l}\text { Aceleradora } \\
\text { Privada }\end{array}$ & \begin{tabular}{|l|} 
Distrito \\
Federal
\end{tabular} & No se obtuvo respuesta \\
\hline $\begin{array}{l}\text { ITESM } \\
\text { México }\end{array}$ & $\begin{array}{l}\text { Aceleradora } \\
\text { privada }\end{array}$ & \begin{tabular}{|l|} 
Distrito \\
Federal \\
\end{tabular} & No se obtuvo respuesta \\
\hline ITESM Santa Fe & $\begin{array}{l}\text { Aceleradora } \\
\text { privada }\end{array}$ & \begin{tabular}{|l|} 
Distrito \\
Federal
\end{tabular} & No se obtuvo respuesta \\
\hline ITESM Edo. Mex. & $\begin{array}{l}\text { Aceleradora } \\
\text { privada }\end{array}$ & \begin{tabular}{|l} 
Estado de \\
México
\end{tabular} & No se obtuvo respuesta \\
\hline $\begin{array}{l}\text { CEPii } \\
\text { Universidad } \\
\text { Panamericana }\end{array}$ & $\begin{array}{l}\text { Aceleradora } \\
\text { privada }\end{array}$ & \begin{tabular}{|l|} 
Distrito \\
Federal
\end{tabular} & No se obtuvo respuesta \\
\hline $\begin{array}{l}\text { Aceleradora } \\
\text { IdeaRSE } \\
\text { Universidad } \\
\text { Anáhuac } \\
\end{array}$ & $\begin{array}{l}\text { Aceleradora } \\
\text { privada }\end{array}$ & $\begin{array}{l}\text { Estado de } \\
\text { México }\end{array}$ & $\begin{array}{l}\text { 06-Feb-2014: "Gusto conocerle } \\
\text { aunque sea por este medio, } \\
\text { quiero comenzar detallando que } \\
\text { la Aceleradora de Empresas de }\end{array}$ \\
\hline
\end{tabular}




\begin{tabular}{|c|c|c|}
\hline & & $\begin{array}{l}\text { la Universidad no es de base } \\
\text { tecnológica, creo que eso es un } \\
\text { punto importante a destacar } \\
\text { debido a que veo que su } \\
\text { investigación parte de estudiar } \\
\text { una Aceleradora con esa } \\
\text { premisa. } \\
\text { Si no es un inconveniente con } \\
\text { gusto podríamos platicar para } \\
\text { que nos proporcione un poco } \\
\text { más de información de su } \\
\text { investigación y ver en que } \\
\text { podemos colaborar." } \\
\text { 07-Feb-2014: "Con todo gusto } \\
\text { entonces, yo estaré un poco } \\
\text { saturada la semana siguiente } \\
\text { porque estoy solicitando fondos } \\
\text { del INADEM, pero después del } \\
18 \text { de febrero estoy mejor } \\
\text { ¿cuándo quieres venir para } \\
\text { platicar?" } \\
\text { Se agendo una reunión para el } \\
\text { día } 27 \text { de Febrero de } 2014 \text {. }\end{array}$ \\
\hline $\begin{array}{l}\text { Aceleradora de } \\
\text { Negocios de la } \\
\text { UPDCE (Instituto } \\
\text { Politécnico } \\
\text { Nacional) }\end{array}$ & $\begin{array}{l}\text { Aceleradora } \\
\text { Pública }\end{array}$ & $\begin{array}{l}\text { 06-Feb-2014:"Por instrucciones } \\
\text { del Ing. Carlos Mario Contreras, } \\
\text { Subdirector de Aceleración de } \\
\text { Empresas me comenta que } \\
\text { podemos agendar una cita, te } \\
\text { doy estos días y me confirmas } \\
\text { según tu conveniencia." } \\
\text { 07-Feb-2014: "Te confirmo por } \\
\text { este medio la cita para el día } \\
\text { Lunes a las 13:00 hrs en } \\
\text { nuestras instalaciones ubicadas } \\
\text { en Av. Wilfrido Massieu s/n, } \\
\text { Edificio Adolfo Ruíz Cortines", } \\
\text { dentro de la Unidad Profesional } \\
\text { "Adolfo Lopez Mateos", Col. } \\
\text { Zacatenco, para mejor ubicación } \\
\text { estamos junto al planetario del } \\
\text { IPN, es un Edificio en forma de } \\
\text { pirámide color beige." }\end{array}$ \\
\hline
\end{tabular}




\begin{tabular}{|l|l|l|}
\hline & $\begin{array}{l}\text { 10-Feb-2014: Entrevista con Lic. } \\
\text { Francisco Melo Fragoso, jefe del } \\
\text { departamento de } \\
\text { posicionamiento comercial y de } \\
\text { exportación de la UPDCE. } \\
\text { 18-Feb-2014: Entrevista con el } \\
\text { Ing. Carlos Mario Contreras } \\
\text { Correa, subdirector de } \\
\text { aceleración de empresas de la } \\
\text { UPDCE. }\end{array}$ \\
\hline
\end{tabular}

Se buscó también un acercamiento personal con representantes de las aceleradoras en la Semana del Emprendedor del 2015, aunque no hubo disposición para participar en el estudio. Los argumentos principales que ofrecieron fueron que ellos se enfocaban en franquicias más que en empresas de base tecnológica y que la información que yo requería no estaba disponible al público.

Se logró concertar la entrevista tanto con la aceleradora de la Universidad Anáhuac y la del IPN. En el primer caso, la información que se obtuvo fue prácticamente la misma que manejan en su publicidad y en su sitio web, aunque se obtuvieron hallazgos importantes como la forma en que se eligió a la titular de la aceleradora y la preparación de la misma, mediante asignación del proyecto y la entrevistada señaló que cuando se le encargó, ella no sabía nada de lo que era acelerar empresas, por lo que dedicó una noche a investigar en internet, lo que fue su base para construir su propuesta de proyecto, mismo que con la experiencia y comparación de modelos en INADEM ha podido ser optimizado.

Otro hallazgo importante fue que la entrevistada sabía que la aceleradora de la Universidad Panamericana ya no estaba en operaciones, por problemas internos que no reveló. De igual manera, recomendó a un par de personas que podrían informar respecto a la dinámica de la aceleración de empresas, por estar directamente involucradas en su promoción. Se extendió la invitación vía correo electrónico pero no se obtuvo respuesta. 
Estudio de caso: Aceleradora de Empresas de la UPDCE del Instituto Politécnico Nacional

La aceleradora de empresas del Instituto Politécnico Nacional ha obtenido recientemente -el 04 de Julio de 2013- el reconocimiento como aceleradora por parte de la Secretaría de Economía a través del instituto mexicano del emprendedor, formando parte de la Red de Aceleradoras de Empresas para mover a México. Es de destacar que es la primera aceleradora perteneciente a una universidad pública en operar un modelo de aceleración en México.

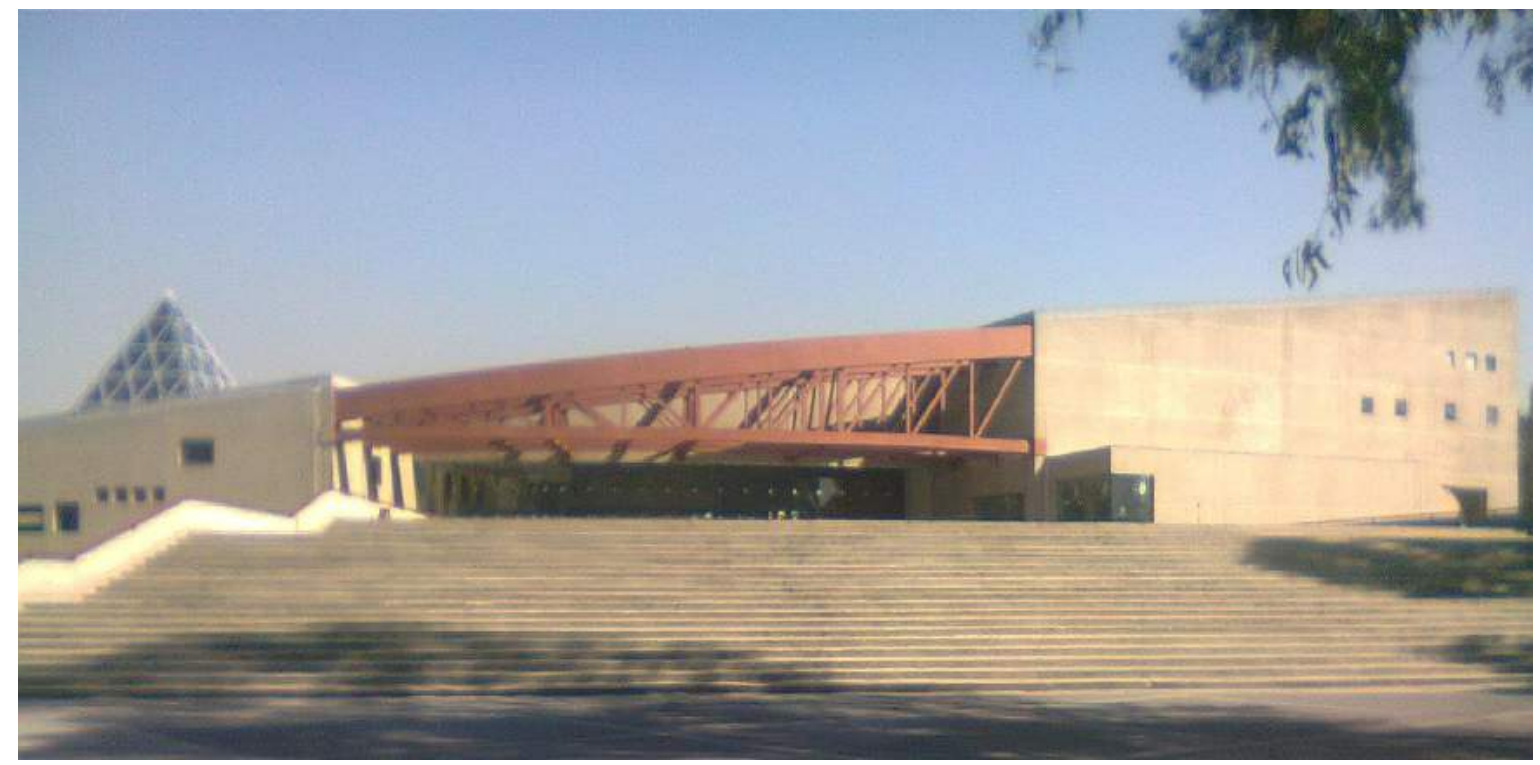

La UPDCE se encuentra ubicada en el Edificio Adolfo Ruiz Cortines, de la Unidad Profesional Adolfo López Mateos del Instituto Politécnico Nacional, en Av. Wilfrido Massieu s/n, Colonia Lindavista, Delegación Gustavo A. Madero, México, Distrito Federal.

Desde su fundación en 1936, el Instituto Politécnico Nacional ha sido la institución pública del Estado encargada de la instrucción y transmisión del conocimiento científico y tecnológico a las nuevas generaciones de mexicanos. Este compromiso sigue vigente en la actualidad, pues se ha consolidado como la principal institución del país especializada en educación científica y tecnológica, gozando de amplio prestigio a nivel nacional e internacional. La vinculación con el sector productivo 
forma parte de la esencia del IPN, dotando a sus egresados de conocimientos técnicos de aplicación inmediata (IPN, 2012: 2).

En 1986 se creó la Dirección de vinculación Académica y Tecnológica, misma que se reestructuró en 1988 en tres divisiones: Vinculación Académica con el sector productivo, Integración y Transferencia de Tecnología y; División de Intercambio Académico. En 1991 comunica la puesta en marcha de la primera incubadora de empresas de base tecnológica en México, lo que la convierte en pionera y modelo a seguir tanto en el ámbito de la incubación de empresas, como en el impulso a la creación de plantas productivas cuyo valor agregado se base en vanguardia tecnológica e innovación. En 1993 se modifica su nomenclatura como Dirección de Vinculación con el Sector Productivo. En 1997 se establece el Centro Multidisciplinario de Competitividad Internacional del IPN (CEMCI). Se establecía como objeto "el apoyar el desarrollo económico y social del país mediante servicios dirigidos a la promoción de las exportaciones que involucren la capacidad académica y científica de las distintas escuelas, centros y unidades del instituto, en materia de informática, investigación, desarrollo y transferencia de tecnología" (ibid: 3). El CEMCl se ubicaba en el quinto piso del edificio World Trade Center de la ciudad de México.

El CEMCI se considera el precursor de la actual Unidad Politécnica para el Desarrollo y la Competitividad Empresarial (UPDCE), establecida el 30 de Marzo de 2004. La UPDCE depende de la Secretaría de Extensión e Integración Social del IPN, y tiene como encomienda "impulsar el fortalecimiento de las empresas mediante la transferencia e intercambio de conocimientos, el desarrollo y transferencia de tecnología y la generación de la cultura tecnológica" (ibid, 4).

Las funciones del CEMCI se incorporaron a la UPDCE para "potenciar, fortalecer e impulsar el desarrollo de tecnologías aplicadas a los negocios y a la exportación; facilitar el acceso de los productos mexicanos a los mercados internacionales; incrementar la capacidad exportadora de las empresas mexicanas a través de servicios de consultoría y desarrollo de planes; la realización de investigaciones, y 
desarrollar procesos de transferencia de tecnología con el propósito de elevar la competitividad de las empresas" (ibid: 4-5).

En el año 2007 la UPDCE asume también las funciones de la Coordinación de Vinculación, asumiendo la responsabilidad de la vinculación institucional con el sector productivo. Para 2010 se transfiere el programa Poliemprende de atención a emprendedores de la UPDCE a la Incubadora de Empresas de Base Tecnológica, asumiendo las funciones de aceleración de empresas; la transferencia de desarrollos tecnológicos y; el fomento a la calidad y la competitividad empresarial por medio de subdirecciones, como lo expresan en su organigrama:

\section{SECRETARIA DE EDUCACIÓN PÚBLICA \\ INSTITUTO POLITECNICA.NACIONAL DIRECCIÓN GENERAL.}

UNIDAD POLITÉCNICA PARA EL DESARROLLO Y LA COMPETITIVIDAD EMPRESARIAL

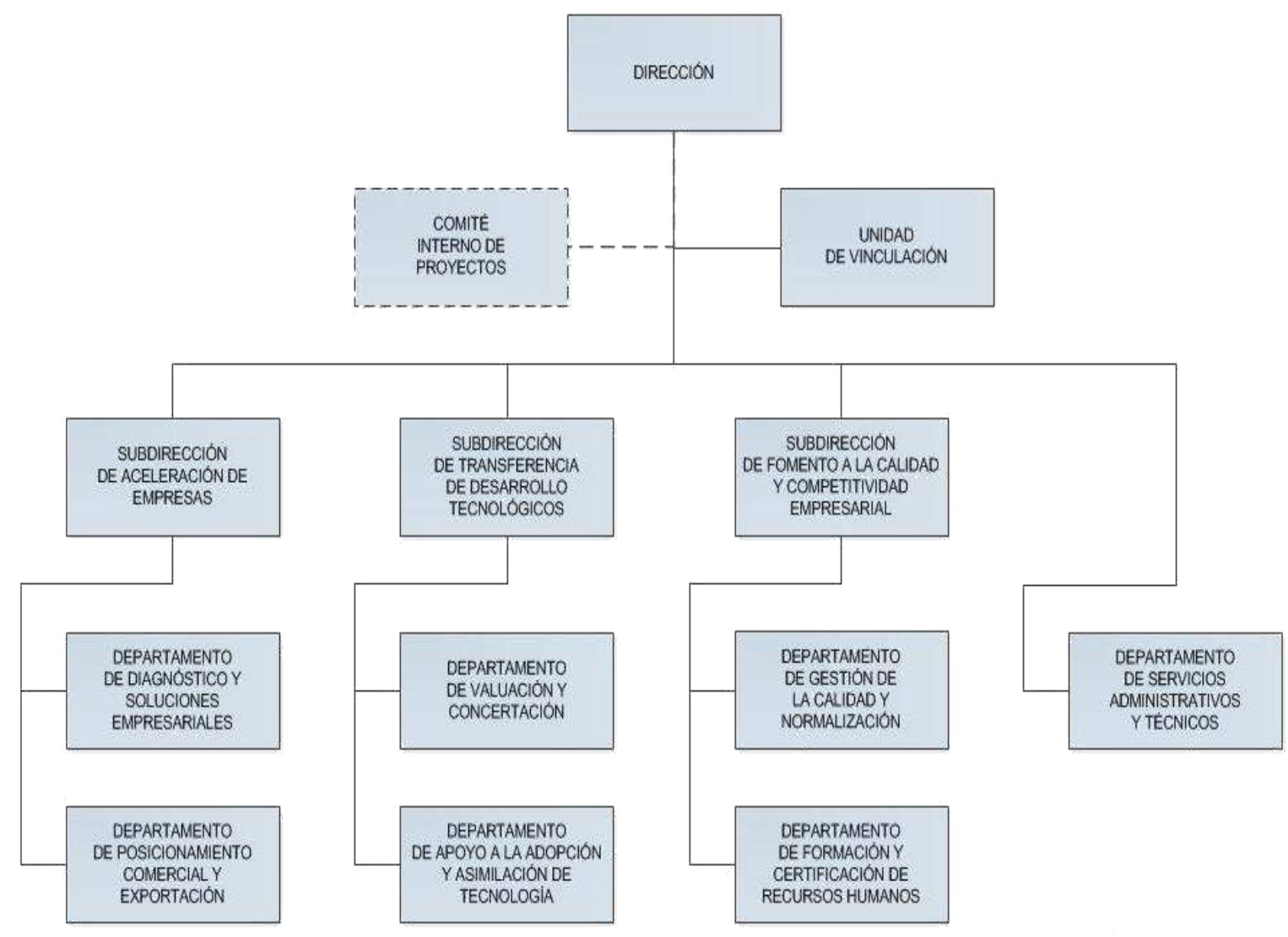




\section{Misión}

Atender con eficiencia y eficacia las demandas del sector productivo de bienes y servicios, a través de la coordinación de las dependencias politécnicas para la prestación de los servicios de aceleración de empresas, fomento a la calidad y transferencia de tecnología, actuando como motor del desarrollo de las empresas.

\section{Visión}

Ser la unidad que vincule a las dependencias politécnicas y a los sectores social y productivo, para generar sinergias además de fomentar estrategias que propicien la competitividad y el desarrollo socioeconómico del país.

\section{Política de la Calidad}

En la UPDCE nos comprometemos a promover el desarrollo y la competitividad de los sectores productivo, privado, público y social, a través del aprovechamiento de las capacidades tecnológicas del Instituto Politécnico Nacional, mediante la mejora continua de nuestros procesos y la atención oportuna, eficiente y profesional del personal.

\section{Objetivos de Calidad}

- Proporcionar servicios que cumplan los requerimientos del cliente.

- Satisfacer de manera oportuna y eficaz las necesidades y expectativas de nuestros clientes. 
- Cumplir con las metas comprometidas en los instrumentos institucionales de planeación.

- Optimizar los recursos asignados para la prestación de los servicios.

- Promover la profesionalización y el mejoramiento de las condiciones de bienestar laboral del personal.

\section{Marco jurídico administrativo de la UPDCE}

Se presentan las principales leyes y otras disposiciones que enmarcan la actuación de la UPDCE:

- Constitución Política de los Estados Unidos Mexicanos

- Código de Comercio

- Ley Orgánica del Instituto Politécnico Nacional

- Ley de Ciencia y Tecnología

- Ley de Comercio Exterior

- Ley de Ingresos de la Federación para el ejercicio fiscal vigente

- Ley de Planeación

- Ley Federal del Derecho de Autor

- Ley Federal para el Fomento de la Microindustria y la Actividad Artesanal

- Ley Federal sobre Metrología y Normalización

- Ley General de Educación

- Ley Orgánica del Consejo Nacional de Ciencia y Tecnología

- Reglamento Interno del Instituto Politécnico Nacional

- Reglamento Orgánico del Instituto Politécnico Nacional

- Reglamento de Integración Social

- Reglamento de Diplomados del Instituto Politécnico Nacional

- Plan Nacional de Desarrollo

- Programa Especial de Ciencia y Tecnología

- Programa Estratégico de Vinculación, Internacionalización y Cooperación 


\section{La Subdirección de Aceleración}

- Proponer a la Dirección de la Unidad las normas, políticas, programas, objetivos y metas para la integración, coordinación, operación, administración, control y evaluación de programas de enlace y alianzas estratégicas que promuevan la interacción entre el Instituto y los sectores productivo, privado, público y social, para impulsar el desarrollo y la competitividad empresarial del país, acorde con los modelos de integración social y educativo y las políticas institucionales en el ámbito de su competencia.

- Asegurar el enlace para la integración de servicios y atención al sector productivo especialmente a las PyMES, a través del capital técnico y humano Institucional, con el propósito de coadyuvar al desarrollo integral competitivo de las PyMES y propiciar una cultura empresarial sustentable

- Coordinar el diseño e implementación de los mecanismos de colaboración y coordinación Institucional para la ejecución de proyectos y/o propuestas integrales de innovación, investigación y desarrollo y fomento de una cultura empresarial basada en tecnología con el compromiso de sumar y potenciar las capacidades institucionales.

- Diseñar el programa de formación empresarial dirigido a los empresarios con el propósito de fortalecer sus capacidades y dotarles de mayores y mejores herramientas en su actividad empresarial.

- Administrar el Sistema Institucional de Servicios del IPN (SISERV), para la integración y actualización de los catálogos de capacidades y servicios y el directorio de asesores y consultores que lo integran.

- Supervisar la atención institucional de las solicitudes de servicios recibidas.

- Brindar asesoría, seguimiento y apoyo integral para dar respuestas satisfactorias a las solicitudes de los sectores productivo, privado, público y social.

- Promover las capacidades Institucionales ante el sector productivo, privado, público y social. 
- Establecer estrategias de comunicación interna con las Unidades Politécnicas de Integración Social (UPIS), para fortalecer al Instituto en su proceso de vinculación con los sectores productivo, privado, público y social.

- Identificar nichos de mercado en los sectores estratégicos, que permitan nuevas oportunidades de negocios a las empresas.

- Diseñar los mecanismos de difusión a fin de dar a conocer al sector privado los servicios que ofrece la UPDCE, en materia de diagnósticos empresariales para detectar problemas de calidad, productividad, operación, administración y en general competitividad.

- Promover y coordinar la realización de diagnósticos empresariales a fin de detectar las áreas de oportunidad y crecimiento de las empresas.

- Coordinar la asesoría a empresas establecidas, especialmente PYMES, en materia de negocios: mercadotecnia, finanzas, administración, derecho laboral, entre otros; con el propósito de ayudarles a resolver problemas puntuales que inciden en su productividad y en general en su desempeño empresarial.

- Coordinar las solicitudes de asesoría especializada en comercio exterior a las empresas que lo requieran.

- Diseñar, implementar y administrar el Programa de Aceleración de Negocios para apoyar a las empresas y favorecer su crecimiento.

- Asegurar la realización y participación de la Unidad en foros de articulación con el sector empresarial y eventos de promoción para dar a conocer los servicios disponibles.

- Elaborar el plan de promoción y difusión de los servicios y actividades de la Unidad, así como gestionar la elaboración de los materiales promocionales tales como pósters, trípticos, videos y discos compactos.

- Promover y difundir los eventos de carácter académico, científico, tecnológico y cultural de la UPDCE.

- Supervisar las funciones establecidas en el sistema de gestión de la calidad en el ámbito de su competencia 
- Participar en la elaboración e integración de los programas Operativo Anual, Estratégico de Desarrollo de Mediano Plazo, y de los reportes para el Sistema Institucional de Información, así como dar seguimiento y presentar los resultados para la toma de decisiones.

- Elaborar e integrar los reportes y estadísticas acerca del desarrollo y los resultados de las funciones y programas a su cargo, así como proporcionar en el ámbito de su competencia la información requerida en el marco de la Ley Federal de Transparencia y Acceso a la Información Pública Gubernamental.

- Informar al Director de la Unidad acerca del desarrollo y los resultados de sus funciones y programas, así como establecer indicadores de gestión para evaluar las acciones emprendidas por el área.

- Atender las demás funciones que se confieran conforme a su competencia.

\section{La construcción discursiva de la aceleración}

De acuerdo con declaraciones del Lic. Melo y el Ing. Contreras, la aceleradora como tal está funcionando recientemente (Julio de 2013), al obtener el reconocimiento por el Instituto Mexicano del Emprendedor. Sin embargo, La gestión para obtenerlo se inició en el año 2011. El IPN ofrece consultoría a empresas desde el año 1999, como un centro de asesoría en comercio internacional.

Principalmente se atiende al sector empresarial del Distrito Federal y del Estado de México, aunque se captan también candidatos del interior de la república gracias a instituciones filiales del IPN, con las cuales se acerca la consultoría a la región para evitar los gastos de traslado y tiempo de los empresarios.

Como puede apreciarse en las declaraciones puestas por escrito en los diferentes materiales proporcionados y en su sitio web, existe un marcado énfasis en el crecimiento económico a través de la consolidación de empresas con alto potencial dentro del sector MiPyME. Desde la esencia misma del Instituto Politécnico Nacional existe una férrea convicción de que la ciencia y la tecnología son factores 
determinantes para atender los problemas y lograr el desarrollo del país. Esta es la razón por la cual se legitima la formación de la UPDCE con el propósito de convertirse en el enlace que vincule al IPN con la sociedad, brindando la infraestructura y el conocimiento del mismo como soporte para el desarrollo industrial, tecnológico y económico del país.

\section{Proceso de aceleración}

A grandes rasgos, el proceso de aceleración consta de tres fases, que en promedio se completan en un periodo entre cuatro y ocho meses:

1. Diagnóstico

2. Diplomado

3. Talleres de asesoría

En la primera fase se realiza un diagnóstico del "Estado organizacional" de la empresa, mediante el cual se "aprecia" el "grado de profesionalización" del empresario y su empresa. Se considera si es apto para continuar con el proceso de aceleración. El diagnóstico no tiene costo y pueden participar empresas o negocios de cualquier tamaño y sector, sean miembros del politécnico (estudiantes, egresados, profesores) o de la sociedad.

Por "Estado organizacional" se entiende el nivel de avance dentro de una categorización propia diferente a la utilizada por la Secretaría de Economía. Estos estados son:

- Estado artesanal

- Taller artesanal

- Taller especializado

- Manufactura regional

- Manufactura global 
La ubicación de la empresa dentro de esta categorización se realiza mediante una "apreciación", tomando como referencia diez aspectos.

1. Demanda

2. Madurez organizacional

3. Información

4. Medio ambiente

5. Finanzas

6. Clientes

7. Personal

8. Innovación

9. Tecnología

10. Seguridad

Esta apreciación permite construir el "radar del perfil competitivo" que es un instrumento gráfico en el que cada uno de los aspectos apreciados de la empresa es valorado en una escala, conformando una especie de red (radar).

La siguiente fase consiste en la participación del empresario en un diplomado, el cual sí tiene un costo. Por medio de éste, se busca desarrollar las habilidades profesionales del empresario para una gestión profesional de su empresa. El eje principal es la "normalización" de la empresa. Esto se refiere a habilitar las actividades y procesos de la misma de acuerdo con las normas oficiales mexicanas (NOM y NMX), considerando los resultados arrojados en la fase previa (diagnóstico) en el "radar del perfil competitivo". Se consideran todas aquellas normas que regulan las actividades de la empresa tanto en temas de calidad, competitividad, ambientales y de seguridad. La normalización coloca a la empresa en condición de competir con mayores probabilidades de éxito al ampliar su conocimiento del entorno en el que compite y contar con las herramientas necesarias para aprovechar las condiciones del mismo. 
Del diplomado también surge la redacción del "plan técnico de desarrollo" de la empresa y un "plan de crecimiento a diez años". Estos instrumentos le permitirán a la empresa solicitar o acceder a financiamiento de programas públicos federales 0 de financiamiento con organizaciones privadas con la intención de utilizar los recursos que se obtengan en reforzar aquellos "aspectos" del "radar del perfil competitivo" que lo requieran. De esta manera se busca avanzar de un "estado organizacional" inicial (al momento del diagnóstico) a otro más avanzado.

La tercera fase consiste en talleres de asesoría especializados e individualizados para los empresarios, en los cuales se atienden los aspectos necesarios para la adecuada gestión de la empresa, incluyendo la utilización de Tecnologías de la Información y Comunicación (TIC's) como herramientas de gestión integral de la empresa.

Destaca el modelo de aceleración de empresas de la UPDCE - IPN respecto a otros modelos de aceleración operando en México por lo siguiente:

1. Es la primera aceleradora de empresas de una universidad pública.

2. Su modelo enfatiza la normalización de la organización, esto es, el cumplimiento de las normas oficiales mexicanas que delimiten la acción y operaciones de la empresa, respecto a calidad, competitividad, ambientales y de seguridad.

3. Dado que el énfasis en la normalización es un sello distintivo, se pone a disposición los recursos que posee el IPN tanto de laboratorios como de especialistas en diferentes áreas del conocimiento, destacando las ciencias básicas y aplicadas, la ingeniería y la tecnología, fungiendo la UPDCE como enlace que vincula a los empresarios con el IPN.

4. Considerando lo anterior, la aceleradora permite no sólo atender a empresas de negocios, sino también a empresas de desarrollo tecnológico, de manera adecuada y con especialistas capacitados en ese terreno.

Durante las entrevistas realizadas con miembros clave de la aceleradora de empresas se tuvo acceso al fundamento teórico de la aceleradora. Dicho documento 
es producto de una investigación de grado de maestría en Ciencias en Estudios Interdisciplinarios para Pequeñas y Medianas Empresas de la Unidad Profesional Interdisciplinaria de Ingeniería y Ciencias Sociales y Administrativas (UPIICSA) del Instituto Politécnico Nacional.

Debido a que ese documento aún se encuentra en proceso de edición, se tuvo acceso a él con la condición de no citarlo textualmente por cuestiones relacionadas al plagio, debido a que el IPN se reserva los derechos de autor de sus producciones académicas y este documento aún no se encuentra disponible al público en general.

Resulta de particular interés este documento debido a que puede considerarse la fuente principal de legitimación de esta aceleradora en concreto, las bases teóricas, técnicas y metodológicas que permiten acercarse al sentido de la acción en la organización. De la investigación contenida en él se desprende el modelo de aceleración propuesto y que se materializa gracias a la creación de la subdirección de aceleración de empresas y la propia aceleradora. Con ello se pretende entonces reconocer el entramado discursivo conformado por las diversas fuerzas que conforman el escenario de acción o terreno de juego, esto es, las restricciones que el IPN establece para la operación de la UPDCE que acotan el accionar de la aceleradora.

\section{Concentrado de Argumentos presentes en el documento}

Se presentan los argumentos en forma de oraciones, tratando de preservar la forma en que son presentados en la redacción original. Esta separación tiene como propósito desentrañar la argumentación lógica presentada para justificar la creación del modelo de aceleración. Las siguientes oraciones se encuentran en el resumen del documento:

\section{El empresario mexicano:}

- Dispone de alternativas para su crecimiento.

- Dispone de alternativas para su crecimiento pero no en abundancia.

- Las alternativas para su crecimiento son escasas y complicadas. 
- No utiliza las alternativas para su crecimiento para la gestión.

- En pocos casos valora los escenarios estratégicamente.

- Debe ser profesional

- El empresario profesional plantea estrategias de desarrollo integral para su organización.

\section{Las alternativas para el crecimiento de los empresarios mexicanos:}

- Pocos empresarios mexicanos demandan alternativas para su crecimiento.

- Las alternativas para el crecimiento de los empresarios son escasas.

- Las escasas alternativas existentes para el crecimiento de los empresarios son complicadas.

- Pocos empresarios mexicanos participan en la formalidad estructural que ofrecen las secretarías e instancias de gobierno.

- Los empresarios mexicanos tienen un desempeño básico.

- La visión de crecimiento de los empresarios mexicanos está ligada a aspectos de otra índole.

- Pueden diseñarse perfiles de empresa que ofrezcan una perspectiva de los caminos alternativos recorridos en búsqueda de crecimiento y consolidación en el mercado.

- Las empresas mexicanas recorren caminos en busca de crecimiento y consolidación en el mercado.

- Las empresas mexicanas que encuentran crecimiento y consolidación en el mercado recorren caminos alternativos.

- Pueden generarse perfiles de empresas mexicanas que encuentran crecimiento y consolidación en el mercado.

- Pocas empresas en México tratan de crear perfiles más competitivos.

- Las pocas empresas en México que tratan de crear perfiles más competitivos son las que ofrecen una posibilidad real de crecimiento a la economía nacional.

- Las pocas empresas en México que tratan de crear perfiles más competitivos son organizaciones que están asumiendo compromisos en niveles técnicos, económicos y en general de mayor profesionalización que el resto de las organizaciones.

- Las empresas que se esfuerzan en planear la producción integrando eficacia, eficiencia y previsión de pérdidas como estrategias obtienen como resultado la competitividad.

- Los esfuerzos conjuntos sustentan a las estrategias de crecimiento de la organización.

- Los esfuerzos conjuntos que sustentan a las estrategias de crecimiento de la organización dan como resultado la competitividad. Si las empresas 
planean las estrategias para que la organización crezca, serán más competitivas.

- Hay empresas que son competitivas sin tener una perspectiva integrada de eficacia, eficiencia y previsión de pérdidas en sus estrategias de crecimiento de la organización. Esta competitividad sólo ofrece crecimiento aparente. La competitividad con crecimiento aparente tiene efectos colaterales que no pueden determinarse en forma simple pero que crean profundos efectos de largo plazo sobre el desarrollo económico y social y representan pérdidas para la sociedad.

- El gobierno ofrece programas para que el empresario que participe crezca o se consolide. Estos programas son alternativas integrales que minimizan los efectos colaterales de la competitividad con crecimiento aparente. Por lo tanto, deben considerarse en todo plan estratégico empresarial.

- Toda iniciativa empresarial debe sustentarse en análisis e información ordenada y estructurada correctamente que ofrezca al empresario las condiciones reales para aterrizar sus alternativas al crecimiento $y$ desarrollar a su organización en forma sustentable.

En esta parte no se encuentran las alternativas de apoyo para el crecimiento de las empresas mexicanas existentes, ni se argumenta si son suficientes o si las que existen son eficaces o eficientes. Tampoco se argumenta las razones de la baja demanda de las mismas. Otra ausencia detectada es la argumentación sobre el porqué es necesario ofrecer esas alternativas de apoyo y a quién le corresponde asumir la responsabilidad y costo de los mismos.

Por otra parte, se cuestiona si es necesario ser un empresario profesional para tener éxito. Aparentemente se correlaciona el éxito con el crecimiento de la empresa, es decir, si la empresa crece, entonces es exitosa. O bien, si quieres que la empresa sea exitosa, entonces debe crecer, lo que se identifica como una lógica propia de la racionalidad lineal de causalidad (causa-efecto).

En el primer capítulo se presentan la justificación y la descripción del problema de investigación. Se recuperan las siguientes frases explícitas del documento:

\section{Las micro, pequeñas y medianas empresas en México:}

- Representan el sector que más oferta empleo. 
- Son las que mayor aportación tienen en materia de desarrollo sustentable de la economía del país.

- Representan en forma consistente la realidad del desarrollo de una sociedad.

- Exigen una teoría y un modelo empresarial propios que puedan seguir, fácil de adoptar, en congruencia con las condiciones del país, pero con miras a competir (proyectarse) en los mercados internacionales.

- La tasa de mortalidad de las organizaciones empresariales es muy elevada.

- Abordar su problemática ofrece la posibilidad de mejorar las condiciones socio-económicas del país.

- Estudiar los fenómenos de crecimiento, consolidación y madurez de las pymes facilita la construcción de una plataforma eficiente para atender a empresarios y sus organizaciones.

- Soportar a las pymes es una necesidad económica actual y una obligación que depende de la sociedad contemporánea. El estudio de las pymes mexicanas debe obedecer las condiciones locales en los mercados globales.

- La implementación de teorías empresariales extranjeras no es una solución que verdaderamente pueda ser adoptada por estas organizaciones, principalmente porque estas teorías están sustentadas en una disciplina o una filosofía de vida, y su comunión permite a las organizaciones y sus empresarios alcanzar el mayor beneficio, originalmente planificado.

- Los programas federales son una fuente de impulso de que dependen estas organizaciones.

- Es importante facilitar el acceso a los programas federales de apoyo sin disminuir requisitos.

- Es necesario que estos requisitos sean bien interpretados y relativamente fáciles de satisfacer por las organizaciones.

- Si los requisitos son bien interpretados y relativamente fáciles de satisfacer por las organizaciones, se asegura la participación de las organizaciones en los programas.

- Resulta de vital importancia que las organizaciones mexicanas y sus empresarios sean capaces de acercarse y participar en todos los programas y en todas las oportunidades de crecimiento. De esta forma, el crecimiento de éstas tendrá mayores alternativas para consolidarse.

- Deben orientarse los esfuerzos a la vinculación de las pymes con las universidades, los centros de investigación y en general con la academia. 
Esto permite que adquieran capacidad de acercarse y participar en todos los programas y en todas las oportunidades de crecimiento.

- Se esperaría que los programas de apoyo estén sustentados en estadística descriptiva del fenómeno empresarial y ésta sea el soporte de los modelos de teoría empresarial mexicana.

- La participación de filosofías y corrientes empresariales extranjeras que participen en la formación de los modelos de teoría empresarial mexicana deben ser tratadas y traducidas en forma correcta para ser incorporadas a las soluciones empresariales que pueden disponer las pymes en México.

- Las filosofías y corrientes empresariales extranjeras son un apoyo para conocer los mercados internacionales, no para ser adoptadas como filosofías de operación de las pymes mexicanas.

Los argumentos son presentados sin ofrecer evidencia empírica, datos, estadísticos o en su defecto referencias bibliográficas y fuentes que respalden lo enunciado. Se aprecia la influencia del discurso hegemónico, dado que se asume lo anterior como por todos conocido. Se resaltan -al igual que en el discurso dominante- las bondades de las MiPyME's, sus fortalezas, sus potencialidades y sus aportaciones porcentuales a la producción y al empleo. No se pretende negar su importancia, sino resaltar que es importante este sector -si se desea asumir como sector, no olvidando su heterogeneidad-por la problemática que lo envuelve y que establece un entorno turbulento e incierto.

Se insiste en la necesidad de crecimiento de las empresas - de hecho, se insistirá en todo el documento y esto se refleja por tanto en el entramado discursivo cotidiano de la aceleradora y contribuye a la reafirmación del discurso dominante- y el tránsito de un estado inicial a uno superior, presuponiendo que el inicial es malo o indeseable, inoperante o sub-óptimo. Estos argumentos provocan el cuestionarse si toda MiPyME debe ascender a un estado superior, ¿cómo debe hacerlo? ¿Hay una mejor manera?, ¿Qué hace al estado actual inferior y al deseado superior? Si a los empresarios les interesa el crecimiento de su empresa ¿por qué no se acercan a buscar apoyos?, o bien, ¿todo empresario busca el crecimiento de su empresa? ¿Existe la posibilidad de que el crecimiento ponga en riesgo la existencia de la 
organización? Si hay empresas que no crecen pero se mantienen por años ¿eso debe considerarse fracaso, falta de competitividad o de ambición?

Otro punto interesante es la formulación que indica que los empresarios son los que deben tomar la iniciativa para informarse y acercarse a los programas de apoyo, lo que sugiere entonces que las entidades que los brindan -sean gubernamentales o privadas- juegan un papel pasivo o reactivo (respuesta a la demanda).

En la justificación de la investigación se presentan las siguientes frases:

\section{Las mipymes mexicanas:}

- Tienen una particular importancia para la economía nacional por su aportación a la producción y al empleo.

- Constituyen el $99.8 \%$ de las unidades económicas del país. (INEGI, Censos Económicos 2009)

- Alcanzan un número significativo. Más de 5.1 millones de organizaciones prestan sus servicios $u$ ofrecen sus productos a sus clientes en México y el mundo.

- Generan el $34.7 \%$ de la producción total del país (INEGI, Censos Económicos 2009)

- Contribuyen con el $73 \%$ de los empleos del país (INEGI, Censos Económicos 2009)

- Son significativamente quienes ofertan la mayor cantidad de empleos a la sociedad.

- La economía del país se sustenta en gran medida por la capacidad de estas organizaciones para continuar ofreciendo empleo, servicios y productos.

- Tienen una particular importancia para la economía nacional por su flexibilidad a los cambios.

- Tienen una particular importancia para la economía nacional por su capacidad de contribuir al proceso de innovación.

- Tienen una particular importancia para la economía nacional por su capacidad de contribuir a mejorar la competitividad de la industria.

- Tienen una particular importancia para la economía nacional por ser un medio para impulsar el desarrollo económico.

- La conformación, crecimiento y maduración de las mipymes mexicanas representa la posibilidad para la sociedad mexicana de acceder a una mejor condición socio-económica y a un nivel de desarrollo que impulse las facultades de los seres humanos que la conforman. 
- Siguen un camino similar en su proceso de crecimiento que puede verificarse mediante las acciones empresariales que estas organizaciones realizan o dejan de realizar, sin importar su sector económico, giro o características internas.

- El uso y el beneficio asociado a los medios disponibles para impulsar el crecimiento y consolidación de las organizaciones empresariales en México depende directamente de la voluntad del empresario, primero para acercarse y utilizarlos y segundo para acceder a más y mejores medios para impulsar a su organización a través de ellos.

- El uso de más y mejores medios disponibles para impulsar el crecimiento y consolidación de las organizaciones empresariales en México logra un ciclo permanente de vinculación, participación y crecimiento.

Se identifica también el entrelazamiento de las frases anteriores con las siguientes que tienen que ver con las fuentes de información de la investigación:

- Diversas entidades de gobierno ofrecen información sobre el comportamiento empresarial (Se consideraron las siguientes entidades: SIEM, Dirección General de Normas, Sistema Nacional de Empleo, INEGI, IMSS, Profeco y Observatorio pyme A.C).

- El Sistema Empresarial Mexicano (SIEM) mantiene un registro nacional vigente, actualizado y confiable de las organizaciones que han alcanzado mayor formalidad en su conformación al registrarse ante alguna de las cámaras empresariales.

- La información proveniente de las diversas fuentes gubernamentales permite inferir (conocer) el comportamiento empresarial.

- La asociación estadística (correlación) entre el uso de las alternativas dispuestas para impulsar el crecimiento y consolidación empresarial por parte de los empresarios y el comportamiento, desempeño y crecimiento de sus organizaciones establece una diferencia clara (obvia) entre los empresarios. Permite inferir que los empresarios que tienen mayor disposición para utilizarlas muestran mejor desempeño y mayor crecimiento y consolidación de sus organizaciones que los de menor o nula disposición.

- No existen estudios profundos y de carácter científico respecto de estos comportamientos, pero sí se cuenta con información estadística básica de los resultados alcanzados por las organizaciones empresariales mexicanas en términos de longevidad, tamaño, nivel de ventas alcanzado, 
número de empleados, cumplimiento de obligaciones patronales asociadas, etc.

- Con esta información pueden dibujarse perfiles organizacionales y empresariales.

- Estos perfiles pueden utilizarse para comprender el desempeño de los empresarios en torno de las opciones que tienen disponibles para impulsar el crecimiento de sus organizaciones o al menos consolidarlo.

Las siguientes frases encontradas en el mismo apartado del documento se refieren a la utilización de métodos cuantitativos en la investigación desarrollada:

- La investigación realizada tuvo como propósito recolectar evidencia estadística de las fuentes gubernamentales disponibles.

- Se recolectó evidencia estadística de las fuentes gubernamentales disponibles con el "sentido" de mostrar los resultados (crecimiento y consolidación) que actualmente alcanzan los empresarios mexicanos.

- Los resultados que actualmente alcanzan los empresarios mexicanos (crecimiento y consolidación) se asociaron con las acciones que se toman o dejan de tomarse al momento de hacer crecer o consolidar sus empresas.

De este apartado se identifica el supuesto de que si una empresa está registrada en alguna cámara empresarial entonces ha alcanzado mayor formalidad en su conformación. Esto es parcialmente verdadero, puesto que para registrarse en una cámara, debe haber formalizado su constitución (acta constitutiva) y otros trámites propios de la "formalidad", como el Registro Federal de Contribuyentes, la firma electrónica del Sistema de Administración Tributaria, establecer un domicilio fiscal, etc. Pero esto hace suponer que sólo las que pertenecen a alguna cámara se han formalizado y esto no es verdad. También supondría que esta formalidad se traduce en una operación al menos aceptable. Por otro lado, supone que las que no pertenecen a una cámara empresarial no son formales, o bien, que no existe formalidad en su organización. Se puede identificar por tanto la ambigüedad del término "formal".Se identifica también el supuesto de que el padrón del SIEM es confiable y se mantiene actualizado, aunque se hace la observación de que registra sólo a las empresas que pertenecen a alguna cámara, lo que cuestiona su 
confiabilidad y actualidad, restringiendo la validez de sus datos sólo para empresas pertenecientes a las cámaras, pero no generalizables a la totalidad de empresas censadas.

Respecto a las cámaras empresariales, cabe recordar que éstas tienen como propósito defender los intereses de sus miembros, lo que implica tanto beneficios como restricciones para los mismos, así como para los que no son miembros, puesto que pueden beneficiarse de los logros de las cámaras o enfrentarse a complots y otras restricciones y presiones para limitar su competencia o eliminarla. En concreto, las cámaras pueden convertirse también en un obstáculo para las empresas que no estén alineadas o simplemente sean una competencia para algunos miembros. Las cámaras están sujetas a relaciones de poder, facciones, conflicto de intereses, negociaciones, luchas, etc. Por lo que hay que cuestionarse ¿Qué intereses salvaguarda?

Del mismo apartado analizado se identifica que se cae en el exceso de suponer que es el empresario el que ejerce las decisiones y la acción de toda la organización, o bien, en antropomorfizar a la misma, antes que considerar que las acciones de las organizaciones son resultado de negociaciones, mediaciones o imposiciones, emergentes de la interacción de los múltiples miembros de la organización, entre sí, con el entorno de las organizaciones y con las diferentes estructuras que acotan su escenario de acción.

También se cede gran parte de la responsabilidad al empresario (incluso obligación) del crecimiento y consolidación de la empresa (asociado con el éxito), de forma radicalmente voluntarista, ubicando al resto de los actores como entes pasivos o reactivos. Se establece el supuesto de que con la información estadística se toman mejores decisiones y que estar informado de los programas y apoyos existentes, así como participar en ellos beneficia el crecimiento y consolidación de las empresas. El poseer información estadística en sí no resulta de mucha utilidad si no se sabe qué hacer con ella, los datos no son los que actúan o toman decisiones, sino los empresarios. Lo mismo sucede con la información respecto a los programas. Primero hay que cubrir los requisitos solicitados por éstos y aun así no 
hay garantías absolutas de éxito. En todo caso sólo puede esperar tener mayores probabilidades de éxito o menores probabilidades de fracaso. ¿Qué asegura que los medios para impulsar a las empresas son los mejores? ¿Estos medios no generan más problemas de los que solucionan?

Como objetivo del estudio se presenta un párrafo, pero a lo largo del documento se encuentran dispersas otras frases presentadas por el autor con sinónimos como finalidad, fin, razón o propósito. Se han reordenado las frases con el propósito de reconstruir la lógica argumentativa. Se presentan primero las premisas que llevan a lo que el autor llama propuesta central de la investigación.

- Todas las organizaciones requieren identificar sus oportunidades para crecer y consolidarse.

- No todas las organizaciones tienen las mismas oportunidades para crecer y consolidarse.

- Algunas organizaciones se posicionan en condiciones de crecimiento y consolidación porque aprovechan las oportunidades que se les presentan. Otras requieren buscar los medios para generarse ese beneficio.

- La gran mayoría de las instancias de gobierno que ofrecen oportunidades de crecimiento a empresarios requieren presentar ciertas herramientas para aplicar o acceder a dichos medios (información de la organización como: directrices básicas establecidas, su ordenamiento alrededor del crecimiento, beneficios que espera obtener de su vinculación con uno u otro medio dispuesto).

- El empresario con perfil profesional mantiene máxima participación en la identificación y aprovechamiento de sus oportunidades para que su organización crezca y se consolide.

- El empresario con perfil profesional usa los medios disponibles para que su organización crezca y se consolide.

- Las investigaciones en materia de conocimiento empresarial, de cualquier corriente o categoría, ofrecen conocimientos sintéticos a los lectores y ofrecen alternativas para que los empresarios cuenten con mejores bases de decisión.

- El empresario puede alcanzar un conocimiento adecuado de las alternativas o medios para impulsar el crecimiento o consolidarlo en beneficio de su organización, por medio de diversos estudios e investigaciones sobre el diseño, puesta en marcha y hasta la operación de una empresa. Estos estudios están asociados en su mayoría a programas institucionales, cuyos objetivos son diversos y enfocados a distintos 
aspectos (capital y financiamiento, capacitación y adiestramiento, crecimiento en ventas y exportación, nuevos productos y procesos, innovación y desarrollo tecnológico, competitividad y productividad, participación en programas especializados, etc.).

- Existen diversas corrientes de estudio del fenómeno empresarial a nivel internacional. Estas investigaciones han sido excluidas como referencias bibliográficas, buscando soportar la investigación sólo en aquellas realizadas en empresas latinoamericanas y sus empresarios.

- El marco de la investigación empresarial en México permite construir una base para delimitar y estructurar la presente investigación, la cual es una consecuencia que busca la continuidad con lo que se ha investigado y escrito en estas teorías empresariales.

- Algunas investigaciones relacionadas a la actividad empresarial mexicana han sido realizadas por universidades públicas y privadas, así como institutos autónomos. Sin embargo, para la comunidad de empresarios promedio, sus resultados no están disponibles o no son accesibles.

Con base en estas frases, el autor establece lo siguiente:

\section{Propuesta central de la investigación:}

Ofrecer una visión a los empresarios de las condiciones actuales en el comportamiento empresarial promedio en México, determinando las acciones típicas que los empresarios siguen, y diferenciándolas de los que buscan utilizar alternativas para crecer.

En el documento se divide en dos partes, identificándose las siguientes frases como parte del objetivo, de acuerdo a la construcción argumentativa del autor:

- Primera parte: Evidenciar el nivel de profesionalización de los empresarios respecto al aprovechamiento de sus oportunidades a través de la construcción de perfiles. Estos perfiles se construyen a partir de la información disponible en las instancias de gobierno mencionadas (bases de datos en línea y solicitudes de acceso a la información pública del IFAI).

- Segunda parte: Ofrecer a los empresarios el medio de construcción de las herramientas para la gestión necesarias para utilizar los medios disponibles y oportunidades de crecimiento y consolidación de sus organizaciones.

- Ayudar a las mipymes a través de la construcción de un escenario empresarial. 
- Ofrecer a los empresarios una perspectiva de cómo impulsar a sus organizaciones mediante el uso de las alternativas dispuestas por el gobierno y la iniciativa privada.

Se recupera también de esta parte del documento una frase que resulta de interés para el análisis del texto y sus implicaciones en el entramado discursivo:

- La acción empresarial centra su perspectiva epistemológica en la diferenciación estadística de los resultados alcanzados en la ciudad de México y el Estado de México por sus empresarios, con el fin de dibujar un escenario cercano a los empresarios, a fin de que se auto diagnostiquen respecto de sus propias acciones empresariales y consideren las alternativas que existen para crecer o consolidarse.

De igual forma se incluyen las preguntas del autor, las cuales busca responder con la investigación:

\section{Preguntas planteadas por el autor}

- ¿Cuál es el perfil del empresario mexicano promedio en el Distrito Federal y Estado de México?

- ¿Cuáles son los resultados alcanzados por este empresario promedio?

- ¿Qué beneficios se pueden esperar al utilizar las oportunidades de crecimiento disponibles en México?

- ¿Qué herramientas son necesarias para acceder a las oportunidades de crecimiento dispuestas en México?

- ¿Qué pasos debe seguir un empresario para construir un modelo de gestión que se beneficie de estas oportunidades?

De lo anterior se plantea lo siguiente: Existe una postura funcionalista que evoca prescripciones, manuales, recetas. Existen dos posturas extremas. La primera es el excesivo funcionalismo que subordina la investigación científica a los intereses de quienes financian la investigación. En este caso se pretende establecer por escrito la serie de pasos a seguir, evocando las pretensiones de H. Simon de establecer decisiones tomadas por anticipado en el departamento pensante, plasmarlas por escrito y entregarlas a los subordinados, de tal manera que no deban esforzarse en pensar de qué manera resolver una situación, puesto que ya existen respuestas a 
las preguntas. Cuando la pregunta es: ¿qué decisión tomar?, basta con revisar el manual y se encontrará los pasos a seguir. Esto aplica también para las consultoras, incubadoras y aceleradoras, las cuales representan el rol de departamento pensante externo o subcontratado por la empresa. Se realiza un diagnóstico y se entrega un manual o una serie de pasos a seguir cuya confiabilidad está basada en el supuesto de que aquellos que los prescriben son expertos y por tanto poseen autoridad y capacidad para hacer las prescripciones.

El extremo opuesto consiste en desvincular la ciencia y el conocimiento de su aplicación práctica, esto es, asumir una postura radical hermenéutica de negación del método científico, considerar utópica la esperanza de conocer la realidad mediante la ciencia o asumir que sólo puede formularse conocimiento respecto del caso concreto, único e irrepetible, del cual no pueden obtenerse abstracciones generalizables y útiles para abordar otros casos.

Ambos extremos poco aportan tanto para la ciencia como para su aplicación práctica en el abordaje de problemas reales y cotidianos. Es necesario y deseable vincular el conocimiento a estos problemas cotidianos sin perder de vista el riesgo de ser excesivamente positivistas y reducirlo todo a números, porcentajes y variables. Los métodos cuantitativos son un gran apoyo y ofrecen información importante y útil, al igual que la lógica hipotético-deductiva positivista, sobre todo si se emplean adecuadamente. Sin embargo, resulta también necesario complementar los resultados e interpretaciones de estas vertientes con las aportaciones cualitativas de los métodos cualitativos hermenéuticos que arrojan significados, subjetividades, interacciones y toda una gama de conocimiento que fortalece el análisis y proporciona mayor cantidad de alternativas, recursos y consecuencias -siguiendo el razonamiento Simoniano-.

Los estudios e investigaciones son fuentes de conocimiento del cual pueden extraerse soluciones o alternativas de solución a los problemas. También permiten criticar la pertinencia y validez de los métodos y herramientas de gestión de moda. La desvinculación entre la investigación académica -y el conocimiento producto de ésta- y los modelos y herramientas de gestión prescritas por las consultoras, así 
como los programas de apoyo diseñados, es lo que ha permitido la proliferación de éstos con poco cuestionamiento de sus bases teóricas o sus resultados obtenidos respecto a los esperados o prometidos, incluyendo los efectos colaterales. Si se atiende a la revisión histórica se puede apreciar que el apoyo a las MiPyME's se ha realizado por alrededor de tres décadas y el apoyo a la industrialización del país desde la segunda mitad del siglo pasado. Durante este tiempo se han implementado los planes más racionales fundamentados en las teorías más vanguardistas de los teóricos más renombrados y se ha impulsado la adopción de modelos, herramientas y estrategias de gestión de las empresas más competitivas de los países industrializados. La pregunta entonces es ¿Por qué los índices de mortandad de las empresas siguen siendo elevados? ¿Cómo es que perturbaciones económicas, políticas, sociales o ambientales provoquen inmediatamente el quiebre, la venta o la desaparición de las MiPyME's?

Respecto a los empresarios, se sugiere la búsqueda o construcción de un perfil deseable del empresario mexicano. Se puede leer en una frase la "existencia de una comunidad de empresarios promedio". Es pertinente cuestionar si realmente se puede hablar de un promedio de empresario, lo que hace suponer que esto se deriva de la óptica cuantitativa con la que se está abordando el estudio, lo que convierte a cada empresario en un número con el cual se pueden realizar operaciones aritméticas, estadísticas e incluso funciones econométricas. El promedio aritmético hipergeneraliza. El ejercicio concreto de la investigación pretende obtener conclusiones generalizables para todas las diferentes regiones del país a partir de observaciones particulares de una región concreta (DF y Edomex). Los resultados alcanzados por el empresario promedio, son resultados promedio. Sin embargo, en la práctica los empresarios no esperan obtener resultados promedio sino los resultados de aquellos que obtienen el máximo beneficio posible y el mayor crecimiento antes que conformarse con lo promedio. Además, ¿cómo medir aspectos cualitativos para poder promediarlos aritméticamente?

Los beneficios que se pueden esperar son los que discursivamente prometen. Pero entre la esperanza y la realidad hay una gran diferencia. Es pertinente la pregunta 
¿Qué reacciones adversas, efectos secundarios, daños colaterales se pueden esperar al utilizar las oportunidades de crecimiento disponibles en México?

También evoca pensar en una estandarización o producción en serie de empresarios con pensamiento homogéneo, que se comporten y tomen decisiones de la misma manera sin importar el tamaño de la empresa, el ramo en el que se desempeñen, la región en la que se encuentren, el mercado que atienden o la competencia que enfrentan. Si se habla de un perfil deseable, ¿Para quién es deseable ese perfil?

Otro supuesto implícito en las líneas presentadas es que el empresario utilizará el documento como guía. También sugiere que el empresario obtendría conocimiento adecuado si conociera las investigaciones (estudios) que señala, así como el informarse de los programas de apoyo existentes. En primer lugar, el empresario tendría que conocer su existencia, tener el interés de conseguirlos y leerlos, entender lo que se plantea y por qué se plantea, de qué manera puede aplicar ese conocimiento en su caso concreto y llevarlo a cabo. Son demasiadas suposiciones, $y$ hay que agregar si esos estudios realmente tienen algo positivo que aportar o son sólo recetarios de modas de gestión con efectos secundarios sin advertencia de "se aplican restricciones". Por último, en este apartado no se ofrecen ejemplos ni se citan las investigaciones a las que se refiere.

El autor establece también los alcances y limitaciones de su investigación mediante frases como las siguientes:

- El estudio contiene una propuesta universal para las pymes en México, de cualquier sector, giro y actividad económica.

- Los datos que la sustentan han sido extraídos de una muestra de empresarios y sus empresas en el Distrito Federal y el Estado de México.

- Se determinó que dicha muestra perteneciera a esta región, principalmente por la cercanía con los centros y organismos consultados durante la realización del estudio.

- Debido a las condiciones que se requieren para el levantamiento de la información relacionada con el estudio, fue necesario hacer una muestra de inferencia no asociada a un nivel de confianza o a un error porcentual deseado en el estudio. 
- Debido a la universalidad de los elementos que conforman la propuesta planteada en este estudio, es posible construir argumentos sobre una teoría empresarial mexicana que sustente la gestión del crecimiento de las pymes en sistemas normalizados o científicos, reconocidos a nivel nacional e internacional y cuya operatividad sea certificable por terceros involucrados.

Reconstruyendo el texto, se pueden resumir las características del estudio como sigue:

- Se realizó una encuesta (Encuesta de necesidades empresariales) a 25 empresarios (25 organizaciones pymes) del Distrito Federal y Estado de México (zona conurbada del DF) de los sectores Alimentos y alimentos procesados, electrónica y transformación. Estos empresarios son miembros de alguna cámara empresarial de su sector. Con base en los datos de la encuesta, se realizó un diagnóstico de Perfil competitivo de los empresarios, valorando 10 aspectos de apreciación empresarial.

Se observa en estas líneas que no se establece ni población ni muestra estadísticamente. La muestra estadística es insuficiente si se considera el tamaño de muestra (25 pymes) contra el universo conocido (número de pymes censadas por INEGI). Si no hay rigor estadístico, ¿cómo se pretende proponer una receta universal?

Se maneja indistintamente el acrónimo pyme y el acrónimo mipyme, lo cual es incorrecto, debido a que el primero deja fuera a las microempresas, que son las de mayor participación porcentual en la conformación del total de mipymes. Por lo tanto, técnicamente no es lo mismo hablar de pymes que de mipymes.

Se propone una serie de pasos estratégicos para normalizar a las pymes y así éstas superen los requerimientos para acceder a beneficios de programas federales $\mathrm{y}, \mathrm{si}$ es el caso, a vincularse en cadenas productivas y mercados internacionales. Este punto puede considerarse como una de las fortalezas reales de la propuesta del IPN respecto a otras aceleradoras, puesto que permite a las empresas participantes del proceso de aceleración satisfacer los requisitos demandados tanto por clientes, sean empresas tractoras o mercados internacionales exigentes, como por entidades 
bancarias y gubernamentales. Dicho de otra manera, permite identificar las restricciones del campo de juego y esto ayuda a mejorar el desempeño de las empresas dentro del mismo, lo que no es lo mismo que decir que serán las más competitivas. La mejora de la comunicación y las relaciones con estas organizaciones que forman parte del entorno de las empresas aceleradas es un punto vital que vale la pena rescatar de la propuesta.

Posteriormente, el autor establece los resultados que espera alcanzar con el estudio, así como los productos y subproductos:

\section{Resultados esperados:}

- El objetivo es proponer una plataforma alternativa para la gestión de las pymes a sus empresarios.

- El estudio pretende conocer el nivel de aceptación que tendría dicha plataforma entre los empresarios como producto o resultado principal.

\section{Subproductos:}

- Conocimiento de las pymes en aspectos específicos relacionados con el crecimiento.

- Apreciación de las pymes mediante un diagnóstico integral y de enfoque sistémico.

- Argumentos estadísticos para la construcción de una teoría empresarial pyme en México.

- Desarrollar programas de apoyo y soporte para las pymes mexicanas, apegados a sus condiciones y características.

Se establece entonces con estos argumentos que se pretende desarrollar una plataforma para la gestión de pymes alternativa a las existentes y proponerla a empresarios de ese sector. De igual manera, se pretende obtener retroalimentación de éstos para conocer el nivel de aceptación de la plataforma de gestión.

Entre los subproductos de la investigación se aprecia la generación de conocimiento sobre las pymes -en general, sin especificar región, lo que supone un conocimiento generalizado para toda pyme sin importar su tamaño, giro o ubicación geográficatemporal-, orientando su enfoque en el crecimiento de éstas. El término crecimiento está asociado no tanto al tamaño -número de empleados-, sino a un sobreentendido crecimiento económico -mayor cobertura de mercado, incremento 
de producción y ventas, incursión en nuevos mercados, principalmente internacionales-.

El segundo subproducto se vincula al primero al referir una apreciación de las pymes -en general- mediante un diagnóstico integral y de enfoque sistémico. Esto implica una propuesta ambiciosa e interesante al utilizar el adjetivo integral, aunque autolimitado por el llamado enfoque sistémico. Sin especificar, se asume que el enfoque sistémico debe ser el considerado desde la ingeniería -Teoría General de Sistemas, o bien su versión más refinada de Sistemas Complejos Adaptables propia del positivismo hipotético-deductivo, y no referida a la visión de Pensamiento Complejo que cuestiona y critica las versiones anteriores-. El diagnóstico integral se utiliza como un argumento poderoso que evoca un estado ideal que considere todos los problemas, todas las causas, todas las consecuencias, todas las alternativas y todas las soluciones, en el sentido de elección racional. La manera en que se logrará es mediante la abstracción de la pyme como un sistema que puede ser descompuesto en partes - procesos o subsistemas con sus entradas y salidas- en los que se aprecien los problemas o causas que impiden su crecimiento -entropía-, ajustar y agregar elementos para corregirlos -homeóstasis y retroalimentación-, y a su vez considerar la pyme como parte de un sistema mayor -sistema económico- en el que requiere una adaptación o acoplamiento para evitar su expulsión del mismo output, residuo-, es decir, su extinción.

El tercer subproducto planteado por el autor posee el elemento más criticable del documento: la pretensión de una teoría empresarial sobre la pyme en México mediante los argumentos estadísticos obtenidos del estudio descrito previamente. Si bien es cierto que existe un interés amplio en la academia por alcanzar nociones generales que permitan abordar la problemática de las MIPyME's, los esfuerzos hasta ahora realizados muestran lo complicado que es pretender una teoría en torno a éstas, tanto en términos metodológicos como en términos prácticos. La aportación de los estudios cuantitativos -como los del INEGI- desde luego que constituyen un apoyo y aporte invaluable y nada despreciable para la comprensión de las MIPyME's, pero ello no significa que de ella emerjan conclusiones irrefutables y válidas para generalizar a todos los casos, sin importar sus particularidades. Se 
puede decir que es una parcialidad válida, útil e importante, pero que requiere ser complementada. En este punto particular, se ha argumentado ya la debilidad de la construcción estadística propuesta por el autor para su estudio. Por tanto, no se puede pretender la obtención de una teoría a partir de una construcción errónea.

El cuarto subproducto parece entonces desarticulado respecto a los tres anteriores. Al referirse a proponer programas de apoyo y soporte de acuerdo con las condiciones y características de las pymes mexicanas, conlleva un reconocimiento de la peculiaridad de estas organizaciones. Es decir, que las pymes mexicanas son distintas a las de otros países. La profundidad de esta reflexión debería ser mayor al considerar que no sólo se diferencian entre países, sino también al interior de éstos. No sólo su tamaño, sino su giro, su ubicación e incluso la conformación de éstas por humanos con intereses diversos. Esta heterogeneidad resalta entonces la complejidad en el sentido de reflexión, de análisis y de operación en la práctica, antes que en la visión de un sistema complejo adaptable. Entonces, mientras el grueso del argumento apunta a la construcción de una teoría empresarial con fundamentos cuantitativos, el cuarto subproducto cuestiona la pretensión de toda su investigación y su argumentación.

\begin{tabular}{|c|c|}
\hline $\begin{array}{ll}\text { Encuesta } & \text { de } \\
\text { necesidades } & \\
\text { empresariales. } & \end{array}$ & $\begin{array}{l}\text { Permitirá conocer en forma general el tipo de PYMES de la } \\
\text { región, información acerca de: } \\
\text { 1. Su nacimiento, crecimiento y estructura. } \\
\text { 2. Su conformación y la configuración que tiene en } \\
\text { función de los miembros que la forman. } \\
\text { 3. Su capacidad para crecer y consolidar su } \\
\text { crecimiento. } \\
\text { 4. El uso de alternativas para crecer dispuestos } \\
\text { mediante programas de gobierno. } \\
\text { 5. La aceptación de la teoría empresarial propuesta, } \\
\text { soportada por las NOM y las NMX. }\end{array}$ \\
\hline $\begin{array}{l}\text { Diagnóstico de } \\
\text { perfil competitivo. }\end{array}$ & $\begin{array}{l}\text { Permite conocer las prioridades de los empresarios según } \\
\text { su estado organizacional, además de dibujar un perfil } \\
\text { competitivo de cada organización diagnosticada, a partir de } \\
10 \text { aspectos clave de su crecimiento, para determinar: } \\
\text { 1. Sus prioridades de gestión. } \\
\text { 2. Su estado organizacional. } \\
\text { 3. Sus fortalezas y debilidades. }\end{array}$ \\
\hline
\end{tabular}


En la descripción de los instrumentos se aprecia la lógica de la construcción de la investigación referenciada previamente. La encuesta de necesidades empresariales y el diagnóstico de perfil competitivo conforman los medios por los que se obtendrán los datos para el análisis estadístico que da sustento a su propuesta de teoría empresarial y su plataforma de gestión. Se acepta el sondeo para obtener la percepción de los empresarios de lo que creen que sus empresas necesitan, aunque se aprecia la visión funcionalista y preminentemente económica en la reiteración del uso del verbo 'crecer' y su sustantivo 'crecimiento'. Lo que resalta en esta parte es la referencia a un concepto central del texto que, sin embargo, no es definido claramente. El 'estado organizacional' que se determinará a partir de las prioridades expresadas por los empresarios en el instrumento de diagnóstico de perfil competitivo -y que a su vez es el principal insumo para la conformación de éste último-.

\section{Construcción de perfiles competitivos empresariales:}

- La investigación se realizó mediante consulta a las diversas bases de datos de gobierno administradas por sus secretarias de estado, institutos y dependencias, también se incluyeron algunas organizaciones empresariales privadas [...]

- El desarrollo de los perfiles empresariales se realizó (sic) en base a los datos estadísticos, filtrando la información para el Estado de México y la C.D. de México, adicionalmente se agregaron filtros para realizar acomodos convenientes de la información (sic) en base a criterios como:

1. Principales sectores económicos en el país.

2. Proveedores del Gobierno.

3. Registro ante el Sistema Empresarial Mexicano o alguna cámara de representación empresarial.

4. Registro de empresas que exportan sus productos y servicios.

5. Registro de empresas con acuerdos con dependencias de gobierno.

6. Registro de empresas con participación en programas de apoyo de las secretarías de gobierno.

7. Registro de empresas con certificaciones de reconocimiento internacional.

- De estas sub clasificaciones se revisaron el total de empresas que siguen el criterio contra el total de empresas en cada categoría según la secretaría de economía, micros, pequeñas, medianas y grandes empresas. El objetivo de esta revisión y sub clasificación es evidenciar el grado de aprovechamiento de estas oportunidades, por parte de los empresarios, lo 
que genera perfiles empresariales y dibuja el desempeño de sus organizaciones.

- Es importante reconocer que las empresas pueden no estar participando de ninguno de estos programas, o no haberse registrado ante ninguna instancia de gobierno o privada, y sin embargo pueden estar creciendo en forma constante y madurando en cada estado de crecimiento en la forma correcta alcanzando su plenitud, esto clarifica que no es necesariamente una relación directa el crecimiento organizacional ni su madurez una condición asociada a la participación de estas alternativas.

- Este análisis representa una valoración objetiva del desempeño de los empresarios frente al mercado de alternativas que ofrece el gobierno mexicano y la iniciativa privada en México.

- La segunda parte de la investigación, centrada en una propuesta para construir una teoría empresarial sustentada y las herramientas de gestión que requiere, siendo congruente con los requisitos de la mayoría de los programas y alternativas empresariales que oferta el gobierno mexicano a los empresarios, con el fin de impulsar el crecimiento de sus organizaciones. Estas herramientas se sugieren al empresario, porque son requisito de acceso y son en general las siguientes:

1. Perfil competitivo y nivel de madurez organizacional.

2. Plan técnico del negocio.

3. Modelo de negocio.

4. Sistema de gestión.

5. Plan de negocio.

Estas herramientas son un requisito común para la solicitud y participación de la gran mayoría de los programas de apoyo empresarial. Y si bien no en todos estos programas solicitan el total de estas herramientas, es indispensable que el empresario considere su uso como un paquete básico de definición y operación del negocio de su organización. La metodología sugerida para la construcción de estas herramientas fue basada en las diversas convocatorias y reglas de operación de los programas más fuertes de apoyo con financiamiento a fondo perdido, que actualmente oferta el gobierno mexicano.

El cuadro anterior concentra el planteamiento del autor para fundamentar de qué manera ha desarrollado los perfiles competitivos empresariales de su propuesta. Resulta relevante porque de acuerdo con el perfil competitivo que se esboce para cada pyme que participe en el proceso de aceleración se prescribirá la atención que se prestará a sus "prioridades de gestión", sus "fortalezas y debilidades" y se identificará en qué "estado organizacional" se encuentra la pyme. 
Los primeros dos párrafos cumplen la función de argumentos de legitimación que otorgan un halo de cientificidad basado en datos empíricos y estadísticos de fuentes oficiales. Se identifica una deducción implícita en estos puntos en la que parece que existe una correlación positiva entre el desempeño empresarial y el aprovechamiento de los programas de apoyo a pymes. Esto puede demostrarse y tomarse por válido; sin embargo, no debe asumirse como válido para todos los casos y en todo momento. Probabilísticamente se puede argumentar que la probabilidad de que el desempeño de una empresa mejore es mayor si se inscribe en los programas de apoyo. Como en todo ejercicio probabilístico, existe un diferencial que completa el $100 \%$ de las probabilidades y que se relaciona con la probabilidad de que no ocurra lo declarado. Las refutaciones pueden ser tanto empresas con un buen desempeño que no participan de los programas de apoyo, como empresas que sí participan y que sin embargo su desempeño no es el esperado -como lo plantea en el cuarto punto, contradiciendo sus propios planteamientos-.

Esto parece sugerirlo el autor en la primera parte del tercer punto presentado en el cuadro anterior. Lo inquietante es el final del párrafo, en donde se establece una valoración subjetiva del desempeño en la que 'bueno' es igual a mayor aprovechamiento de programas de apoyo, y 'malo' es no participar en los programas. Con esta valoración se "gradúa" a cada caso de pyme a acelerar, en la que parte del proceso se orientará a insertar al mayor número de programas de apoyo y, con ello, a modificar estructuras, procesos y configuración de la pyme para satisfacer los diversos requerimientos para ser considerada candidata a los programas.

Vale la pena rescatar también el hecho de que un número importante de MIPyME's no se registra ante las secretarías, institutos y dependencias gubernamentales $u$ organizaciones empresariales, sea por desconocimiento o por elección racional. El segundo caso tiene que ver con experiencias negativas al haberlo hecho anteriormente, principalmente por la excesiva burocratización, la 
corrupción, la presión por parte de funcionarios, el cobro de cuotas, o el tiempo que demanda la militancia ${ }^{1}$.

En este punto se puede observar retrospectivamente la coherencia de la línea argumentativa de la propuesta y es evidente que la construcción discursiva se encuentra impregnada de supuestos enunciados como verdades dadas por hecho, provenientes del sentido común, del conocimiento popular o de la literatura que sustenta el discurso hegemónico de la Economía ortodoxa, el funcionalismo administrativo y el imperialismo neocolonial que persiste a través del mismo. Resulta relevante recordar que el documento emerge de una institución superior educativa pública cuyo prestigio y diferenciación proviene precisamente de la exaltación de la ciencia y tecnología, con lo que es de esperarse por lo menos un estricto apego al método hipotético-deductivo positivista, lo que justificaría hasta cierto punto un enfoque cuantitativo estadístico como el que se sugiere en el texto. También se esperaría una batería de respaldo de literatura como argumento de evidencia empírica que sustentara los enunciados mostrados hasta ahora, de acuerdo a lo que se acostumbra en las comunidades científicas, recordando que el documento es una propuesta de tesis de grado de maestría. Más aún si se agrega el hecho de que el modelo ya ha sido puesto en práctica, se ha generado una subdirección a la que se le han asignado recursos para materializar la aceleradora, ésta ha sido sujeta a evaluación por un cuerpo de expertos multidisciplinario de la Secretaría de Economía y éste lo ha aprobado y no sólo eso, ha obtenido felicitaciones y premios por su modelo de aceleración.

Si se considera entonces que el documento ha superado múltiples revisiones y observaciones por diferentes expertos tanto del IPN como externos, ¿cómo es que no se han corregido estas inconsistencias? Los resultados de este planteamiento teórico-metodológico se han materializado, están operando y atendiendo cada día a empresas bajo los supuestos antes enlistados. Entonces, ¿en verdad se pueden

\footnotetext{
${ }^{1}$ Rafael Montesinos (2007) dedica una obra sustanciosa a las agrupaciones empresariales para la participación política en defensa e impulso de sus intereses. Para explorar con mayor detenimiento este punto se recomienda a manera de ejemplo el anexo dedicado a los discursos empresariales ( $p .437$ ) en el que confronta discursos de grandes empresarios mexicanos con líderes de confederaciones y con pequeños y medianos empresarios, éstos últimos que ofrecen testimonio de lo enunciado en este párrafo (p. 486-512).
} 
producir empresarios profesionales en serie en México? ¿Cómo se logró generalizar a partir de un estudio de 25 empresarios de la región central -por cierto, con mayor acceso a infraestructura y programas de apoyo, así como mayor concentración de actividad comercial e industrial- una receta igualmente aplicable para las regiones rurales del sur y sureste del país?

A pesar de lo demostrado en este análisis, la aceleradora funciona. Esto implica que las prácticas discursivas desarrolladas en su interior y puestas en marcha en foros destinados a MiPyME's, en reuniones con el INADEM, con la propia Secretaría de Economía, con aceleradoras competidoras, incluso de la talla de Endeavor conformada y respaldada por reconocidos empresarios nacionales e internacionales- o TechBA -con alto impacto en el continente y Europa y en colaboración con FUMEC y el CONACyT- ha logrado posicionar favorablemente su proceso, el mismo proceso emergido del documento referido. No ha sido la solidez teórico-metodológica del modelo o al menos no parece haber jugado un papel determinante como se esperaría. 


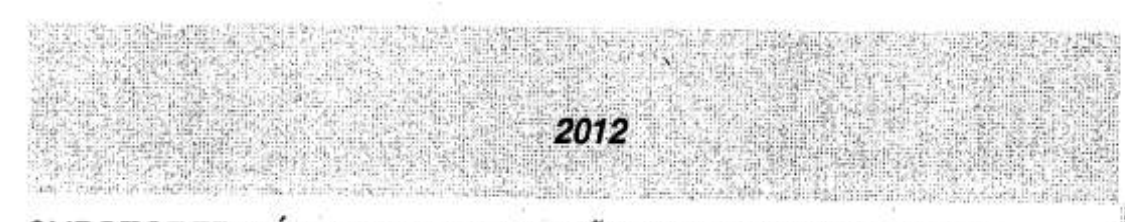

\section{SUBSECRETARIAA PARA LA PEQUEÑA Y MEDIANA EMPRESA DIRECCIÓN GENERAL DE DESARROLLO EMPRESARIAL $Y$ OPORTUNIDADES DE NEGOCIO}

Oficio No. 212.2012 .896 Asunto: Solicitud de Reconocimiento

México, D.F., a 6 ge diciembre de 2012

\section{Fernando Vázquez Torres}

Director Interino de la Unidad

Profesional Interdisciplinaria de

Ingeniería y Ciencias Sociales

PRESENTE

Me refiero a su oficio fechado el 11 de octubre del presente, mediante el cual remite una carpeta con el Modelo de Aceleración de Empresas de la Unidad Profesional Interdisciplinaria de Ingeniería y Ciencias Sociales y Administrativas UPIICSA y EI Centro de Investigación \& Desarrollo de Procesos de Negocios Sociedad Civil.

Al respecto, le comunico que el modelo de aceleración presentado, se pondrá a consideración de la nueva administración que en breve estará recibiendo los asuntos pendientes de esta Direccion General, los cuales ya han sido comentados.

Así mismo y con la intención de que el documento presentado cumpla con lo requerido en el Manual de Procedimientos, le solicito sea enviado a esta oficina el modelo de aceleración en formato digital (C.D.) para incluirlo en la carpeta que contiene dicho modelo

Sin más por el momento, aprovecho la ocasión para enviarle un cordial saludo.

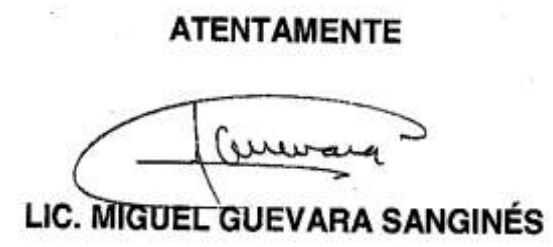

Av. Insurgentes Sur No. 1940, piso 9, Col. Florida, C.P. 01030 , México, D.F. 5229.6100 ext. 32300 


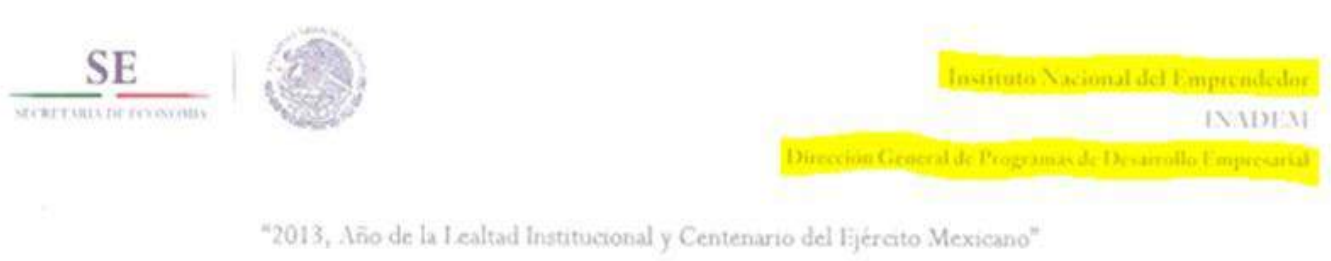

Oficio No. 200.2013.259

Asunto: Resultado Proceso de Reconocimiento México, D.F., a 04 de Julio de 2013.

Dr. Reynold Ramón Farrera Rebollo

Director

Instituto Politécnico Nacional (UPDCE)

\section{PRESENTE}

El Instituto Nacional del Emprendedor en su labor de impulsar estrategias para el ecosistema emprendedor realizó un Proceso de Reconocimiento de Aceleradoras e Incubadoras de empresas que formarán parte de una red de atención a emprendedores para desarrollar empresas y consolidarlas.

Se integró un Comité de Reconocimiento conformado por instituciones del ecosistema emprendedor, dando como resultado un grupo con un enfoque multidisciplinario, que realizó recomendaciones de manera transparente y equitativa alineada a la visión del Instituto Nacional del Emprendedor de generar las condiciones propicias para que las buenas ideas se transformen en empresas exitosas que hagan de México un pais más próspero.

En este sentido le comunico que la aceleradora de empresas Instituto Politécnico Nacional (UPDCE) a la que usted representa ha completado exitosamente el proceso, por lo que el Instituto Nacional del Emprendedor le extiende el reconocimiento para formar parte de la Red de Aceleradoras de Empresas para Mover a México.

Sin más por el momento aprovecho el presente para envar le un cordial saludo.

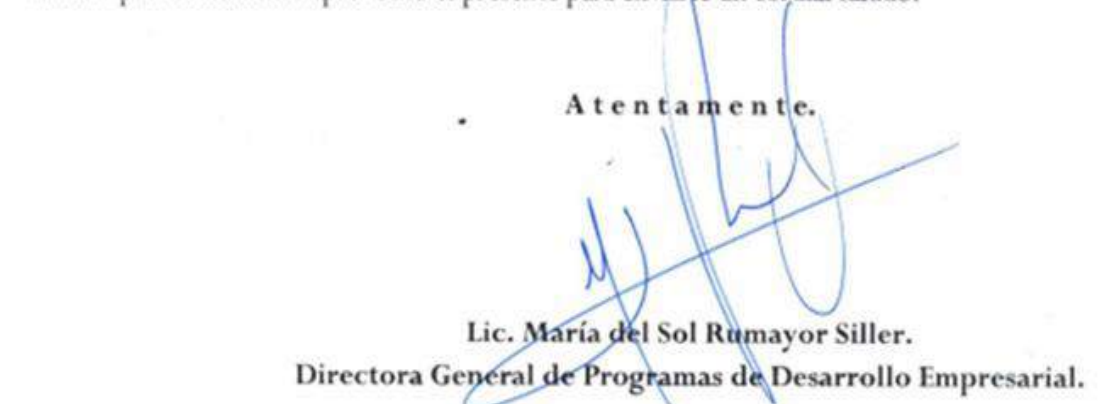




\section{Conclusiones}

Gracias al acercamiento con el Subdirector de Aceleración de la UPDCE, se ha tenido acceso a documentos de carácter confidencial de la unidad, en los que se encuentra sustentada gran parte de la información presentada en el tercer capítulo. Como parte del trabajo de maestría del subdirector (Estudios Interdisciplinarios para Pequeñas y Medianas Empresas del IPN), se ha formulado el modelo de aceleración presentado ante la Secretaría de Economía. Se aprecian virtudes sobre todo en la parte de implementación de normas como parte fundamental del proceso de aceleración. Dado que el documento que fundamenta su modelo se encuentra en proceso de revisión para la obtención del grado y es necesario que se publique por parte del IPN, los detalles continúan siendo de carácter restringido.

Se puede adelantar que se plantea el modelo de aceleración como un modelo propio de la UPDCE, aunque siguiendo los patrones de organismos internacionales como la International Standard Organization, y los argumentos teóricos provenientes de Estados Unidos y Europa, los cuales se pueden encuadrar en lo que se ha expuesto como Teoría de la Organización y acompañado con postulados propios de la Teoría Económica y Estadística como fuentes de legitimación científica. Sin embargo, se encuentran múltiples inconsistencias que no corresponden con el rigor científico que debiera sostener un modelo que busca asegurar el crecimiento de las empresas.

El más destacado es que el modelo de aceleración se basa en un estudio realizado a veinticinco empresas del Distrito Federal y Estado de México, con lo que se pretende argumentar estadísticamente un comportamiento generalizado para todas las MiPyME's mexicanas. No se aprecia un rigor estadístico en la construcción muestral respecto a la población de MiPyME's que presumiblemente existen, tomando como referencia los Censos Económicos del INEGI.

Este modelo se presentó a la Secretaría de Economía y ésta lo ha validado, lo que hace pensar que no ha habido una revisión detallada de los fundamentos argumentativos de la propuesta. No se ponen en duda los resultados que seguramente ofrece, dado que la propuesta de organización con apego a las 
normas mexicanas basadas en ISO representan un ordenamiento lógico que disminuye sustancialmente los problemas de las empresas. Sin embargo, los fundamentos teóricos del modelo presentan cuestiones como que los empresarios son los que deben hacerse cargo de informarse sobre qué programas existen para hacer crecer a su empresa. Otro argumento cuestionable es el de que se puede hablar de una teoría para la empresa mexicana o la conformación de un perfil del empresario mexicano, cayendo en una generalización que se encuentra fundamentada sólo en un estudio de veinticinco empresas de la región central del país, que como se ha visto en el capitulo dos, presenta condiciones muy distintas a la de otros estados.

Actualmente existe la posibilidad de que participar como observador en el proceso de aceleración de la UPDCE, el cual tiene una duración promedio de ocho meses, aunque está sujeto a la confirmación del subdirector de aceleración, quien ya ha externado su interés por la presente investigación.

Respecto a las preguntas planteadas por la investigación, se ofrecen algunos acercamientos sin pretender que sean concluyentes, dado que todavía se encuentra en desarrollo la misma.

1. ¿En qué consiste el modelo de aceleración de empresas, cuál es su fundamento teórico, de dónde surge, cómo se da su reproducción, cuál es el proceso que sigue y cómo son medidos los resultados esperados y los obtenidos?

Luego de la revisión de las propuestas de algunas aceleradoras, se puede establecer que no existe una concertación respecto a lo que implica acelerar, más allá de su relación con el crecimiento económico, lo que da lugar a la variedad de propuestas bajo el término de aceleradoras de empresas o de negocios. Para unas, la aceleración implica vincular con las cadenas productivas, para otras es vincular a las empresas con inversionistas o fondos de apoyo; otras tantas plantean en realidad un modelo de franquicias para expandirse. 
Todas argumentan seguir un modelo propio, aunque en realidad parece ser la imitación o importación de una moda estadounidense, cuyos resultados obtenidos se encuentran relacionados con la vinculación entre las empresas y las universidades y centros de investigación y desarrollo tecnológico, cosa que no sucede en México y que la UPDCE apenas propone un intento.

2. ¿Por qué se busca acelerar a empresas de base tecnológica, cómo se sustenta este objetivo y de qué manera se legitima y promueve, qué importancia tiene en México para el desarrollo en los pilares económico, social y ecológico?

El interés particular por la aceleración del crecimiento de empresas de base tecnológica se encuentra sustentado en la literatura económica que argumenta que la clave del éxito económico de los países desarrollados se encuentra en el agregado de valor de sus bienes de calidad de exportación, mismos que obtienen un alto valor agregado a través de la innovación y la ciencia y tecnología aplicada en ellos. Por tal razón, la estrategia sugerida es la conformación de una planta productiva que explote los conocimientos aplicados desarrollados para aprovechar los recursos con que cuenta el país, así como las condiciones socioeconómicas y políticas del mismo en la construcción de una sinergia que llevará al desarrollo económico.

Sin embargo, en México se puede apreciar un mayor interés en la aceleración de negocios más que en empresas de base tecnológica, lo que impide lo anterior al no incentivar la innovación y el desarrollo científico y tecnológico, ni su aprovechamiento tanto para la consolidación de la planta productiva ni el desarrollo económico. La proliferación de negocios no asegura el encadenamiento productivo ni la generación de valor, y sí resulta vulnerable a la inestabilidad económica y financiera.

Adicionalmente se destaca un énfasis notable en el crecimiento económico, o bien, en el desarrollo económico -al menos discursivamente-. Sin embargo, se 
aprecia menos la atención al desarrollo social y ambiental como parte de un desarrollo sostenible. Se argumenta que el desarrollo económico trae consigo el desarrollo en los otros dos pilares, aunque se ha demostrado que la riqueza no necesariamente genera mejores índices de desarrollo humano si la riqueza generada no es redistribuida se queda acumulada en unas cuantas manos.

3. ¿Cuál es la relación entre el discurso y la transferencia de modelos organizacionales en el caso de las aceleradoras de empresas de base tecnológica en México? ¿Las prácticas de transferencia de modelos como modas han incidido en la crisis de desarrollo industrial en México?

La relación se encuentra en que mediante el discurso o prácticas discursivas se promueve y legitima la transferencia de modelos organizacionales bajo argumentos como las "mejores prácticas", lo cual supone por un lado el ahorro de tiempo y recursos en el análisis de la organización, es decir, en el proceso racional de identificar lo que requiere una organización particular. Resulta más práctico y económico adoptar o imitar lo que otras organizaciones hacen, suponiendo que si a esas organizaciones les funciona y son exitosas, entonces hay que imitarlas.

Los argumentos de crecimiento económico se encuentran dictados por organismos internacionales como la OCDE, el FMI, el BM, el Consenso de Washington o la UNESCO. Algo similar ocurre con la normalización de calidad, seguridad y ambiental, a través del ISO. Esto implica una subordinación a criterios ajenos basados en una homogenización que reduce las explicaciones a términos económicos y que desconoce la complejidad particular de cada país.

4. ¿De qué manera podría ser reconfigurado el modelo de aceleración para incrementar su pertinencia y apropiación en México (si es el caso)? 
Es innegable la buena intención con que se actúa al buscar la consolidación de empresas y su crecimiento económico. Sin embargo, la adopción de estos modelos sin realizar un análisis cuidadoso de sus beneficios y consecuencias, ni considerar el conocimiento disponible de otros aspectos propios del país, parece estar llevando a una simple imitación o una implantación del modelo, pasando por alto que la estructura económica, política, industrial y cultural del país que prescribe los modelos es significativamente diferente a la del país receptor.

Como resultado de la exposición de los avances de la investigación en el transcurso de la misma ante compañeros del propio posgrado en Estudios Organizacionales maestría y doctorado-, así como ante diversos académicos expertos en diversos temas relacionados o afines, se han concentrado en este apartado las preguntas que se han planteado al autor, con el propósito de ofrecer una respuesta que permita esclarecer las lagunas que voluntaria o involuntariamente hayan emergido al respecto. Estas respuestas constituyen una reflexión más detenida que permite al autor ofrecer su punto de vista a los cuestionamientos señalados por sus interlocutores en diferentes momentos y que son considerados parte importante dentro del espíritu de los Estudios Organizacionales de establecer una serie de conversaciones, un diálogo y un puente entre disciplinas y expertos de diferentes áreas con el propósito de construir conocimiento de utilidad y con mayores bases de legitimidad. Por tanto, se encuentran sujetas también a debate y controversia, antes que significar un cierre dogmático y una cancelación de la discusión.

Se ha argumentado en este documento la hegemonía discursiva de la Economía como ciencia rectora en las Ciencias Sociales, dada su base en argumentos cuantitativos, modelación de escenarios, elecciones racionales, variables medibles y la supuesta objetivación de la realidad que aborda. Esto le otorga cierta legitimidad ante otras ciencias -las duras y las aplicadas- y éstas la reconocen como tal al tratar de ceñirse al método hipotético-deductivo positivista. Se ha argumentado también cómo este discurso dominante ha sido la base de la teoría de la 
organización ortodoxa, subordinando otras contribuciones a la lógica de la racionalidad económica. De tal manera, se puede argumentar que la conciencia teórica de la práctica administrativa -la ejecución/implementación/acción- ha sido la Teoría económica.

De lo anterior se desprende entonces que existen diversos factores que facilitan el florecimiento de modelos de aceleración, lo cual es considerado una moda de gestión en este documento. En principio, la lógica económica se ha implantado en la gran mayoría de los países occidentales y en algunos referentes importantes del mundo oriental. Desde los trabajos de Smith, Ricardo y Marx -por ser éstos los más reconocidos, sin que sean los únicos- se ha señalado el ascenso del modo de producción capitalista y sus implicaciones. Si bien se han erigido numerosas críticas tanto teóricas como políticas, lo cierto es que sigue siendo el principal modo de producción y sistema político-económico en el mundo. El propio sistema desarrolla mecanismos de preservación que aseguren su perpetuidad, contrarrestando las anomalías o minimizándolas, así como suprimiendo o asimilando las amenazas al mismo.

La adhesión a la comunidad de naciones unidas y sus organismos implica enfrentar fuerzas o tensiones que demandan la adopción de políticas macroeconómicas como condición para recibir los apoyos y otros beneficios a los que se tiene acceso por medio de éstos. Se trae a manera de ejemplo el caso de los países sumidos en crisis, a los considerados tercermundistas, subdesarrollados o en vías de desarrollo. La necesidad de participar en los mercados internacionales y de hacerlo en condiciones mínimas que puedan calificarse como 'competitivas', conlleva ajustes de acuerdo a los dictados económicos internacionales. Negarse significa enfrentar cierre de fronteras, altos aranceles e incluso bloqueos económicos, es decir, mayores obstáculos para superar sus problemas y para poder hacerlo por sus propios medios.

Por otro lado, las disposiciones internacionales se establecen desde los 'evangelizadores' del desarrollo, es decir, los países industrializados, con mayor tecnología, los que cuentan con las mejores universidades y mayor número de 
premios nobel, lo cual parece otorgarles el derecho, la legitimidad y la misión de llevar el desarrollo a los desfavorecidos, a los paganos que no han sido iluminados. Basta revisar los programas universitarios y las bibliografías que se utilizan para encontrar el rastro de editoriales y autores estadounidenses o europeos. De esta manera, la formación de las nuevas generaciones se lleva a cabo por adoctrinamiento para aprender, reproducir, fortalecer y perpetuar un discurso que favorece el sistema. Los estudios de caso de éxito, las teorías y doctrinas, los métodos, instrumentos y técnicas son los que se señalan desde realidades ajenas, que no corresponden a las particularidades locales.

Los dos puntos anteriores permiten construir entonces el escenario en el que florecen modas de gestión tanto en el gobierno como en el sector privado. La formación de profesionales que tomarán decisiones como se les ha enseñado a tomarlas -racionalidad instrumental y económica-, a resolver problemas como han aprendido a resolverlos -manuales y bestsellers importados, o recurrir a consultores internacionales-, buscar la aprobación de externos -adscripción a organismos internacionales, firma de tratados, certificaciones de calidad, ambientales, etc.-, un entorno de competencia internacional feroz en el que la duda para tomar una decisión rápida significa pérdidas millonarias, y la dependencia de apoyos externos -económicos, teóricos, ideológicos, políticos, bélicos- conforman un campo fértil para la adopción de modas de gestión externas como algo natural y positivo.

Se puede interpretar la respuesta anterior como una determinación a condiciones estructurales o sistémicas de las que los sujetos son simples entes pasivos que reaccionan ante los estímulos de las mismas, sin capacidad creativa o de resistencia e insubordinación. En realidad, se plantea lo contrario. Si bien es innegable la existencia de las condiciones mencionadas, también lo es el surgimiento de movimientos tanto teóricos como políticos que buscan contrarrestar y que equilibran en algunos casos la situación. Pueden citarse las utopías de Saint-Simon, Owen o Fourier, la propuesta de Marx y los intentos socialistas y comunistas, los multicitados casos de los países nórdicos o las economías mixtas, las formas de organización cooperativa, la tentativa de áreas o regiones comunes de comercio como la europea, asiática o sudamericana, por señalar algunos ejemplos. 
En el ámbito académico se vive actualmente un periodo prometedor ante la crisis de la teoría económica ortodoxa en sus propias entrañas, ante la rebelión que los propios estudiantes de economía han iniciado en contra de sus profesores y facultades para exigir la inclusión de alternativas de análisis económico y de teorías económicas heterodoxas. Se ha hecho énfasis en el primer capítulo sobre la emergencia de los Estudios Organizacionales para cuestionar la ortodoxia de la Teoría de la Organización. Otros movimientos críticos contribuyen a ejercer una fuerza de resistencia, como el caso de los Estudios Críticos en Administración (Crítical Management Studies), la Etnoeconomía, el Pensamiento Complejo, las Epistemologías del Sur, el Análisis Crítico del Discurso, etc.

Si bien no existe un consenso ni un programa en común, constituyen una fuente de alternativas que permiten formar profesionales y tomadores de decisiones con enfoques alternos, y en la medida en que se incrementen estas posturas críticas, se puede esperar la conformación de nuevas propuestas teóricas y alternativas de solución innovadoras a los problemas.

Los obstáculos que enfrentan los modelos de aceleración son los intrínsecos. Esto es, hasta ahora su mayor preocupación son sus propias inconsistencias tanto de fundamento como de ejecución. Por lo expuesto en la pregunta uno de este apartado, la poca difusión de alternativas a la corriente dominante hace que se ignoren o no se cuestionen sus falacias, adoptándose como se ha expuesto en los ministerios de Estado sin mayores problemas. Parece importar poco las estadísticas de mortandad de las empresas apoyadas y el contraste entre los recursos destinados y los casos exitosos -pensando en términos de eficacia y eficiencia-. Las explicaciones ofrecidas se atribuyen a externalidades o contingencias, términos etéreos que no referencian a culpables de carne y hueso.

Como toda moda, ésta 'pasará de moda' en algún momento, por lo que no será necesario esperar el colapso del modo de producción o del sistema políticoeconómico, simplemente la emergencia de una nueva moda propuesta por un nuevo gurú en un nuevo bestseller e impulsado, validado y legitimado por el discurso hegemónico. 
Sus obstáculos inmediatos son la falta de difusión y la falta de consenso respecto a lo que significa 'acelerar'. Esto es, están de acuerdo en la metáfora del verbo que implica aumentar la velocidad del crecimiento de la empresa, pero no hay consenso en la mejor manera de hacerlo, pues mientras para unos el camino es conceder franquicias, para otros implica obtener financiamiento público o privado, o bien, asociarse con empresas tractoras en cadenas productivas, o tal vez, expandir su mercado hacia el exterior, e incluso normalizar sus procesos de acuerdo a estándares internacionales. Estas discusiones permanecen ajenas a los empresarios que desconocen el debate teórico y las inconsistencias internas de las aceleradoras. La lógica del empresario que asume que su empresa o negocio debe crecer y debe ofrecer cada vez mayores ganancias y atender a más clientes lo lleva a identificarse con los cantos de sirena del discurso hegemónico que promete todo eso y más con letras pequeñas y aplican restricciones.

En el caso de estudio abordado se contemplan las normas oficiales mexicanas del Sistema Mexicano de Metrología, Normalización y Evaluación de la Conformidad (SISMMENEC), así como las normas ISO para el ámbito internacional. Esto implica las versiones ISO 14000 y 26000 de responsabilidad ambiental y social respectivamente.

La dimensión social y ambiental, en conjunto con la dimensión económica, constituyen el centro de discusión respecto al Desarrollo sostenible/sustentable de los últimos treinta años. Por tanto, se ha convertido en un aspecto que no puede evadirse. Sin embargo, en la práctica la dimensión económica subordina a las otras dos dimensiones de múltiples formas, una de ellas la que se ha expuesto en este documento. Por tanto, estas normas son adoptadas como estrategia de competencia, aquellos que cuentan con la certificación son convidados a la competencia, mientras que aquellos que no cuentan con ella son relegados. Esto no es con el fin de asegurar la reivindicación social y medioambiental sino como barrera administrativa a los competidores. No es difícil encontrar casos de empresas con todas las certificaciones que sin embargo implementan reingeniería de procesos recortando personal o subcontratándolo, es decir, mientras se cuenta por 
un lado con la certificación internacional de responsabilidad social, por el otro se violenta lo social para resguardar el beneficio económico.

Se identificó de igual manera que no es homogénea la consideración de estas dimensiones en el resto de las aceleradoras, pues todas hacen énfasis en la dimensión económica -aceleración del crecimiento- antes que en las otras dimensiones -aceleración del desarrollo social o ambiental-. Si bien se puede argumentar que las empresas o negocios privados tienen como prioridad la generación de beneficios -riqueza-, éstos deben cumplir con un compromiso social y ambiental con la comunidad que las cobija y ofrece los medios y la mano de obra para que ésta emerja y pueda operar. Por tanto, esta empresa o negocio se vuelve contra los que lo protegieron para su florecimiento, actitud propia del individualismo occidental y trasladado a las creaciones de éste.

En realidad el interés que originó la investigación siempre ha estado centrado en las aceleradoras como organizaciones. De ello se ha desprendido el observar también el proceso de aceleración como un modelo de gestión y como una forma de organización o de intervención. De aquí, el siguiente paso fue pensar en el verbo acelerar como una acción llevada a cabo por alguien, en este caso un grupo de personas organizadas y constituidas legalmente como aceleradoras. Esta acción tiene una incidencia sobre alguien más, en este caso, las empresas aceleradas. Para participar en los programas de aceleración, uno de los requisitos es ser considerada una empresa 'gacela', es decir, metafóricamente, una empresa pequeña o mediana con un rápido crecimiento sostenido en los últimos años, los cuales también son los primeros de la misma. Entonces, el término 'gacela' lleva a contemplar el vasto campo de las MiPyME's, en las que se encuentran insertas las primeras y en donde la primera exclusión del término es no considerar a las Micros como 'gacelas' ni a todas las pequeñas y medianas empresas, sino sólo a las de ritmo rápido y sostenido -como las gacelas- de crecimiento en cuanto a ventas y cobertura de mercado. Esto lleva a la reflexión de que si estas empresas 'gacela' han tenido ese crecimiento vertiginoso y sostenido sin ningún apoyo para su 'aceleración', ¿por qué ahora necesitarían de este apoyo? La respuesta obvia e inmediata es el estancamiento de su crecimiento, por lo que, para seguir creciendo 
y eventualmente mudar de pequeñas o medianas 'gacelas' a grandes empresas, incluso 'tractoras' para seguir con las metáforas utilizadas por la Secretaría de Economía y el discurso de la aceleración.

Por tanto, este estancamiento nos remite nuevamente a la problemática que enfrentan las MiPyME's mexicanas, vistas como bloque homogéneo. Sin embargo, como se ha argumentado en el documento, la heterogeneidad tanto de región como de sector y de tamaño hace que la problemática que enfrenta cada organización de este campo sea diferente, por tanto, no pueden aplicarse medidas homogéneas a problemas heterogéneos. En principio, estos párrafos constituyeron la lógica argumentativa que resulto insuficiente ante las primeras exposiciones del protocolo de investigación, por lo que resulto necesario extender y profundizar -relativamente, pues no se considera un estudio exhaustivo- el apartado de las MiPyME's.

De igual manera, al establecer la heterogeneidad de organizaciones en el ámbito teórico, resulta evidente que existen relaciones entre éstas. En este caso, la primera obvia es la relación entre una organización empresarial -la 'gacela' pequeña o mediana- y la organización aceleradora -una consultora, una subdirección de un instituto público de educación superior, un grupo financiero, una universidad privada. Si se considera la particularidad de la primera -su región, su ramo y su tamaño- y de la segunda -su fin y su carácter público o privado-, comienza la complejidad de establecer relaciones y generalizaciones con pretensión de teoría.

La complejidad se incrementa al considerar que no sólo existen estas relaciones, sino que otras organizaciones se encuentran también involucradas: proveedoras (materias primas, financiamiento, personal, servicios), competidoras (sean bienes o servicios competidores, sustitutos o complementarios), clientes (intermediarios, consumidores finales), así como del Estado (Hacienda pública, Salud, Medio Ambiente, Seguridad Social, del trabajo, etc.).Por tanto, abordar el tema de la aceleración y del discurso sin argumentar previamente lo descrito proyectaría la ilusión de una investigación superficial y poco seria, lo cual no ha sido el objetivo del investigador. 
Desde la óptica del autor, no se considera exhaustivo el abordaje de la Teoría de la Organización y la emergencia de los Estudios Organizacionales. Al contrario, se supone que se ofrece un ejercicio escueto, partiendo del supuesto de que si existe interés en profundizar en ello, los referentes bibliográficos serán de utilidad para remitirse a esa discusión. Sin embargo, no puede partirse de la nada, es necesario fundamentar las bases teóricas. Esta investigación se inscribe en el campo de los Estudios Organizacionales, tratando de recuperar los aportes de la ortodoxia de la Teoría de la Organización cuando sean pertinentes, así como de las disciplinas que puedan ofrecer soporte para esclarecer ciertos aspectos. Por ejemplo: La Economía brinda la explicación de la lógica macroeconómica en las políticas de desarrollo industrial y en las decisiones microeconómicas de las empresas que buscan incrementar sus ventas y expandir sus mercados. La Linguïstica, la Semiótica, la Hermenéutica ofrecen instrumentos y explicaciones para abordar el aspecto discursivo que se ha resaltado en la investigación.

Sin embargo, es necesario precisar y anclar los fundamentos teóricos y metodológicos desde el principio, sin que por ello se desarrolle todo un estado del arte, ya que esa tarea ya ha sido llevada a cabo y se puede encontrar en los aclamados Handbooks de la Teoría de la Organización y de los Estudios Organizacionales.

Este cuestionamiento se encuentra vigente, principalmente por la incursión reciente de las universidades privadas en el presupuesto para investigación del CONACyT. Como punto de vista, no se considera ni nuevo ni necesariamente ni censurable, pues muchas veces en distintos momentos de la historia y en distintos lugares del mundo se han invertido recursos públicos en 'empresas privadas', pues esto supone no sólo beneficio para los privados, sino un beneficio mayor que se extiende hasta el bienestar social. Sin embargo, es necesario dejar en claro previamente si de verdad se lograrán los beneficios esperados y prometidos, si estas 'empresas' además de beneficios generarán afectaciones o agravarán los problemas ya existentes. 
Esto se puede lograr mediante la cuidadosa valoración de los proyectos que la administración pública considerará. Es en este sentido que se ha desarrollado la presente investigación, pues se ha argumentado la adopción de la moda por parte del ministerio de Economía sin considerar lo previamente expuesto, es decir, sin la suficiente valoración crítica. Por tanto, el problema no es tanto si se destinan recursos públicos a emprendimientos privados, sino que los beneficios de éstos no retribuyan y sí perjudiquen social, ambiental y hasta económicamente a la comunidad en su conjunto. Nuevamente, el problema no está -desde la perspectiva del autor- en destinar recursos públicos, sino en descuidar a dónde van a parar esos recursos, con qué intensión se utilizarán y no existir un control, evaluación y rendición de cuentas de esos recursos por parte de la administración pública y de los privados beneficiados.

Esta controversia ha sido constante en las diversas presentaciones de la investigación, lo que descubre la falta de consenso sobre conceptos fundamentales sobre los que se construye teoría y se formulan soluciones y recetas. Existe la facción que defiende como sinónimos indistintamente Empresa y Negocio. Se puede advertir en toda la trama discursiva de la aceleración en México, en donde 'Aceleradora de Negocios' o 'Business Accelerator' se utiliza indistintamente y con la misma connotación que el término de 'Aceleradora de empresas'.

La investigación se desarrolla en torno a la convicción de que los conceptos de Empresa y Negocio son distintos. El primer argumento es el etimológico: Negocio refiere a la negación del ocio (del latín negotium), es decir, la actividad que se emprende en el tiempo libre, en el cual se puede optar entre el ocio u otra actividad productiva o que devuelva algún tipo de beneficio. Elegir en la decisión entre el ocio y lo segundo, es el negocio.

Por otro lado, Empresa parece compartir su raíz etimológica con el verbo emprender (del latinprae [antes] -endere [agarrar, atrapar, sujetar]), -del cual se derivan emprendimiento, emprendedor y empresario. Emprender como verbo implica la acción realizada por un sujeto. Por tanto, la Empresa es la acción en marcha o en curso, ya iniciada por el sujeto, en participio irregular con voz femenina, según las 
reglas del español-castellano. De acuerdo con lo anterior, el participio irregular se caracteriza por las terminaciones -to, -so, -cho, como en escrito, occiso y dicho. Estos a su vez pueden tener voz femenina: escrita, occisa, dicha. Una particularidad del participio en el español es su rasgo compartido con adjetivos y verbos, por ejemplo: abstraer (abstraído y abstracto) o bendecir (bendecido y bendito). En este caso, se puede homologar con el verbo recluír (recluído y recluso), que si se cambia a voz femenina queda recluída y reclusa. Como se señaló, emprender deviene de su raíz etimológicaprae-endere, por lo que al traerlo al español comparte también la particularidad del participio: una actividad emprendida, un emprendimiento, una empresa. Quien lleva a cabo tal, es un emprendedor o un empresario.

Hasta este punto no hay divergencia, pues se puede establecer la línea entre comenzar una empresa como negación del ocio. De hecho, en el inglés no hay diferenciación entre uno y otro. Sin embargo, como los conceptos cambian con el tiempo, el uso de las palabras ha sido resignificado, pues cabe recordar que el término 'empresa' no existía en la época de los romanos. En la edad media, comenzar una expedición de conquista, una cruzada o alguna otra actividad que reportara beneficios a quienes la emprendían se podía considerar una empresa. Pero es hasta la transformación del taller artesano en fabril y el advenimiento de la revolución industrial que cobra fuerza el término de empresa para referirse a la inversión de capital en el montaje de un edificio con maquinaria para la producción de bienes mercancías que redituarían un plus-valor, lo que otorga entonces el sentido de beneficio económico al término 'negocio'.

Pero desde la época en que una fábrica, una empresa y un negocio podían homologarse como sinónimos ha pasado mucho tiempo y las transformaciones del modo de producción y del sistema socio-político han sido vertiginosos. De tal manera que, si se considera la separación entre sectores primario, secundario y terciario, en sentido estricto puede considerarse cualquiera de estas actividades como 'negación del ocio', pero no con la connotación de transformación o manufactura que había adquirido el término 'empresa', pues éste se concentraría en el sector secundario solamente. El sentido de negocio, significado como beneficio económico por una actividad, se destacaría en el sector terciario, es decir, 
el de servicios privados, pues estos implican una actividad o trabajo en el que no hay transformación o manipulación material, y cuyo valor agregado es simbólico, intangible, mediado entre el prestador y el cliente.

Para aclarar este argumento se propone el ejemplo del comercio, catalogado en el sector terciario o de servicios. Los insumos para la actividad comercial son bienes mercancías terminados. La transformación se ha dado en un proceso ajeno en el que se ha dado su presentación final. El comerciante, sea mayorista o menudista, asume la actividad de adquirir estas mercancías mediante contrato de compraventa, con el que obtiene el derecho de propiedad. El traslado, almacenaje, exhibicióny promoción de las mercancías permite llevar a una nueva operación de compra-venta, en la que el comerciante -comprador en el primer momento- funge ahora como vendedor. Éste establece un diferencial entre el monto al que adquirió la mercancía y el monto al que trasladará la propiedad. Esta diferencia implica una ganancia, descontando los costos de operación, un plusvalor, o bien, un negocio. Las mercancías no sufrieron transformación o manufactura alguna, sin embargo, gracias a la habilidad y visión del comerciante, éstas incrementaron su valor ante el nuevo comprador, quien ha estado dispuesto a desembolsar un precio mayor, pues desconoce su costo de producción y el monto al que fue adquirido por el comerciante, además de que la apreciación valorativa del comprador sobre la mercancía es tal para acceder a desprenderse de la cantidad de dinero demandada por el vendedor.

De lo anterior se puede concluir que, siguiendo los argumentos de la competitividad basada en el agregado de valor en la transformación -sector secundario- que constituye la base de las políticas de desarrollo industrial, no es lo mismo la creación de empresas que la creación de negocios, pues éstos son más vulnerables a la inestabilidad de los mercados, los precios, los cambios de divisas, etc. Fincar la economía de un país sobre terreno tan inestable significaría una catástrofe. La apuesta por el sector secundario, apuntalada con inversión en educación, en ciencia y tecnología e investigación y desarrollo, parece una alternativa más confiable, pues se han observado casos de economías que han prosperado al adoptar estas medidas (Alemania, Japón, Estados Unidos, recientemente Brasil, China, India). 
Para el caso abordado por la investigación presentada en este documento se puede entonces argumentar que mientras se mantenga la idea de considerar empresa y negocio como sinónimos (aceleradoras de empresas / aceleradoras de negocios), existirá una tendencia a acelerar en la práctica negocios antes que empresas. Esto se acentúa más al agregar el calificativo 'de base tecnológica', pues la noción es apostar precisamente por aquellas pequeñas y medianas empresas que explotan un nicho de mercado de tecnología de vanguardia sobre el que se pueden fincar expectativas de desarrollo, gracias al alto grado de valor que pueden alcanzar sus productos o servicios. Pero la realidad mexicana muestra que las aceleradoras se preocupan más por negocios, puesto que requieren de menos tiempo, inversión y trabajo para obtener resultados visibles que puedan ser exhibidos como casos de éxito que legitimen su operación. 


\section{BIBLIOGRAFÍA}

Brewerton, Paul y Lynne Millward (2001), Organizational Research Methods: A guide for Students and Researchers, SAGE, London.

Instituto Politécnico Nacional (2012), Historia de la UPDCE, Secretaría de Extensión e Integración Social IPN, México.

Montesinos, Rafael (2007), El discurso político de las organizaciones empresariales. La transición mexicana desde la teoría de los sistemas, Universidad Autónoma Metropolitana Unidad Iztapalapa, México, D.F.

Morales López, Valentino (2008), "Análisis epistemológico de los estudios organizacionales", en VI Congreso Internacional de Análisis Organizacional 2008, Perspectivas multidisciplinarias en Análisis Organizacional: Complejidad, Ambigüedad y Subjetividad, Nayarit.

Pacheco, Arturo (2013), El problema (reto) metodológico en el análisis socioorganizacional, Material de apoyo visual (diapositivas) para el Seminario de Investigación II del Doctorado en Estudios Organizacionales de la Universidad Autónoma Metropolitana-Unidad Iztapalapa, México. 


\section{Conclusiones de la investigación}

Los propósitos de la investigación buscaban generar conocimiento respecto a las aceleradoras de empresas. Se partió del supuesto de un fenómeno emergente en la cotidianidad mexicana, circunscrito al ámbito de negocios y extendido a los sectores productivos extracción, manufactura y servicios.

Mientras se piensa en aceleración de negocios, se abarca toda actividad económica que retribuya económicamente, excluyendo empresas estatales y organizaciones no gubernamentales sin fines de lucro. Por tanto, el comercio, entendido como una acción intermediaria de compra y reventa, o bien negocios tradicionales como tiendas, estéticas, tortillerías o restaurantes se pueden catalogar como negocios y son sujetos de ser acelerados por este tipo de organizaciones.

Referirse a aceleración de empresas evoca a pensar en el ramo industrial o de transformación -sector secundario-, en donde los conceptos de competitividad, valor agregado, innovación y nichos de mercado son más tangibles y se cuenta con mayor potencial de desarrollarlos o acelerarlos. La precisión o especificidad del concepto 'aceleración de empresas de base tecnológica' hace un mayor énfasis en esos elementos, esto es, que la operación principal de la empresa se basa en tecnología, sea en la extracción, manufactura e incluso en el servicio que presta, valiéndose por ejemplo de Tecnologías de información y comunicación o aprovechando nuevos implementos como el uso de drones o el internet de las cosas (loT).

El punto clave se encuentra entonces en cómo la generación de empresas con un potencial de rápido crecimiento basado en tecnología se encuentra reflejado en su resistencia a los factores que inciden en la mortandad de las nuevas empresas en los primeros años de operación, en donde lejos de batallar con su supervivencia, logran una consolidación y crecimiento meteórico evidente en su conquista de mercados, altas ventas y con ello de ganancias, un periodo de 
recuperación de la inversión mucho más corto, sensibilidad y adaptación al entorno turbulento, capacidad para continuar generando innovaciones y nuevos nichos de mercado, adoptar o desarrollar tecnología en sus operaciones, convertirse en una fuente de empleo estable y creciente, e incluso, cumplir con la expectativa de "crecer" de MIPyME a gran empresa, no por sus dimensiones físicas o número de trabajadores, sino por la riqueza generada y los mercados conquistados.

Como se ha referido en la investigación, la lógica de origen se encuentra precisamente en la aceleración de sectores como la microelectrónica y la informática que cumplieron en ese momento con todas esas condiciones, por lo que se convirtió en una práctica digna de imitar, replicar y exportar -o importar, según la perspectiva-. En cuanto a los perfiles objetivo de la aceleración de base tecnológica se encuentran la biotecnología, dispositivos médicos, pruebas clínicas, nuevos fármacos, mecatrónica y manufactura avanzada, Tecnologías de la Información y Comunicación, -cómputo en la nube, tecnologías móviles, multimedia-, que pueden considerarse nichos de mercado; o bien desplazar las fronteras por medio de la innovación en sectores como la química, petroquímica, tecnologías limpias -energía alternativa, construcción sustentable, protección de biodiversidad, consumo sustentable, reciclado, tratamiento de residuos, purificación de agua y aire-, y sector alimenticio y agroindustrial.

No está puesto a debate el beneficio que representa el apoyo a estos sectores, pues es evidente que éstos sobrepasan los económicos de los empresarios 0 accionistas, pues beneficia en términos macroeconómicos al país con la generación de patentes, el impacto en la balanza comercial y de pagos, así como en la generación de empleos, el poder adquisitivo de las familias, el PIB nacional y per cápita, el dinamismo que adquiere el mercado interno y su participación en el exterior, el fortalecimiento de la planta industrial nacional. Teóricamente estos beneficios económicos deben impactar positivamente en los ámbitos social y ambiental, como se aspira en el ideal del desarrollo sostenible, por lo que se convierten en poderosos argumentos para legitimar ante el gobierno y la 
sociedad. No es de extrañar por tanto su reiteración en las prácticas discursivas y en los textos producidos. La comparación con el éxito vertiginoso observable en el Silicon Valley y las historias de empresas como Microsoft, Apple, Intel, Google y tantas otras, así como la legitimidad que otorga el soporte de universidades como Harvard, Stanford, CalTech o el MIT constituyen un referente que deja poco espacio para el cuestionamiento.

Sin embargo, hay aspectos que se pueden revisar críticamente con un propósito constructivo y complementario que enriquezca el modelo tanto en la teoría como en la práctica.

En la revisión a corto plazo -comprendido en el momento de emergencia de las aceleradoras en los años noventas hasta la actualidad- se tiene la impresión de una estrategia progresista basada en la tecnología. Al ampliarse el rastreo de los fundamentos argumentativos del discurso de aceleración, éste forma parte del discurso liberal positivista -orden y progreso basado en la ciencia-, cuyas raíces son más profundas. De igual manera se vincula al discurso del desarrollo que los organismos internacionales de la ONU gestionan desde su creación a mediados del siglo XX. En el caso latinoamericano existe una tradición teórica al respecto desde la CEPAL y las teorías del desarrollo-dependencia que se han inscrito en el debate internacional.

Ambos aspectos coinciden en la complejidad de teorizar acerca del desarrollo y de la planeación e implementación de políticas públicas que logren un desarrollo real. Por tanto se requiere ampliar las explicaciones y aportaciones de la teoría económica, por medio de la colaboración de otras ciencias y disciplinas para una mayor comprensión de esta complejidad. Visto desde esta óptica, el abordar el caso de la aceleración de empresas no representa más que una pieza de un rompecabezas mayor. Sin embargo, por la interconexión de los ámbitos económico, político, social y ambiental, característicos de la complejidad, cada modificación, aun siendo ligera, incide de diferentes maneras y con múltiples intensidades en el resto del conjunto. 
Lo anterior sustenta el argumento del autor al plantear un abordaje crítico del caso de la aceleración de empresas más allá de una lógica económica y de negocios. La perspectiva organizacional se constituye así como una alternativa que puede complementar lo generado para ampliar su impacto positivamente. Si bien en términos metodológicos puede abordarse con diferentes métodos e instrumentos de que disponen los Estudios Organizacionales, la elección del autor por el análisis del discurso es solamente una que permite arrojar hallazgos sobre el tema, sin pretender que sea la única ni la mejor alternativa.

De hecho, uno de los retos se encuentra en la formación y propuesta de una agenda de investigación que permita extraer más conocimiento del fenómeno, dar cuenta de la dinámica a través del tiempo y proponer incluso áreas de oportunidad de mejora. De igual manera, la diversidad de perspectivas de análisis de discurso y la falta de consenso de los especialistas obliga a elegir una postura, lo cual lleva una carga subjetiva por parte del investigador. El conocer el interior de las aceleradoras, adentrarse en su dinámica cotidiana resulta útil para determinar qué método puede ser más adecuado para el caso particular, y dado el hermetismo mostrado por las aceleradoras, ha influido para la elección de partir de lo que se encuentra más accesible, con miras a generar interés en esas organizaciones y conseguir mayor acceso a las mismas. Por tanto, no puede hablarse de conclusiones finales de la investigación, sino de un corte y reporte de lo avanzado hasta ahora.

Entretejer los argumentos discursivos del liberalismo positivista con el desarrollismo y las teorías de dependencia latinoamericanas, así como el pragmatismo de los negocios estadounidense, permiten traer de la oscuridad o el olvido elementos que son indispensables en la construcción de teoría y en la formulación de políticas públicas, políticas, planes y estrategias. Este rastreo profundo requiere más tiempo y complejidad de teoría y análisis, además de que toma diferentes rutas de acceso que las de la teoría económica, las cuales por practicidad se toman ya sus argumentos como de una caja de herramientas, es decir, supuestos que son aceptados sin análisis o crítica. Parte de la legitimidad 
y éxito de la ciencia se basa en su cuestionamiento constante y la verificación de las verdades, sujetándolas a comprobación, validación e incluso falsación. Resulta contradictorio entonces no seguir esa lógica con los argumentos económicos que sustentan las prácticas organizativas contemporáneas.

El objetivo de rastrear los fundamentos teóricos de la aceleración llevan a los casos de éxito estadounidenses, replicados en México con una óptica de negocios y trasfondo teórico económico ortodoxo. Sin embargo, de la investigación se desprende que el modelo se propuso desde la iniciativa privada y que la Secretaría de Economía lo adoptó y apoyó. En los años siguientes se ha buscado un consenso para homogenizar el modelo de aceleración a través de la certificación que realiza el INADEM. Sin embargo, se perciben ciertas disparidades en cuanto a la población objetivo de la aceleración. Mientras unas aceleradoras se enfocan en sectores vanguardistas de tecnología, otros buscan proyectos ambientales sostenibles, otros más generalizan sobre incubación de negocios en tanto sean negocio y otros más sólo replican modelos de franquicias.

Resulta cuestionable que si las aceleradoras son un medio para fortalecer a un sector reducido de MIPyME's -particularmente aquellas que no muestran problemas serios, puesto que dentro de los requisitos para ingresar al programa están el crecimiento reciente y un estado consolidado-, al revisar el directorio de aceleradoras certificadas por el INADEM exista poca regularidad, pues mientras unas se mantienen renovando su certificación, otras desaparecen al menos del directorio, lo que significa que no acreditaron el proceso los años siguientes en el menor de los casos, o bien, que han dejado de operar. Entonces, si estas organizaciones pregonan ayudar al fortalecimiento de las empresas que aceleran, ¿cómo es que éstas también desaparecen o no son capaces de mantener un crecimiento en cuanto a casos de éxito, mayor número de empresas atendidas o incluso mantenerse como referentes en el directorio de aceleradoras certificadas por el INADEM? 
No se encuentra evidencia o referencia alguna de estudios técnicos, teóricos o de algún tipo realizados explícitamente para justificar el modelo de aceleración en México, por lo que la referencia llevará a argumentos discursivos como las "mejores prácticas" y la transferencia de modelos exitosos, de lo cual se encuentra saturado el cuerpo de textos producidos por las aceleradoras en México, tanto impresos como en internet, así como en los discursos de videos, pláticas informativas en la semana del emprendedor y eventos destinados a las MIPyME's.

Se ha referido en el documento el destaque de los casos de éxito de las aceleradoras como un fuerte argumento legitimador, aunque en el análisis del discurso se considera siempre un complemento lo no dicho, o el silencio. De esta manera, por oposición se debe considerar el número de casos de éxito en relación al total de casos atendidos. Si bien es una apuesta segura el acelerar empresas que por sí solas han sabido abrirse paso entre la competencia y sobreponerse a la difícil etapa de arranque, no se habla de casos fallidos o situación de conflicto o diferencias de opinión durante el proceso. Esta veta de investigación queda aún pendiente para valorar con mayor precisión el éxito o la pertinencia del modelo de aceleración.

Adicionalmente se plantea también el contrastar los fondos destinados a la aceleración en comparación con los éxitos alcanzados, esto es, valorar si la inversión vale la pena o se están utilizando ineficientemente los recursos. Para el caso de las aceleradoras, el INADEM debe regular las operaciones y establecer rendición de cuentas como parte de los requisitos para la certificación. En el caso de la INADEM, las auditorías internas y la vigilancia por parte de la Secretaría de Economía e incluso de la Auditoría Superior de la Federación deben actuar como reguladores de este programa.

Como se ha descrito en el documento, existe un hermetismo por parte de las organizaciones aceleradoras, pues para el estudio de caso se obtuvo poca respuesta o participación, al igual que por parte del INADEM. A pesar de que se 
obtuvo el nombre de informantes clave, éstos tampoco respondieron a la petición de entrevista por razones desconocidas.

La disposición de la titular de la aceleradora de la Universidad Anáhuac accedió a la entrevista en su oficina, ofreciendo hallazgos de utilidad, como los informantes clave ya mencionados, el cese de funciones de la aceleradora de la Universidad Panamericana o la revelación de cómo se asignó a su persona el proyecto de aceleración y cómo lo desarrolló a partir de investigación en internet en una sola noche, partiendo del desconocimiento absoluto de lo que era un proceso de aceleración.

En el caso de estudio se tuvo una mayor aproximación, pues se pudo entrevistar a dos funcionarios que toman parte en las etapas de aceleración y un par de entrevistas con el responsable de la subdirección de aceleración. Gracias a ello, se tuvo acceso a documentos de acceso restringido, los cuales sólo pudieron revisarse en el interior de la oficina del subdirector. Se indicó que la carpeta formaba parte de una investigación de maestría del IPN, cuyos derechos eran reservados y por lo tanto, no era posible que éstos se hicieran públicos, al menos no hasta que la investigación fuera publicada. Por voz del propio subdirector, autor del documento, creador del modelo de aceleración y gestor de la certificación ante el INADEM, se supo que esa carpeta era la que se había presentado ante el INADEM para obtener la certificación, por lo que se sustenta lo argumentado en el capítulo de estudio de caso de este documento.

El poco acceso a más estudios de caso limitaron un análisis comparativo más allá del que puede hacerse por medio de la investigación exploratoria en su producción de textos y discursos, así como el acercamiento y punto de vista del INADEM sobre el tema. Existe una posibilidad de acceso por medio del subdirector del estudio de caso referenciado, por la invitación expresa del mismo para acompañarle como observador en un proceso de aceleración, así como la búsqueda de aprobación para asistir con él a las reuniones en el INADEM con otros representantes de aceleradoras. Lo anterior se reflejó en el planteamiento metodológico y su desarrollo, pues tuvo que ajustarse a lo que se tuvo acceso y 
trabajar con ello. Esos son los principales obstáculos enfrentados durante la investigación.

Respecto al modelo de aceleración se destaca que ha sido afinado durante los últimos años, en comparación con los primeros años, lo que ha homogenizado hasta cierto punto los procesos en las diferentes aceleradoras. Esto se hace evidente en la incorporación de la estandarización con apego a normas mexicanas e internacionales, el cual no estaba presente en casi ninguna aceleradora en los primeros años y que en la aceleradora del IPN destacan como uno de sus elementos fuertes. Esta voluntad por mejorar continuamente el modelo indica un avance respecto a la simple importación del modelo, puesto que los ajusten indican una adecuación al contexto local o tal vez una "tropicalización" del modelo.

Si es un modelo a partir del cual se puede adaptar para obtener uno propio que funcione para las condiciones existentes en el país, resulta necesario entonces enriquecerlo con una visión de mayor amplitud por medio de intervenciones adicionales a la económica y administrativa de negocios. La inclusión en el análisis modifica los criterios de selección si se contemplan el impacto social y ambiental, por ejemplo, en los empleos que se generan, las patentes desarrolladas, la relación de la innovación tecnológica con el impacto al ecosistema, incluso si las empresas candidatas a la aceleración tienen el potencial para afrontar los cambios organizacionales que conlleva, puesto que el crecimiento y la incursión en un mayor mercado implica mayor capacidad ante los competidores, enfrentar mayores distancias para satisfacer la demanda de clientes más lejanos, aumentar la producción para cubrir esa demanda, mejorar los procesos de calidad, etcétera. Estos cambios hacen reflexionar que la empresa puede funcionar adecuadamente en pequeña escala, pero al aumentar a otra, su habilidad se verá disminuida. Esto no se hace evidente sólo con diagnósticos económicos, financieros o funcionales. La intervención organizacional requiere atención a aquellos aspectos poco estudiados 0 considerados no relevantes, por lo que el cuerpo de expertos que intervienen en 
la aceleración y en la decisión sobre qué candidatos son aceptados debe ser más interdisciplinario. Esto impacta también en un enriquecimiento del modelo, ajustándolo a las necesidades identificadas en la fase de diagnóstico.

En el ámbito teórico, es necesaria la desambigüación de aceleradora de empresas y aceleradora de negocios, pues aunque difícilmente pueden separarse los términos, no todas las empresas tienen como propósito el negocio o el lucro, puesto que los beneficios perseguidos pueden ser de naturaleza distinta a la de las ganancias, los ingresos o las ventas. La precisión de base tecnológica permite distinguirlas de los negocios tradicionales de poco valor agregado pero resulta insuficiente y genera incluso el cuestionamiento de si en realidad toda empresa tiene una base tecnológica, aunque ésta sea anticuada $u$ obsoleta. De igual manera, se ha planteado la dificultad de referirse a los objetivos como MIPyME's cuando más del noventa por ciento pertenecen al conjunto de las microempresas y que existe mayor concentración en el comercio y servicios. En realidad se destinan recursos para potenciar a un porcentaje bastante reducido de empresas que, como se ha argumentado, son las que menos problemas de supervivencia enfrentan.

Más allá también se encuentra el cuestionamiento de hasta qué punto deben utilizarse recursos públicos para beneficiar proyectos de la iniciativa privada, antes que proyectos de beneficio social. Es claro que los argumentos ofrecidos previamente del impacto en la economía y el desarrollo son bastante convincentes, pero al final se observa que gran parte de las aceleradoras son de tipo privado, lo que también significa que éstas buscan un lucro con sus operaciones. Por ello, el estudio de caso sobre la primera aceleradora de una universidad pública resulta alentador por representar una alternativa distinta y que a su vez sea una opción de salida para los proyectos de investigación del propio IPN. El vínculo entre la investigación científica y tecnológica generada por el Politécnico y la aceleradora de empresas del mismo instituto representa la posibilidad de potenciar productos de esa investigación hacia la sociedad, 
acceso a financiamiento y un soporte de expertos que acompañen en la transición del proyecto al emprendimiento.

Como se ha observado en el análisis del estudio de caso, existen puntos susceptibles de mejora, pero que discursivamente se han maquillado, dejando intacta la legitimidad al no ser de conocimiento público. De igual manera, al mejorar continuamente tanto los procesos como su soporte teórico, el papel del discurso es fundamental para hacer parecer que siempre ha sido así y que es producto de un ejercicio racional cuidadosamente pensado y ejecutado, aunque en realidad sea un proceso gradual de ajustes, conflictos, negociaciones, consensos, desencuentros y a veces imposiciones.

Las aportaciones de la investigación se resumen en la generación de conocimiento respecto a un tipo de organización particular de reciente aparición en México como son las aceleradoras de empresas y su incidencia en la búsqueda del ideal de desarrollo económico. La óptica organizacional representa un complemento a lo que se ha generado respecto al tema de la aceleración principalmente desde la economía y la administración funcional. El cuestionar las doctrinas y las prácticas provoca también acción y producción, tanto de discursos, de textos, de conversaciones, que contribuyen a avanzar en el ideal de desarrollo. Desde luego que el contraste de la investigación con otros trabajos y otras perspectivas enriquecerán el conocimiento en torno al tema, por lo que son bienvenidas aún si se encuentran en oposición a lo aquí planteado. 